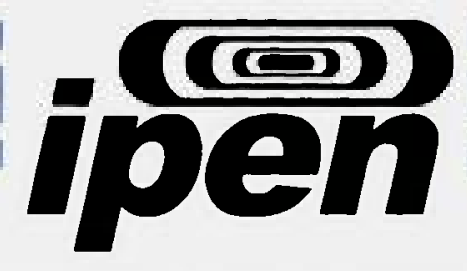

AUTARQUIA ASSOCIADA À UNIVERSIDADE DE SÃO PAULO

\title{
ANÁLISE POR IMPEDÂNCIA ELETROQUÍMICA "ON-LINE" DE CONJUNTOS ELETRODO/MEMBRANA (MEA) DE CÉLULAS A COMBUSTÍVEL A MEBRANA POLIMÉRICA (PEMFC)
}

\section{ANTONIO RODOLFO DOS SANTOS}

Tese apresentada como parte dos requisitos para obtenção do Grau de Doutor em Ciências na Área de Tecnologia Nuclear - Materiais.

Orientador:

Dr. Marcelo Linardi 


\section{tक्जि}

INSTITUTO DE PESQUISAS ENERGÉTICAS E NUCLEARES Autarquia Associada à Universidade de São Paulo

ANÁLISE POR IMPEDÂNCIA ELETROQUÍMICA “ON-LINE" DE CONJUNTOS ELETRODO/MEMBRANA (MEA) DE CÉLULAS A COMBUSTÍVEL A MEMBRANA POLIMÉRICA (PEMFC)

24068

ANTONIO RODOLFO DOS SANTOS

Tese apresentada como parte dos requisitos para obtenção do Grau de Doutor em Ciências na Área de Tecnologia Nuclear - Materiais.

Orientador: Dr. Marcelo Linardi 


\section{DEDICATÓRIA}

Aos meus pais pelo carinho e amor sem os quais eu jamais poderia ter chegado até aqui.

Aos meus irmãos pelo incentivo e tudo o que têm feito por mim. 


\section{AGRADECIMENTOS}

Ao Prof. Dr. Marcelo Linardi pela amizade, confiança depositada e pela enorme disposição em orientar esta tese.

Aos Pesquisadores do Programa de Células a Combustível (PROCEL), Dr. Almir O. Neto, Dra. Eliana Aricó, Dra. Elisabete I. Santiago, Dr. Estevam V. Spinacé e Dr. Fábio C. Fonseca pelas dicas e contribuições sobre esta tese.

A Profa. Dra. Christina Roth e o Prof. Dr. Hartmut Fuess da Technische Universität Darmstadt (Alemanha) pelo carinho e pelas importantes dicas sobre esta tese.

A todos os colegas de laboratório por manterem um ambiente descontraído e produtivo.

À FAPESP e à CAPES pelo apoio financeiro concedido.

Enfim, a todos que diretamente ou indiretamente contribuíram para o andamento deste trabalho. 
"Nós, cientistas, acreditamos que o que nós e nossos semelhantes fizermos ou deixarmos de fazer nos próximos anos determinará o destino de nossa civilização. E consideramos nossa tarefa explicar incansavelmente essa verdade, ajudar as pessoas a perceber tudo o que está em jogo e trabalhar, não para contemporizar, mas para aumentar o entendimento e conseguir, finalmente, a harmonia entre os povos e nações de diferentes pontos de vista." 


\section{SUMÁRIO}

LISTA DE ABREVIAÇÕES.................................................................. i

LISTA DE FIGURAS............................................................................... ii

LISTA DE TABELAS.......................................................................... xi

1 - INTRODUÇÃO

2 - OBJETIVOS

3 - TEORIA 1 - CÉLULAS A COMBUSTÍVEL .......................................... 4

3.1 Histórico e Conceito das Células a Combustível........................................... 4

3.2 Tipos de Células a Combustível................................................................... 6

3.3 Células a Combustível do Tipo PEM........................................................... 7

3.4 Eletrodos de Difusão Gasosa..................................................................... 9

3.5 Eficiência de uma Célula a Combustível................................................... 10

3.6 Cinética de Eletrodo............................................................................... 11

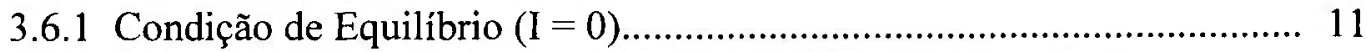

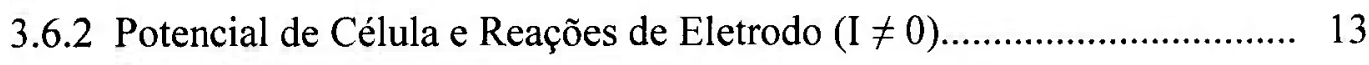

3.7 Reações de uma Célula a Combustível......................................................... 16

3.7.1 Reação de Redução do Oxigênio (RRO).................................................. 16

3.7.2 Oxidação Anódica do Hidrogênio sobre Platina........................................ 17

3.7.3 Oxidação Anódica do Metanol sobre Platina........................................... 19

3.7.4 Oxidação Anódica de Etanol sobre Platina............................................... 22

3.8 Revisão da Literatura sobre o Método de Redução por Álcool para Produção dos Eletrocatalisadores....................................................................... 25

4 - TEORIA 2 - IMPEDÂNCIA ELETROQUÍMICA................................... 28

4.1 Definição de Impedância............................................................................... 28 
4.2 Elementos Elétricos Componentes da Impedância................................. 32

4.2.1 Impedância de uma Resistência........................................................ 33

4.2.2 Impedância de um Capacitor......................................................... 34

4.2.3 Impedância de um Indutor............................................................ 35

4.3 Elementos em Série e Paralelo Componentes do Circuito Elétrico............ 36

4.4 Elementos e Reações Envolvidas na Célula a Combustível....................... 38

4.4.1 Resistência do Eletrólito.............................................................. 38

4.4.2 Resistência de Transferência de Carga............................................. 38

4.4.3 Resistência de Difusão.................................................................. 39

4.4.3.1 Impedância de Warburg.......................................................... 39

4.4.3.2 Impedância de Nernst............................................................... 41

4.4.4 Capacitância da Dupla Camada Elétrica........................................... 42

4.4.5 Elemento de Fase Constante........................................................ 43

4.5 Espectro de Espectroscopia de Impedância Eletroquímica (EIE)............... 44

4.6 Modelos de EIE para uma Célula Eletroquímica.................................... 45

4.7 Revisão da Literatura sobre EIE Aplicada a Células a Combustível.......... 47

5 - MATERIAIS E MÉTODOS................................................................. 49

5.1 Preparação dos Eletrocatalisadores Dispersos - Método de Redução por

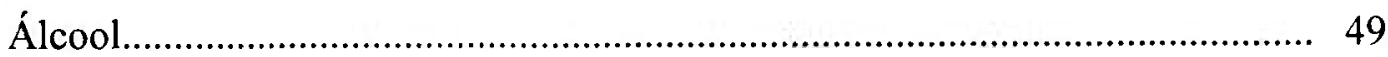

5.2 Produção dos MEAs....................................................................... 50

5.3 Operação das Células Unitárias........................................................... 52

5.4 Caracterização Morfológica, Química e Eletroquímica dos

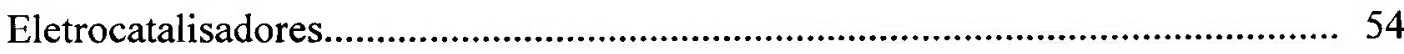

6 - RESULTADOS E DISCUSSÃO................................................... 57

6.1 Refinamento do Método de Preparação dos MEAs................................... 57

6.2 Avaliação do Método de Redução por Álcool.......................................... 63

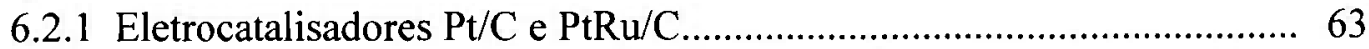

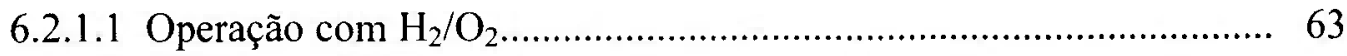

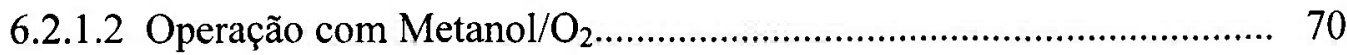

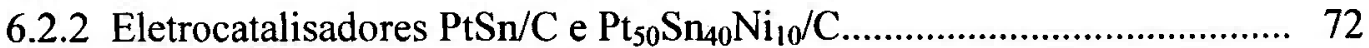

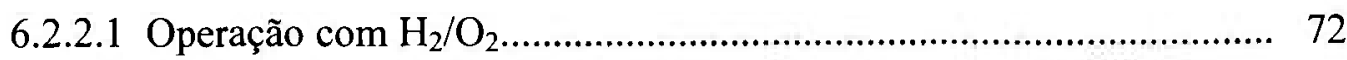

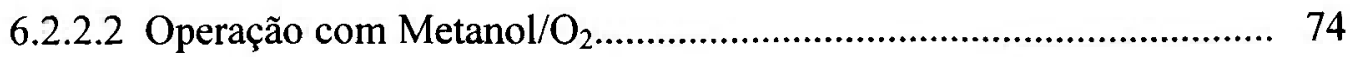

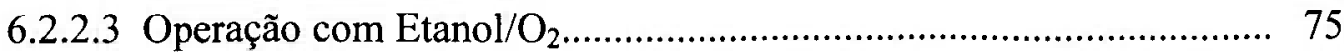


6.3 EIE

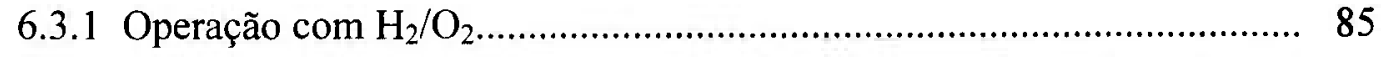

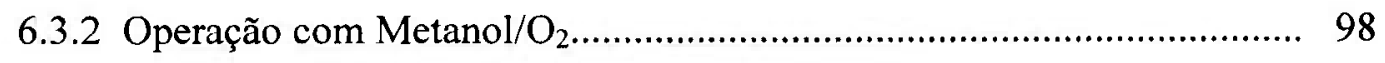

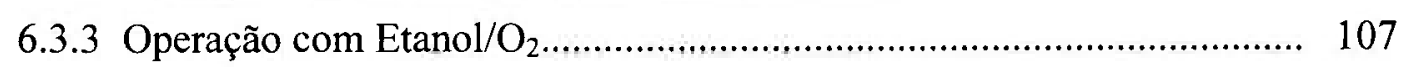

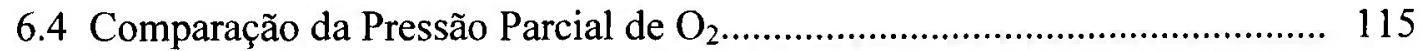

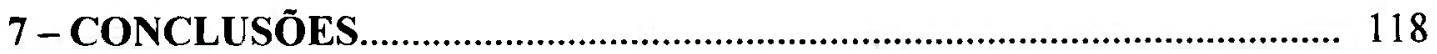

8 - REFERÊNCIAS BIBLIOGRÁFICAS............................................... 120 


\section{ANÁLISE POR IMPEDÂNCIA ELETROQUÍMICA “ON-LINE" DE CONJUNTO ELETRODO/MEMBRANA (MEA) DE CÉLULAS A COMBUSTÍVEL A MEMBRANA POLIMÉRICA (PEMFC)}

\section{Antonio Rodolfo dos Santos}

\section{RESUMO}

Este trabalho apresenta resultados de estudos e caracterizações de Conjuntos Eletrodo/Membrana (MEAs) de Células a Combustível a Membrana Polimérica (PEMFC). Algumas condições de operação de células e diferentes processos de produção de MEA foram investigados. A técnica de Espectroscopia de Impedância Eletroquímica (EIE) (em situ - 0 a 16 A) foi usada "on-line" como uma ferramenta de diagnóstico, relativa ao desempenho de célula. As medidas de EIE foram feitas através do Sistema de EIE para células a combustível FC350 (GAMRY), junto a um PC4 Potentiostato/Galvanostato e conectado à carga dinâmica (TDI) para experimentos de EIE "on-line" (100 mHz $10 \mathrm{kHz}, \mathrm{dU}=5 \mathrm{mV}$ ). MEAs com $25 \mathrm{~cm}^{2}$ de área ativa, usando eletrocatalisadores $\mathrm{PtM} / \mathrm{C} 20 \%$ (M = Ru, Sn ou Ni) fabricados usando o Método de Redução por Álcool (MRA). A tinta catalítica foi diretamente aplicada no Tecido de Carbono (GDL) e este prensado na membrana de $\mathrm{Nafion}^{\circledR}(105)$. MEAs usando eletrocatalisadores $\mathrm{Pt} / \mathrm{C}$ e PtRu/C $20 \%$ da E-TEK foram fabricados para comparação. Todos os catodos foram confeccionados com Pt/C $20 \%$ da E-TEK. Foram fixadas as concentrações de metal nobre em $0,4 \mathrm{mg} \mathrm{Pt.cm}{ }^{-2}$ no anodo e $0,6 \mathrm{mg} \mathrm{Pt.cm}{ }^{-2}$ no catodo (E-TEK). Diagramas de Nyquist dos MEAs com Pt/C e PtRu/C da E-TEK ou PtM/C MRA apresentaram as mesmas resistências de ôhmicas para os MEAs. Este fato pode ser explicado por supressão de aglomerados durante o processo de preparação do MEA ou pela homogeneidade do eletrocatalisador ancorado ao carbono. Também pôde ser observado, a baixas densidades atuais que há uma diferença de desempenho significante entre o eletrocatalisadores da ETEK e os preparados pelo MRA. Os resultados das curvas de polarização confirmaram que $\mathrm{PtM} / \mathrm{C}$ MRA apresentara um aumento de atividade para as células alimentadas com metanol e etanol. A técnica de EIE se mostrou eficiente para a avaliação do método de preparação dos MEAs e do desempenho da célula, os resultados de EIE mostraram uma coerência na escolha do modelo do circuito elétrico para os MEAs utilizando hidrogênio, metanol e etanol. Esta coerência indica que outras resistências não consideradas no modelo não são relevantes na resistência total dos MEAs. 


\title{
ANALYSIS FOR IMPEDANCE ELECTROCHEMISTRY "ON-LINE" OF MEMBRANE/ELECTRODE ASSEMBLE (MEA) OF PROTONS EXCHANGE MEMBRANE FUEL CELLS (PEMFC)
}

\section{Antonio Rodolfo dos Santos}

\begin{abstract}
This work reports results of studies and characterization on Membrane Electrode Assemblies (MEAs) for Proton Exchange Membrane Fuel Cell (PEMFC). Some cell operation conditions and different processes of MEA production were investigated. The Electrochemical Impedance Spectroscopy Technique (EIS) (in situ - 0 to 16 A) was used "on-line" as a tool for diagnosis, concerning the cell performance. The EIS measurements were carried out with a FC350 Fuel Cell EIS System (GAMRY), coupled to a PC4 Potentiostat/Galvanostat and connected to the electronic load (TDI) for "on-line" EIS experiments $(100 \mathrm{mHz}-10 \mathrm{kHz}, \mathrm{dU}=5 \mathrm{mV})$. MEAs with $25 \mathrm{~cm}^{2}$ surface area, using $\mathrm{PtM} / \mathrm{C} 20 \%(\mathrm{M}=\mathrm{Ru}, \mathrm{Sn}$ or $\mathrm{Ni})$ electrocatalysts were manufactured using the Alcohol Reduction Process (ARP). The catalytic ink was applied directly into the Carbon Cloth (GDL) and pressed in the Nafion ${ }^{\circledR}$ membrane (105). MEAs using Pt/C and PtRu/C $20 \%$ from E-TEK electrocatalysts were manufactured by comparison. All the cathodes were sprayed with Pt/C $20 \%$ from E-TEK. The noble metal concentrations used were set to $0.4 \mathrm{mg} \mathrm{Pt.cm}{ }^{-2}$ at the anode and $0.6 \mathrm{mg} \mathrm{Pt.cm}{ }^{-2}$ at the cathode (E-TEK). Nyquist diagrams of the MEAs with Pt/C and PtRu/C from E-TEK or PtM/C $(M=R u, S n$ or Ni) ARP showed essentially the same ohmic resistances for the MEAs. This fact can be explained by suppression of agglomerates during the MEA preparation process or by the homogeneity of the anchored electrocatalysts at the carbon surface. It could also be observed, at low current densities, that there was a significant performance difference between the electrocatalysts from E-TEK and those prepared with the Alcohol Reduction Process. The polarization curves results confirmed that the PtM/C $(M=R u, S n$ or Ni) ARP showed an activity increase for the methanol and ethanol fed cells. The technique of EIE was shown efficient for the evaluation of the method preparation of MEAs and the acting of the cell, the results of EIE showed coherence in the choice of the model the electric circuit for MEAs using hydrogen, methanol and ethanol. This coherence indicates that other resistances no considered in the model are not relevant in the total resistance of MEAs.
\end{abstract}




\section{LISTA DE ABREVIAÇÕES}

$\begin{array}{ll}\text { MEA } & \text { Conjunto Membrana Eletrodo } \\ \text { PEMFC } & \text { Célula a Combustível a Membrana Polimérica } \\ \text { DMFC } & \text { Célula a Combustível Direta a Metanol } \\ \text { DEFC } & \text { Célula a Combustível Direta a Etanol } \\ \text { EIE } & \text { Espectroscopia de Impedância Eletroquímica } \\ \text { AFC } & \text { Célula a Combustível Alcalina } \\ \text { PAFC } & \text { Célula a Combustível de Ácido Fosfórico } \\ \text { MCFC } & \text { Célula a Combustível de Carbonato Fundido } \\ \text { SOFC } & \text { Célula a Combustível de Óxido Sólido } \\ \text { GDL } & \text { Camada de Difusão de Gás } \\ \text { DCE } & \text { Dupla Camada Elétrica } \\ \text { RRO } & \text { Reação de Redução de Oxigênio } \\ \text { ERH } & \text { Eletrodo Reversível de Hidrogênio } \\ \text { FTIR } & \text { Infravermelho com Transformada de Fourier } \\ \text { EDX } & \text { Energia Dispersiva de raios X } \\ \text { DRX } & \text { Energia de Difração de raios X } \\ \text { XPS } & \text { Energia Fotoeletrônica de raios X } \\ \text { MET } & \text { Microscopia Eletrônica de Transmissão } \\ \text { MEV } & \text { Microscopia Eletrônica de Varredura } \\ \text { EM } & \text { Espectroscopia Mössbauer } \\ \text { XAS } & \text { Energia de Absorção de raios X } \\ \text { CPE } & \text { Constante de Elemento de Fase } \\ \text { IPEN } & \text { Instituto de Pesquisas Energéticas e Nucleares } \\ \text { MRA } & \text { Método de Redução por Álcool } \\ & \end{array}$




\section{LISTA DE FIGURAS}

FIGURA 1 - "Bateria a gás" desenvolvida pelo Sir William Grove, primeiro protótipo de uma célula a combustível

FIGURA 2 - Modelo de funcionamento de uma célula a combustivel ácida do tipo PEMFC

FIGURA 3 - Modelo de um eletrodo de difusão gasosa utilizado em célula a combustível a baixa temperatura (PEMFC). Sendo: a) lado gás, b) camada difusora, c) camada catalisadora, d) eletrólito, e) catalisador suportado; f) coletor de corrente, g) Nafion ${ }^{\circledR}$, h) canais dos gases, i) membrana de Nafion ${ }^{\circledR}$, k) catalisador e l) poros.

FIGURA 4 - Comparação da eficiência máxima de uma célula a combustível e de um motor regido pelo ciclo de Carnot

FIGURA 5 - Célula eletroquímica com dois eletrodos e seu correspondente circuito elétrico equivalente.

FIGURA 6 - Célula eletroquímica com três eletrodos. Onde R, T e C são: o eletrodo de referência, eletrodo de trabalho e o contra eletrodo, respectivamente.

FIGURA 7 - Representação de uma curva de polarização de uma célula a combustível.

FIGURA 8 -Curva de Vulcano: densidade de corrente de intercâmbio de hidrogênio versus a entalpia de adsorção do hidrogênio atômico em diferentes metais 
FIGURA 10 - Gráfico de corrente alternada (i) e tensão alternada $(u)$ com a freqüência $(\omega)$ versus o tempo $(t)$

FIGURA 11 - Representação de impedância por meio do diagrama de Nyquist..

FIGURA 12 - Representação de impedância por meio do diagrama de Bode......

FIGURA 13 - Impedância de uma resistência ideal sobre o diagrama de Nyquist $(R=1 \Omega)$.

FIGURA 14 - Impedância de um capacitor ideal sobre o diagrama de Nyquist $(C=1 \Omega, \omega=0,16 \mathrm{mHz}-10 \mathrm{kHz})$.

FIGURA 15 - Impedância de um indutor ideal sobre o diagrama de Nyquist $(L=1 \mathrm{H}, \omega=1 \mu \mathrm{Hz}-0,16 \mathrm{~Hz})$.

FIGURA 16 - Elementos de impedância associados em série.

FIGURA 17 - Elementos de impedância associados em paralelo.

FIGURA 18 - a) Representação da associação de elementos de impedância em série e paralelo e b) diagrama de Nyquist da mesma associação.

FIGURA 19 - Diagrama de impedância de Warburg para difusão finita, a) Curto Circuito $\left(Z_{S}\right)$ e b) Circuito Aberto $\left(Z_{O}\right)$; onde $R_{W}=1000, T_{W}=0,1 \mathrm{e}$ $\varphi=0,5$.

FIGURA 20 - Representação da dupla camada elétrica entre eletrodo/eletrólito, onde $Z_{\mathrm{el}}$ é a impedância do eletrólito, $Z_{\mathrm{dl}}$ é a impedância da dupla camada elétrica, $Z_{M}$ é a impedância do metal e $Z_{\text {ges }}$ é a impedância total do sistema.

FIGURA 21 - Impedância do CPE por variação de parâmetros $\varphi$ em freqüência de $0,5 \mathrm{~Hz}$ a $25 \mathrm{kHz}$, onde $A=1 F . \mathrm{cm}^{2 I} \cdot \mathrm{s}^{2 \varphi}$.

FIGURA 22 - a) Modelo de circuito equivalente para uma meia célula eletroquímica, b) Diagrama de Nyquist para medida de EIE de uma meia célula eletroquímica.

FIGURA 23 - Modelo para uma célula eletroquímica sem separação de compartimentos. 
FIGURA 24 - Modelo para uma célula eletroquímica com separação de compartimentos. $\mathrm{O}$ anodo está representado à esquerda e o catodo à direita.

FIGURA 25 - Painéis de controle das células a combustivel.

FIGURA 26 - Curvas de polarização de MEAs com $25 \mathrm{~cm}^{2}$ de área eletródica, confeccionados com Pt/C comercial da E-TEK com $0,4 \mathrm{mg}$ de Pt.cm ${ }^{-2}$ no anodo e $0,6 \mathrm{mg}$ de Pt.cm ${ }^{-2}$ no catodo, operando com $\mathrm{H}_{2} / \mathrm{O}_{2}$. Símbolos cheios representam tecido de carbono ElectroChem e símbolos vazados tecido de carbono ELAT. Temperaturas: célula a $70^{\circ} \mathrm{C}$ e umidificador a $85^{\circ} \mathrm{C}$.

FIGURA 27 - Diagramas de Nyquist (a) e Bode (b) para MEAs com $25 \mathrm{~cm}^{2}$, confeccionados com Pt/C comercial da E-TEK com $0,4 \mathrm{mg}$ de Pt.cm ${ }^{-2}$ no anodo e $0,6 \mathrm{mg}$ de Pt.cm ${ }^{-2}$ no catodo, em operação com $\mathrm{H}_{2} / \mathrm{O}_{2}$ a $1 \mathrm{~A}$ de corrente. Símbolos cheios representam tecido de carbono ElectroChem e símbolos vazados representam tecido de carbono ELAT. Temperaturas: célula a $70{ }^{\circ} \mathrm{C}$ e umidificador a $85^{\circ} \mathrm{C}$

FIGURA 28 - Micrografias de MEV de MEAs com Pt/C comercial da E-TEK em: (a) tecido de carbono ElectroChem com a tinta aplicada sobre a Membrana, (b) tecido de carbono ElectroChem com a tinta aplicada sobre o tecido de carbono, (c) tecido de carbono ELAT com a tinta aplicada sobre a Membrana e (d) tecido de carbono ELAT com a tinta aplicada sobre o tecido de carbono

FIGURA 29 - Curvas de polarização de MEAs com $25 \mathrm{~cm}^{2}$ de área eletródica operando com $\mathrm{H}_{2} / \mathrm{O}_{2}$, sendo os eletrocatalisadores confeccionados pelo método de redução por álcool, fixando ou não o pH da solução, aplicados diretamente no tecido de carbono somente no anodo $\left(0,4 \mathrm{mg}\right.$ de $P$ t. $\left.\mathrm{cm}^{-2}\right)$, no catodo $(0,6 \mathrm{mg}$ de $P$ t.cm ${ }^{-2}$ ) foi aplicado o eletrocatalisador $\mathrm{Pt} / \mathrm{C}$ comercial da E-TEK diretamente no tecido de carbono. Temperaturas: célula a $70{ }^{\circ} \mathrm{C}$ e umidificador a $85^{\circ} \mathrm{C}$

FIGURA 30 -Difratogramas de raios $\mathrm{X}$ de diferentes eletrocatalisadores: (a) $\mathrm{PtRu} / \mathrm{C}$ método de redução por álcool sem controle do $\mathrm{pH}$; (b) $\mathrm{PtRu} / \mathrm{C}$ método de redução por álcool com controle do $\mathrm{pH}$; (c) $\mathrm{PtRu} / \mathrm{C}$ comercial da E-TEK e (d) Pt/C comercial da E-TEK 
FIGURA 31 - Micrografias de MET de eletrocatalisadores Pt/C e PtRu/C obtidos pelo método de redução por álcool: (a) $\mathrm{Pt} / \mathrm{C}$ com controle do $\mathrm{pH}$, (b) $\mathrm{Pt} / \mathrm{C}$ sem controle do $\mathrm{pH}$, (c) $\mathrm{PtRu} / \mathrm{C}$ com controle do $\mathrm{pH}$ e (d) $\mathrm{PtRu} / \mathrm{C}$ sem controle do $\mathrm{pH}$

FIGURA 32 - Micrografias de MET do eletrocatalisador Pt/C comercial da E-TEK

FIGURA 33 - Micrografias de MET do eletrocatalisador PtRu/C comercial da E-TEK.

FIGURA 34 - Histogramas do tamanho de partícula dos eletrocatalisadores preparados pelo método de redução por álcool, confeccionados a partir das micrografias de MET: (a) PtRu/C com controle do $\mathrm{pH}$ e (b) $\mathrm{PtRu} / \mathrm{C}$ sem controle do $\mathrm{pH}$

FIGURA 35 - Histogramas do tamanho de partícula dos eletrocatalisadores comerciais da E-TEK, ambos confeccionados a partir das micrografias de MET: (a) $\mathrm{Pt} / \mathrm{C}$ e (b) $\mathrm{PtRu} / \mathrm{C}$

FIGURA 36 - Curvas de polarização de MEAs com $25 \mathrm{~cm}^{2}$ de área eletródica operando com metanol 2,0 mol. $\mathrm{L}^{-1}$, sendo os eletrocatalisadores confeccionados pelo método de redução por álcool, fixando ou não o pH da solução, tinta aplicada diretamente no tecido de carbono do anodo $\left(0,4 \mathrm{mg} \mathrm{de} \mathrm{Pt.cm}{ }^{-2}\right)$, sendo no catodo $\left(0,6 \mathrm{mg}\right.$ de Pt.cm $\left.{ }^{-2}\right)$ aplicado o eletrocatalisador $\mathrm{Pt} / \mathrm{C}$ comercial da E-TEK diretamente no tecido de carbono. Temperaturas: célula a $85^{\circ} \mathrm{C}$ e umidificador a $95^{\circ} \mathrm{C}$.

FIGURA 37 - Curvas de polarização de MEAs com $25 \mathrm{~cm}^{2}$ de área eletródica, preparados com PtSn/C e $\mathrm{Pt}_{50} \mathrm{Sn}_{40} \mathrm{Ni}_{10} / \mathrm{C}$ MRA e PtRu/C comercial da E-TEK. Todos os MEAs com $0,4 \mathrm{mg}$ de Pt.cm ${ }^{-2}$ no anodo e $0,6 \mathrm{mg}$ de Pt.cm ${ }^{-2}$ no catodo (Pt/C comercial da E-TEK), utilizando membrana de Nafion ${ }^{\circledR} 105$, operando com $\mathrm{H}_{2} / \mathrm{O}_{2}$. Temperaturas: célula a $70{ }^{\circ} \mathrm{C}$ e umidificador a $85^{\circ} \mathrm{C}$ 
FIGURA 38 - Curvas de polarização de MEAs com $25 \mathrm{~cm}^{2}$ de área eletródica, preparados com $\mathrm{PtSn} / \mathrm{C}$ e $\mathrm{Pt}_{50} \mathrm{Sn}_{40} \mathrm{Ni}_{10} / \mathrm{C}$ MRA e PtRu/C comercial da E-TEK. Todos os MEAs com 0,4 mg de Pt.cm ${ }^{-2}$ no anodo e $0,6 \mathrm{mg}$ de Pt. $\mathrm{cm}^{-2}$ no catodo (Pt/C comercial da E-TEK), utilizando membrana de Nafion ${ }^{\circledR} 105$, operando com Metanol/ $\mathrm{O}_{2}$. Temperaturas: célula a $100^{\circ} \mathrm{C}$ e umidificador a $90{ }^{\circ} \mathrm{C}$.

FIGURA 39 - Curvas de polarização de MEAs com $25 \mathrm{~cm}^{2}$ de área eletródica, preparados com $\mathrm{PtSn} / \mathrm{C}$ e $\mathrm{Pt}_{50} \mathrm{Sn}_{40} \mathrm{Ni}_{10} / \mathrm{C}$ MRA e PtRu/C comercial da E-TEK. Todos os MEAs com 0,4 mg de Pt.cm ${ }^{-2}$ no anodo e $0,6 \mathrm{mg} \mathrm{de} \mathrm{Pt.cm}{ }^{-2}$ no catodo (Pt/C comercial da E-TEK), utilizando membrana de Nafion ${ }^{\circledR} 105$, operando com Etanol $/ \mathrm{O}_{2}$. Temperaturas: célula a $100{ }^{\circ} \mathrm{C}$ e umidificador a $90{ }^{\circ} \mathrm{C}$.

FIGURA 40 - Difratogramas de raios $\mathrm{X}$ dos eletrocatalisadores: (a) $\mathrm{PtSn} / \mathrm{C}$ MRA, (b) $\mathrm{Pt}_{50} \mathrm{Sn}_{40} \mathrm{Ni}_{10} / \mathrm{C}$ MRA e (c) $\mathrm{PtRu} / \mathrm{C}$ comercial da E-TEK.....

FIGURA 41 - Micrografias de MET de eletrocatalisadores obtidos pelo método de redução por álcool: (a) $\mathrm{PtSn} / \mathrm{C}$ e (b) $\mathrm{Pt}_{50} \mathrm{Sn}_{40} \mathrm{Ni}_{10} / \mathrm{C}$.

FIGURA 42 - Histogramas do tamanho de partícula dos eletrocatalisadores preparados pelo método de redução por álcool, obtidos a partir de dados das micrografias de MET: (a) $\mathrm{PtSn} / \mathrm{C}$ e (b) $\mathrm{Pt}_{50} \mathrm{Sn}_{40} \mathrm{Ni}_{10} / \mathrm{C}$.

FIGURA 43 - Espectro de XPS para o eletrocatalisador PtSn/C MRA 80

FIGURA 44 - Espectro detalhado do fotopico Pt 4f para o eletrocatalisador $\mathrm{PtSn} / \mathrm{C}$ MRA

FIGURA 45 - Espectro detalhado do fotopico Sn 3d para o eletrocatalisador $\mathrm{PtSn} / \mathrm{C}$ MRA

FIGURA 46 - Espectro de XPS para o eletrocatalisador $\mathrm{Pt}_{50} \mathrm{Sn}_{40} \mathrm{Ni}_{10} / \mathrm{C}$ MRA.....

FIGURA 47 - Espectro detalhado do fotopico Pt 4f para o eletrocatalisador $\mathrm{Pt}_{50} \mathrm{Sn}_{40} \mathrm{Ni}_{10} / \mathrm{C}$ MRA.

FIGURA 48 - Espectro detalhado do fotopico Sn 3d para o eletrocatalisador $\mathrm{Pt}_{50} \mathrm{Sn}_{40} \mathrm{Ni}_{10} / \mathrm{C}$ MRA

FIGURA 49 - Análise de Mössbauer para os eletrocatalisadores $\mathrm{PtSn} / \mathrm{C}$ e $\mathrm{Pt}_{50} \mathrm{Sn}_{40} \mathrm{Ni}_{10} / \mathrm{C}$.MRA 
FIGURA 50 - Diagramas de Nyquist, para MEA Pt/C comercial da E-TEK com $25 \mathrm{~cm}^{2}$ de área eletródica, com tinta catalítica aplicada sobre o tecido de carbono com $0,4 \mathrm{mgPt}_{\mathrm{cm}}{ }^{-2}$ no anodo e $0,6 \mathrm{mgPt} . \mathrm{cm}^{-2}$ no catodo $(\mathrm{Pt} / \mathrm{C}$ comercial da E-TEK), utilizando membrana de $\mathrm{Nafion}^{\circledR} 105$, em várias correntes de operação com $\mathrm{H}_{2} / \mathrm{O}_{2}$. Temperaturas: célula a $70{ }^{\circ} \mathrm{C}$ e umidificador a $85{ }^{\circ} \mathrm{C}$

FIGURA 51 - Diagramas de Nyquist, para MEA PtRu/C comercial da E-TEK com $25 \mathrm{~cm}^{2}$ de área eletródica, com tinta catalítica aplicada sobre o tecido de carbono com $0,4 \mathrm{mgPt}_{\mathrm{cm}} \mathrm{cm}^{-2}$ no anodo e $0,6 \mathrm{mgPt}_{\mathrm{cm}}{ }^{-2}$ no catodo $(\mathrm{Pt} / \mathrm{C}$ comercial da E-TEK), utilizando membrana de $\mathrm{Nafion}^{\circledR} 105$, em várias correntes de operação com $\mathrm{H}_{2} / \mathrm{O}_{2}$. Temperaturas: célula a $70{ }^{\circ} \mathrm{C}$ e umidificador a $85{ }^{\circ} \mathrm{C}$

FIGURA 52 - Diagramas de Nyquist, para MEA PtSn/C MRA com $25 \mathrm{~cm}^{2}$ de área eletródica, com tinta catalítica aplicada sobre o tecido de carbono com $0,4 \mathrm{mgPt} . \mathrm{cm}^{-2}$ no anodo (MRA) e $0,6 \mathrm{mgPt}^{-\mathrm{cm}^{-2}}$ no catodo (Pt/C comercial da E-TEK), utilizando membrana de Nafion ${ }^{\circledR} 105$, em várias correntes de operação com $\mathrm{H}_{2} / \mathrm{O}_{2}$. Temperaturas: célula a $70{ }^{\circ} \mathrm{C}$ e umidificador a $85^{\circ} \mathrm{C}$

FIGURA 53 - Diagramas de Nyquist, para MEA $\mathrm{Pt}_{50} \mathrm{Sn}_{40} \mathrm{Ni}_{10} / \mathrm{C}$ MRA com $25 \mathrm{~cm}^{2}$ de área eletródica, com tinta catalítica aplicada sobre o tecido de carbono com $0,4 \mathrm{mgPt.cm}{ }^{-2}$ no anodo (MRA) e $0,6 \mathrm{mgPt}_{\mathrm{cm}}{ }^{-2}$ no catodo (Pt/C E-TEK), utilizando membrana de $\mathrm{Nafion}^{\circledR} 105$, em várias correntes de operação com $\mathrm{H}_{2} / \mathrm{O}_{2}$. Temperaturas: célula a $70{ }^{\circ} \mathrm{C}$ e umidificador a $85^{\circ} \mathrm{C}$

FIGURA 54 - Modelo escolhido de circuito elétrico para EIE "on-line" em operação com $\mathrm{H}_{2} / \mathrm{O}_{2}$

FIGURA 55 - Diagrama de Nyquist para Pt/C comercial da E-TEK, operando com $\mathrm{H}_{2} / \mathrm{O}_{2}$. a) $1 \mathrm{~A}-40 \mathrm{~mA} . \mathrm{cm}^{-2}$, b) $4 \mathrm{~A}-160 \mathrm{~mA} . \mathrm{cm}^{-2}$, c) $8 \mathrm{~A}-320 \mathrm{~mA} . \mathrm{cm}^{-2}$, d) $16 \mathrm{~A}-320 \mathrm{~mA} \cdot \mathrm{cm}^{-2}$

FIGURA 56-Diagrama de Nyquist para PtRu/C comercial da E-TEK, operando com $\mathrm{H}_{2} / \mathrm{O}_{2}$. $\quad$ a) $1 \mathrm{~A}-40 \mathrm{~mA} \cdot \mathrm{cm}^{-2}, \quad$ b) $4 \mathrm{~A}-160 \mathrm{~mA} \cdot \mathrm{cm}^{-2}$, c) $8 \mathrm{~A}-320 \mathrm{~mA} \cdot \mathrm{cm}^{-2}$, d) $16 \mathrm{~A}-320 \mathrm{~mA} \cdot \mathrm{cm}^{-2}$. 
FIGURA 57 - Diagrama de Nyquist para PtSn/C MRA, operando com $\mathrm{H}_{2} / \mathrm{O}_{2}$.
a) $1 \mathrm{~A}-40 \mathrm{~mA} \cdot \mathrm{cm}^{-2}$,
b) $4 \mathrm{~A}-160 \mathrm{~mA} \cdot \mathrm{cm}^{-2}$,
c) $8 \mathrm{~A}-320 \mathrm{~mA} \cdot \mathrm{cm}^{-2}$,
d) $16 \mathrm{~A}-320 \mathrm{~mA} \cdot \mathrm{cm}^{-2}$

FIGURA 58 - Diagrama de Nyquist para $\mathrm{Pt}_{50} \mathrm{Sn}_{40} \mathrm{Ni}_{10} / \mathrm{C}$ MRA, operando com $\mathrm{H}_{2} / \mathrm{O}_{2}$. a) $1 \mathrm{~A}-40 \mathrm{~mA} \cdot \mathrm{cm}^{-2}$, b) $4 \mathrm{~A}-160 \mathrm{~mA} \cdot \mathrm{cm}^{-2}$, c) $8 \mathrm{~A}-320 \mathrm{~mA} \cdot \mathrm{cm}^{-2}$, d) $16 \mathrm{~A}-320 \mathrm{~mA} \cdot \mathrm{cm}^{-2}$

FIGURA 59 - Variação da resistência de transferência de carga no anodo (símbolo cheio) e no catodo (simbolo vazado) dos MEAs utilizados sob operação com $\mathrm{H}_{2} / \mathrm{O}_{2}$.

FIGURA 60 - Diagramas de Nyquist, para MEA PtRu/C comercial da E-TEK com $25 \mathrm{~cm}^{2}$ de área eletródica, com tinta catalítica aplicada sobre o tecido de carbono com $0,4 \mathrm{mgPt} . \mathrm{cm}^{-2}$ no anodo e $0,6 \mathrm{mgPt} . \mathrm{cm}^{-2}$ no catodo $(\mathrm{Pt} / \mathrm{C}$ comercial da E-TEK), utilizando membrana de $\mathrm{Nafion}^{\circledR} 105$, em várias correntes de operação com Metanol $/ \mathrm{O}_{2}$. Temperaturas: célula a $100^{\circ} \mathrm{C}$ e umidificador a $90^{\circ} \mathrm{C}$

FIGURA 61 - Diagramas de Nyquist, para MEA PtSn/C MRA com $25 \mathrm{~cm}^{2}$ de área eletródica, com tinta catalítica aplicada sobre o tecido de carbono com $0,4 \mathrm{mgPt} . \mathrm{cm}^{-2}$ no anodo e $0,6 \mathrm{mgPt} . \mathrm{cm}^{-2}$ no catodo (Pt/C comercial da E-TEK), utilizando membrana de Nafion $^{(1)} 105$, em várias correntes de operação com Metanol $/ \mathrm{O}_{2}$. Temperaturas: célula a $100{ }^{\circ} \mathrm{C}$ e umidificador a $90{ }^{\circ} \mathrm{C}$

FIGURA 62 - Diagramas de Nyquist, para MEA $\mathrm{Pt}_{50} \mathrm{Sn}_{40} \mathrm{Ni}_{10} / \mathrm{C}$ MRA $20 \%$ com $25 \mathrm{~cm}^{2}$ de área eletródica, com tinta catalítica aplicada sobre o tecido de carbono com $0,4 \mathrm{mgPt} . \mathrm{cm}^{-2}$ no anodo e $0,6 \mathrm{mgPt} . \mathrm{cm}^{-2}$ no catodo (Pt/C comercial da E-TEK), utilizando membrana de Nafion ${ }^{\circledR} 105$, em várias correntes de operação com Metanol $/ \mathrm{O}_{2}$. Temperaturas: célula a $100^{\circ} \mathrm{C} \mathrm{e}$ umidificador a $90{ }^{\circ} \mathrm{C}$

FIGURA 63 - Modelo proposto de circuito elétrico para EIE "on-line" em operação com Metanol/ $\mathrm{O}_{2}$ 
FIGURA 64 - Diagrama de Nyquist para PtRu/C comercial da E-TEK, operando com Metanol $/ \mathrm{O}_{2}$. a) $0 \mathrm{~A}-00 \mathrm{~mA} \cdot \mathrm{cm}^{-2}$, b) $1 \mathrm{~A}-40 \mathrm{~mA} \cdot \mathrm{cm}^{-2}$, c) $2 \mathrm{~A}-80 \mathrm{~mA} \cdot \mathrm{cm}^{-2}$, d) $3 \mathrm{~A}-120 \mathrm{~mA} \cdot \mathrm{cm}^{-2}$, e) $4 \mathrm{~A}-160 \mathrm{~mA} \cdot \mathrm{cm}^{-2}$

FIGURA 65 - Diagrama de Nyquist para PtSn/C MRA, operando com Metanol $/ \mathrm{O}_{2}$. a) $0 \mathrm{~A}-00 \mathrm{~mA} \cdot \mathrm{cm}^{-2}$, b) $1 \mathrm{~A}-40 \mathrm{~mA} \cdot \mathrm{cm}^{-2}$, c) $2 \mathrm{~A}-80 \mathrm{~mA} \cdot \mathrm{cm}^{-2}$, d) $3 \mathrm{~A}-120 \mathrm{~mA} \cdot \mathrm{cm}^{-2}$.

FIGURA 66 - Diagrama de Nyquist para $\mathrm{Pt}_{50} \mathrm{Sn}_{40} \mathrm{Ni}_{10} / \mathrm{C}$ MRA, operando com Metanol/O2. a) $0 \mathrm{~A}-00 \mathrm{~mA} \cdot \mathrm{cm}^{-2}$, b) $1 \mathrm{~A}-40 \mathrm{~mA} \cdot \mathrm{cm}^{-2}$, c) $2 \mathrm{~A}-80 \mathrm{~mA} \cdot \mathrm{cm}^{-2}$, d) $3 \mathrm{~A}-120 \mathrm{~mA} \cdot \mathrm{cm}^{-2}$.

FIGURA 67 - Variação da resistência de transferência de carga no anodo (símbolo cheio) e no catodo (símbolo vazado), e da resistência de adsorção (símbolos semi vazados) dos MEAs utilizados, sob operação com Metanol/ $\mathrm{O}_{2} \ldots .106$ FIGURA 68 - Diagramas de Nyquist, para MEA PtRu/C comercial da E-TEK com $25 \mathrm{~cm}^{2}$ de área eletródica, com tinta catalítica aplicada sobre o tecido de carbono com $0,4 \mathrm{mgPt} . \mathrm{cm}^{-2}$ no anodo e $0,6 \mathrm{mgPt} . \mathrm{cm}^{-2}$ no catodo $(\mathrm{Pt} / \mathrm{C}$ comercial da E-TEK), utilizando membrana de Nafion $^{\circledR} 105$, em várias correntes de operação com Etanol/ $/ \mathrm{O}_{2}$. Temperaturas: célula a $100^{\circ} \mathrm{C}$ e umidificador a $90^{\circ} \mathrm{C}$.

FIGURA 69 - Diagramas de Nyquist, para MEA PtSn/C MRA com $25 \mathrm{~cm}^{2}$ de área eletródica, com tinta catalítica aplicada sobre o tecido de carbono com $0,4 \mathrm{mgPt} . \mathrm{cm}^{-2}$ no anodo e $0,6 \mathrm{mgPt} . \mathrm{cm}^{-2}$ no catodo (Pt/C comercial da E-TEK), utilizando membrana de Nafion ${ }^{\circledR} 105$, em várias correntes de operação com Etanol/ $\mathrm{O}_{2}$. Temperaturas: célula a $100{ }^{\circ} \mathrm{C}$ e umidificador a $90{ }^{\circ} \mathrm{C}$

FIGURA 70 - Diagramas de Nyquist, para MEA $\mathrm{Pt}_{50} \mathrm{Sn}_{40} \mathrm{Ni}_{10} / \mathrm{C}$ MRA com $25 \mathrm{~cm}^{2}$ de área eletródica, com tinta catalítica aplicada sobre o tecido de carbono com $0,4 \mathrm{mgPt} . \mathrm{cm}^{-2}$ no anodo e $0,6 \mathrm{mgPt} . \mathrm{cm}^{-2}$ no catodo (Pt/C comercial da E-TEK), utilizando membrana de Nafion $^{\circledR} 105$, em várias correntes de operação com Etanol/ $/ \mathrm{O}_{2}$. Temperaturas: célula a $100^{\circ} \mathrm{C}$ e umidificador a $90^{\circ} \mathrm{C}$. 
FIGURA 71 - Modelo proposto de circuito elétrico para EIE "on-line" em operação com Etanol/ $\mathrm{O}_{2}$

FIGURA 72 - Diagrama de Nyquist para PtRu/C comercial da E-TEK, operando com Etanol $/ \mathrm{O}_{2}$ a $1,0 \mathrm{~A}-40 \mathrm{~mA} . \mathrm{cm}^{-2}$.

FIGURA 73 - Diagrama de Nyquist para PtSn/C MRA, operando com Etanol $/ \mathrm{O}_{2}$ sob várias correntes de operação.

FIGURA 74 - Diagrama de Nyquist para $\mathrm{Pt}_{50} \mathrm{Sn}_{40} \mathrm{Ni}_{10} / \mathrm{C}$ MRA, operando com Etanol/O2. a) 0 A - 00 mA.cm ${ }^{-2}$, b) 0,4 A - $10 \mathrm{~mA} \cdot \mathrm{cm}^{-2}$,

FIGURA 75 - Variação da resistência de transferência de carga no anodo (símbolo cheio) e no catodo (símbolo vazado), e da resistência de adsorção (símbolo semi vazado) dos MEAs utilizados sob operação com Etanol $/ \mathrm{O}_{2}$

FIGURA 76 - Diagramas de Nyquist, para MEA PtRu/C comercial da E-TEK com $25 \mathrm{~cm}^{2}$ de área eletródica, com tinta catalítica aplicada sobre o tecido de carbono com $0,4 \mathrm{mgPt} . \mathrm{cm}^{-2}$ no anodo e $0,6 \mathrm{mgPt} . \mathrm{cm}^{-2}$ no catodo (Pt/C comercial da E-TEK), utilizando membrana de Nafion ${ }^{105}$, em várias correntes de operação com $\mathrm{Metanol} / \mathrm{O}_{2}$ a 1 e 2 bar de pressão de oxigênio. Temperaturas: célula a $100^{\circ} \mathrm{C}$ e umidificador a $90^{\circ} \mathrm{C}$

FIGURA 77 - Diagramas de Nyquist, para MEA PtRu/C comercial da E-TEK com $25 \mathrm{~cm}^{2}$ de área eletródica, com tinta catalítica aplicada sobre o tecido de carbono com $0,4 \mathrm{mgPt} . \mathrm{cm}^{-2}$ no anodo e $0,6 \mathrm{mgPt} . \mathrm{cm}^{-2}$ no catodo (Pt/C comercial da E-TEK), utilizando membrana de Nafion $^{\circledR} 105$, em várias correntes de operação com Etanol/ $\mathrm{O}_{2}$ a 1 e 2 bar de pressão de oxigênio. Temperaturas: célula a $100^{\circ} \mathrm{C}$ e umidificador a $90^{\circ} \mathrm{C}$ 


\section{LISTA DE TABELAS}

TABELA 1 - Tipos de células a combustível

TABELA 2 - Valores termodinâmicos para as reações envolvidas nas células dos tipos PEMFC, DMFC e DEFC nas condições padrão.

TABELA 3 - Definição e símbolo dos elementos elétricos e suas impedâncias.....

TABELA 4 - Proporção atômica dos eletrocatalisadores a base de PtRu e comparação do tamanho médio de partícula dos eletrocatalisadores por XRD e a partir dos dados de MET

TABELA 5 - Proporção atômica dos eletrocatalisadores a base de PtSn e comparação do tamanho médio de partícula dos eletrocatalisadores por XRD e a partir dos dados de MET

TABELA 6 - Valores dos elementos componentes do circuito elétrico para os MEAs da FIGURA 55, 56, 57 e 58.

TABELA 7 - Valores dos elementos componentes do circuito elétrico para os MEAs da FIGURA 64, 65 e 66

TABELA 8 - Valores dos elementos componentes do circuito elétrico para os MEAs da FIGURA 72,73 e 74 


\section{INTRODUÇÃO}

A melhoria do padrão de vida da sociedade brasileira requer o crescimento da economia nacional e este crescimento somente pode ser garantido, dentre outros fatores, se houver um aumento compatível e uma melhor qualidade da energia fornecida, incluindo, os serviços que podem ser oferecidos a partir do uso dessa energia. É desejável, entretanto, que esse crescimento seja sustentável, ou seja, ocorra sem o esgotamento dos recursos naturais e sem a deterioração das condições ambientais.

O modelo energético atual, dependente de combustíveis fósseis, não atende a essas características, já que esses combustíveis não são renováveis e o seu beneficiamento e usos geram contaminantes atmosféricos, provocando danos ambientais. Além disso, existem fatores políticos e econômicos que devem ser considerados, pois suas jazidas estão concentradas em poucas regiões do mundo e seus preços estão sujeitos a grandes instabilidades.

Nos dias atuais, o rumo de desenvolvimento tecnológico aponta para sistemas inovadores que não se mostrem ambientalmente agressivos. Com isso, as células a combustível se apresentam como sistemas altamente atraentes de conversão de energia, pois os produtos gerados durante a oxidação do hidrogênio são somente água e calor. Mesmo no caso da utilização de combustíveis primários reformados (metanol, etanol, gás natural ou gasolina) para a produção de hidrogênio, a poluição gerada é significativamente reduzida.

As células a combustível são um dos sistemas mais estudados na área de eletroquímica atualmente ${ }^{[1-10]}$. Este fato se deve ao crescimento da procura por fontes energéticas alternativas que possam suprir as necessidades crescentes de uma sociedade cada vez mais automatizada, que tem na eletricidade a sua base de funcionamento, mas que se preocupa com o meio ambiente. 

de Células a Combustível a Membrana Polimérica (PEMFC)

A invenção das células a combustível ocorreu já há mais de 150 anos. Entretanto, por terem custo muito elevado sua aplicação prática deu-se somente na década de 60 , no programa espacial norte-americano ${ }^{[11]}$. As células a combustivel representam atualmente, uma alternativa para aplicação em dispositivos eletrônicos e já em médio prazo, uma alternativa tanto para motores a combustão (unidades móveis), como para geradores de energia de médio porte $(100 \mathrm{~kW})$ até plantas da ordem de alguns MW de potência (unidades estacionárias). A grande e principal vantagem desta tecnologia é a baixa emissão de poluentes, associada a uma alta eficiência. Este aspecto pode garantir às células a combustível um lugar de destaque num planejamento econômico/ambiental na matriz energética nacional. 


\section{OBJETIVOS}

O objetivo deste trabalho de pesquisa é a produção, caracterização e o estudo de Conjuntos Eletrodo/Membrana (ou MEAs, do inglês "Membrane Electrode Assembles") para aplicação em célula a combustível do tipo PEMFC (do inglês Proton Exchange Membrane Fuel Cell) para oxidação de Hidrogênio, DMFC (do inglês Direct Methanol Fuel Cell) para oxidação de Metanol e DEFC (do inglês Direct Ethanol Fuel Cell) para oxidação de Etanol sob várias condições de operação da célula com tecnologia nacional, utilizando-se a técnica de Espectroscopia de Impedância Eletroquímica (EIE) "on-line" (em tempo real), ou seja, com a célula a combustível em operação, como ferramenta de diagnóstico do desempenho da célula.

A parte inovadora do presente projeto de pesquisa pode ser resumida como a análise "on-line", sob diferentes solicitações de carga, de diagnóstico dos MEAs, com a técnica de EIE, sob diferentes condições de fabricação e operação.

A representação de resultados de EIE por circuito elétrico que será utilizado neste trabalho já se encontra na literatura, entretanto dados com a célula em funcionamento, ou seja, em condições reais de operação (valores altos de corrente elétrica) são escassos.

Além deste objetivo principal, outros objetivos não tão menos importante serão abordados, como o refinamento do método de preparação de MEAs e também a análise do método de redução por álcool para a oxidação de Hidrogênio, Metanol e Etanol nas células a combustível. 


\section{TEORIA 1 - CÉLULAS A COMBUSTÍVEL}

\subsection{Histórico e Conceito das Células a Combustível}

Apesar da associação da célula a combustivel às tecnologias modernas, o princípio de funcionamento desta foi descoberto a mais de 150 anos, em 1839, por intermédio de um jurista britânico, Sir William Robert Grove (1811-1896) que veio a tornar-se cientista. A tecnologia das células a combustivel é anterior a do motor de combustão interna, inventado por Nikolaus Otto em 1876, e a do motor de compressão/ignição, inventado por Rudolf Diesel em $1892^{[11]}$.

A partir de uma experiência simples, Sir Grove descobriu que a eletrólise da água em ácido sulfúrico diluído era reversível. Utilizando dois eletrodos de platina parcialmente mergulhados nesta solução aquosa ácida, com a parte restante dos eletrodos acondicionada em dois reservatórios contendo oxigênio e hidrogênio, Sir Grove conseguiu verificar que o sistema produzia corrente elétrica. Assim, Sir Grove verificou que ao combinar, em série, diversos sistemas deste tipo podia produzir corrente elétrica suficiente para fazer a eletrólise da água (FIGURA 1). Sir Grove chamou o sistema descoberto como "bateria a gás" [11].

Depois de 1920, o elétrodo de difusão de gás foi reconhecido como a chave para o sucesso do funcionamento das células a combustível funcionando a baixa temperatura. A. Schmid foi pioneiro ao desenvolver o primeiro eletrodo tubular para hidrogênio com platina impregnada em carbono poroso. A partir deste momento, as células a combustível passaram a ser construídas a partir da associação de eletrodos tubulares, um para o hidrogênio e outro similar para o ar (oxidante) ${ }^{[11]}$.

No Reino Unido, Francis Thomas Bacon (1904-1992) investigou o sistema de células a combustível alcalinas com eletrodos porosos metálicos. Deste modo, houve um aumento na área disponível para a reação. Este sistema serviu como protótipo para as células a combustível utilizadas nos programas espaciais Apollo e Gemini (NASA) ${ }^{[11]}$. 
Comparativamente com outras fontes de energia, as células a combustível disponibilizaram a melhor densidade de corrente $\left(\mathrm{kWh}_{\mathrm{kg}}{ }^{-1}\right)$ com uma potência específica aceitável $\left(\mathrm{kW} \cdot \mathrm{kg}^{-1}\right)$.

Na década de 1970 houve um interesse crescente na investigação das células a combustível. O sistema alcalino, que alcançou o nível máximo de desenvolvimento durante os programas espaciais, foi substituído pelo sistema ácido fosfórico que, por sua vez, era mais indicado para sistemas estacionários de produção de energia elétrica. Em paralelo foram realizados esforços no desenvolvimento de reformadores de hidrocarbonetos. Os esforços para o desenvolvimento de sistemas de produção de energia elétrica de elevado porte foram mais evidenciados no Japão, depois de uma queda de interesse por parte dos Estados Unidos ['I].

No entanto, nas décadas de 80 e 90, devido à sua melhor eficiência e possibilidade de co-geração de calor, houve um aumento de interesse no desenvolvimento dos sistemas de células a combustível de carbonato fundido e de óxido sólido ${ }^{[11]}$.

Outro acontecimento surpreendente na tecnologia das células a combustível aconteceu durante os anos 90 . As células a combustível ácidas reapareceram no meio científico com o desenvolvimento de novas membranas (introdução da membrana de Nafion $^{(\widehat{\mathbb{R}})}$, como eletrólito) e eletrocatalisadores (redução na quantidade de eletrocatalisador

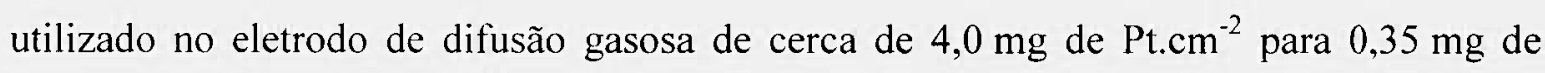
Pt.cm ${ }^{-2[12]}$, obtendo elevadas densidades de corrente e um maior tempo de vida útil.

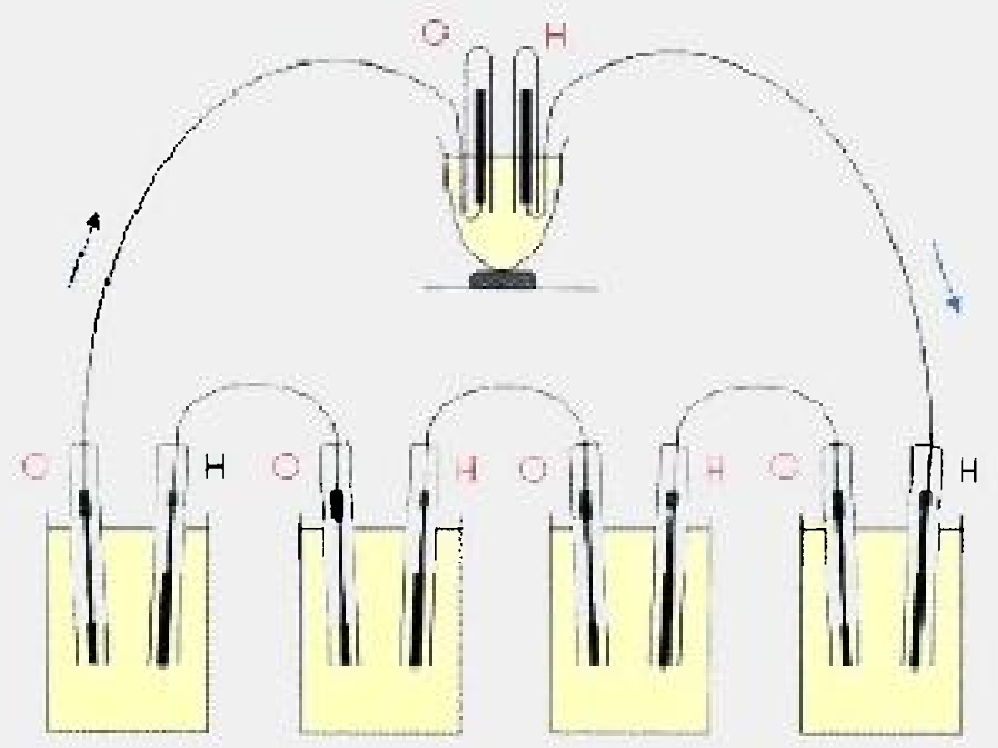

FIGURA 1 - "Bateria a gás" desenvolvida pelo Sir William Grove, primeiro protótipo de uma célula a combustível. 
Células a combustível são sistemas eletroquímicos capazes de transformar a energia química de um combustível diretamente em energia elétrica e calor, não ficando limitadas à eficiência do ciclo de Carnot para as máquinas térmicas ${ }^{[13]}$.

O princípio de funcionamento de uma célula a combustível é muito semelhante ao de uma bateria, consistindo de um anodo e um catodo separado por um eletrólito. No compartimento anódico da célula a combustível ocorre a oxidação do combustível, e os elétrons produzidos são usados no compartimento catódico na redução do agente oxidante. Separando estas reações, o eletrólito (condutor iônico) bloqueia a passagem dos elétrons do compartimento anódico para o catódico, fazendo com que os elétrons passem por um circuito externo onde se pode realizar trabalho elétrico.

Uma diferença marcante entre as células a combustível e as baterias é a contínua alimentação do combustível externo às células, enquanto as baterias têm todo o combustível estocado em seu interior, podendo (se a bateria for secundária) ser recarregadas eletroquimicamente.

\subsection{Tipos de Células a Combustível}

Atualmente cinco tipos de células a combustível são os mais pesquisados; sendo classificadas em dois grupos conforme a temperatura de funcionamento. A "alkaline fuel cell" (AFC), "proton exchange menbrane fuel cell" (PEMFC) e "phosphoric acid fuel cell" (PAFC) estão presentes no grupo das de baixa temperatura, e "molten carbonate fuel cell" (MCFC) e "solid oxide fuel cell" (SOFC) presentes no grupo de alta temperatura. A TABELA 1 apresenta os diferentes tipos de células a combustível, seus eletrólitos, suas temperaturas típicas de operação e as reações envolvidas em seu funcionamento.

Por causa de suas temperaturas de funcionamento, as células a combustível de alta temperatura e a PAFC são geralmente utilizadas para aplicações estacionárias, enquanto a PEMFC é potencialmente indicada para aplicações móveis, mas também se adequa para aplicações estacionárias e portáteis.

No começo da década de 1960 a AFC foi descoberta e serviu como gerador de energia na produção de água para os astronautas nos projetos da NASA. Entretanto, a AFC não se encontra como principal alternativa para uso comercial hoje em dia, pois ela necessita de gases ultra puros para o funcionamento. Se este empecilho for superado, haverá também um grande mercado para este tipo de célula a combustível.

Desde a década de 1990 a indústria automobilística vem centrando seus esforços em carros com emissão zero de poluentes. Neste conceito, as células a 
combustivel do tipo PEM vem se destacando com um conceito promissor para aplicações móveis.

TABELA 1 - Tipos de células a combustivel.

\begin{tabular}{|c|c|c|c|}
\hline Tipo & $\begin{array}{c}\text { Temperatura de } \\
\text { Funcionamento }\left({ }^{\circ} \mathrm{C}\right)\end{array}$ & Eletrólito & Reações Envolvidas \\
\hline $\mathrm{AFC}$ & $70-90$ & Hidróxido de Potássio & $\begin{aligned} \mathrm{H}_{2}+2 \mathrm{OH}^{-} & \rightarrow 2 \mathrm{H}_{2} \mathrm{O}+2 \mathrm{e}^{-} \\
1 / 2 \mathrm{O}_{2}+\mathrm{H}_{2} \mathrm{O}+2 \mathrm{e}^{-} & \rightarrow 2 \mathrm{OH}^{-}\end{aligned}$ \\
\hline PEMFC & $70-90$ & Membrana Polimérica & $\begin{aligned} \mathrm{H}_{2} & \rightarrow 2 \mathrm{H}^{+}+2 \mathrm{e}^{-} \\
1 / 2 \mathrm{O}_{2}+2 \mathrm{H}^{+}+2 \mathrm{e}^{-} & \rightarrow \mathrm{H}_{2} \mathrm{O}\end{aligned}$ \\
\hline PAFC & 200 & Ácido Fosfórico & $\begin{aligned} \mathrm{H}_{2} & \rightarrow 2 \mathrm{H}^{+}+2 \mathrm{e}^{-} \\
1 / 2 \mathrm{O}_{2}+2 \mathrm{H}^{+}+2 \mathrm{e}^{-} & \rightarrow \mathrm{H}_{2} \mathrm{O}\end{aligned}$ \\
\hline MCFC & 650 & $\begin{array}{l}\text { Carbonato de Lítio ou } \\
\text { Carbonato de Potássio }\end{array}$ & $\begin{aligned} & \mathrm{H}_{2}+\mathrm{CO}_{3}{ }^{2-} \rightarrow \mathrm{H}_{2} \mathrm{O}+\mathrm{CO}_{2}+2 \mathrm{e} \\
& \mathrm{CO}+\mathrm{CO}_{3}{ }^{2-} \rightarrow 2 \mathrm{CO}_{2}+2 \mathrm{e}^{-} \\
& 1 / 2 \mathrm{O}_{2}+\mathrm{CO}_{2}+2 \mathrm{e}^{-} \rightarrow \mathrm{CO}_{3}{ }^{2-}\end{aligned}$ \\
\hline SOFC & $850-1000$ & Zircônia & $\begin{aligned} \mathrm{H}_{2}+\mathrm{O}_{2}^{-} & \rightarrow \mathrm{H}_{2} \mathrm{O}+2 \mathrm{e}^{-} \\
\mathrm{CO}+\mathrm{O}_{2}^{-} & \rightarrow \mathrm{CO}_{2}+2 \mathrm{e}^{-} \\
\mathrm{CH}_{4}+4 \mathrm{O}_{2}^{-} & \rightarrow 2 \mathrm{H}_{2} \mathrm{O}+\mathrm{CO}_{2}+8 \mathrm{e}^{-} \\
1 / 2 \mathrm{O}_{2}+2 \mathrm{e}^{-} & \rightarrow \mathrm{O}_{2}^{-}\end{aligned}$ \\
\hline
\end{tabular}

\subsection{Células a Combustível do Tipo PEMFC}

Dentre os vários tipos de células a combustível, a que utiliza um polímero como eletrólito (tipo PEMFC, do inglês "Proton Exchange Membrane Fuel Cell"), tem-se mostrada promissora para aplicação em veículos elétricos, em residências (e outras aplicações estacionárias) e em sistemas portáteis, devido à ausência de líquidos e partes móveis no seu interior, à sua densidade de potência elevada (compatíveis com motores à explosão) e à temperatura de operação relativamente baixa (em torno de $80^{\circ} \mathrm{C}$ ).

O eletrólito polimérico mais largamente estabelecido em células PEM é o Nafion $^{\mathbb{R}}$, um polímero hidrofilico semelhante ao Teflon ${ }^{\mathrm{B}}$ (hidrofóbico). É comercializado pela Du Pont na forma de membranas com espessuras entre 51 e $183 \mu \mathrm{m}$. Esta membrana polimérica é um isolante eletrônico, e quando hidratada torna-se um excelente condutor de prótons, que na célula são transportados no sentido do anodo para o catodo através dos grupos sulfônicos ácidos presentes na cadeia do polimero.

Na FIGURA 2 é mostrado o funcionamento de uma célula a combustivel a baixa temperatura (PEMFC) operando com hidrogênio e oxigênio.

Pode-se observar na FIGURA 2, que o combustível entra na célula pelo anodo, penetra no tecido de carbono (GDL, do inglês "Gás Difusion Layer") atingindo os eletrocatalisadores onde são gerados elétrons (que escoam pelo circuito elétrico gerando 
trabalho elétrico) e os cátions $\mathrm{H}^{+}$que permeiam a membrana de $\mathrm{Nafion}^{\mathrm{R}}$, atingindo o catodo da célula. $O$ agente oxidante entra na célula pelo catodo, penetra no GDL atingindo os eletrocatalisadores onde sofre um enfraquecimento da ligação O-O, este se liga ao $\mathbf{H}^{+}$ proveniente do anodo favorecendo a formação de $\mathrm{H}_{2} \mathrm{O}$. Como esta última reação é exotérmica, ocorre na célula a geração de calor.

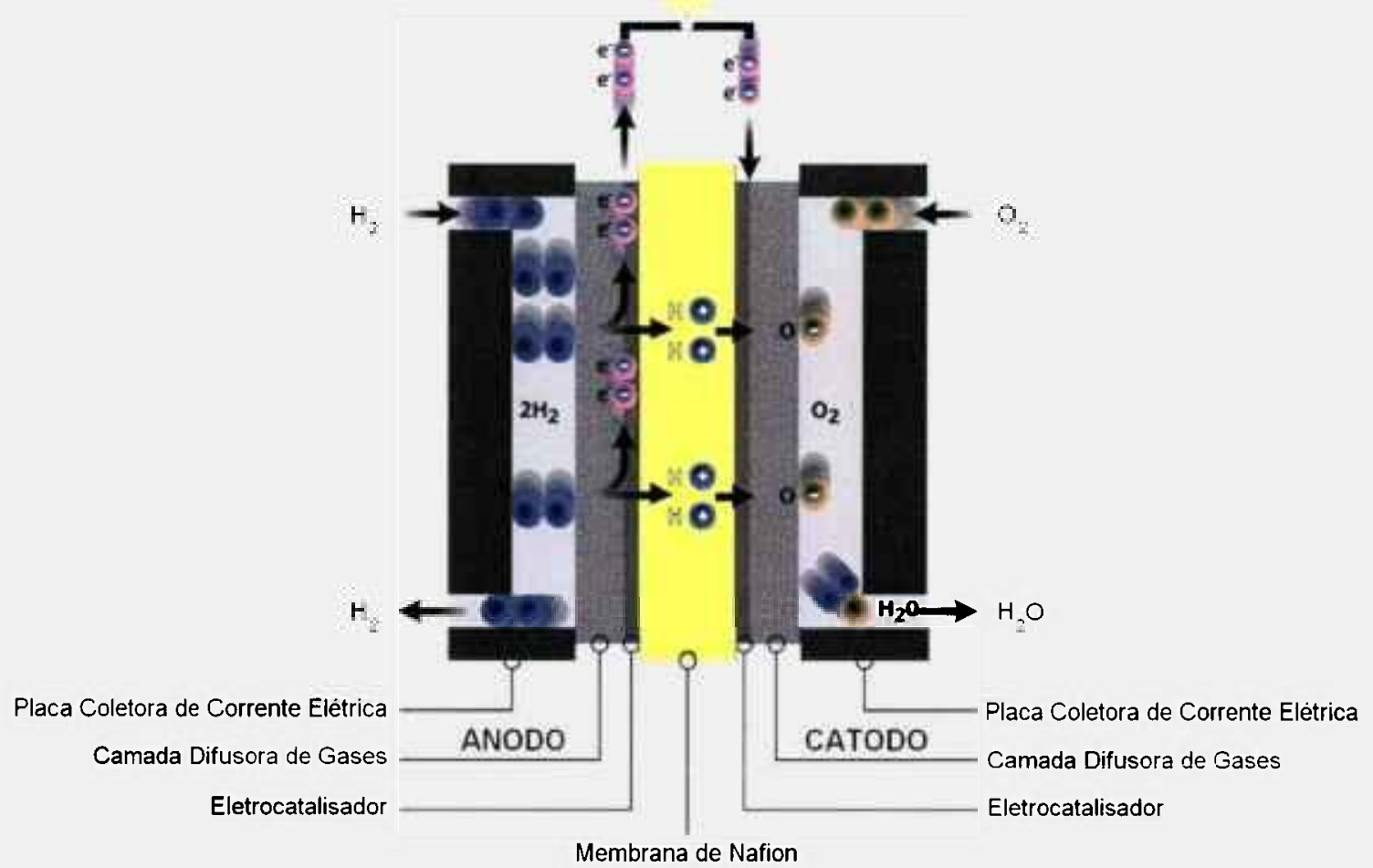

FIGURA 2 - Modelo de funcionamento de uma célula a combustível ácida do tipo PEMFC.

Muitos problemas ainda terão que ser solucionados para que as células a combustivel se tornem fontes efetivas de produção em quantidades consideráveis de energia num futuro próximo. Questões de custo e tecnologias compõem estes problemas. O tempo de vida deste tipo de célula a combustivel também não é satisfatoriamente alto para aplicações comerciais.

Os eletrocatalisadores usados em células PEM consistem fundamentalmente de nanopartículas de Pt (2-6nm de diâmetro) ancorados num suporte de partículas de carbono (negro de fumo), que medem entre $2-10 \mathrm{~nm}^{[1+-18]}$. Tem-se pesquisado a inserção 
inserção de nanotubos de carbonos como suporte para melhorar a eficiência do processo de ancoragem dos eletrocatalisadores ${ }^{[18,19]}$.

Com o objetivo de aumentar a tolerância ao monóxido de carbono, bloqueador dos sítios de Pt, vários trabalhos recentes tratam da incorporação de um ou mais metais não nobres à platina dispersa, geralmente na forma de liga ${ }^{[8,9,13,19]}$, O papel destes componentes baseia-se na sua relativa facilidade de formar óxidos hidratados em baixos sobrepotenciais. Estas espécies desempenham o papel de agentes oxidantes, convertendo o $\mathrm{CO}$ quimissorvido a dióxido de carbono, a baixos potenciais, que rapidamente se dessorve da superfície do eletrocatalisador, liberando a superfície da $\mathrm{Pt}$, permitindo a oxidação do combustível. Dentre os metais já investigados ( $\mathrm{Ru}, \mathrm{Os}, \mathrm{Mo}$, Sn etc.) o Ru associado à platina apresenta os resultados mais promissores ${ }^{[8,9,18-38]}$ para sistemas binários.

\subsection{Eletrodos de Difusão Gasosa}

Eletrodo de difusão gasosa é uma estrutura porosa condutora de elétrons do sistema eletrodo/eletrocatalisador, utilizado, por exemplo, em células a combustível de baixa temperatura de operação do tipo PEMFC. A construção deste eletrodo tem como função a maximização da interface trifásica gás-líquido-sólido, aumentando consideravelmente a velocidade dos processos eletródicos. Os eletrodos de difusão gasosa devem satisfazer a exigência importante de possuir alta atividade catalítica, a fim de se obter alta densidade de corrente, além de possuir uma distribuição de tamanho de poros adequada.

A superfície interna dos poros do eletrodo é contatada por um filme delgado do ionômero do eletrólito (solução de $\operatorname{Nafion}^{\circledR}$ ), de modo a aumentar a interface eletrodo/eletrólito. Os eletrodos de difusão gasosa são extremamente delgados, a fim de se obter uma menor resistência ôhmica possível. As partículas do eletrocatalisador estão numa faixa de distribuição de tamanho nanométrica, dispersas em partículas de carvão ativo ou nanotubos de carbono para se obter uma maior área superficial disponível para a eletrocatálise sem aglomerados de partículas (com a formação de aglomerados diminui-se a área ativa).

Na FIGURA 3 está representado o modelo de um eletrodo de difusão gasosa utilizado em célula a combustível a baixa temperatura (PEMFC). 


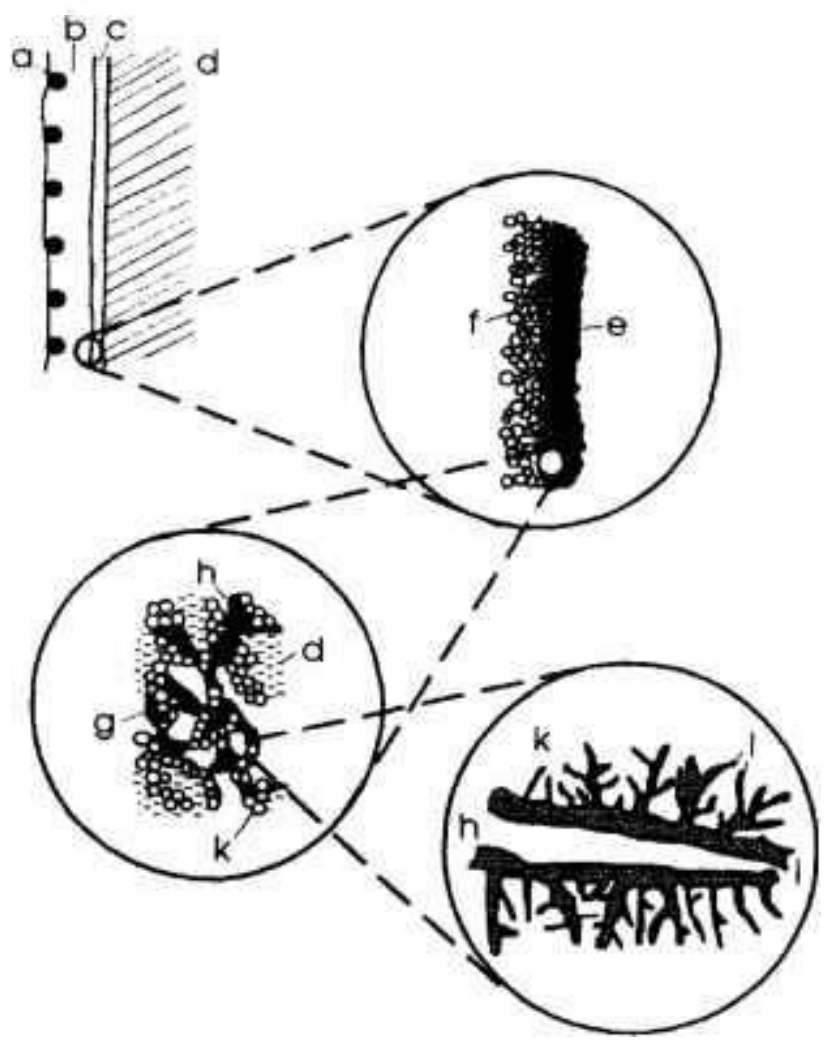

FIGURA 3 - Modelo de um eletrodo de difusão gasosa utilizado em célula a combustível a baixa temperatura (PEMFC). Sendo: a) lado gás, b) camada difusora, c) camada catalisadora, d) eletrólito, e) catalisador suportado, f) coletor de corrente, g) Nafion ${ }^{\circledR}$, h) canais dos gases, i) membrana de Nafion ${ }^{\mathbb{Q}}$, $\mathbf{k}$ ) catalisador e l) poros.

\subsection{Eficiência de uma Célula a Combustível}

A célula a combustível, como toda célula galvânica, diferente dos motores a combustão interna, não é regida pelo ciclo de Carnot. Com isto, a eficiência teórica máxima, ou eficiência termodinâmica, da célula a combustível é alta e por ser um processo irreversível pode ser calculada a partir das reações químicas que se realizam no anodo e catodo da célula. A energia produzida por tais processos é a variação da entalpia $(\Delta \mathrm{H})$ por unidade de reação (por mol), que se manifesta sob a forma de calor trocado com o meio externo $\left(Q_{p}\right)$ a $T$ e $P$ constantes.

$$
\Delta \mathrm{H}=\Delta \mathrm{G}+\mathrm{T} \Delta \mathrm{S}=\mathrm{Q}_{\mathrm{p}}
$$

Onde, $\Delta \mathrm{G}$ e $\mathrm{T} \Delta \mathrm{S}$ se manifestam na forma de calor se a reação se conduzir de forma irreversível. Entretanto, muitas reações REDOX podem ser conduzidas reversivelmente numa célula galvânica, neste caso $\Delta G$ pode aparecer sob a forma de 
trabalho elétrico e apenas $\mathrm{T} \Delta \mathrm{S}$ se manifesta sob a forma de calor trocado reversivelmente com o meio ambiente.

Desta maneira, se a reação for conduzida reversivelmente, uma fração de $\Delta \mathrm{H}$ poderá ser convertida em energia elétrica, porém $\mathrm{T} \Delta \mathrm{S}$ sempre se manifesta na forma de calor. Assim a $\Delta \mathrm{G}$ representa a parte máxima de $\Delta \mathrm{H}$ que pode se manifestar na forma de trabalho elétrico. A relação entre $\Delta \mathrm{G}$ e $\Delta \mathrm{H}$ é chamada de eficiência teórica máxima (ou eficiência termodinâmica) representada pela letra $\eta_{\mathrm{th}}$.

$\mathrm{Na}$ célula a combustível operando com $\mathrm{H}_{2} / \mathrm{O}_{2}$, temos $\eta_{\text {MáxTeórico }} \cong 83 \%$ a $\mathrm{T}=25^{\circ} \mathrm{C}$, superior aos melhores motores a combustão que têm eficiência máxima real da ordem de $25 \%$.

Na FIGURA 4 estão representadas as eficiências máximas de uma célula a combustível e de um motor regido pelo ciclo de Carnot.

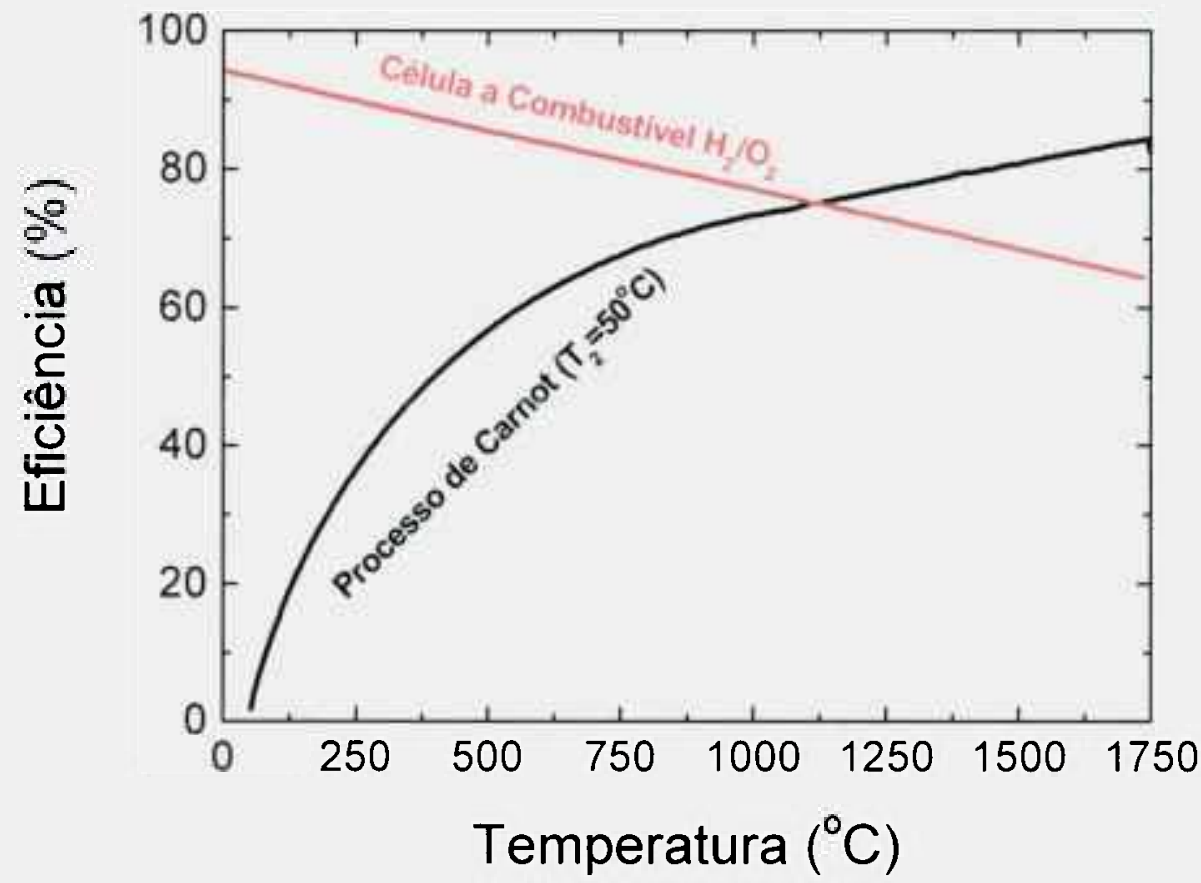

FIGURA 4 - Comparação da eficiência máxima de uma célula a combustível e de um motor regido pelo ciclo de Carnot.

\subsection{Cinética de Eletrodo}

\subsubsection{Condição de Equilíbrio $(I=0)$}

A descarga de uma célula galvânica corresponde a um processo eletroquímico que pode ser dividido em duas reações de eletrodo. Estas podem ser combinadas para formar uma célula com reação global eletronicamente neutra. Neste caso, uma parte dos 
reagentes é transformada em produtos na célula galvânica, e trabalho elétrico é gerado $(n \mathrm{~F} \Delta \mathrm{E})$. O máximo trabalho elétrico que pode ser obtido para uma reação específica corresponde ao equilíbrio (zero de corrente) e a voltagem de célula é $E_{0}$, que é a força eletromotriz (FEM) da célula.

$$
\mathrm{W}_{\mathrm{el}}=n \mathrm{~F} \Delta \mathrm{E}
$$

Onde, $n=$ número de elétrons trocados; $\mathrm{F}=$ constante de Faraday e $\Delta \mathrm{E}=$ diferença de potencial entre os eletrodos.

Mas, pode-se ter um caso exclusivo onde a reação tem uma velocidade infinitamente lenta (mas ainda com $I=0$ ). Assim, a força eletromotriz nas condições padrão $\left(\mathrm{E}^{0}\right)$ assume as propriedades dos ions participantes e da pressão parcial dos reagentes que é igual à pressão padrão $\left(\mathrm{p}^{0}\right)$, e este cálculo é possível utilizando a energia livre de Gibbs $(\Delta G)$.

$$
E^{0}=-\Delta G^{0} / n F
$$

Além disso, a dependência da concentração e da pressão parcial dos gases reagentes é determinada pela equação geral de Nernst:

$$
E_{0}=E^{0}+\frac{R T}{n F} \ln \prod_{i} a_{i}^{n_{t}}
$$

Onde,

$E_{0}=$ força eletromotriz, $E^{0}=$ força eletromotriz padrão, $R=$ constante universal dos gases, $\mathrm{T}=$ temperatura, $a_{\mathrm{i}}=$ atividade e $\mathrm{n}_{\mathrm{i}}=$ coeficiente estequiométrico.

Na Tabela 2 estão os valores termodinâmicos para as reações envolvidas em PEMFC, DMFC e DEFC nas condições padrão. 
TABELA 2 - Valores termodinâmicos para as reações envolvidas nas células dos tipos

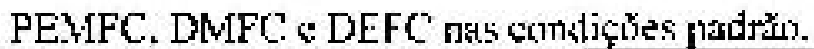

\begin{tabular}{|l|c|c|c|c|c|}
\hline Reação & $\mathbf{\Delta H}^{\mathbf{0}}[\mathbf{k J} / \mathbf{m o l}]$ & $\mathbf{\Delta G}^{\mathbf{0}}[\mathbf{k J} / \mathbf{m o l}]$ & $\mathbf{\Delta G}^{\mathbf{0}} / \mathbf{\Delta} \mathbf{H}^{\mathbf{0}}$ & $\mathbf{E}^{\mathbf{0}}[\mathbf{V}]$ & $\mathbf{n}$ \\
\hline Hidrogênio & $-285,9$ & $-237,5$ & $83,07 \%$ & 1,23 & 2 \\
\hline Metanol & $-726,0$ & $-707,9$ & $97,50 \%$ & 1,22 & 6 \\
\hline Etanol & -1366 & -1325 & $97,00 \%$ & 1,14 & 12 \\
\hline
\end{tabular}

\subsubsection{Potencial de Célula e Reações de Eletrodo $(I \neq 0)$}

Sob passagem de corrente, tem-se que considerar a cinética de eletrodo e, portanto sua interface e a variação da Dupla Camada Elétrica (DCE).

Na FIGURA 5 está representada uma célula eletroquímica com dois eletrodos e o seu correspondente circuito elétrico equivalente. A resistência do eletrólito $\left(\mathrm{R}_{\mathrm{e}}\right)$ é independente da magnitude ou direção da corrente, onde as $R_{1}$ e $R_{I I}$ são resistências não ôhmicas. A força eletromotriz da célula é a diferença do potencial entre os dois eletrodos sem fluxo de corrente $\left(E_{r}\right)$, ou seja, em equilibrio.

Permitindo que ocorra um fluxo de corrente elétrica pela célula, o potencial global da célula diminuirá devido à contribuição (perdas) relativa à resistência de transferência de cargas na superfície do eletrodo (polarização por ativação), à resistência ôhmica dos componentes da célula, principalmente o eletrólito, e à resistência por transporte de massa (por difusão) nos eletrodos. Na equação 5 está descrita a relação do desvio do potencial de equilíbrio $E_{r}$ da célula. A magnitude da divergência do potencial de cada eletrodo em relação ao de equilíbrio $\mathrm{E}_{\mathrm{r}}$ determina o sobrepotencial $\eta$.

$$
E=E_{r}-\left(\eta_{A}-\eta_{C}\right)-I \cdot R
$$

onde, $\eta_{\mathrm{A}}$ e $\eta_{\mathrm{C}}$ são os sobrepotenciais anódico $\left(\eta_{\mathrm{A}}=\eta_{A}^{* \prime}+\eta_{A}^{\eta \mathrm{Mi}}\right)$ e catódico

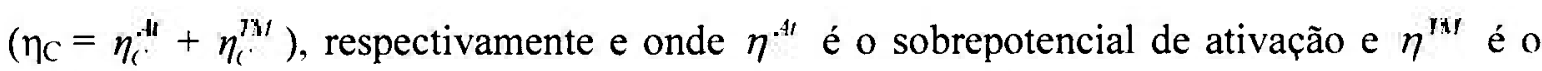
sobrepotencial por transferência de massa, que serão discutidos mais adiante.

Em uma célula eletroquímica com dois eletrodos, o potencial do eletrodo de trabalho não pode ser definido exatamente. Para que o potencial seja definido, introduz-se na célula um terceiro eletrodo (eletrodo de referência), podendo assim medir correntes mínimas em relação ao eletrodo de trabalho. 
Este sistema é denominado de célula de três eletrodos e está representado na FIGURA 6 e é essencial para todas as medidas de características de eletrodo, contanto que as contribuições da resistência do eletrólito e do contra eletrodo não sejam desprezíveis. Adicionalmente, a fim de reduzir a resistência do eletrólito, utiliza-se uma ponte salina com um capilar de Haber-Luggin, com a ponta terminando diretamente em frente ao eletrodo de trabalho.

Em cinética de eletrodo a taxa de reação global é determinada pela etapa mais lenta para a cinética da reação. É exatamente esta etapa que determina a magnitude e o tipo do sobrepotencial de eletrodo. Podem ser distinguidos três tipos diferentes de sobrepotencial de reação: sobrepotencial por ativação, sobrepotencial por concentração e sobrepotencial por queda ôhmica.

O sobrepotencial por ativação reflete uma limitação imposta pela resistência de transferência de cargas na interface eletrodo/eletrólito. $O$ eletrocatalisador incorporado na estrutura do eletrodo aumenta a velocidade das reações e, com isso, pode gerar uma redução dos sobrepotenciais de ativação.

O sobrepotencial por concentração resulta da lentidão de transporte, ou seja, da falta do reagente ou excesso de produto na interface eletrodo/eletrólito. Isto ocorre quando o consumo do reagente na reação eletródica é mais rápido que a sua chegada, por difusão, ao sítio ativo da reação durante a operação do sistema. Para garantir o contínuo acesso dos reagentes e minimizar esta polarização, os eletrodos devem ser porosos e possuir elevada área interfacial, pois em geral, para processos em meios aquosos ou similares, a porosidade do eletrodo e sua maior área afetam a velocidade da reação de transferência de carga.

O sobrepotencial por queda ôhmica resulta da existência de resistências elétricas ôhmicas no interior das células. $\mathrm{O}$ eletrólito, os contatos elétricos e os eletrodos são os maiores responsáveis pela queda ôhmica.

$\mathrm{Na}$ FIGURA 7 observa-se uma curva de polarização de uma célula a combustível, com o decaimento do potencial acarretado por sobrepotenciais presentes nas reações da célula.

Esta curva de polarização é uma forma de se avaliar o desempenho de uma célula a combustível. Observando a região e o tamanho do decaimento de potencial, podese ter uma idéia de como está o desempenho da célula, e fazer alterações para a melhoria do sistema que está sendo estudado. 


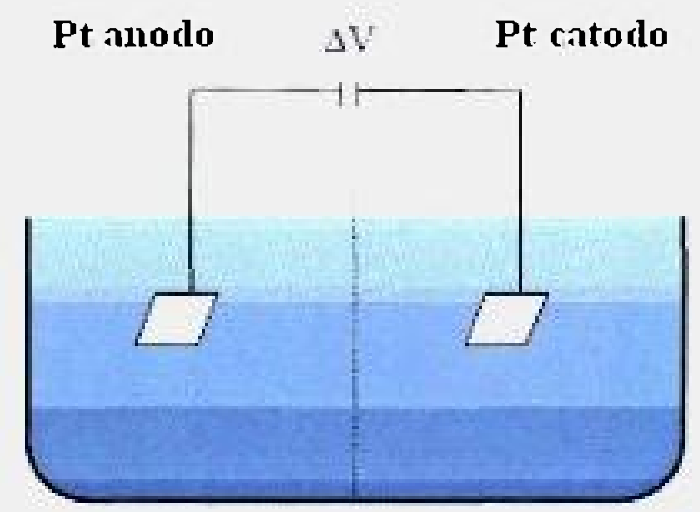

FIGURA 5 - Célula eletroquímica com dois eletrodos.

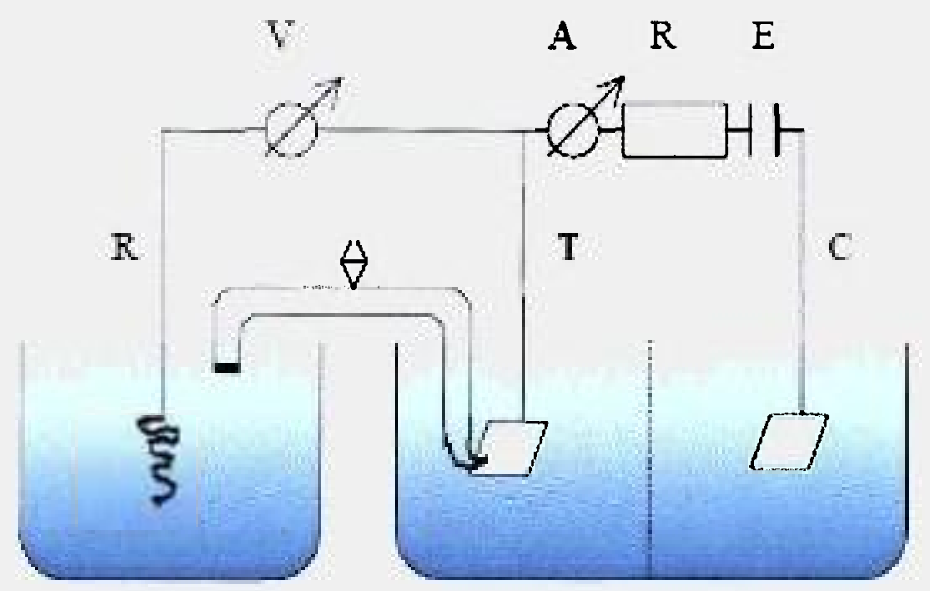

FIGURA 6 - Célula eletroquímica com três eletrodos. Onde R, T e C são: o eletrodo de referência, eletrodo de trabalho e o contra eletrodo, respectivamente.

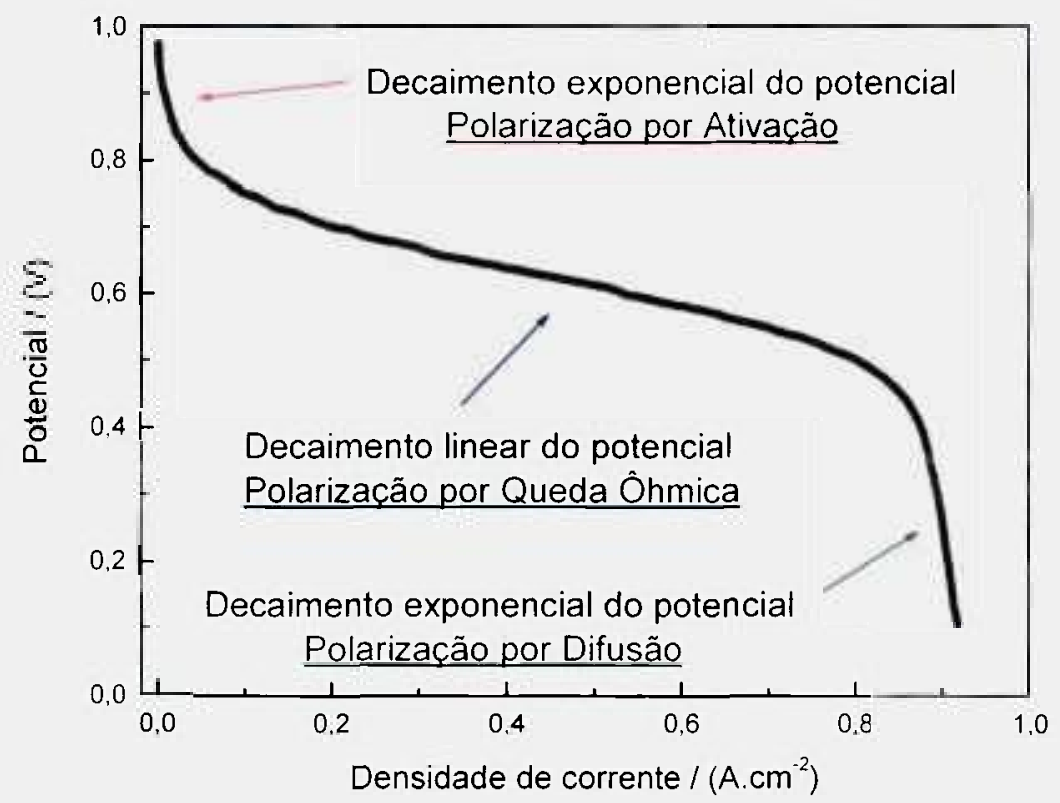

FIGURA 7 - Representação de uma curva de polarização de uma célula a combustível. 


\subsection{Reações de uma Célula a Combustível}

\subsubsection{Reação de Redução do Oxigênio (RRO)}

A reação de redução do oxigênio ocorre por dois mecanismos diferentes, o mecanismo direto que envolve a transferência de quatro elétrons e o mecanismo indireto com formação de peróxido envolvendo a transferência de dois elétrons ${ }^{[16]}$. O mecanismo direto pode ocorrer por uma série de etapas que conduzem a formação de $\mathrm{OH}^{-}$ou $\mathrm{H}_{2} \mathrm{O}$. O mecanismo indireto tem como principal produto formado o peróxido de hidrogênio. No ESQUEMA 1 observa-se os possíveis mecanismos da RRO.

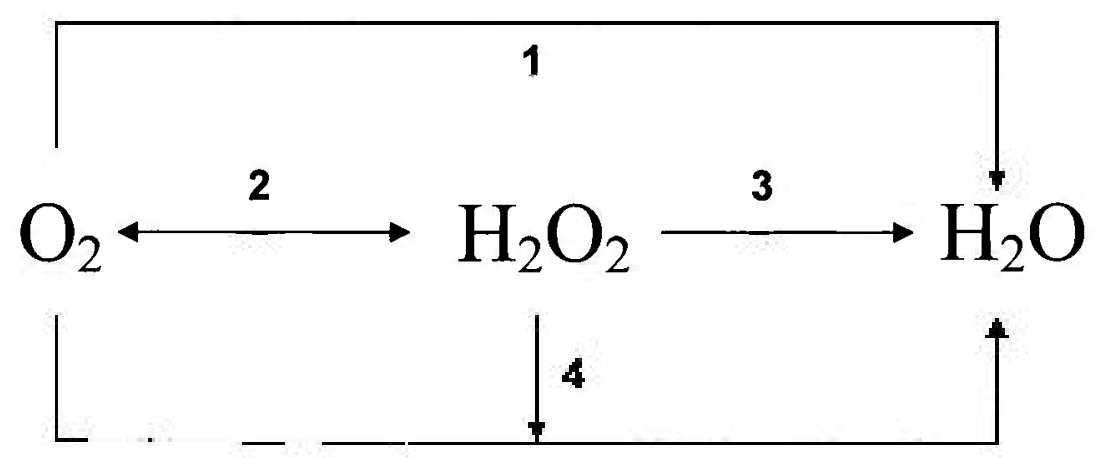

ESQUEMA 1 - Mecanismos das reações envolvidas na RRO.

Onde:

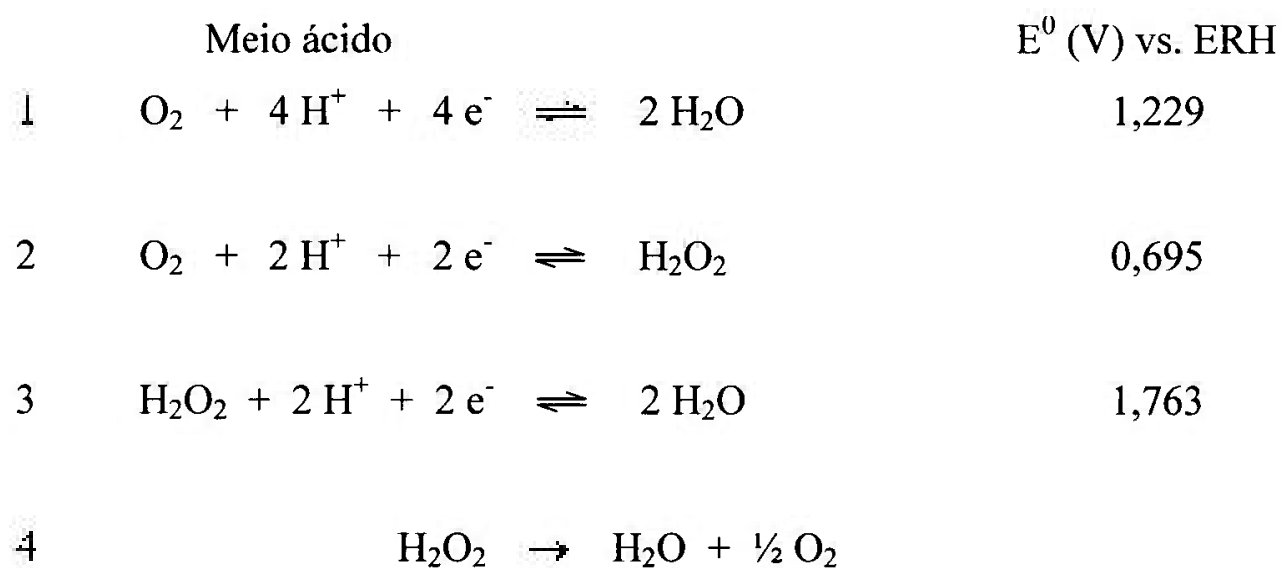

Nas células a combustivel a membrana trocadora de prótons a reação de redução de oxigênio possui uma cinética lenta, tornando-se responsável pela maior parte das polarizações na célula a combustível a hidrogênio. Nestas células procura-se empregar eletrodos de difusão gasosa com uma estrutura desenvolvida para maximizar a tripla fase reacional a fim de se obter maiores densidades de correntes. Para a reação de redução do oxigênio tem sido largamente empregado o catalisador de platina com partículas 
nanodispersas em negro de fumo. Neste caso, a reação de redução do oxigênio processa-se quase que exclusivamente pelo mecanismo de quatro elétrons.

A estrutura do eletrodo de difusão gasosa influencia bastante o desempenho da célula a combustível. Por isso, alguns modelos teóricos têm sido desenvolvidos com o intuito de verificar esta influência. Entretanto, muitos problemas ainda persistem devido ao não conhecimento detalhado da estrutura destes eletrodos e as equações necessárias para descrever o transporte de massa e a distribuição do potencial.

\subsubsection{Oxidação do Hidrogênio sobre Platina}

Por definição, o potencial de equilíbrio da reação de oxidação do hidrogênio é zero ( $0 \mathrm{~V}$ versus Eletrodo Reversível de Hidrogênio (ERH)). Na oxidação do hidrogênio sobre a platina, após o transporte da molécula de hidrogênio à superfície do eletrodo ocorre a adsorção molecular e a seguir a ruptura da ligação $\mathrm{H}-\mathrm{H}$.

$$
\begin{gathered}
\mathrm{H}_{2} \rightleftharpoons \mathrm{H}_{2, \text { ads }} \\
\mathrm{H}_{2, \text { ads }} \rightleftharpoons 2 \mathrm{H}_{\mathrm{ads}}
\end{gathered}
$$

As seguintes etapas da reação (ionização e a hidratação), que podem ocorrer em duas diferentes vias de reações, segundo o mecanismo de Tafel-Volmer ou o de Heyrovski-Volmer.

\section{i) Mecanismo de Tafel-Volmer}

Reação de Tafel $\quad \mathrm{H}_{2, \text { ads }} \rightleftharpoons 2 \mathrm{H}_{\mathrm{ads}}$

Reação de Volmer $\quad \mathrm{H}_{\text {ads }}+\mathrm{H}_{2} \mathrm{O} \rightleftharpoons \mathrm{H}_{3} \mathrm{O}^{+}+\mathrm{e}^{-}$

\section{ii) Mecanismo de Heyrovski-Volmer}

Reação de Heyrovski $\quad \mathrm{H}_{2, \text { ads }}+\mathrm{H}_{2} \mathrm{O} \rightleftharpoons \mathrm{H}_{3} \mathrm{O}^{+}+\mathrm{H}_{\text {ads }}+\mathrm{e}^{-}$

Reação de Volmer

$$
\mathrm{H}_{\mathrm{ads}}+\mathrm{H}_{2} \mathrm{O} \rightleftharpoons \mathrm{H}_{3} \mathrm{O}^{+}+\mathrm{e}^{-}
$$

O caminho da reação depende da entalpia de adsorção de hidrogênio do material de eletrodo utilizado. Devido ao fato de que sobre platina metálica a reação de 
Tafel é bastante favorecida cataliticamente, a oxidação de hidrogênio ocorre praticamente só via mecanismo de Tafel-Volmer. Também devido ao fato de que uma grande parte da energia necessária para a ruptura da ligação $\mathrm{H}-\mathrm{H}$ vem da entalpia de adsorção dos átomos de hidrogênio (a energia de dissociação do hidrogênio é $432 \mathrm{~kJ} / \mathrm{mol}$ ), a reação de Tafel ocorre tanto mais rapidamente quanto maior for a entalpia de adsorção do hidrogênio em cada metal. Por outro lado, uma entalpia de adsorção muito alta leva a uma desaceleração da reação de Volmer, que contém a ruptura da ligação hidrogênio-metal.

Assim chega-se a um máximo da densidade de corrente de troca (que representa a contribuição da reação catódica que se iguala à anódica quando o sistema está em equilíbrio) a um valor médio da entalpia de adsorção, como fica visível na curva de Vulcano ${ }^{[39]}$ apresentada na FIGURA 8 , onde se tem correlacionada a energia de adsorção com a densidade de corrente de troca da oxidação/evolução de hidrogênio.

Da curva de Vulcano nota-se, que as maiores densidades de corrente de troca para a evolụção/oxidação de hidrogênio são medidas em platina metálica, dando $7,9 \times 10^{-4}$ A.cm ${ }^{-2}$, sob condições normais.

Este valor é bastante superior à densidade de corrente de troca da redução de oxigênio, com $0,5 \times 10^{-6} \mathrm{~A} \cdot \mathrm{cm}^{-2}$, ou seja, a oxidação anódica do hidrogênio não é, quando se usa platina, limitante, sendo a platina o catalisador escolhido para o anodo em células a combustível de baixa temperatura para operação com hidrogênio puro.

Com partículas de platina nanodispersas num suporte de carbono obtêm-se superfícies específicas de até $150 \mathrm{~m}^{2}$.(gPt) ${ }^{-1} \mathrm{e}$ densidades de corrente de troca superiores a $1000 \mathrm{~A}$.(gPt $)^{-1}$. Assim, anodos podem conter cargas de catalisadores bastante baixas para a produção de corrente elétrica a partir de hidrogênio puro; sendo que o preço da platina para o catalisador do anodo representa um papel secundário para o custo da célulạ, não sendo necessário um novo desenvolvimento nesta área. 


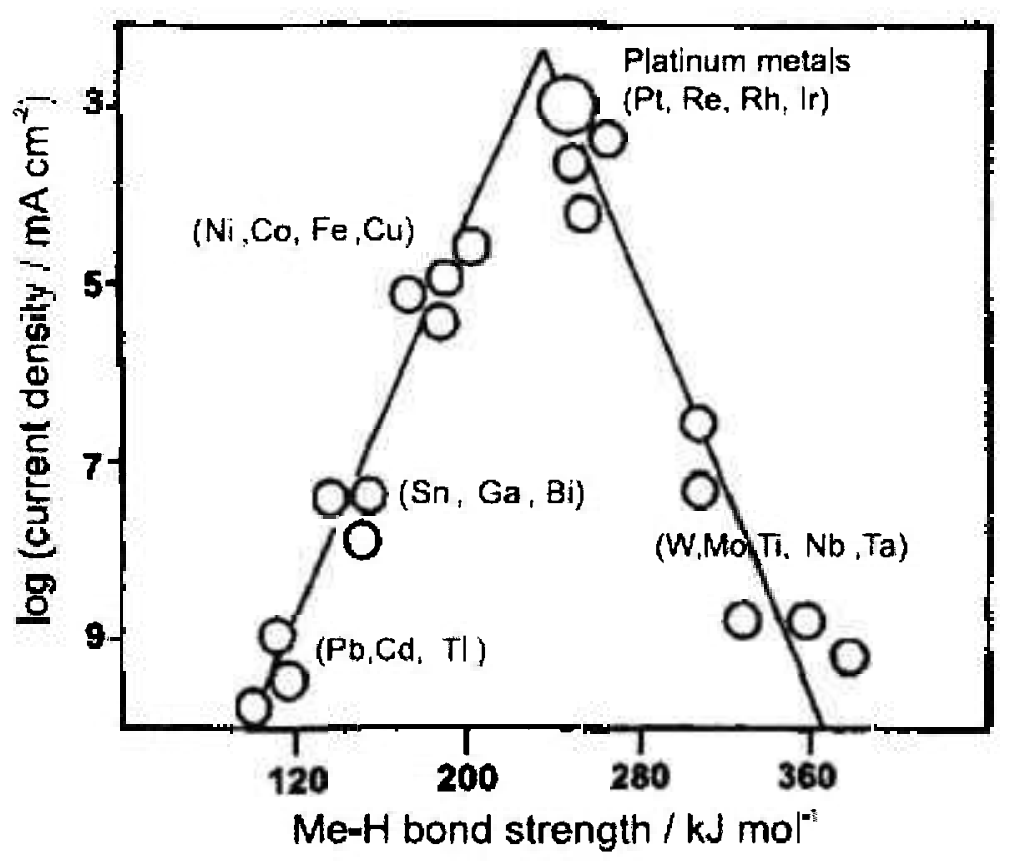

FIGURA 8 - Curva de Vulcano: densidade de corrente de troca de hidrogênio versus a entalpia de adsorção do hidrogênio atômico em diferentes metais ${ }^{[\$ 1]}$.

\subsubsection{Oxidação do Metanol sobre Platina}

O mecanismo da oxidação de metanol foi revisado por Parsons e Vandernoot em $1988^{[40]}$ e por Hamnett ${ }^{[41]}$ em 1997, e apresenta dois aspectos fundamentais, sendo a eletrossorção de metanol e a adição de oxigênio ao intermediário contendo carbono para gerar $\mathrm{CO}_{2}$.

Poucos são os materiais sobre os quais o metanol se adsorve. Em solução ácida somente platina e ligas de platina apresentam atividade para a oxidação do metanol. Esta é a razão principal para que quase todos os estudos mecanísticos estejam concentrados sobre estes materiais.

A existência de vários intermediários na oxidação do metanol é de consenso de diversos pesquisadores, entretanto ainda não está completamente esclarecido o mecanismo pelo qual esta oxidação ocorre. A seguir apresentam-se as possíveis etapas aceitas para a oxidação de metanol sobre platina

Primeiramente ocorre a adsorção do metanol na superfície do catalisador e então uma dehidrogenação do metanol com a formação de hidrogênio adsorvido, $\mathrm{H}_{\mathrm{ads}}$, resultando em monóxido de carbono adsorvido, $\mathrm{CO}_{\mathrm{ads}}$, como Pt-CO. Estas reações são denominadas de adsorção dissociativa do metanol. 


$$
\begin{aligned}
\mathrm{CH}_{3} \mathrm{OH}+\mathrm{Pt} & \rightarrow \mathrm{Pt}_{-}-\mathrm{CH}_{2} \mathrm{OH}_{\mathrm{ads}}+\mathrm{H}^{+}+\mathrm{e}^{-} \\
\mathrm{Pt}_{-} \mathrm{CH}_{2} \mathrm{OH}_{\mathrm{ads}}+\mathrm{Pt} & \rightarrow \mathrm{Pt}_{2}-\mathrm{CHOH}_{\mathrm{ads}}+\mathrm{H}^{+}+\mathrm{e}^{-} \\
\mathrm{Pt}_{2}-\mathrm{CHOH}_{\mathrm{ads}}+\mathrm{Pt} & \rightarrow \mathrm{Pt}_{3}-\mathrm{COH}_{\mathrm{ads}}+\mathrm{H}^{+}+\mathrm{e}^{-} \\
\mathrm{Pt}_{3}-\mathrm{COH}_{\text {ads }} & \rightarrow \mathrm{Pt}^{-} \mathrm{CO}_{\text {ads }}+2 \mathrm{Pt}+\mathbf{H}^{+}+\mathrm{e}^{-}
\end{aligned}
$$

Para a oxidação do $\mathrm{CO}_{\text {ads }}$ a $\mathrm{CO}_{2}$ em platina é necessária a presença de um adsorbato na superfície da platina. Este adsorbato é chamado de "água ativada", embora ainda não esteja totalmente esclarecido, qual é a espécie responsável pela referida ativação. A seguir formula-se a "água ativada" à Platina como Pt-OH, que corresponde a um hidróxido de superfície na platina.

$$
\mathrm{Pt}+\mathrm{H}_{2} \mathrm{O} \rightarrow \mathrm{Pt}_{-}-\mathrm{OH}_{\mathrm{ads}}+\mathrm{H}^{+}+\mathrm{e}^{-}
$$

A etapa seguinte pode ocorrer através da reação (21) ou (22):

$$
\begin{aligned}
& \mathrm{Pt}-\mathrm{CO}_{\mathrm{ads}}+\mathrm{Pt}-\mathrm{OH}_{\mathrm{ads}} \rightarrow \mathrm{Pt}-\mathrm{COOH}_{\mathrm{ads}} \\
& \text { ou } \\
& \mathrm{Pt}-\mathrm{CO}_{\mathrm{ads}}+\mathrm{H}_{2} \mathrm{O} \rightarrow \mathrm{Pt}^{-\mathrm{CO}_{\text {ads }}}+\mathrm{H}^{+}+\mathrm{e}^{-}
\end{aligned}
$$

A dehidrogenação do metanol segundo as reações (16) a (19) ocorrem em platina desde potenciais um pouco acima de $0 \mathrm{~V}$ vs. ERH, enquanto que a oxidação do adsorbato com a formação de $\mathrm{CO}_{2}$ ocorre somente com potenciais acima de $450 \mathrm{mV}$ vs. ERH. Para a adsorção dissociativa de metanol com a formação de CO são necessários três átomos vizinhos de platina. De um a dois átomos serão novamente liberados no decorrer das reações de dehidrogenação do metanol, dependendo se a dehidrogenação forma ligações de $\mathrm{CO}$ lineares ou por pontes.

Gasteiger e colaboradores ${ }^{[42]}$ determinaram para a oxidação anódica do metanol um valor de 0,5 moléculas de $\mathrm{CO}$ por átomo de platina a um potencial de 
$500 \mathrm{mV}$ vs. ERH, enquanto que para a adsorção de CO da fase gasosa determinaram valores de 0,85 a 0,9 moléculas de $\mathrm{CO}$ por átomo de platina. Destes resultados pode-se concluir que na dehidrogenação do metanol há a formação preferencial de $\mathrm{CO}_{\mathrm{ads}}$ ligado por ponte, enquanto que para a adsorção de CO da fase gasosa há a formação preferencial da ligação de $\mathrm{CO}_{\text {ads }}$ linear.

A etapa cinética determinante da oxidação anódica do metanol em platina é a reação (19), entre 300 e $500 \mathrm{mV}$ vs. ERH que é a faixa de potencial de operação de uma célula a combustível direta a metanol. Este fato se explica devido à platina apresentar um alto potencial padrão de redução:

$$
\mathrm{Pt}(\mathrm{OH})_{2}+2 \mathrm{H}^{+}+2 \mathrm{e}^{-} \rightleftharpoons \mathrm{Pt}+2 \mathrm{H}_{2} \mathrm{O} \quad 980 \mathrm{mV} \text { vs. ERH }
$$

A ativação da água, (que representa uma oxidação dos átomos da superfície da platina) em platina policristalina ocorre em proporções significativas somente a potenciais acima de $700 \mathrm{mV}$ vs. ERH. Devido ao fato de que as oxidações de CO e metanol em células a combustível podem ocorrer a potenciais anódicos significativamente menos positivos, a sua explicação é devido à fina distribuição de tamanhos de partículas dos eletrocatalisadores ou também à utilização de cocatalisadores, que permitem a ativação da água a potenciais mais negativos do que em platina policristalina.

Devido a seu envenenamento, a platina sozinha não é suficientemente ativa para ser usada comercialmente na oxidação do metanol. Uma outra alternativa é o uso de catalisadores bifuncionais onde o segundo metal (menos nobre que a $\mathrm{Pt}$ ) fornece o oxigênio de forma ativa, facilitando a oxidação dos intermediários. Na presença de rutênio, em valores de potencial acima de $200 \mathrm{mV}$ vs. ERH ocorre a formação de espécies oxigenadas que modificam as etapas anteriormente mencionadas. No intervalo de potenciais entre 350 e $600 \mathrm{mV}$ vs. ERH para a oxidação de metanol sobre ligas de rutênio, Iwasita e colaboradores ${ }^{[43]}$ prepuseram o seguinte mecanismo bifuncional:

$$
\begin{aligned}
\mathrm{CH}_{3} \mathrm{OH}+\mathrm{Pt}\left(\mathrm{H}_{2} \mathrm{O}\right) & \rightarrow \mathrm{Pt}-\mathrm{CH}_{3} \mathrm{OH}_{\text {ads }}+\mathrm{H}_{2} \mathrm{O} \\
\mathrm{Pt}-\mathrm{CH}_{3} \mathrm{OH}_{\mathrm{ads}} & \rightarrow \mathrm{Pt}-\mathrm{CO}_{\mathrm{ads}}+4 \mathrm{H}^{+}+4 \mathrm{e}^{-} \\
\mathrm{Ru}\left(\mathrm{H}_{2} \mathrm{O}\right) & \rightarrow \mathrm{RuOH}+\mathrm{H}^{+}+\mathrm{e}^{-}
\end{aligned}
$$




$$
\begin{aligned}
& \mathrm{Pt}-\mathrm{CO}_{\mathrm{ads}}+\mathrm{RuOH} \rightarrow \mathrm{Pt}+\mathrm{Ru}+\mathrm{CO}_{2}+\mathrm{H}^{+}+\mathrm{e}^{-} \\
& \mathrm{Ru}-\mathrm{CO}_{\mathrm{ads}}+\mathrm{RuOH} \rightarrow 2 \mathrm{Ru}+\mathrm{CO}_{2}+\mathrm{H}^{+}+\mathrm{e}^{-}
\end{aligned}
$$

Aqui é admitida a adsorção de metanol na equação (24) como troca de uma molécula de água adsorvida por uma molécula de metanol. A reação passa por várias etapas e requer a presença de sítios vizinhos de Pt para facilitar a dissociação do metanol. Caso existam átomos de Pt suficientes nos sítios vizinhos, a reação (24) não é a etapa determinante no intervalo de potenciais entre 350 e $600 \mathrm{mV}$ vs. ERH. Acima de $700 \mathrm{mV}$ vs. ERH a adsorção de água começa a ser mais forte que a fisissorção do metanol. Este fato favorece a formação de $\mathrm{Pt}(\mathrm{OH})_{\mathrm{ads}}$, diminuindo a velocidade de reação. Entretanto, na reação (25), a dissociação de metanol para formar $\mathrm{CO}$ pode acontecer a potenciais relativamente baixos. Para a Pt isto acontece em $150 \mathrm{mV}$ vs. ERH tendo um máximo em $250 \mathrm{mV}$ vs. ERH. Na presença de Ru eletrodepositado, a adsorção dissociativa do metanol é deslocada $50 \mathrm{mV}$ vs. ERH para valores menos positivos, o que torna difícil assinalar esta reação como a etapa determinante da reação no intervalo de potenciais entre 350 e $600 \mathrm{mV}$ vs. ERH, a não ser que existam insuficientes átomos de platina nos sítios vizinhos.

Visando o uso como combustível, é de interesse determinar a melhor relação platina-rutênio para a oxidação de metanol, assim, os autores mostram que para ligas de platina-rutênio com composições superficiais entre 10 e $40 \%$ de $\mathrm{Ru}$, a reação é independente do conteúdo de $\mathrm{Ru}$, concluindo que a reação entre o $\mathrm{CO}_{\text {ads }}$ e o $\mathrm{OH}$ deve ser a responsável pela velocidade do processo no intervalo de potenciais entre 350 e $600 \mathrm{mV}$ vs. ERH.

\subsubsection{Oxidação de Etanol sobre Platina}

O etanol é um combustível, proveniente de fontes renováveis no Brasil e menos tóxico que o metanol, o que o torna bastante atrativo para o emprego em células a combustível.

A oxidação de pequenas moléculas orgânicas, $\mathrm{CH}_{3} \mathrm{OH}$ e $\mathrm{CH}_{3} \mathrm{CH}_{2} \mathrm{OH}$, sobre eletrodos de platina são acompanhadas pela formação de intermediários que se adsorvem fortemente na superfície do catalisador, bloqueando a atividade catalítica. Utilizando-se técnicas espectroquímicas, tem-se observado que dióxido de carbono, acetaldeído e ácido 
acético são os principais produtos da oxidação do etanol em eletrodos de platina policristalina ${ }^{[44-46]}$.

Um mecanismo para a reação de oxidação eletroquímica do etanol, sobre eletrodos de Pt, é apresentado no ESQUEMA $2^{[44]}$.

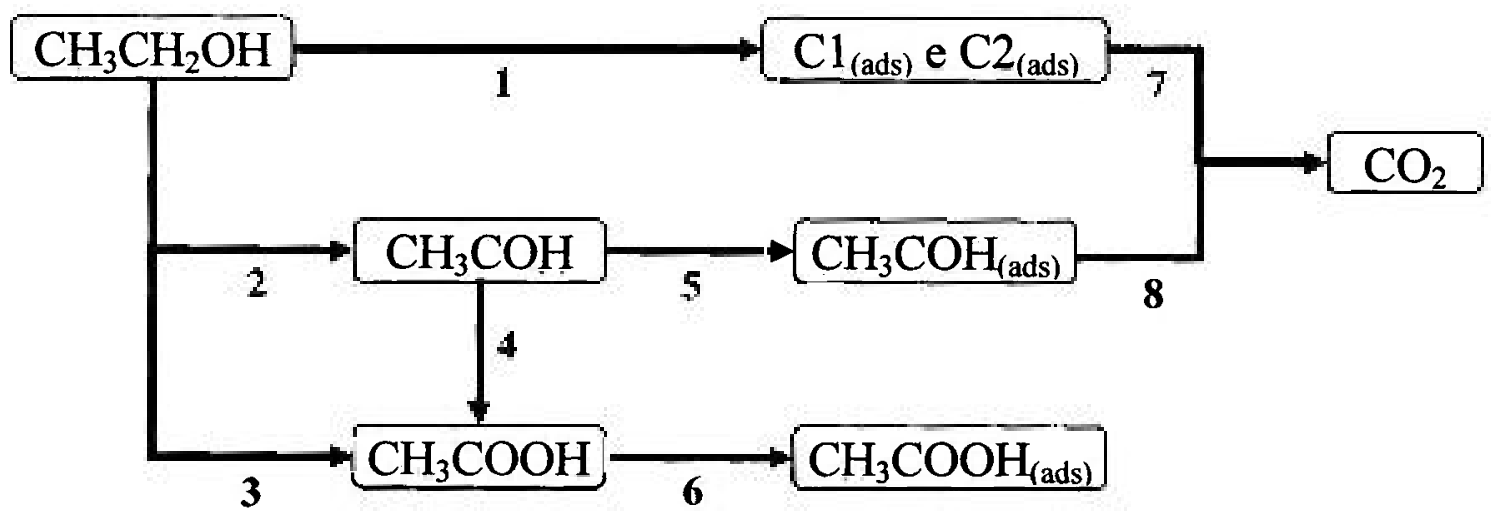

ESQUEMA 2 - Mecanismo de oxidação de etanol.

As etapas propostas neste mecanismo apresentam evidências experimentais que as sustentam ${ }^{[47-50]}$. A formação dos produtos, $\mathrm{CO}_{2}, \mathrm{CH}_{3} \mathrm{CHO}$ e $\mathrm{CH}_{3} \mathrm{COOH}$ são confirmadas por medidas espectro-eletroquímicas e cromatográficas ${ }^{[47,48]}$, sendo que a rota

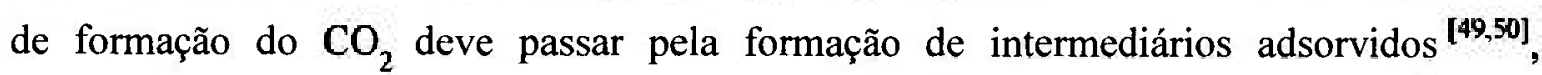
representados por $\mathrm{C}_{\text {ads }}$ e $\mathrm{C}_{\text {ads }}$, para adsorbatos do etanol com 1 e 2 átomos de carbono, respectivamente.

A etapa 5, que representa a adsorção do $\mathrm{CH}_{3} \mathrm{CHO}$, formado na etapa 2 , é proposta com base no fato de que experimentos eletroquímicos confirmam sua adsorção sobre Pt. Os resultados de FTIR in situ mostram também a formação de $\mathrm{CO}_{2}$ e $\mathrm{CH}_{3} \mathrm{COOH}$ durante a oxidação de $\mathrm{CH}_{3} \mathrm{CHO}$ dissolvido em meio ácido. Evidentemente, as etapas 5 e 8 só devem ocorrer em baixas concentrações de etanol, devido à competição com as etapas 1 e 7. A adsorção de $\mathrm{CH}_{3} \mathrm{COOH}$ (etapa 6) foi proposta por Shin e colaboradores ${ }^{\text {[48] }}$ com base nos resultados de FTIR in situ.

Apesar dos avanços na elucidação do mecanismo de oxidação eletroquímica do etanol, muitos aspectos relativos ao mecanismo geral apresentado no ESQUEMA 1 ainda necessitam de maior investigação. $\mathrm{Na}$ formação de $\mathrm{CH}_{3} \mathrm{COOH}$, por exemplo, ainda é matéria de controvérsia se a etapa predominante é a oxidação direta (etapa 3) ou via uma 
reação consecutiva, sendo o $\mathrm{CH}_{3} \mathrm{CHO}$ um intermediário, conforme as etapas 2 e 4 . A natureza e a relação quantitativa das espécies adsorvidas também é um tema polêmico.

Existem estudos que concluem pela predominância de espécies adsorvidas que preservam a ligação C-C do etanol intacta ${ }^{[48,49]}$ (maior quantidade de espécies $\mathrm{C} 2{ }_{\text {ads }}$ ). Já em outros trabalhos, conclui-se que os adsorbatos, predominantemente, devem conter apenas um átomo de carbono ${ }^{[50,51]}$ (maior quantidade de espécies $\mathrm{C} 1_{\text {ads }}$, principalmente o $\mathrm{CO}_{\text {ads }}$ ). Isto, de certa forma, reflete a complexidade das etapas reacionais envolvidas durante a eletrooxidação do etanol.

A grande maioria dos estudos relativos à oxidação eletroquímica do etanol foi realizada usando eletrodos bimetálicos de Pt com diferentes estruturas (policristalinas, monocristais, eletrodepositadas etc.). Trabalhos usando eletrodos bi-metálicos ${ }^{\text {[52-54] na }}$ oxidação de etanol, não menos encontrados na literatura comparados à quantidade de estudos na eletrooxidação do metanol.

Wang e colaboradores ${ }^{[52]}$, usando eletrodos comerciais de platina-rutênio (Eletrodos Giner, Inc. - carga de catalisador de $4 \mathrm{mg} \cdot \mathrm{cm}^{-2}$ e composição atômica PtRu não especificada) em protótipos de célula a combustível, compararam o desempenho da célula quando alimentada por metanol e por etanol. Os autores observaram que o desempenho da célula de etanol foi muito próximo da alimentada por metanol, atestando a viabilidade do uso do etanol em células a combustível.

Neto e colaboradores ${ }^{[53]}$ utilizaram eletrocatalisadores de $\mathrm{PtRu} / \mathrm{C}$ e $\mathrm{PtMo} / \mathrm{C}$ preparados pelo método de redução via ácido fórmico para a eletrooxidação de etanol. Os autores observaram que aumentando a concentração do segundo metal na composição (de 10 para 20, 30 até $40 \%$ ), há um aumento na corrente de oxidação do etanol. Os autores observaram também, que na região de hidrogênio há uma diminuição da corrente com o aumento da concentração de etanol desde 0,1 até 1 mol. $\mathrm{L}^{-1}$, já em potenciais maiores que $500 \mathrm{mV}$ vs. ERH, o aumento da corrente é diretamente proporcional ao aumento da concentração de etanol. É improvável que a presença de Ru inibe a adsorção de reagentes em Pt locais, pois nos resultados de absorção de raios $\mathrm{X}$, as propriedades eletrônicas da $\mathrm{Pt}$ não foram modificadas significativamente na liga. Assim, pôde-se concluir que o aumento em corrente com o aumento da concentração é devido a um encarecimento da oxidação de adsorbatos intermediários promovidos por espécies oxigenadas formadas no Ru através do mecanismo bifuncional. Além disto, os autores observaram que a oxidação do etanol produz $\mathrm{CO}$ e possivelmente outros adsorbatos intermediários, que podem ser oxidados com 
a participação de espécies hidrogenadas formadas na superfície das partículas. Os autores chegaram a conclusão que o eletrocatalisador $\mathrm{PtRu} / \mathrm{C}$ é melhor para a eletrooxidação de etanol, pois oxida o etanol a potenciais mais baixos que o eletrocatalisador $\mathrm{PtMo} / \mathrm{C}$.

Em outro trabalho, Neto e colaboradores ${ }^{[54]}$ estudaram eletrocatalisadores $\mathrm{PtRh} / \mathrm{C}, \mathrm{PtSn} / \mathrm{C}$ e $\mathrm{PtSnRh} / \mathrm{C}$ preparados pelo método de redução por álcool utilizando as técnicas de EDX, difração de raios X e voltametria cíclica. A eletrooxidação direta de etanol foi estudada por voltametria cíclica utilizando a técnica do eletrodo de camada fina porosa. Na região de interesse para aplicações em células a combustível a etanol direto (300 a $400 \mathrm{mV}$ vs. ERH) os eletrocatalisadores $\mathrm{PtSn} / \mathrm{C}$ e $\mathrm{PtSnRh} / \mathrm{C}$ se móstraram mais ativos que os eletrocatalisadores $\mathrm{PtRh} / \mathrm{C}$ que apresentaram altos valores de correntes somente em potenciais acima de $600 \mathrm{mV}$ vs. ERH. O eletrocatalisador $\mathrm{Pt}_{50} \mathrm{Sn}_{40} \mathrm{Rh}_{10} / \mathrm{C}$ apresentou valores de corrente próximos ao do eletrocatalisador $\mathrm{PtSn} / \mathrm{C}$ e superior ao eletrocatalisador PtRu/C comercial da E-TEK na faixa de potencial de interesse para uma célula a combustível direta a etanol.

\subsection{Revisão da Literatura sobre o Método de Redução por Álcool para Produção dos Eletrocatalisadores}

Durante os últimos anos tem havido um esforço intenso nas pesquisas de oxidação de metanol e etanol, como conseqüência do dèsenvolvimento das células do tipo PEM.

Wang e Hsing ${ }^{[55]}$ prepararam eletrocatalisadores $\mathrm{Pt} / \mathrm{C}$ e $\mathrm{PtRu} / \mathrm{C}$ através do método da redução por álcool. Para isto uma solução metanol-água contendo os sais de platina e de rutênio foi refluxada na presença de um agente estabilizante (surfactante SB12) e do suporte de carbono. As análises por DRX, MET e XPS mostraram que as nanopartículas (tamanho médio de $2,5 \mathrm{~nm}$ ) apresentavam-se bem dispersas e suportadas no carbono. A caracterização eletroquímica mostrou que, em comparação ao eletrocatalisador comercial da E-TEK, o eletrocatalisador $\mathrm{Pt} / \mathrm{C}$ apresentou atividade catalítica similar para a $\mathrm{RRO}$, enquanto que, o eletrocatalisador $\mathrm{PtRu} / \mathrm{C}$ apresentou uma maior tolerância ao envenenamento pelo monóxido de carbono.

Chen e colaboradores ${ }^{[56]}$ prepararam o eletrocatalisador $\mathrm{Pt} / \mathrm{C}$ pelo método da redução por álcool. Uma solução aquosa de $\mathrm{H}_{2} \mathrm{PtCl}_{6} \cdot 6 \mathrm{H}_{2} \mathrm{O}$ foi adicionada ao álcool e uma pequena quantidade de solução aquosa de $\mathrm{KOH}$ foi adicionada gota a gota. Uma razão molar $\mathrm{KOH} / \mathrm{Pt}=8$ foi usada para induzir a formação de nanopartículas pequenas e bem 
uniformes. O suporte de carbono foi disperso nesta solução usando ultra-som e a mistura resultante foi aquecida em um forno de microondas por $60 \mathrm{~s}$. A suspensão resultante foi filtrada, lavada com acetona e seca. As medidas por EDX indicaram a incorporação de 9,5; 13,6 e 18,6\% em massa para as amostras preparadas a partir de 10,15 e $20 \%$ em massa de platina. As análises por MET mostraram que as nanopartículas de platina obtidas apresentavam-se bem uniformes e distribuídas na superficie do carbono. O material contendo $18,6 \%$ em massa de platina apresentou nanopartículas na faixa de 3,5 a 4,0 nm e poucas partículas maiores que $5,0 \mathrm{~nm}$. O eletrocatalisador Pt/C comercial da E-TEK ( $20 \%$ em massa de Pt), usado para comparação, apresentou tamanho médio de nanopartículas de $5,1 \mathrm{~nm}$ e uma ampla distribuição entre 2 e $10 \mathrm{~nm}$.

Zhou e colaboradores ${ }^{[57]}$ estudaram através de voltametria cíclica e caracterizações fisicas (DRX, XPS e MET) como se comportam os eletrocatalisadores baseados em nanopartículas de Pt na operação da célula com etanol. Descobriram que os melhores eletrocatalisadores são: $\mathrm{PtSn} / \mathrm{C}>\mathrm{PtRu} / \mathrm{C}>\mathrm{PtW} / \mathrm{C}>\mathrm{PtPd} / \mathrm{C}>\mathrm{Pt} / \mathrm{C}$. Mencionaram ainda que as distintas diferenças de desempenho na célula a combustível direta a etanol entre os eletrocatalisadores estudados podem ser atribuídas ao mecanismo bifuncional e a interação eletrônica entre a Pt e seus aditivos.

Léger ${ }^{[58]}$ publicou uma revisão sobre a eletrooxidação de metanol e etanol, estudando vários eletrocatalisadores para estas duas reações. Neste estudo, ele chegou à conclusão que o melhor eletrocatalisador para a oxidação de metanol é $\mathrm{Pt}+\mathrm{Ru} / \mathrm{C}$ (nanopartículas de Pt com ilhas de átomos de Ru), seguido de PtRu/C (liga PtRu), de Pt/C e $\mathrm{Pt} / \mathrm{C}+\mathrm{Ru} / \mathrm{C}$ (nanopartículas separadas) que obteve o menor desempenho. A explicação seria de que provavelmente os sítios de $\mathrm{Pt}$ e $\mathrm{Ru}$ são adjacentes para iniciar a adsorção dissociativa da água (pouco nos sítios de $\mathrm{Ru}$, mas em maior quantidade nos de $\mathrm{Pt}$ ) e metanol (pouco nos sítios de Pt, mas em maior quantidade nos de Ru). Entretanto, um bom eletrocatalisador para a oxidação de etanol não foi baseado em PtRu, e sim em PtSn, e o melhor eletrocatalisador estudado foi $\mathrm{PtSn} / \mathrm{C}$ (90:10), seguido de PtRe/C (75:25), $\mathrm{Pt} / \mathrm{C}$, $\mathrm{PtRu} / \mathrm{C}$ (80:20) e PtRh/C (80:20) que obteve o menor desempenho.

$\mathrm{O}$ autor observou ainda que com o incremento de Sn a Pt houve um aumento na corrente de oxidação do etanol, principalmente a baixos potenciais (400 $600 \mathrm{mV}$ vs. ERH), que é realmente o potencial em que opera uma célula direta a etanol. A explicação seria de que a presença de Sn limita a região de potencial da formação de espécies hidrogenadas (adsorbatos de CO). Para potenciais maiores que $300 \mathrm{mV}$ vs. ERH, a superfície vem a estar livre de adsorbatos de $\mathrm{CO}$, bom para readsorção de moléculas de 
etanol que podem vir a ser oxidadas (em acetaldeídos e ácido acético), sem quebrar as . ligações C-C.

Jiang e colaboradores ${ }^{[59]}$ prepararam $\mathrm{PtSn} / \mathrm{C}$ pelo método de redução por poliol, e também pela modificação deste método que consistiu em um tratamento com $\mathrm{H}_{2} / \mathrm{Ar}\left(600^{\circ} \mathrm{C}\right.$ por $2 \mathrm{~h}$ na presença de $10 \%$ em volume de $\left.\mathrm{H}_{2}\right)$, após a redução por poliol, objetivando com isso a obtenção de diferentes fases metálicas. Observou-se nos eletrocatalisadores após o tratamento com $\mathrm{H}_{2} / \mathrm{Ar}$, o surgimento de outros picos em 41,5; 43,7 e $62,3^{\circ}$ que são atribuídos a $\mathrm{PtSn}(102), \mathrm{PtSn}(110)$ e $\mathrm{PtSn}(202)$ respectivamente. $\mathrm{O}$ tamanho de partícula aumentou de 2,3 para $5,7 \mathrm{~nm}$ após o tratamento com $\mathrm{H}_{2} / \mathrm{Ar}$.

Spinacé e colaboradores ${ }^{[54]}$ estudaram os eletrocatalisadores $\mathrm{PtSn} / \mathrm{C}$ preparados pelo método da redução por álcool (MRA) e observaram que estes eletrocatalisadores apresentam boa atividade na eletrooxidação de etanol e foram os pioneiros em verificar que a adição de uma pequena quantidade de níquel a estes eletrocatalisadores, ou seja, eletrocatalisador $\mathrm{PtSnNi} / \mathrm{C}$, leva a um aumento na atividade catalítica.

Neto e colaboradores ${ }^{[60]}$ estudaram eletrocatalisadores $\mathrm{PtSn} / \mathrm{C}, \mathrm{PtRh} / \mathrm{C}$ e $\mathrm{PtSnRh/C} \mathrm{preparados} \mathrm{pelo} \mathrm{MRA} \mathrm{para} \mathrm{a} \mathrm{eletrooxidação} \mathrm{de} \mathrm{etanol.} \mathrm{O} \mathrm{eletrocatalisador}$ $\mathrm{PtRh} / \mathrm{C}$ apresentou uma atividade catalítica inferior ao eletrocatalisador comercial $\mathrm{PtRu} / \mathrm{C}$ E-TEK, tendo atividade catalítica somente em valores de potencial acima de $0,6 \mathrm{~V}$, os quais não são de interesse para aplicações tecnológica, já $\mathrm{PtSn} / \mathrm{C}$ e $\mathrm{PtSnRh} / \mathrm{C}$ apresentaram-se mais ativos em toda a faixa de potencial de interesse $(0,2-0,6 \mathrm{~V})$. $\mathrm{O}$ eletrocatalisador $\mathrm{Pt}_{50} \mathrm{Sn}_{50} / \mathrm{C}$ apresentou um melhor desempenho em relação ao eletrocatalisador com razão atômica $\mathrm{Pt}_{90} \mathrm{Sn}_{10} / \mathrm{C}$, indicando que são necessários maiores teores de estanho no eletrocatalisador para que se observem melhores valores de corrente na faixa de potencial de interesse. 


\section{TEORIA 2 - IMPEDÂNCIA ELETROQUÍMICA}

A Espectroscopia de Impedância Eletroquímica (EIE) é um método de análise, que nos últimos anos vem sendo muito utilizado para caracterização de sistemas eletroquímicos. $\mathrm{O}$ método acarreta em medidas relativamente rápidas e em diferentes materiais, e acima de tudo, sem causar danos ao material estudado. Por isso, é indicada para muitos experimentos in-situ.

\subsection{Definição de Impedância ${ }^{[61]}$}

Geralmente conhecida como resistência de elementos que conduzem eletricidade (cabos, fios etc.). Na realidade é a descrição da Lei Ôhmica: o potencial $(U)$ sobre um condutor metálico, é proporcional, em temperatura constante, ao fluxo elétrico de corrente através do condutor (I). A FIGURA 9 apresenta a definição de Resistência Ôhmica.

$$
U \sim I \quad,
$$

onde:

$$
\begin{aligned}
& I=\frac{U}{R} \quad \mathrm{e} \\
& R=\frac{\Delta U}{\Delta I}=\text { constante }
\end{aligned}
$$




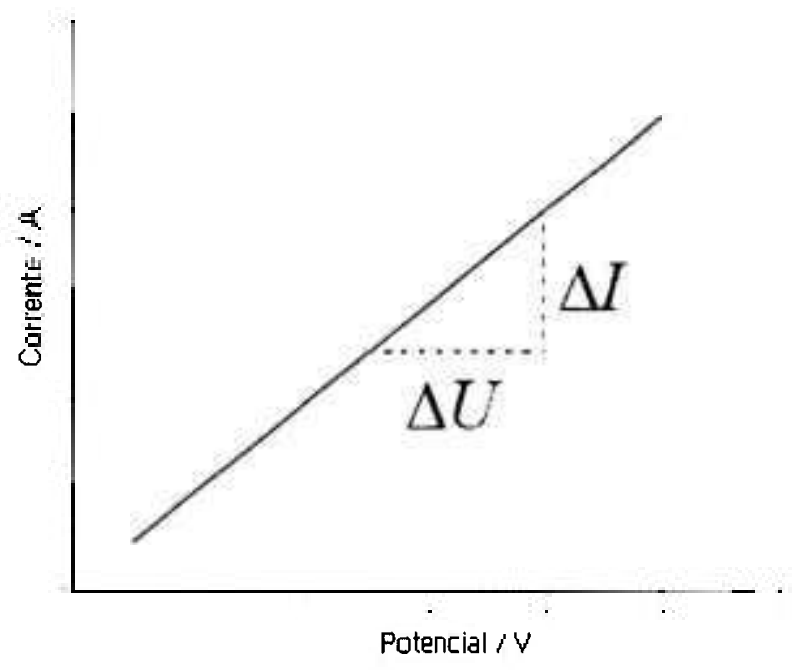

FIGURA 9 - Definição de resistência ôhmica.

A constante proporcional vem a ser a resistência elétrica, conhecida como $R$. A unidade utilizada vem a ser $1 \mathrm{Ohm}=1 \Omega=1 \mathrm{~V} \cdot \mathrm{A}^{-1}$.

As definições de uma resistência ideal são: A lei ôhmica vale para todas as correntes e todos os potenciais elétricos; a resistência é independente da freqüência da corrente; a corrente alternada e o potencial estão sempre em fase.

A lei Ôhmica e a lei de Kirchoff valem em análogo para correntes alternadas, sendo que a impedância é interpretada como um número complexo. Com isso, pode ocorrer uma diferença de fase entre corrente e potencial, sendo que no elemento indutivo a corrente está atrasada em relação ao potencial e no elemento capacitivo a corrente está adiantada. Neste caso, o potencial é dado por:

$$
\begin{aligned}
& U(t)=Z \cdot I(t)=|Z| \cdot|I| \exp (\omega t-\varphi) \quad \text { ou: } \\
& u(t)=u_{0}(\cos \omega t) \\
& i(t)=i_{0}(\cos \omega t+\varphi),
\end{aligned}
$$

onde: $u_{0}$-corresponde à amplitude do potencial, $\boldsymbol{i}_{0}$ - corresponde à amplitude da corrente, $\omega$ - a freqüência angular $(\omega=2 \pi f)$ e $\varphi$-a diferença de fase entre a corrente $i(t)$ e o potencial $u(t)$ 
A diferença de fase $\varphi$ entre a corrente $i(t)$ e o potencial $u(t)$ pode ser graficamente vista na FIGURA 10 . Onde a relação do potencial $u(t)$ para uma medida de corrente $i(t)$, prevê que:

$$
Z(t)=\frac{u(t)}{i(t)}=\frac{u_{0} \cos (\omega t)}{i_{0} \cos (\omega t-\varphi)}=Z_{\theta} \frac{\cos (\omega t)}{\cos (\omega t-\varphi)}
$$

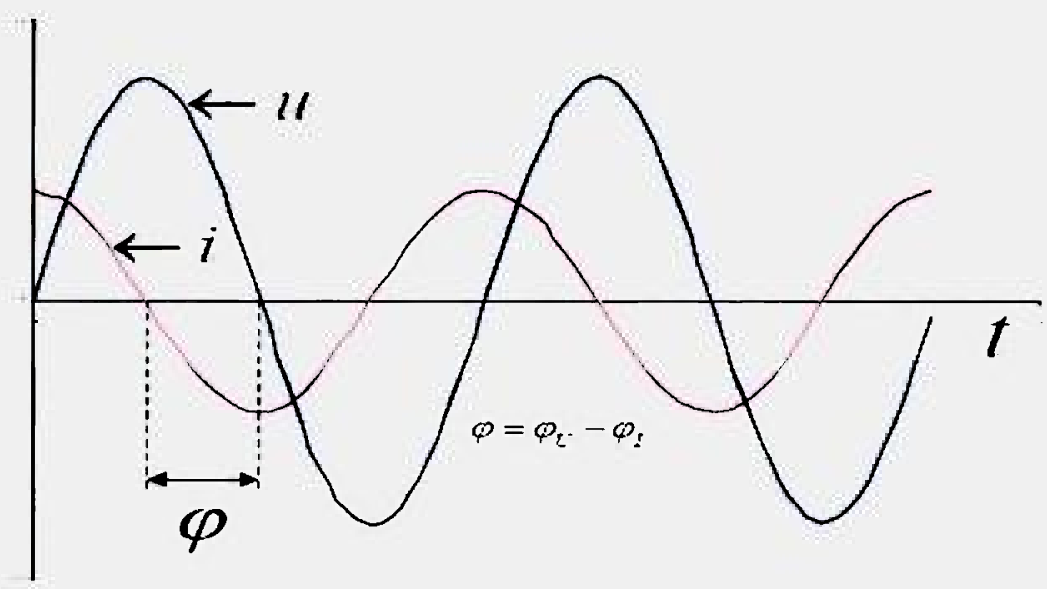

FIGURA 10 - Gráfico de corrente alternada $(i)$ e tensão alternada $(u)$ com a freqüência $(\omega)$ versus o tempo $(t)$

A impedância também pode ser escrita como uma relação de Euler:

$$
\begin{aligned}
& \exp (j \cdot \varphi)=\cos \varphi+j \cdot \operatorname{sen} \varphi \\
& u(t)=u_{0} \exp (j \cdot \omega t) \\
& i(t)=i_{0} \exp (j \cdot \omega t+j \cdot \varphi),
\end{aligned}
$$

podendo assim, a impedância ser representada por:

$$
Z=\frac{u(t)}{i(\eta)}=|Z| \exp (j \varphi)=|Z| \exp (\cos \varphi+j \operatorname{sen} \varphi)
$$

A impedância sendo complexa pode ser representada por vetores. Os vetores assumem componentes reais e imaginárias:

$$
Z=Z^{\prime}+j \cdot Z^{\prime \prime}
$$


A parte real corresponde a valores de resistência ôhmica, onde $Z^{\prime}=R$, e a parte imaginária corresponde a valores de reatâncias indutivas e capacitivas, onde $\mathrm{Z} "=\mathrm{X}$.

$$
Z=R+j X=|Z| \exp (j \varphi)
$$

onde:

$$
\begin{aligned}
& R=|Z| \cos \varphi \\
& X=|Z| \sin \varphi
\end{aligned}
$$

A impedância $|Z|$ (vetor distância) pode ser então definida:

$$
|Z|=\sqrt{\left(Z^{\prime}\right)^{2}+\left(Z^{\prime \prime}\right)^{2}}
$$

E o diferença de fase como:

$$
\varphi=\operatorname{arctg} \frac{X}{R}
$$

Um gráfico que representa a impedância pode ser observado na FIGURA 11 que é conhecido como gráfico de Nyquist ${ }^{[62]}$. A parte real está representada no eixo X e a parte imaginária no eixo $\mathrm{Y}$.

A impedância é atribuída ao $|Z|$, e $\varphi$ será sempre o ângulo entre este vetor e o eixo $\mathrm{X}$, onde $\varphi=\operatorname{arctg}(Z)$. Esta interpretação é atribuída a Nyquist, sendo conhecido como diagrama de Nyquist.

Uma segunda maneira de representação do gráfico de impedância é atribuída a Bode, sendo conhecido como diagrama de Bode ${ }^{|*| !}$, e pode ser observado na FIGURA 12. 


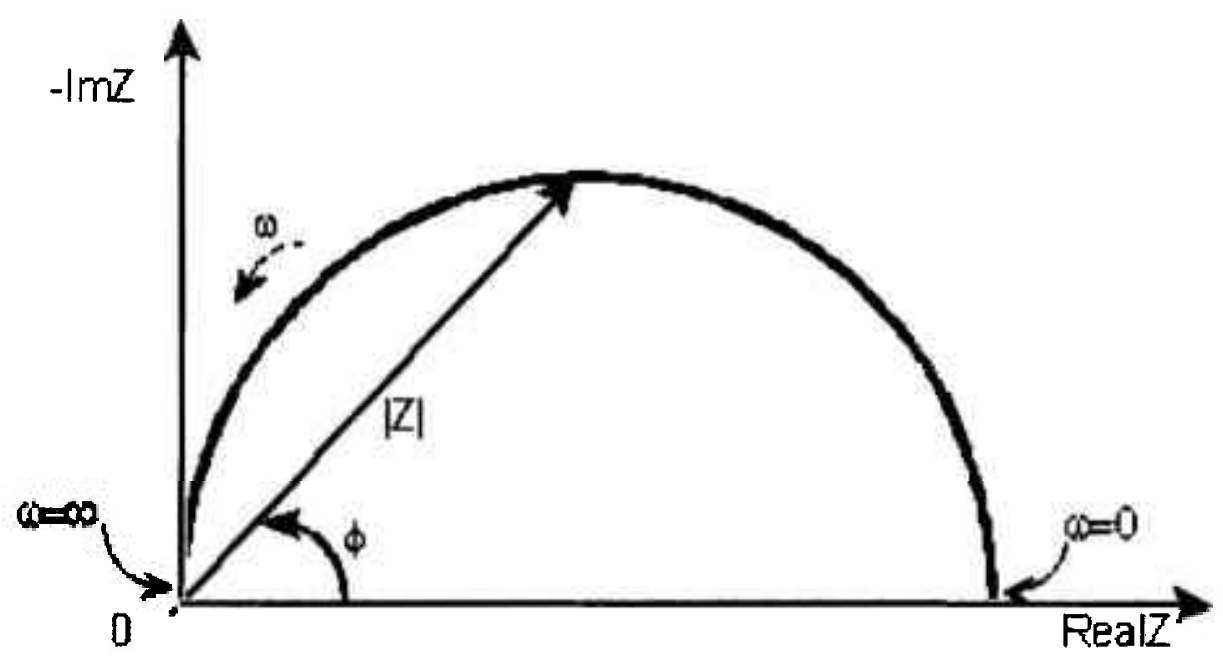

FIGURA 11 - Representação de impedância por meio do diagrama de Nyquist.

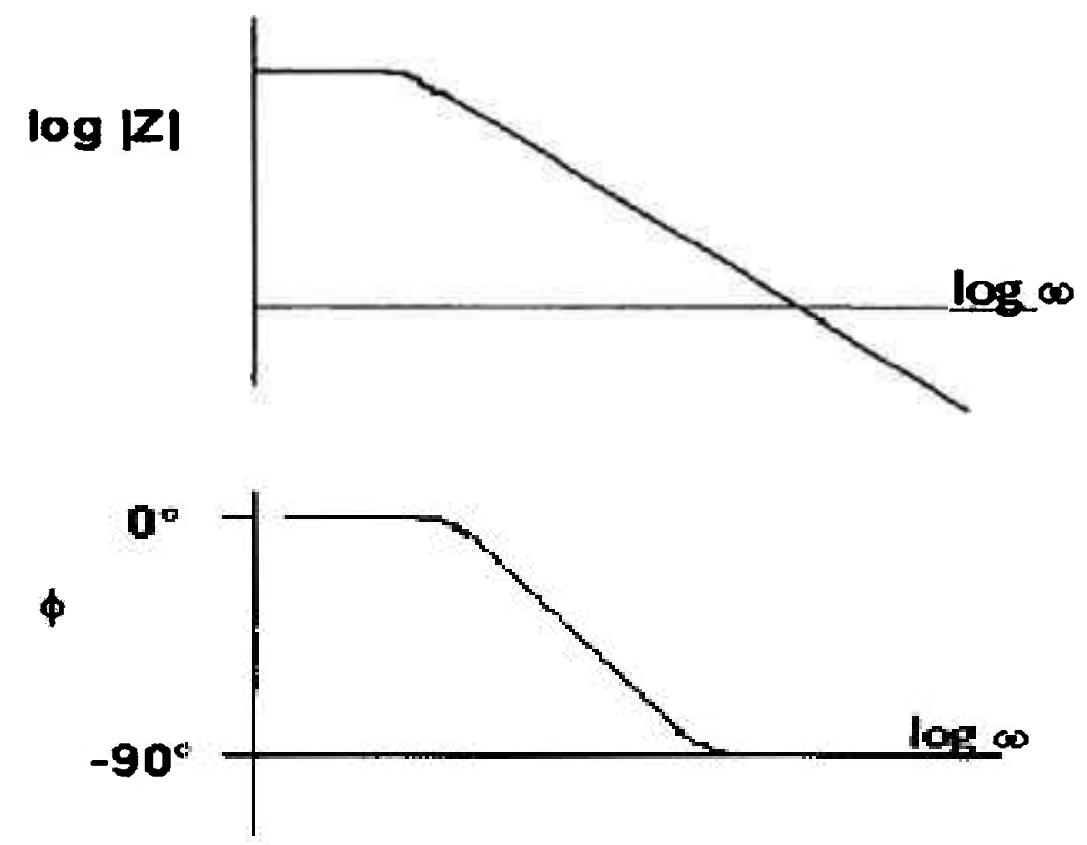

FIGURA 12 - Representação de impedância por meio do diagrama de Bode.

\subsection{Elementos Elétricos Componentes da Impedância ${ }^{|63-65|}$}

A medida da impedância eletroquímica pode ter um circuito elétrico associado. Sabe-se que os elementos utilizados em eletrotécnica como o resistor $(R)$, capacitor $(C)$ e o indutor $(L)$, têm valores de impedância distintos, como se pode observar na TABELA 3. 
TABELA 3 - Definição e símbolo dos elementos elétricos e suas impedâncias.

\begin{tabular}{|l|l|l|l|}
\hline Elementos & \multicolumn{1}{|c|}{ Relação U por I } & Impedância \\
\hline Resistor & $U=I \cdot R$ & $Z=R$ \\
\hline Capacitor & $I=C \cdot d u / d t$ & $\circ-1 / \frac{\mathrm{C}}{2}$ & $Z=1 / j \omega C$ \\
\hline Indutor & $U=L \cdot d i / d t$ & $Z=j \omega L$ \\
\hline
\end{tabular}

\subsubsection{Impedância de um Resistor}

O resistor $R$ é um elemento linear e sua impedância não é condicionada à freqüência.

$$
Z_{R}=R
$$

A impedância de um resistor é uma resistência ôhmica, assim no diagrama de Nyquist aparece somente um ponto sobre o eixo real (eixo X). Então se pode afirmar que o resistor não é condicionado à freqüência. Na FIGURA 13 está apresentada uma impedância de um resistor ideal

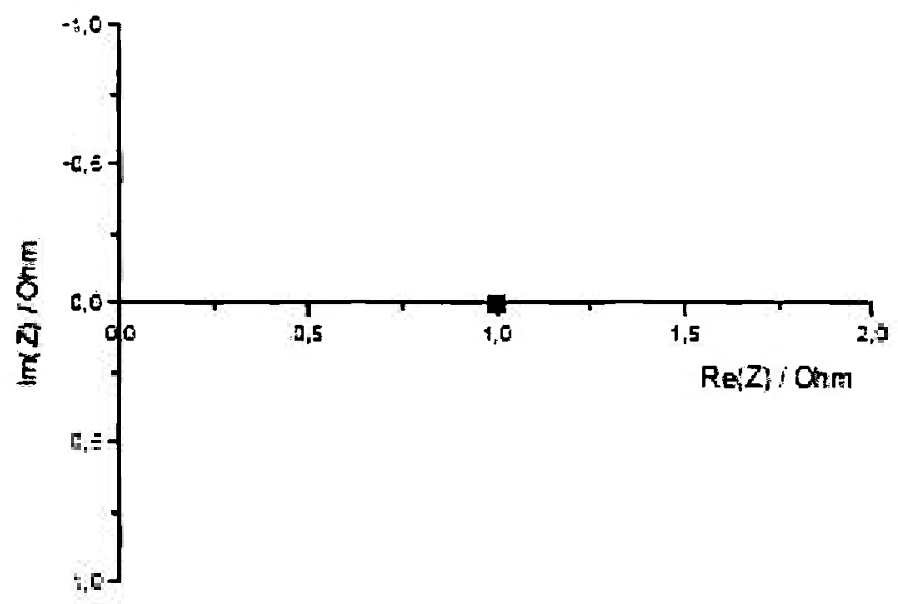

FIGURA 13 - Impedância de um resistor ideal sobre o diagrama de Nyquist $(R=1 \Omega)$. 


\subsubsection{Impedância de um Capacitor}

Um capacitor, também chamado condensador, é um componente que armazena energia num campo elétrico, acumulando um deslocamento interno de carga elétrica. Um capacitor consiste em dois eletrodos ou placas que armazenam cargas opostas; estas duas placas são condutoras e são separadas por um isolante ou dielétrico. A carga é armazenada na superfície das placas, no limite com o dielétrico. Devido ao fato de cada placa armazenar cargas iguais, porém opostas, a carga total no dispositivo é sempre zero. A capacitância de uma capacitor de placas paralelas constituído de dois eletrodos planos idênticos de área $A$ separados à distância constante $d$ é aproximadamente igual a:

$$
C=\frac{\varepsilon_{0} \cdot \varepsilon_{r} \cdot A}{d},
$$

onde, $C$ é a capacitância em farad, $\varepsilon_{0}$ - permissividade eletrostática do vácuo ou espaço livre e $\varepsilon_{r}$-constante dielétrica ou a permissividade relativa do isolante utilizado.

A impedância do capacitor pode ser representada pela equação diferencial:

$$
Z_{C}=\frac{1}{j \omega C}=\frac{1}{j X_{C}}
$$

onde $X_{C}$ é a reatância capacitiva medida em ohms.

A impedância de um capacitor representado no diagrama de Nyquist gera uma reta paralela ao eixo negativo da impedância imaginária como pode ser observado na FIGURA 14. 


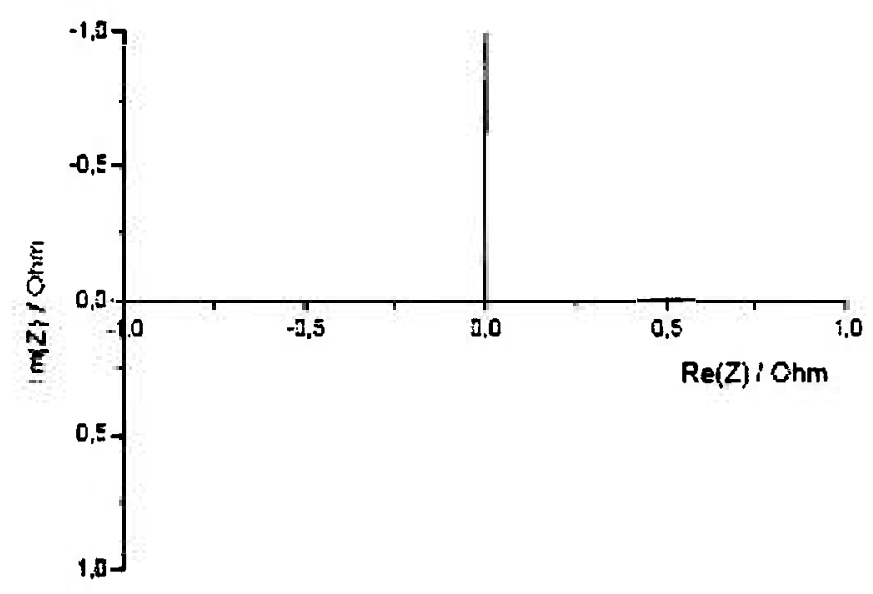

FIGURA 14 - Impedância de um capacitor ideal sobre o diagrama de Nyquist $(C=1 \Omega$, $\omega=0,16 \mathrm{mHz}-10 \mathrm{kHz})$. Lid i?

\subsubsection{Impedância de um Indutor}

Um indutor é um dispositivo elétrico passivo que armazena energia na forma de campo magnético, normalmente combinando o efeito de várias voltas da corrente elétrica. Um indutor é geralmente construído como uma bobina de material condutor, por exemplo, um fio de cobre. Um núcleo de material ferromagnético aumenta a indutância concentrando as linhas de força de campo magnético que fluem pelo interior das espiras.

A indutância é a grandeza física associada aos indutores, e é simbolizada pela letra L, medida em henry $(\mathrm{H})$, e representada graficamente por um fio helicoidal. Em outras palavras é um parâmetro dos circuitos lineares que relaciona o potencial induzido por um campo magnético variável à corrente responsável pelo campo.

O potencial entre os terminais de um indutor é proporcional à taxa de variação da corrente que o atravessa. Matematicamente tem-se:

$$
u_{\mathrm{C}}=L \cdot \frac{d i_{C}}{d t}
$$

onde, $L$ é a indutância do indutor.

A impedância do indutor pode ser representada pela equação diferencial: 


$$
Z_{L}=j \omega L=j X_{L}
$$

onde $X_{L}$ é a reatância indutiva.

A impedância de um indutor representado no diagrama de Nyquist gera uma reta paralela ao eixo positivo da impedância imaginária como pode ser observado na FIGURA 15.

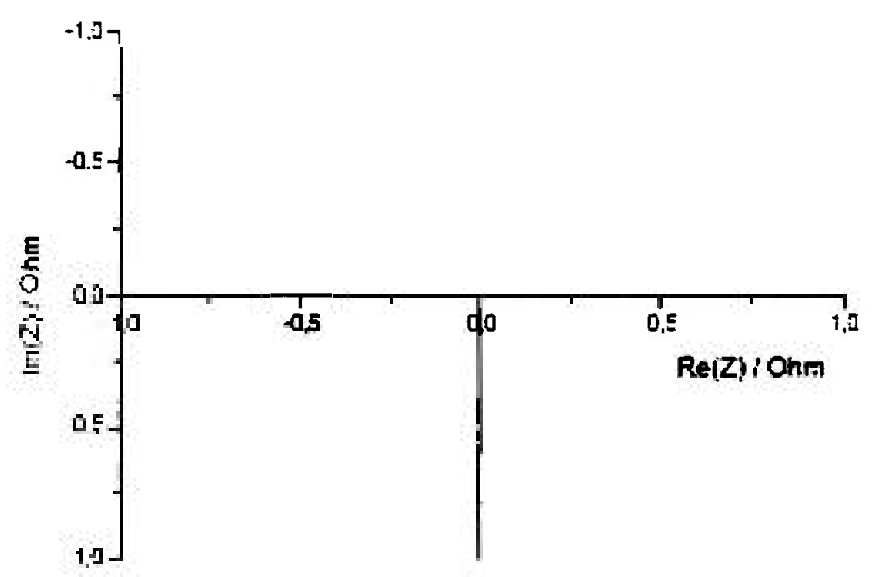

FIGURA 15 - Impedância de um indutor ideal sobre o diagrama de Nyquist $(L=1 \mathrm{H}$, $\omega=1 \mu \mathrm{Hz}-0,16 \mathrm{~Hz}$ ).

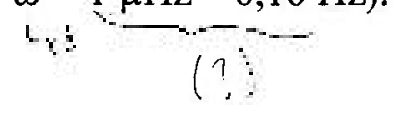

$X_{1} \cdot[0-1]-\Omega$

\subsection{Elementos em Série e Paralelo Componentes do Circuito Elétrico}

Uma célula eletroquímica pode ter entre seus elementos constituintes, componentes que se comportem como, por exemplo, resistências, capacitores e indutores. Estes elementos podem estar em séric ou em paralelo e assim pode-se montar um modelo para o tipo de funcionamento em questão. $\mathrm{Na}$ impedância de um sistema completo, podem estar associados entre si vários elementos em série, como pode ser observado na FIGURA 16:

$$
Z_{e q}=Z_{1}+Z_{2}+Z_{3}+Z_{4}+\ldots+Z_{n}
$$

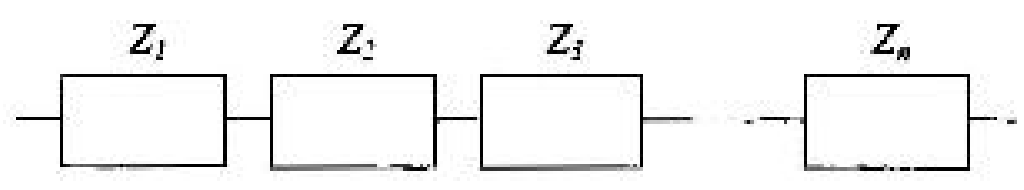

FIGURA 16 - Elementos de impedância associados em série. 
Estes elementos podem também estar associados em paralelo, como mostra a FIGURA 17:

$$
\frac{1}{Z_{e q}}=\frac{1}{Z_{1}} \cdot \frac{1}{Z_{2}}+\frac{1}{Z_{3}}+\frac{1}{Z_{4}}+\ldots+\frac{1}{Z_{n}}
$$

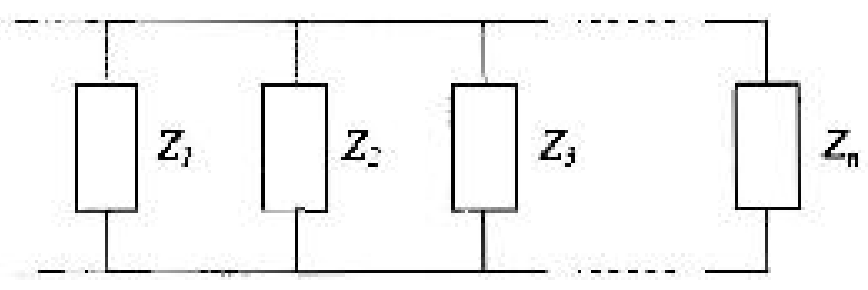

FIGURA 17 - Elementos de impedância associados em paralelo.

Neste caso, para elementos em paralelo com somente dois elementos, a representação é dada pela equação 53:

$$
Z_{e q}=\frac{Z_{1} \cdot Z_{2}}{Z_{1}+Z_{2}}
$$

Uma representação esquemática da impedância da associação de uma resistência e um capacitor com uma freqüência $\omega$ de 0 ao máximo, está representada na FIGURA 18.
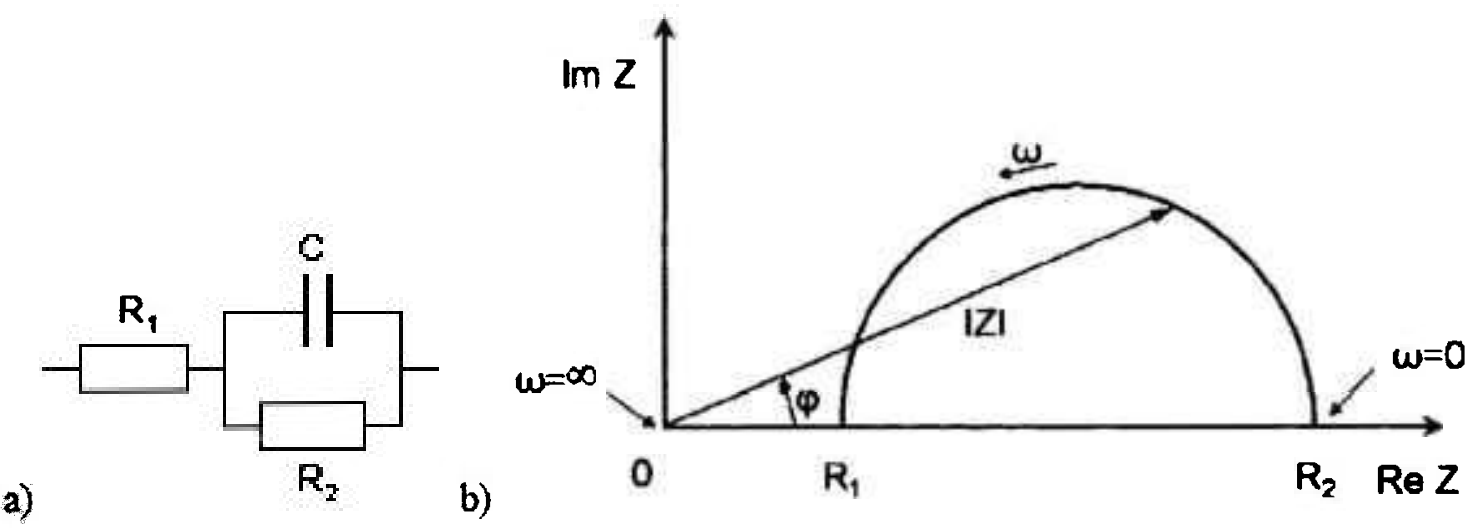

FIGURA 18 - a) Representação da associação de elementos de impedância em série e paralelo e b) diagrama de Nyquist da mesma associação. 


\subsection{Elementos e Reações Envolvidas na Célula a Combustível}

Neste capítulo são mostrados os elementos elétricos associados aos componentes e às respectivas equações envolvidas na operação de uma célula a combustivel.

\subsubsection{Resistência do Eletrólito}

A resistência do eletrólito $\left(R_{\mathrm{el}}\right)$, ou resistência da membrana de uma célula a combustivel do tipo PEM é a resistência associada ao fluxo de corrente no eletrólito (condutor iônico). $A \mathrm{R}_{\mathrm{el}}$ é um fator de máxima importância em uma célula eletroquímica. $\mathrm{Na}$ medida de impedância com 3 eletrodos a membrana está entre e em contato com os dois eletrodos (anodo e catodo). Em princípio esta resistência depende da solução iônica (espessura e tipo da membrana), da concentração de íons, do tipo de íons e da temperatura. A resistência do eletrólito está diretamente relacionada com a resistividade $(\rho)$, a área ou seção transversal $(A)$ e o comprimento $(l)$ como mostra a equação 54 :

$$
R_{e l}=\rho \cdot \frac{l}{A}
$$

\subsubsection{Resistência de Transferência de Carga}

A resistência de transferência de carga $\left(R_{c t}\right)$ é uma resistência que está aliada à densidade de corrente faradaica para transferência eletrônica e a concentração iônica dos reagentes e produtos na interface eletrodo/eletrólito num momento $t$. De acordo com a lei de Faraday, a passagem de corrente elétrica através da interface eletrodo/eletrólito sempre leva a uma reação eletroquímica, onde reagentes se transformam em produtos ${ }^{[66]}$ :

$$
M e \Leftrightarrow M e^{n+}+n e^{-} \quad,
$$

ou ainda,

$$
\operatorname{Red} \Leftrightarrow O x+n e^{-}
$$

Quando ocorre uma troca de elétrons em um metal o correspondente íon metálico é transferido ao eletrólito. Quando o transporte de massa pode ser desprezado podemos correlacionar a equação entre o potencial e a corrente gerada através da equação de Butler-Volmer : 


$$
-i_{i}=i_{0} \cdot\left[\exp -\frac{n F}{R T} \cdot \alpha\left(E-E_{r}\right)-\exp \frac{n F}{R T} \cdot(1-\alpha)\left(E-E_{r}\right)\right.
$$

onde, $i_{F}$-densidade de corrente faradaica, $i_{0}$-densidade de corrente de troca, $n$-número de elétrons, $F$-constante de Faraday, $R$-constante universal dos gases, $T$ - Temperatura, $\alpha$-coeficiente de transferência e $E_{\mathrm{r}}$ - potencial de equilíbrio.

Quando o coeficiente de transferência for igual a 0,5 a equação 57 pode ser escrita como [60]:

$$
R_{s}=\frac{R T}{n F i_{0}}
$$

\subsubsection{Resistência de Difusão}

\subsubsection{Impedância de Warburg}

A difusão em uma célula eletroquímica em geral aparece como uma impedância de Warburg. Nas freqüências utilizadas normalmente $(10 \mathrm{kHz}$ a $0,1 \mathrm{~Hz})$, esta impedância é relativamente pequena e aumenta com a diminuição da freqüência. Neste caso a impedância de Warburg é dada por:

$$
Z_{W}=\sigma \cdot(j \omega)^{-1 / 2}
$$

onde, $\sigma$ é o coeficiente de Warburg que depende do potencial de difusão das espécies e não da freqüência:

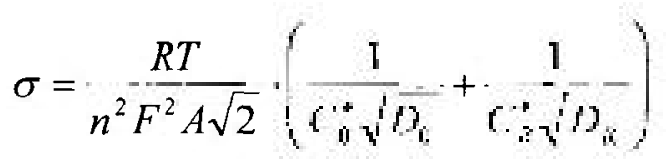

onde, $D_{O}$-coeficiente de difusão das espécies oxidantes do sistema redox; $D_{R}$ - coeficiente de difusão das espécies redutoras do sistema redox; $C^{*}$ - concentração das espécies difundidas no seio da solução $\left(\mathrm{mol} . \mathrm{cm}^{-3}\right)$. 
A impedância de Warburg dada pela equação (59) vale somente para uma camada de difusão semi-infinita. Para restringir o volume da camada de difusão (volume finito), temos que escrever a impedância em domínio de baixas freqüências, como:

$$
Z_{0}=\sigma \omega^{-1 / 2} \cdot(1-j) \cdot \tanh \left[\sigma\left(\frac{j \omega}{D}\right)^{1 / 2^{-}}\right. \text {, }
$$

onde, $\sigma$-espessura da camada de difusão de Nernst e $D$ - média do coeficiente de difusão das espécies difundidas.

$\mathrm{Na}$ prática têm-se dois tipos de impedância de Warburg para difusão finita (Impedância Anômala), um denominado curto circuito (do inglês, Short Circuit) $\left(Z_{S}\right)$, mostrada na equação 62 e na FIGURA 19a, e outro denominado circuito aberto (do inglês, Open Circuit) $\left(Z_{O}\right)$, mostrada na equação 63 e na FIGURA 19b. A diferença entre estes dois tipos de impedâncias é que a de curto circuito tem uma maior resistência capacitiva devido a espécies refletidas na região final da camada de difusão finita, enquanto a impedância de circuito aberto tem uma maior resistência capacitiva devido a espécies adsorvidas no começo da camada de difusão finita (região de fronteira). Na FIGURA 19 estão representados os diagramas de impedância de Warburg para difusão finita.

$$
\begin{aligned}
& Z_{S}=\frac{R_{W} \cdot \tanh \left[\left(j \cdot T_{i w^{\prime}} \cdot \omega\right)^{-}\right]}{\left(j \cdot T_{\kappa^{\prime}} \cdot \omega\right)^{\prime}} \\
& Z_{\theta}=\frac{R_{W} \cdot \operatorname{ctnh}\left[\left(j \cdot T_{w} \cdot \omega\right)^{\prime \prime}\right]}{\left(j \cdot T_{w} \cdot \omega\right)^{-}},
\end{aligned}
$$

onde, $R_{W}, T_{W}$ - são parâmetros de Warburg e $T_{W}$ podem ser definidos por:

$$
T_{H}=\frac{s^{\vdots}}{D_{n}},
$$

onde, $D_{a}$ - coeficiente de difusão das espécies $a$. 

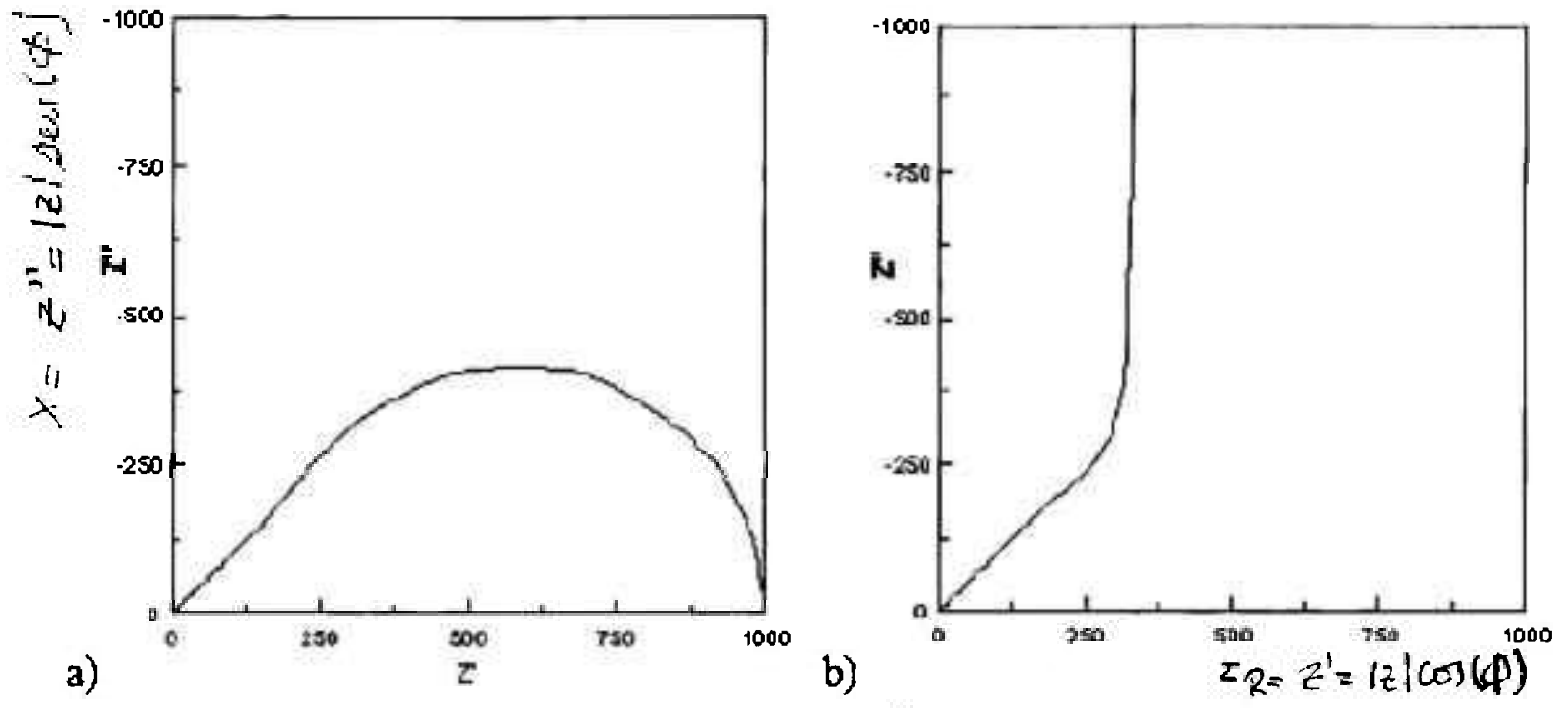

FIGURA 19 -Diagrama de impedância de Warburg para difusão finita, a) Curto Circuito $\left(Z_{S}\right)$ e b) Circuito Aberto $\left(Z_{O}\right)$; onde $R_{W}=1000, T_{W}=0,1$ e $\varphi=0,5$.

\subsubsection{Impedância de Nernst}

$$
\begin{aligned}
& \text { f-angub de ase } \\
& |z|=\sqrt{\left(z^{\prime}\right)^{2}+\left(z^{\prime \prime}\right)^{2}}
\end{aligned}
$$$$
\rightarrow-\operatorname{Arctg}\left(\frac{x}{12}\right)
$$$$
z=R+j * X=|z| * e^{\prime}
$$

Este tipo de impedância aparece em altas densidades de corrente com um potencial de célula muito pequeno. Forma-se no limite de interface sólido/líquido sobre a influência da convecção da camada hidrodinâmica. Em células operando a $\mathrm{H}_{2} / \mathrm{O}_{2}$, em altas correntes de operação, o limite de transporte de massa insuficiente afeta principalmente o teor de água no eletrólito e no catalisador do anodo ${ }^{[67]}$. O transporte de massa no catodo pode ser escrito através da equação de Nernst, que somente apresenta um transporte de massa difusivo. A impedância para a espessura finita da camada de difusão é designada impedância de Nernst $\left(Z_{N}\right)$, como mostra a equação 68 :

$$
Z_{n}=Z_{H} \cdot f_{N}(\omega)
$$

onde, $Z_{W}$-impedância de Warburg, e $f_{N}(\omega)$ é dado por:

$$
f_{N}(\omega)=\tanh \left(\delta_{N} \sqrt{i \omega / D}\right)
$$

É verdade dizer que a parte real da impedância de Nernst é ${ }^{[68]}$ : 
Análise por Impedância Eletroquímica "on-line" de Conjuntos Eletrodo/Membrana (MEA)

$$
R_{N}=\frac{2 R T \cdot \delta_{N}}{z^{2} F^{2} D \cdot c^{0}}
$$

onde, $D$ - coeficiente de difusão e $c^{0}$ - concentração inicial.

A impedância de Nernst é descrita como uma combinação de resistores e capacitores.

\subsubsection{Capacitância da Dupla Camada Elétrica}

A capacitância da dupla camada elétrica $C_{d l}$ pode ser definida, analogamente a uma resistência ideal, pela derivada da densidade de carga $(\sigma)$ no eletrodo com referência ao potencial $(E)$, como definida pela equação 71 :

$$
C_{\omega}=\left(\frac{\partial \sigma}{\partial E}\right)_{T, P, \mu}
$$

onde, $T$ - temperatura; $P$ - pressão e $\mu$-potencial químico.

A capacitância da dupla camada elétrica pode ter uma variação com a mudança da freqüência. Uma variação no valor da capacitância revela informações como uma mudança de umidificação do eletrólito, por exemplo ${ }^{[69]}$. Na FIGURA 20 está representado o gráfico da dupla camada elétrica entre eletrodo/eletrólito. 


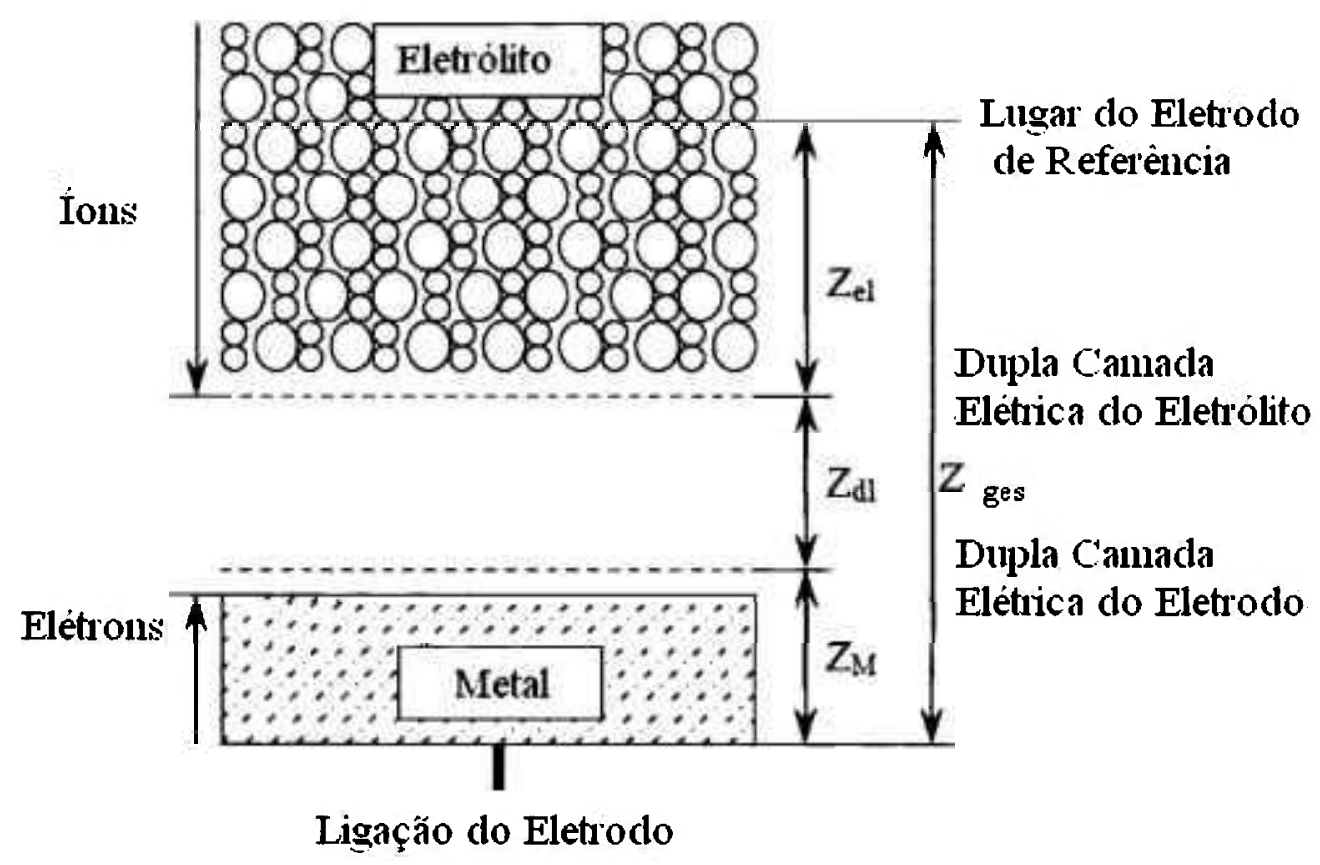

FIGURA 20 - Representação da dupla camada elétrica entre eletrodo/eletrólito, onde $Z_{\mathrm{el}}$ é a impedância do eletrólito, $Z_{\mathrm{dl}}$ é a impedância da dupla camada elétrica, $Z_{\mathrm{M}}$ é a impedância do metal e $Z_{\text {ges }}$ é a impedância total do sistema.

\subsubsection{Elemento de Fase Constante}

A impedância não somente determina os elementos de resistência, capacitores e indutores, mas gera um deslocamento de fase entre corrente e potencial, que é condicional à freqüência. A impedância eletroquímica pode ser equacionada como:

$$
Z=A(j \omega)^{-\varphi \cdot \alpha}
$$

O elemento de fase constante (do inglês, Constant Phase Element, CPE) pode ser uma resistência ideal, onde $A=R$ e $\varphi=0$. Quando estes elementos forem capacitores ideais, teremos $A=1 / C$ e $\varphi=1$. Se os elementos forem indutores ideais, teremos $A=L \mathrm{e}$ $\varphi=-1$. Também pode vir a ser $\varphi=0,5$ se existir Warburg entre os elementos.

Em princípio, a impedância do CPE é útil para descrição da dupla camada elétrica de um eletrodo de camada irregular. Em uma célula real, temos a capacitância da dupla camada elétrica como um $\mathrm{CPE}$ e não como um capacitor. $\mathrm{O}$ valor físico aplicado ao CPE com $\varphi \neq-1,0,0,5$ e 1 também é encontrado na literatura ${ }^{[70-78]}$. A FIGURA 21 apresenta a impedância de um CPE. 


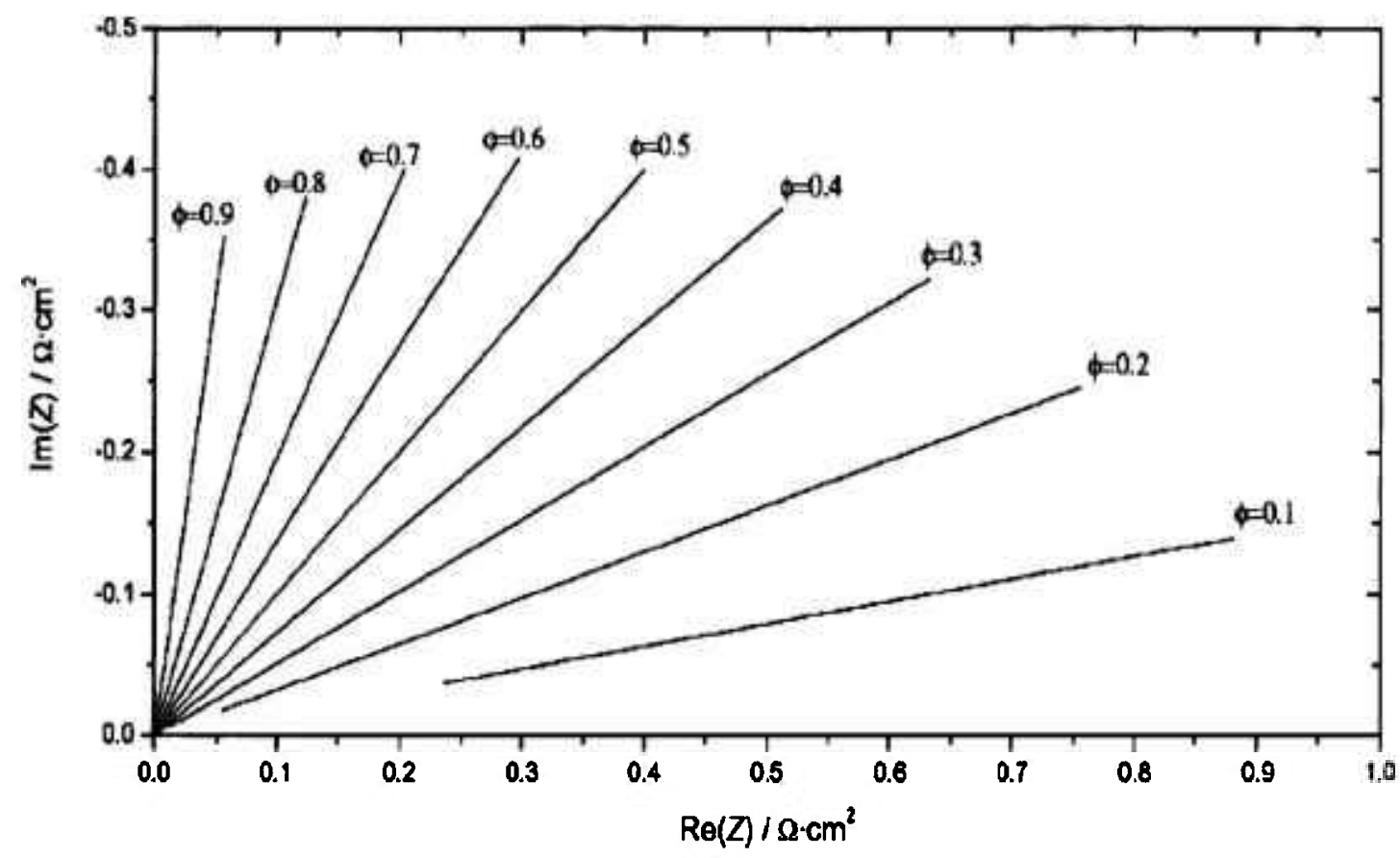

FIGURA 21 - Impedância do CPE por variação de parâmetros $\varphi$ em freqüência de $0,5 \mathrm{~Hz}$ a $25 \mathrm{kHz}$, onde $A=1 F . \mathrm{cm}^{-1} . \mathrm{s}^{* \varphi}$.

\subsection{Espectro de Espectroscopia de Impedância Eletroquímica (EIE)}

Em princípio podemos medir a EIE em uma meia célula eletroquímica como mostra o circuito elétrico ilustrado na FIGURA 22a. Na FIGURA 22b tem-se o diagrama de Nyquist de uma EIE da meia célula eletroquímica descrita anteriormente.

O diagrama de Nyquist da FIGURA 22b pode ser dividido em três partes, uma em baixa, uma em média e outra em altas freqüências. $\mathrm{O}$ início do primeiro semicírculo a altas freqüências, maiores que $1 \mathrm{kHz}$, refere-se a processos ôhmicos como a resistência da membrana, que tem relação direta da temperatura de funcionamento da célula e do grau de umidificação, mas não tem relação com a corrente de operação. O segundo semicírculo, em freqüências intermediárias, entre $10-1000 \mathrm{~Hz}$, representa a resistência de transferência de carga e o terceiro semicírculo, em baixas freqüências, menores que $10 \mathrm{~Hz}$, é relacionado ao efeito do transporte de massa. 


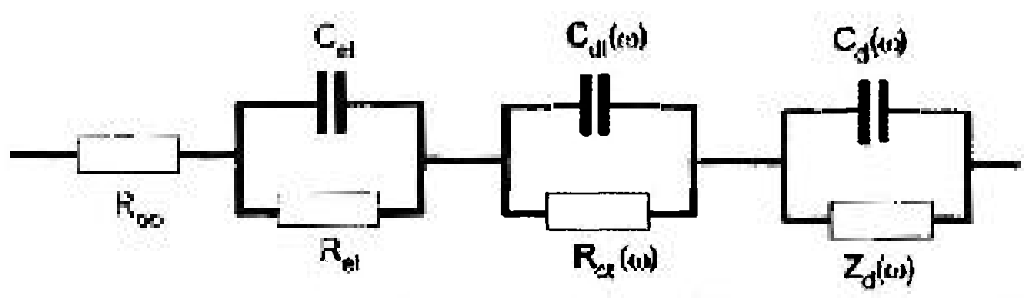

(a)

Electrolyle

Charge transfer

Mass transport

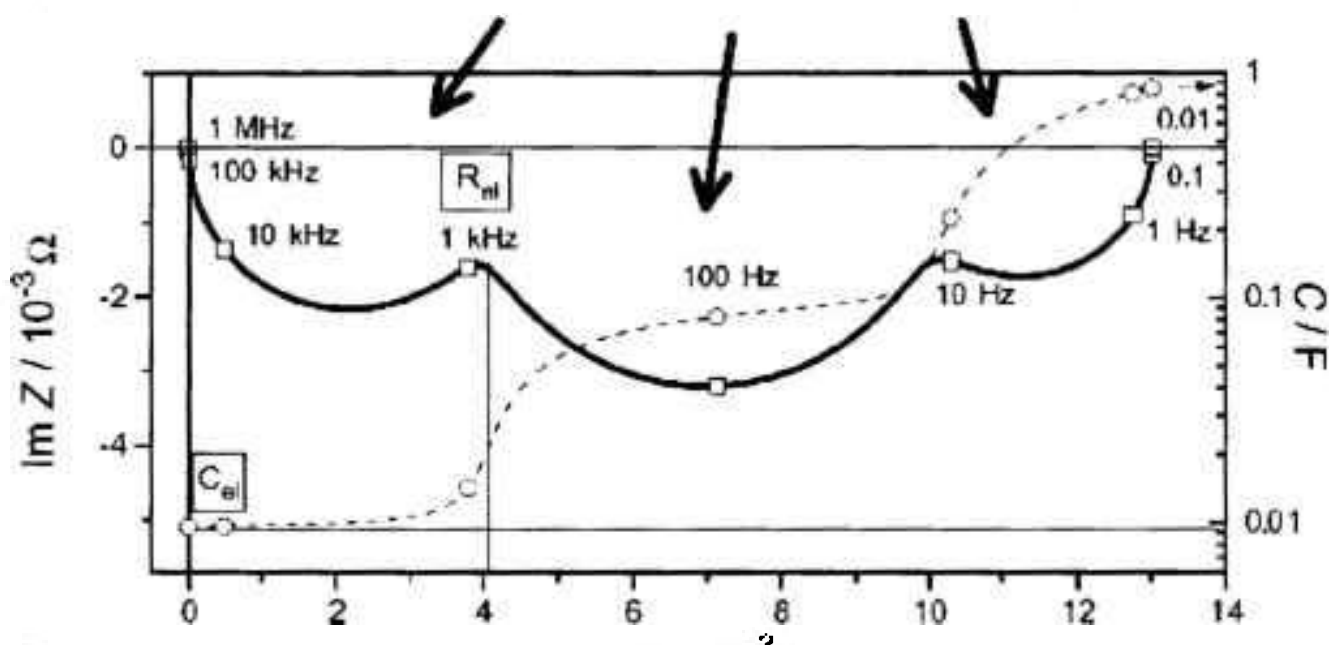

(b)

$\operatorname{Re} Z / 10^{-3} \Omega$

FIGURA 22 - a) Modelo de circuito equivalente para uma meia célula eletroquímica, b) Diagrama de Nyquist para medida de EIE de uma meia célula eletroquímica ${ }^{[68]}$.

\subsection{Modelos de EIE para uma Célula Eletroquímica}

Para a interpretação das medidas de EIE, pode-se criar modelos (circuitos elétricos) que representem os elementos e as reações envolvidas na operação de uma célula a combustível. Entretanto, muitos fatores devem ser levados em conta, como por exemplo, tipos diferentes de combustível, presença de monóxido de carbono ou ainda outros contaminantes na reação do combustível utilizado.

Na FIGURA 23 está representado um modelo elétrico associado à uma meia célula eletroquímica. Este modelo contém uma resistência ôhmica $\left(R_{\Omega}\right)$, uma resistência de transferência de carga $\left(R_{c t}\right)$, uma impedância de Warburg $(W)$ e uma capacitância da célula $\left(C_{g e s}\right)$. A capacitância da meia célula é dependente do eletrólito e proporcional a capacitância geométrica da célula. A impedância de Warburg origina-se pelo transporte de gás ineficiente na meia célula. 


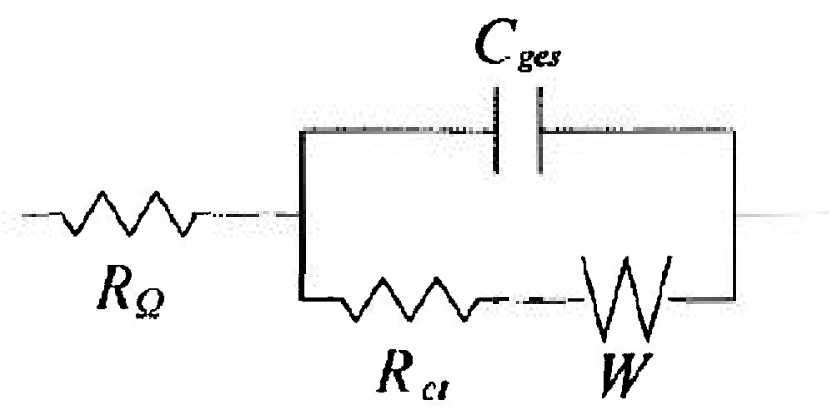

FIGURA 23 - Modelo para uma meia célula eletroquímica.

Este modelo apresenta poucas informações sobre os processos eletroquímicos envolvidos na meia célula. Numa célula eletroquímica ocorrem simultaneamente reações no anodo e no catodo.

Para descrever mais corretamente as reações envolvidas em uma célula eletroquímica, tem que tratar separadamente o compartimento anódico do catódico como representado na FIGURA 24. No anodo a difusão do gás é muito rápida ao contrário da difusão no catodo, assim a impedância de Warburg aparece somente no catodo. $O$ anodo apresenta assim uma capacitância $\left(C_{l}\right)$ e uma resistência à transferência de carga $\left(R_{c t}\right)$. O catodo apresenta uma capacitância da dupla camada elétrica $\left(C_{d l}\right)$ e a impedância de Warburg $\left(W_{c}\right)$.

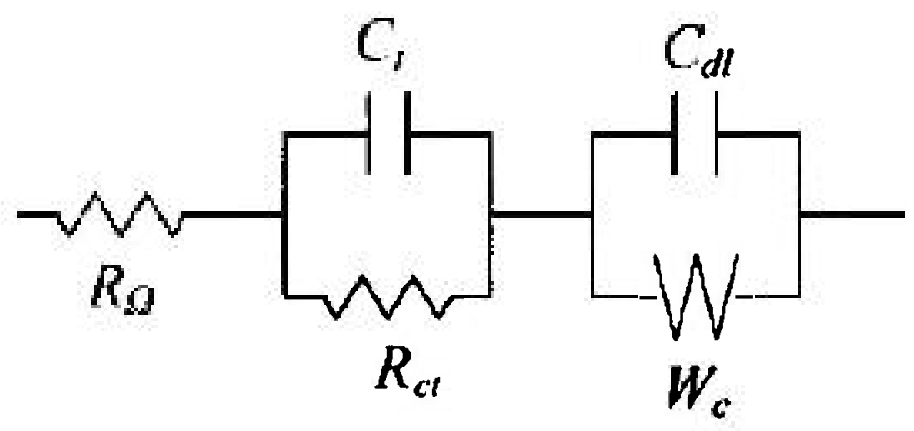

FIGURA 24 - Modelo para uma célula eletroquímica com separação de compartimentos. $\mathrm{O}$ anodo está representado à esquerda e o catodo à direita. 


\subsection{Revisão da Literatura sobre EIE Aplicada a Células a Combustível}

Para aperfeiçoar o desempenho das células do tipo PEMFC, alguns autores realizaram estudos de Espectroscopia de Impedância Eletroquímica (EIE) para avaliar os efeitos de resistência de vários componentes como: da membrana de $\mathrm{Nafion}^{\circledR}{ }^{[79-89]}$, do $\operatorname{MEA}^{[90,91]}$, do catodo ${ }^{[92-94]}$ e do anodo ${ }^{[94-100]}$.

Andreaus e colaboradores ${ }_{79}^{[78]}$ estudaram a origem físico-química da perda de eficiência da PEMFC operando em grandes densidades de corrente. Estes efeitos podem ser atribuídos a duas razões: quando se usa membranas espessas para melhorar a estabilidade mecânica, ou quando se utiliza ar no cátodo da célula a combustível. Estes autores verificaram também que, em pequenas densidades de corrente, a eficiência da célula a combustível é controlada pela RRO.

Freire e Gonzalez ${ }_{80}^{[79]}$ estudaram o efeito das membranas de Nafion ${ }^{\circledR}$ de diferentes espessuras e as condições de umidificação na resposta de impedância de $\mathrm{H}_{2} / \mathrm{O}_{2}$ em PEMFC. Os resultados são atribuidos em alta freqüência a contribuição da transferência de carga envolvida na RRO e em baixa freqüência a processos de relaxação. Estes estudos são analisados em termos da espessura da membrana, da temperatura de funcionamento e das condições de umidificação dos gases. Os resultados mostram claramente que as membranas mais finas apresentam melhores características de controle de água, sendo muito menos sensível a temperatura e densidade de corrente de troca.

Diard e colaboradores ${ }_{81}^{[80]}$ estudaram um novo método para monitorar a impedância de célula a combustíveis operando com uma carga constante. Verificaram que a impedância apresenta um comportamento indutivo como uma bateria, e dois arcos capacitivos da combinação da impedância de PEM, operando com uma carga constante em série, com uma indutância devido à conecção e aos instrumentos de medida.

Paganin e colaboradores ${ }_{89}^{[88]}$ estudaram os aspectos de polarização envolvidos na célula a combustível do tipo PEM. Os autores relatam uma queda de potencial da célula e correlacionam esta perda de desempenho com os resultados obtidos pela técnica de EIE frente à cinética das reações de interface, a difusão do oxigênio, a espessura e o balanço de água da membrana e a distribuição dos aglomerados dos eletrocatalisadores dispersos na camada catalítica. Os autores observaram que os arcos do diagrama de Nyquist dependem do potencial de funcionamento da célula, observaram ainda que para todos os eletrodos e todas as condições experimentais que estes arcos representam à capacitância da dupla camada elétrica combinada com a resistência de transferência de carga da RRO. Os autores observaram ainda que a baixos sobrepotenciais, a etapa determinante da célula a 
Análise por Impedância Eletroquímica "on-line" de Conjuntos Eletrodo/Membrana (MEA) de Células a Combustível a Membrana Polimérica (PEMFC)

combustível é a cinética da RRO e assim o raio do diagrama de Nyquist é determinado pela resistência de transferência de carga que depende do potencial do eletrodo e é governada pela equação de Tafel.

Mueller e colaboradores $\underset{90}{[89]}$ aplicaram a técnica de espectroscopia de impedância eletroquímica para caracterizar o funcionamento de uma DMFC. Os autores estudaram o efeito tanto no anodo como no catodo, utilizando a técnica de meia célula onde se borbulha $\mathrm{H}_{2}$ na câmara oposta à estudada para atuar como eletrodo de referência (ERH). No anodo, observaram três semicírculos distintos nas variadas faixas de freqüência:

- $\mathrm{O}$ arco em altas freqüências (entre $65 \mathrm{e} 0,9 \mathrm{kHz}$ ) está relacionado à resistência iônica da membrana (observa-se uma diminuição da resistência com o aumento da temperatura, típico de condutores iônicos) que forma uma combinação paralela com a capacitância.

- $\mathrm{O}$ arco em médias freqüências (entre $3 \mathrm{kHz}$ e $1 \mathrm{~Hz}$ ) é correlacionado em função do potencial de ânodo, onde esta resistência diminui com o aumento do sobrepotencial, sendo o processo relacionado à cinética de eletrooxidação do metanol.

- $\mathrm{O}$ arco em baixas freqüências (menores que $1 \mathrm{~Hz}$ ) é correlacionado à transferência de metanol no anodo. A magnitude desta resistência cresce com o aumento do fluxo de metanol ou também quando a concentração de metanol é diminuída.

No catodo foi observado somente um semicírculo em médias freqüências (entre 900 e $1 \mathrm{~Hz}$ ) que está relacionado com a resistência de transferência de carga da reação de redução de oxigênio ( $R R O$ ), e mostra que com o aumento da densidade de corrente (aumento do sobrepotencial), o diâmetro do arco diminui. 


\section{MATERIAIS E MÉTODOS}

\subsection{Preparação dos Eletrocatalisadores Dispersos - Método de Redução por Álcool}

O método da redução por álcool foi desenvolvido por Toshima e Yonezawa $^{[101]}$ e modificado no $\operatorname{IPEN}^{[54,60,102]}$, acarretando em uma patente INPI-RJ, PI0304121-2 ${ }^{[103]}$. Neste trabalho, foi feito o refluxo de uma solução alcoólica (etileno glicol) contendo o íon metálico desejado na presença de um agente estabilizante, normalmente um polímero ou até mesmo o controle do $\mathrm{pH}$ da solução, fornece dispersões coloidais homogêneas das nanopartículas metálicas correspondentes. $\mathrm{O}$ álcool funciona como solvente e agente redutor ao mesmo tempo, sendo oxidado a aldeídos e cetonas, proporcionando dispersões coloidais de nanopartículas com tamanho reduzido e distribuição uniforme. O Esquema 3 mostra as etapas deste processo.
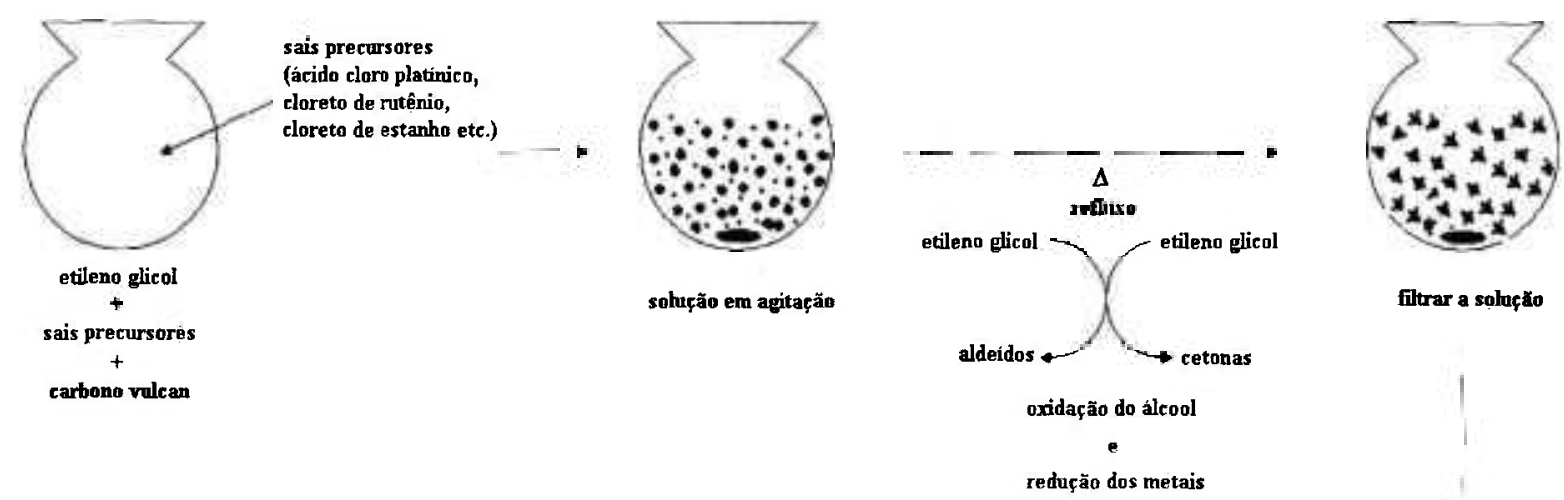

Esquema 3 - Preparação dos eletrocatalisadores pelo Método de Redução por Álcool. 
Neste método as seguintes vantagens são destacadas: i) O procedimento é muito simples e reprodutível, ii) As nanopartículas obtidas são pequenas e apresentam-se bem distribuídas, iii) $\mathrm{O}$ tamanho das nanopartículas pode ser controlado alterando as condições de preparação, como escolha do álcool, pH e temperatura de redução, quantidade e variedade do agente estabilizante, concentração do íon metálico e uso de aditivos, $i v)$ As dispersões coloidais das nanopartículas apresentam alta atividade catalítica e v) As dispersões obtidas são bastante estáveis.

\subsection{Produção dos MEAs}

Os MEAs serão confeccionados pelo método híbrido de Spray-Prensagem a quente, desenvolvido e patenteado no IPEN ${ }^{[104]}$. Os seguintes critérios foram determinados para o desenvolvimento deste método:

1) Etapas simples no processo de fabricação para redução de custos;

2) Produzir MEAs com área de $25 \mathrm{~cm}^{2}$;

3) Utilizar água deionizada como solvente para a produção da suspensão do catalisador;

4) Utilizar como eletrólito uma membrana de Nafion ${ }^{\circledR} 105$ da Du Pont;

5) Utilizar uma mesa de vácuo própria com aquecimento para produção dos eletrodos pelo método de spray, pintando na camada difusora (tecido de carbono) ou na membrana;

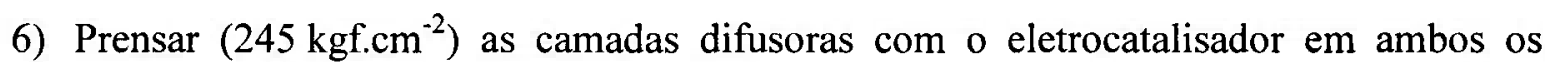
lados da membrana com uma prensa hidráulica aquecida $\left(125^{\circ} \mathrm{C}\right)$ por $2 \mathrm{~min}$;

7) Trabalhar com variáveis selecionadas de operação da célula de acordo com a experiência anterior do grupo;

8) Realizar experimentos de impedância e polarização para avaliar os MEAs e eletrocatalisadores produzidos.

Foram utilizadas células EletroChem (EUA) para realização de ensaios nos MEAs produzidos. $O$ procedimento escolhido para a ativação, hidratação e limpeza das membranas é descrito a seguir: a) a membrana é lavada com água deionizada durante $1 \mathrm{~h}$ a $80^{\circ} \mathrm{C}$; b) a membrana é tratada com água oxigenada $3 \%$ (água oxigenada 10 volumes) durante $1 \mathrm{~h}$ a $80^{\circ} \mathrm{C}$ para eliminar as impurezas orgânicas; c) lavagem com água deionizada por 3 vezes para eliminar os traços de água oxigenada, durante $1 \mathrm{~h}$ a $80^{\circ} \mathrm{C}$; d) lavar com solução aquosa de ácido sulfúrico $1 \mathrm{~mol} \mathrm{~L}^{-1}$ durante $1 \mathrm{~h}$ a $80^{\circ} \mathrm{C}$ para eliminar as impurezas 
metálicas; e) lavagem com água deionizada por 3 vezes para eliminar os traços de ácido sulfúrico, durante $1 \mathrm{~h}$ a $80^{\circ} \mathrm{C}$.

A produção da tinta precursora dos eletrodos, a ser utilizada pelo método Spray sobre a camada difusora tem sua composição caracterizada por água ultrapura como solvente (de 2,5 a 10,0 mL); negro de fumo de alta área superficial (do inglês, Carbon Black), contendo o eletrocatalisador nanodisperso $(0,1$ a $0,4 \mathrm{~g}$ com $20 \%$ de eletrocatalisador) em água. Esta suspensão é colocada em um ultra-som por ponta, chamado de Desruptor de Células Ultra-Sônico, diferente dos banhos de ultra-som comum (pois toda a energia do equipamento é concentrada num pequeno volume (a ponta)) para a ruptura dos aglomerados de negro de fumo mais eficientemente. $\mathrm{O}$ tempo do tratamento pode variar de 15 a $60 \mathrm{~s}$. Depois de produzida a suspensão, é adicionada a solução de Nafion $^{\circledR}\left(0,5\right.$ a $2,0 \mathrm{~mL}$ de solução de Nafion ${ }^{\circledR}$ em água a $10 \%$ em massa). A tinta deve permanecer em agitação magnética por um período de $24 \mathrm{~h}$.

A produção dos MEAs pelo método Spray Prensagem a Quente, é caracterizada pelo seguinte procedimento:

1) Cortar um pedaço de material poroso condutor eletrônico e parcialmente hidrofóbico (tecido de carbono) ou a membrana, e montar em uma moldura metálica, utilizando juntas de teflon para garantir uma superfície lisa;

2) Colocar a moldura contendo o tecido de carbono ou a membrana sobre a mesa de vácuo aquecida, que consiste numa superfície perfurada ligada a uma bomba de vácuo, para garantir que a membrana permaneça sempre esticada;

3) Ajustar a temperatura da mesa de vácuo e a pressão do compressor de ar;

4) Aplicar verticalmente o spray da tinta com um aerógrafo comercial para fabricação do $1^{\circ}$ eletrodo;

5) Retirar a moldura metálica com o tecido de carbono ou a membrana da mesa de vácuo e colocar na balança para o controle de massa do eletrocatalisador;

6) Repetir o procedimento de 1) a 6) para o outro eletrodo;

7) Colocar a membrana e os tecidos de carbono entre duas placas metálicas na prensa hidráulica a quente, previamente aquecida na temperatura desejada;

8) Aplicar ao conjunto a pressão desejada num tempo desejado;

9) Retirar o conjunto ainda quente da prensa, deixando-o esfriar no ambiente.

Após o resfriamento, o MEA estará pronto para ser utilizado na célula a combustível. O processo de fabricação de MEA descrito abdica do uso de aditivos na tinta precursora dos eletrodos, simplificando o processo. 


\subsection{Operação das Células Unitárias}

O sistema membrana/eletrodos (MEA) mais os espaçadores são acondicionados em placas de grafite com dois orifícios, sendo que um deles permite a entrada do gás que alimenta a célula e o outro é o responsável pela evacuação do excesso de gás que não reagiu. Os gases passam através de câmara de umidificação, onde são aquecidos e saturados com vapor de água, em seguida são distribuídos uniformemente pelo eletrodo através de canais em forma de serpentina, pontuais ou com formas específicas, presentes entre os dois orifícios das placas de grafite.

Estas placas contêm ainda orifícios para a entrada de um termopar e um conjunto de resistências que permitem a programação e o controle de temperatura. $\mathrm{O}$ sistema compactado e parafusado permite a mobilidade da célula e assim podem ser conectados aos coletores de corrente.

A célula, já montada, é monitorada por uma estação de trabalho (FIGURA 25) que permite o controle da temperatura da câmara de umidificação, da pressão e vazão mássica (MKS, USA) dos gases reagentes, além do controle de corrente e potencial. As células podem ser alimentadas com hidrogênio e oxigênio, sendo que podem ter sua montagem modificada para operar com metanol ou etanol.

A linha de nitrogênio é controlada somente por um rotâmetro e as vazões de hidrogênio e oxigênio são controladas por controladores de vazão mássica, utilizando-se, entretanto, rotâmetros para visualização. O hidrogênio é umidificado antes de ser introduzido na célula por um sistema de umidificação apropriado instalado na entrada do anodo; e quando se usa metanol ou etanol, o umidificador é instalado no catodo da célula. A célula é conectada a carga dinâmica, que recebe a corrente elétrica produzida pela mesma. Este equipamento permite variar a corrente (carga), para a determinação da curva de polarização (Potencial/Densidade de corrente). As temperaturas dos diversos sistemas e da célula são controladas com controladores microprocessados P.I.D. 


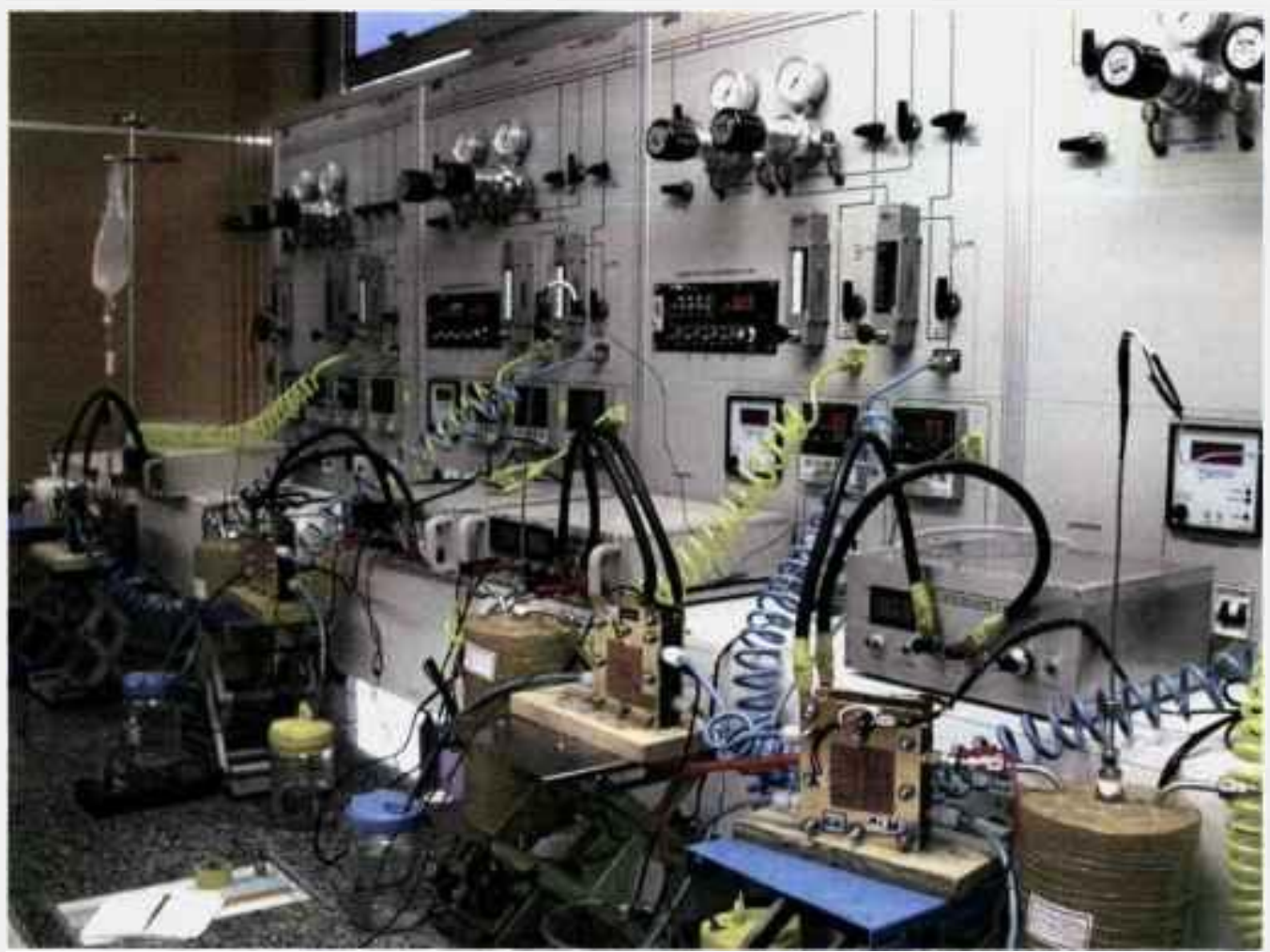

FIGURA 25 - Painéis de controle das células a combustível.

A curva de polarização, medida na célula unitária ligada à carga dinâmica, é uma medida direta do desempenho c eficiência do MEA. A curva de polarização é realizada sob a condição de valor constante de excesso de gases segundo a corrente produzida, ou seja, os valores de vazões dos gases são ajustados ponto a ponto. Assim, as condições de umidificação da membrana são mantidas constantes em toda a curva. $\mathrm{O}$ procedimento adotado para a construção da curva de polarização será o seguinte:

1) Após um tempo de acondicionamento do MEA, aciona-se a carga dinâmica na corrente máxima, ajustando exatamente a vazão dos gases. Após 2 minutos fazem-se as medições de corrente e tensão.

2) Reduz-se o valor da corrente na carga dinâmica em 0,1 A e aguarda-se dois minutos para registrar os valores de corrente e tensão obtidos (caso sejam obtidas leituras muito oscilantes, o valor da corrente deve ser reduzido até que valores estáveis sejam atingidos). Repete-se este procedimento nos próximos pontos (região do sobrepotencial por difusão, exponencial). 
3) Reduz-se o valor da corrente na carga dinâmica em $0,5 \mathrm{~A}$ e aguarda-se 2 minutos para registrar os valores de corrente e tensão obtidos (região do sobrepotencial por queda ôhmica, linear).

4) Reduz-se o valor da corrente na carga dinâmica novamente em $0,1 \mathrm{~A}$ e repete-se o procedimento até onde for possivel reduzir o valor da corrente (região do sobrepotencial por ativação, exponencial). Com os dados obtidos construir a curva de polarização.

Observa-se que no início e no final do experimento (região exponencial) são realizadas medições com intervalos menores de corrente (de $0,1 \mathrm{em} 0,1 \mathrm{~A})$ para que pontos mais próximos no gráfico possam ser obtidos, aumentando a precisão. Com isso obtemos uma maior confiabilidade nos resultados.

\subsection{Caracterização Física, Química e Eletroquímica dos Eletrocatalisadores e MEAs}

A completa caracterização estrutural dos eletrocatalisadores e dos eletrodos de difusão gasosa produzidos, contendo nanopartículas do eletrocatalisador, não é simples. A utilização de co-catalisadores na confecção de eletrodos aumenta a importância da caracterização estrutural destes eletrodos, relacionando estrutura, fases presentes e homogeneidade dos dois metais com relação ao desempenho da célula. Esta importância se explica, pois as propriedades químicas dos metais podem ser modificadas pela formação de uma liga ou por óxidos amorfos. Para que esta caracterização seja efetiva, não apenas as técnicas eletroquímicas de análise das células, normalizadas por gramas de Pt, passam a ser necessárias, mas, também outras técnicas descritas na seqüência. Existem vários métodos, sendo que os mais importantes são discutidos brevemente a seguir, considerando-se a potencialidade de cada um deles para estes sistemas.

1. DRX: A Difração de Raios X (DRX) pode, por um lado aplicando-se a equação de Scherrer, dar informações sobre o tamanho médio de cristalito e a distribuição de tamanhos, por outro lado dá informação sobre a presença de ligas em partículas nanométricas. Problemas com a aplicação do DRX para eletrocatalisadores PEM é o fato de que a largura das raias de difração aumenta com a diminuição do tamanho da partícula e então só podem ser caracterizadas, significativamente, partículas com um diâmetro maior que 2 ou $3 \mathrm{~nm}$. Além disso, somente fases cristalinas podem ser registradas, ou seja, fases amorfas existentes não são detectadas no DRX. As análises de difração de raios $\mathrm{X}$ foram feitas, utilizando-se o difratômetro STOE STADI-P com um monocromador de radiação $\mathrm{Cu} \mathrm{K} \alpha$ e um detetor posição-sensitiva com abertura de $40^{\circ} \mathrm{em}$ modo transmissão. 
2. EDX: A Análise de Energia Dispersiva de Fluorescência de Raios X (EDX) dá uma informação quantitativa sobre os elementos existentes no catalisador. Executado como nano-EDX pode ser determinada a composição elementar de uma nanopartícula. Esta é uma opção muito importante para determinar a estequiometria real de uma nanopartícula e a composição da fase cataliticamente ativa, que não coincide necessariamente com a composição nominal do catalisador, ou seja, com a composição utilizada na preparação.

3. MET: A Microscopia Eletrônica de Transmissão (MET) dá informações sobre o tamanho, a distribuição de tamanhos e o grau de cristalinidade das nanopartículas e sobre a distribuição de espaço das partículas no negro de fumo. Para partículas aproximadamente de 1 a $5 \mathrm{~nm}$ a MET é decididamente indispensável, já que o tamanho da partícula e também a superfície específica do metal (que está relacionada ao tamanho da partícula) são fundamentais para o julgamento da atividade catalítica de um sistema. As análises de Microscopia Eletrônica de Transmissão foram realizadas utilizando um microscópio da Philips CM20 UT com $200 \mathrm{kV}$ juntamente com as análises de nano-EDX.

4. MEV: A Microscopia Eletrônica de Varredura (MEV) é utilizada para se avaliar a morfologia, porosidade e a superfície dos eletrodos. Utilizou-se um MEV Philips XL30 com $20 \mathrm{keV}$ e equipado com uma microanálise EDAX DX-4.

5. XPS: Com ajuda da Espectroscopia Fotoeletrônica de Raios X (XPS), determinam-se, principalmente, os estados de oxidação dos elementos existentes no catalisador, embora este método abranja somente a superfície, ou seja, camadas mais superiores de alguns $\AA$ de espessura. Os experimentos de Espectroscopia Fotoeletrônica de Raios X foram realizados em uma câmara de ultra alto vácuo (UHV) com uma pressão de $1,0 \times 10^{-9}$ mbar. As medidas foram realizadas com raios X não-monocromático do $\mathrm{Mg} \mathrm{K \alpha}$ $(\mathrm{E}=1253,6 \mathrm{eV})$ e com um analisador de elétrons de hemisférios concêntricos (CLAM2 da VG Microtech) com energia de 1,5 keV. As energias de ligação dos picos foram corrigidas com relação ao pico referência do C (1s) situado a $284,6 \mathrm{eV}$.

6. EM: A espectroscopia de Mössbauer (EM) envolve a emissão e absorção ressonante de raios gama pelos núcleos dos elementos. Para compensar eventuais diferenças de energias ou desdobramentos das linhas devido às interações quadrupolares ou magnéticas dos núcleos, o emissor é colocado em movimento oscilatório longitudinal para que a radiação gama seja emitida com um intervalo de energia modulado através do efeito Doppler.

7. EIE: A Espectroscopia de Impedância Eletroquímica (EIE) dá informações sobre as resistências dos diversos MEAs e também os processos que ocorrem durante o 
funcionamento da célula. Utilizou-se um analisador de freqüência (do inglês, Frequency Response Analyser) e um potenciostato/galvanostato da Gamry, para separar e analisar a resposta das medidas de impedância via carga dinâmica.

8. Curvas de Polarização: A curva de polarização, medida em células unitárias experimentais ligadas às cargas dinâmicas, é uma medida direta do desempenho e eficiência de cada MEA. A medida da curva de polarização é realizada sob a condição de valor constante de excesso de gases, ou seja, os valores de vazões são ajustados ponto a ponto, segundo a corrente produzida, para um mesmo fator de utilização. Assim, as condições de umidificação da membrana são mantidas constantes em toda a curva (ver Capítulo 4.3). Os desempenhos dos MEAs são avaliados pela posição da curva de polarização da célula. Para uma comparação, utiliza-se o valor da densidade de corrente a $600 \mathrm{mV}$ de potencial, pois este é o valor prático de operação de células do tipo PEM.

A construção dos histogramas foi feita através das imagens das micrografias de MET dos eletrocatalisadores. A micrografia foi inserida no programa ImageTool Versão $3.0^{[105]}$ da UTHSCSA (The University of Texas Health Science Center at San Antonio) e medido o diâmetro de no mínimo 300 partículas do eletrocatalisador analisado. Com os dados do diâmetro das partículas em uma tabela, gerou-se o histograma. 


\section{RESULTADOS E DISCUSSÃo}

\subsection{Refinamento do Método de Preparação dos MEAs}

A princípio, iniciou-se uma comparação no método de preparação dos MEAs, já desenvolvido no IPEN, para as avaliações e melhoria de desempenho das célula a combustível do tipo PEM. Foram preparados MEAs aplicando-se a tinta catalítica diretamente na membrana de $\mathrm{Nafion}^{\circledR}$ ou diretamente no tecido de carbono, para se verificar qual teria uma menor resistência de contato, e assim um melhor desempenho na célula a combustível.

Utilizaram-se dois tipos de camada difusora, tecidos de carbono ElectroChem EC-CC1-060T e tecido de carbono ELAT, ambos sem camada catalítica. A tinta catalítica foi preparada com eletrocatalisadores $\mathrm{Pt} / \mathrm{C}$ comercial da E-TEK (Lote: 3182602) e $\mathrm{PtRu} / \mathrm{C}$ comercial da E-TEK (Lote: 3028401) ou com eletrocatalisadores preparados através do método de redução por álcool ${ }^{[54,60,103,104]}$, ambos os casos com $20 \%$ de material catalítico e $35,8 \%$ de solução aquosa de Nafion ${ }^{\circledR}$ a $10 \%$ em massa. Foram feitas curvas de polarização para todos os MEAs utilizando-se hidrogênio e oxigênio ultrapuros. Foram feitos experimentos de impedância eletroquímica para os MEAs para se verificar o comportamento destes, frente a variação da corrente de operação da célula.

Através do estudo dos diagramas de Bode e Nyquist foi possível analisar, os efeitos capacitivos da dupla camada elétrica, além de efeitos resistivos (resistência do eletrólito, resistência por transferência de carga, resistência por transferência de massa etc.) que podem ocorrer numa célula eletroquímica.

Na FIGURA 26 estão representadas curvas de polarização de MEAs com $25 \mathrm{~cm}^{2}$ de área eletródica, confeccionado com Pt/C comercial da E-TEK $20 \%$, com 0,4 mg de Pt.cm ${ }^{-2}$ no anodo e $0,6 \mathrm{mg}$ de Pt.cm ${ }^{-2}$ no catodo. Nestes MEAs aplicou-se a tinta catalisadora diretamente no tecido de carbono ElectroChem ou diretamente na membrana de Nafion ${ }^{\circledR}$. Nos MEAs cujas curvas estão representadas com símbolos cheios foram 
utilizados tecidos de carbono ElectroChem como camada difusora $(0,346 \mathrm{~mm}$ de espessura) e nos MEAs representados por símbolos vazados foram utilizados tecidos de carbono ELAT $\left(0,424 \mathrm{~mm}\right.$ de espessura). A temperatura da célula foi de $70^{\circ} \mathrm{C}$ e do umidificador de $85^{\circ} \mathrm{C}$.

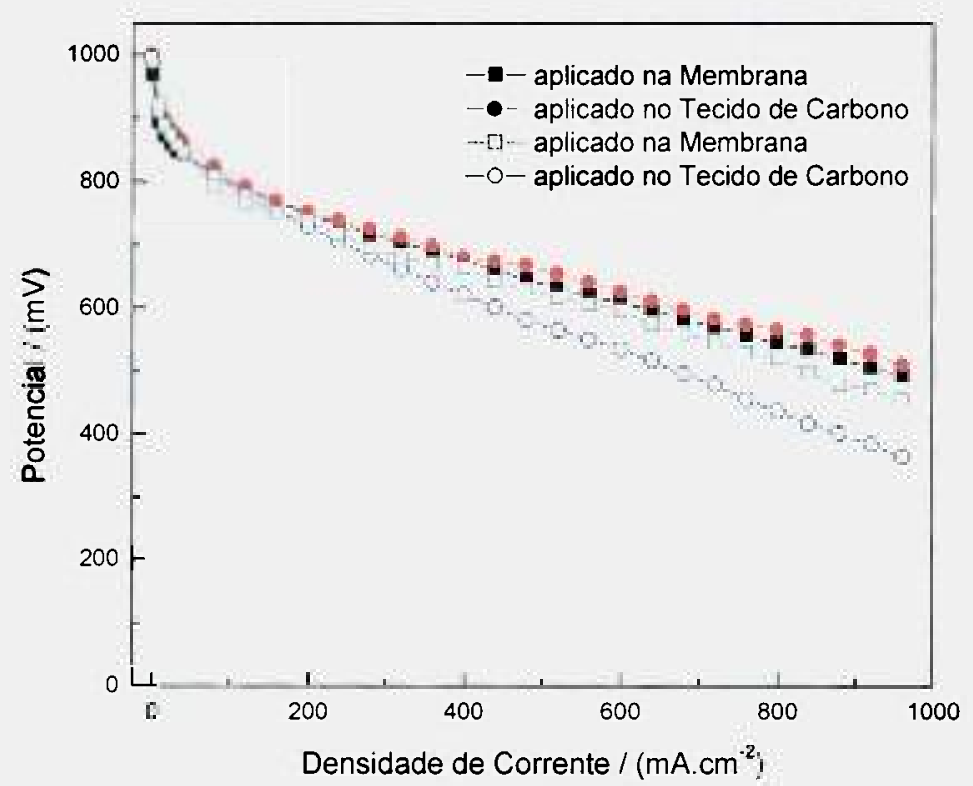

FIGURA 26 - Curvas de polarização de MEAs com $25 \mathrm{~cm}^{2}$ de área eletródica, confeccionados com Pt/C comercial da E-TEK com $0,4 \mathrm{mg}$ de Pt.cm ${ }^{-2}$ no anodo e $0,6 \mathrm{mg}$ de Pt.cm ${ }^{-2}$ no catodo, operando com $\mathrm{H}_{2} / \mathrm{O}_{2}$. Símbolos cheios representam tecido de carbono ElectroChem e símbolos vazados tecido de carbono ELAT. Temperaturas: célula a $70^{\circ} \mathrm{C}$ e umidificador a $85^{\circ} \mathrm{C}$.

Nas curvas de polarização dos MEAs da FIGURA 26, observam-se claramente duas regiões: uma região com queda acentuada de potencial a baixas densidades de corrente, determinada pela resistência à transferência de cargas (queda exponencial), chamada polarização por ativação, e uma região com queda de potencial linear a densidade de corrente mais elevadas, determinada pela resistência ôhmica. A região caracterizada pela resistência à transferência de cargas é devida. principalmente, à reação de redução de oxigênio que, a baixas temperaturas, é fortemente desfavorecida.

Não se observa nas curvas, no entanto, a região que é controlada por transporte de massa (queda exponencial acentuada no final do trecho reto da curva de polarização), devido às condições operacionais de vazões de gases em excesso $(50 \%)$ estabelecidas nos experimentos, na faixa de densidades de corrente estudada. 
Comparando-se os resultados dos tecidos de carbono ElectroChem, menos espessos, porém mais vazados, observa-se que estes têm uma menor polarização por queda ôhmica. Este fato pode estar relacionado a uma menor resistência ao fluxo de gases à região catalítica, devida à sua maior porosidade. Pode-se observar que o MEA com a tinta catalítica aplicada no tecido de carbono apresenta um pequeno aumento na densidade de corrente (640 para $680 \mathrm{~mA} . \mathrm{cm}^{-2}$ a $600 \mathrm{mV}$ ). Este comportamento pode ser explicado pelo fato de que quando a tinta foi aplicada diretamente sobre a membrana, o sistema permaneceu um maior tempo na mesa de vácuo aquecida a uma temperatura de $125^{\circ} \mathrm{C}$ para ocorrer a evaporação do solvente (água) da tinta catalítica. Com isto a membrana ficou totalmente seca, dificultando a umidificação e comprometendo o transporte catiônico. Outro fato que pode ser evidenciado é que o solvente contido na tinta propicia uma melhor dispersão da tinta na superfície hidrofóbica do tecido de carbono (com $35 \%$ em massa de Teflon ${ }^{\circledR}$ ).

Ainda na FIGURA 26, observa-se que o tecido de carbono ELAT (mais espesso, $0,424 \mathrm{~mm}$ de espessura) tem um aumento na densidade de corrente (437 para $580 \mathrm{~mA} . \mathrm{cm}^{-2}$ a $600 \mathrm{mV}$ ) quando a tinta foi aplicada diretamente na membrana, isto pode ser devido à formação de aglomerados de catalisadores quando a pintura é feita no tecido de carbono, visto que ele é bem entrelaçado (diferente do ElectroChem que a tinta permeava por entre a malha). Pode-se observar ainda, comparando-se os dois tecidos de carbono, que os MEAs confeccionados com o tecido de carbono ELAT apresentam maior polarização no decorrer de toda a curva de polarização. O efeito é de se esperar, pois o ELAT por ser mais espesso, tem uma maior resistência ôhmica e por isso atinge uma menor densidade de corrente num mesmo potencial.

Na FIGURA 27 estão representados os diagramas de Nyquist dos MEAs descritos na FIGURA 26 com a célula operando com uma corrente de 1,0 A (40 mA.cm $\left.{ }^{-2}\right)$. Observa-se na análise dos diagramas de Nyquist da FIGURA 27, um semicírculo bem definido, indicando uma polarização por transferência de carga, onde a etapa determinante de velocidade é a transferência de carga na interface onde ocorre a reação de redução de oxigênio (catodo), cuja dependência com o potencial é governada pela equação de Tafel ${ }^{[106]}$. Além disso, os diagramas fornecem um valor da resistência ôhmica dos MEAs: 49,$1 ; 48,6 ; 55,3 ; 55,4 \mathrm{~m} \Omega$; respectivamente; onde o valor de impedância ( $Z$ real) correspondente ao menor valor de freqüência $(0,1 \mathrm{mHz})$, representa a resistência total do

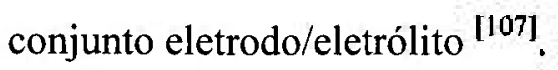




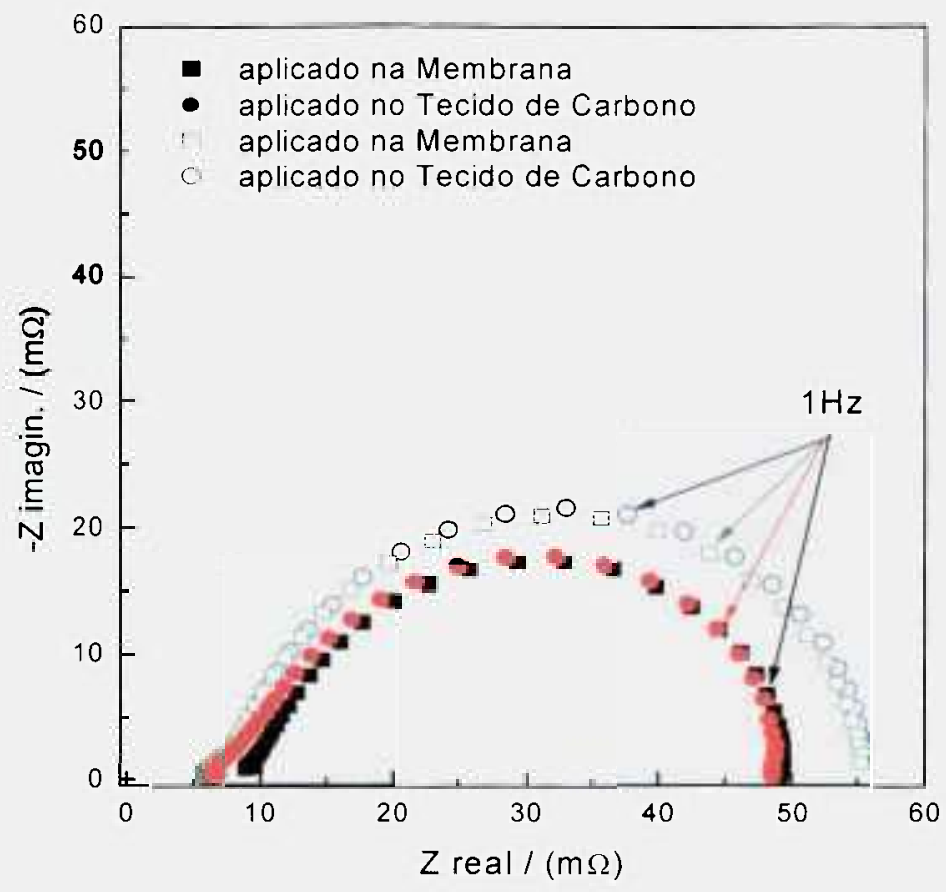

FIGURA 27 - Diagramas de Nyquist para MEAs com $25 \mathrm{~cm}^{2}$, confeccionados com Pt/C comercial da E-TEK com $0,4 \mathrm{mg}$ de Pt.cm ${ }^{-2}$ no anodo e $0,6 \mathrm{mg}$ de $\mathrm{Pt} . \mathrm{cm}^{-2}$ no catodo, em operação com $\mathrm{H}_{2} / \mathrm{O}_{2}$ a $1 \mathrm{~A}$ de corrente. Símbolos cheios representam tecido de carbono ElectroChem e símbolos vazados representam tecido de carbono ELAT. Temperaturas: célula a $70{ }^{\circ} \mathrm{C}$ e umidificador a $85^{\circ} \mathrm{C}$.

Pode-se observar ainda que os MEAs confeccionados com o tecido de carbono ELAT apresentam uma maior resistência em relação aos MEAs com tecido de carbono ElectroChem. Como já verificado pela curva de polarização, este fato está relacionado ao grande entrelaçamento da malha deste tecido de carbono, além da diferença de espessura, que depois de pintado apresenta uma maior resistência à passagem dos gases. Para os MEAs com tecido de carbono ElectroChem, o que teve a tinta catalítica aplicada diretamente no tecido de carbono apresentou uma menor resistência ôhmica.

Assim, podem-se confirmar os resultados das curvas de polarização com os resultados dos diagramas de Nyquist da FIGURA 27, onde o MEA que possui tecido de carbono ElectroChem, com a tinta catalítica aplicada diretamente no tecido de carbono obteve uma menor resistência ôhmica.

As micrografias de MEV para os MEAs com tecido de carbono ElectroChem e ELAT são mostradas na FIGURA 28. Sendo na FIGURA 28a tecido de carbono ElectroChem com a tinta aplicada sobre a Membrana (vista de topo), FIGURA 28b tecido de carbono ElectroChem com a tinta aplicada sobre o tecido de carbono (vista de topo), 
FIGURA 28c tecido de carbono ElectroChem com a tinta aplicada sobre a Membrana (corte transversal), FIGURA 28d tecido de carbono ElectroChem com a tinta aplicada sobre o tecido de carbono (corte transversal), FIGURA 28e tecido de carbono ELAT com a tinta aplicada sobre a Membrana (corte transversal) e FIGURA 28f tecido de carbono ELAT com a tinta aplicada sobre o tecido de carbono (corte transversal).

Nas micrografias da FIGURA 28 pode-se observar que o método de aplicação da tinta tanto sobre a membrana quanto sobre o tecido de carbono mostram uma boa homogeneidade da tinta catalítica, sendo que quando a tinta é aplicada sobre o tecido de carbono (FIGURA 28b), tende-se a aumentar a área ativa, pois a tinta catalítica permeia por entre o tecido de carbono.

As análises das micrografias da FIGURA 28 vêm corroborar com as análises da FIGURA 27, onde se pode afirmar que o melhor método de aplicação da tinta catalítica foi obtido pela pintura diretamente sobre o GDL e utilizando o tecido de carbono ElectroChem como GDL no MEA.

Desta forma, utilizando o tecido de carbono ElectroChem e aplicando-se a tinta diretamente sobre o GDL, obtém-se uma menor resistência ôhmica do MEA, aliado a uma maior área ativa da camada catalítica, o que faz com que o MEA obtenha um melhor potencial de célula na curva de polarização.

A técnica de EIE aplicada a diferentes procedimentos de fabricação de MEAS mostrou-se útil nas análises de desempenho da célula. 


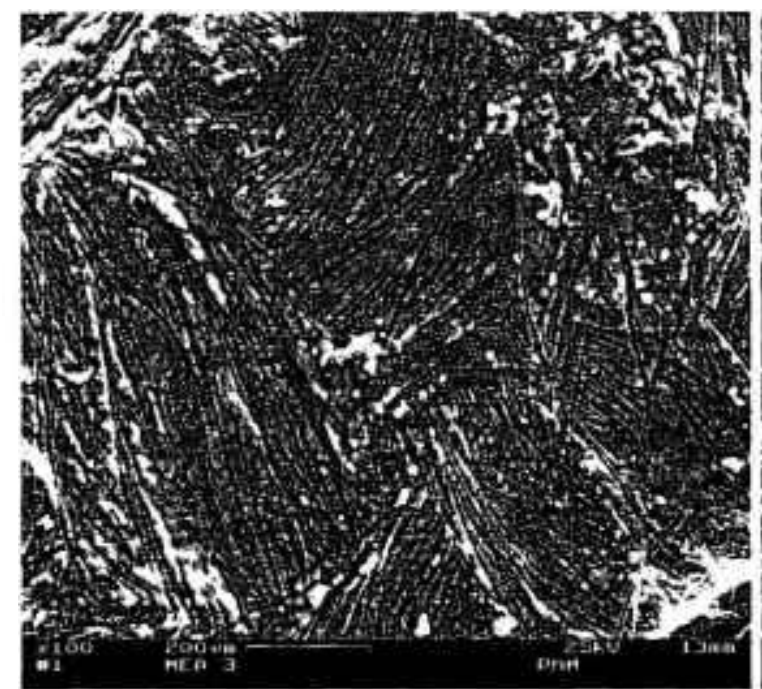

(a)

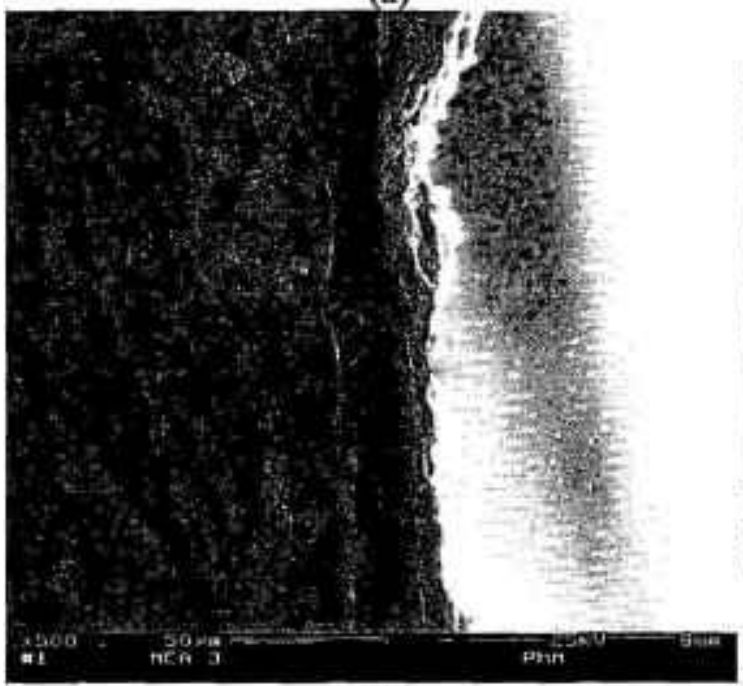

(c)

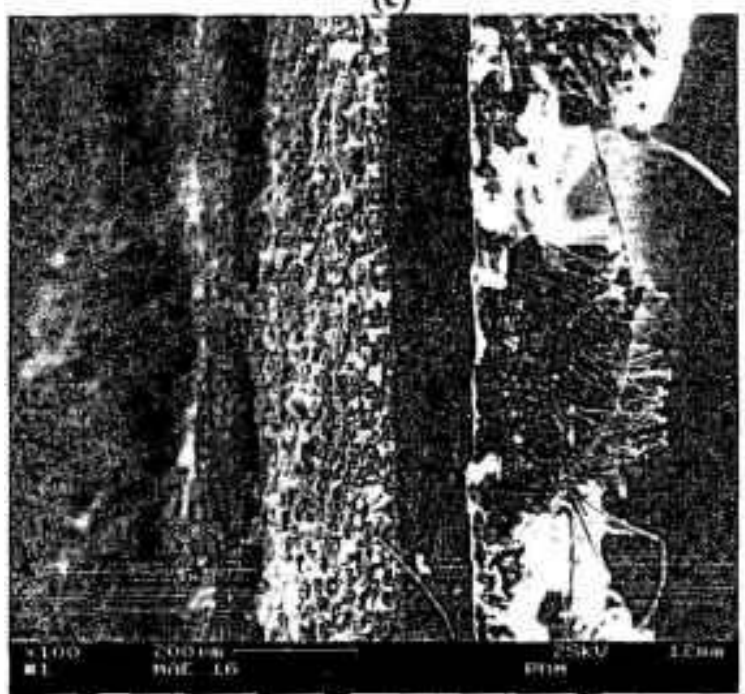

(e)

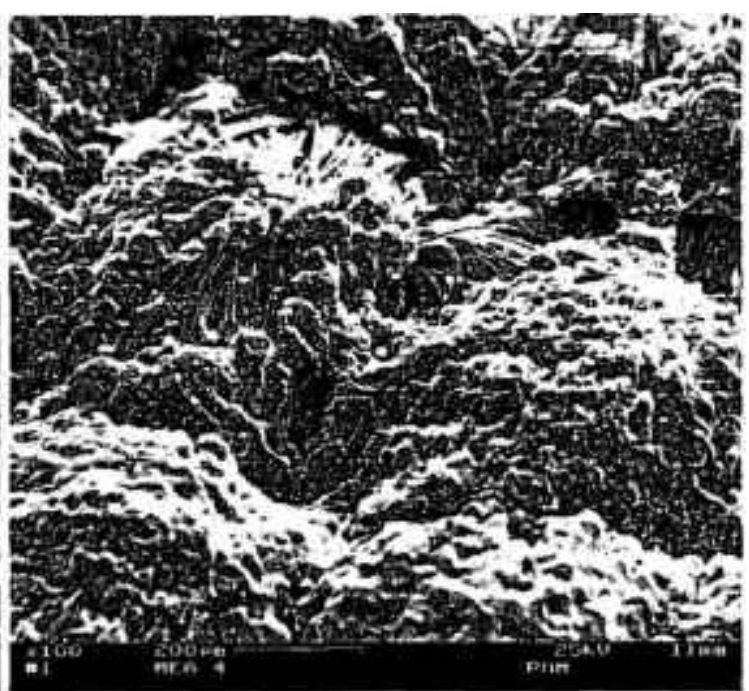

(b)

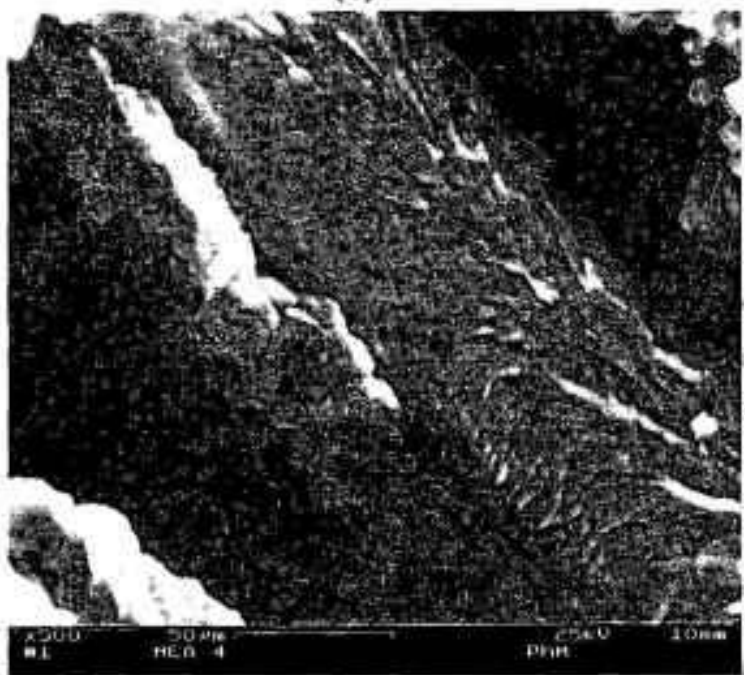

(d)

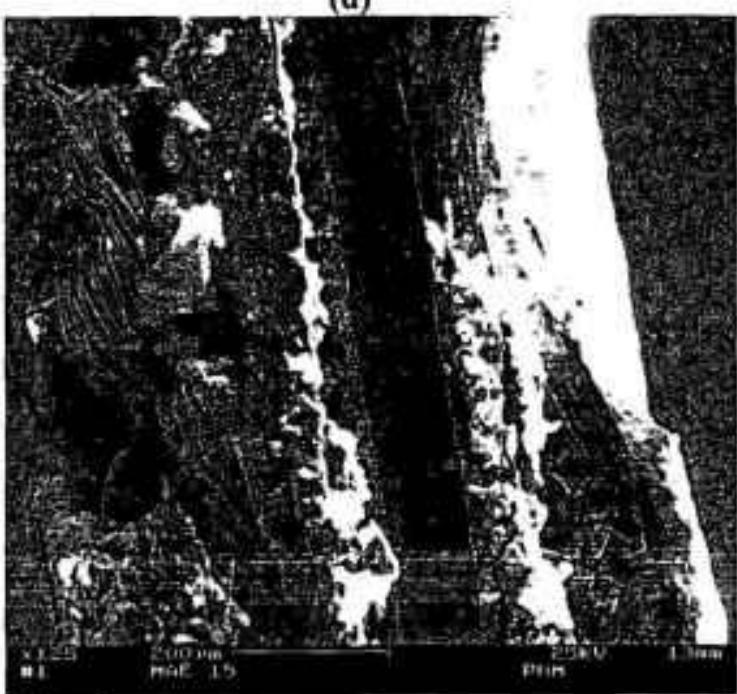

(f)

FIGURA 28 - Micrografias de MEV de MEAs com Pt/C comercial da E-TEK em: (a) tecido de carbono ElectroChem com a tinta aplicada sobre a Membrana (vista de topo), (b) tecido de carbono ElectroChem com a tinta aplicada sobre o tecido de carbono (vista de topo), (c) tecido de carbono ElectroChem com a tinta aplicada sobre a Membrana, (d) tecido de carbono ElectroChem com a tinta aplicada sobre o tecido de carbono, (e) tecido de carbono ELAT com a tinta aplicada sobre a Membrana e (f) tecido de carbono ELAT com a tinta aplicada sobre o tecido de carbono. 


\subsection{Avaliação dos Eletrocatalisadores Obtidos pelo Método de Redução por Álcool 6.2.1 Eletrocatalisadores $\mathrm{Pt} / \mathrm{C}$ e $\mathrm{PtRu} / \mathrm{C}$}

\subsubsection{Operação com $\mathrm{H}_{2} / \mathrm{O}_{2}$}

Como o objetivo principal deste trabalho envolve a avaliação de MEAs para a utilização em células a combustível operando com hidrogênio, metanol e etanol como combustíveis, utilizando eletrocatalisadores produzidos por um método desenvolvido no IPEN, para a fabricação destes MEAs, optou-se pelo método de redução por álcool ${ }^{[54,60,103,104]}$, descrito no Capítulo 4.

Os eletrocatalisadores foram preparados em solução de etileno glicol com os sais precursores, sendo que a solução normalmente tem o $\mathrm{pH}$ em torno de 5 . Em tentativa de melhorar o processo da preparação dos eletrocatalisadores, fixou-se o pH da solução em 11 com a adição de uma solução de $\mathrm{KOH} 0,5$ mol.L $\mathrm{L}^{-1}$.

Na FIGURA 29 estão representadas curvas de polarização de MEAs com $25 \mathrm{~cm}^{2}$ de área eletródica sob operação com $\mathrm{H}_{2} / \mathrm{O}_{2}$, sendo os eletrocatalisadores confeccionados pelo método de redução por álcool. A tinta destes catalisadores foi aplicada diretamente no tecido de carbono do anodo, sendo o catodo pintado com $\mathrm{Pt} / \mathrm{C}$ comercial da E-TEK $20 \%$ (Lote: 3182602). Nos MEAs representados por símbolos vazados, fixou-se o $\mathrm{pH}$ da solução em 11, e nos MEAs representados por símbolos cheios não foi fixado o $\mathrm{pH}$ da solução. Os MEAs de $\mathrm{Pt} / \mathrm{C}$ e os de $\mathrm{PtRu} / \mathrm{C}$, têm carga de $\mathrm{Pt}$ de $0,4 \mathrm{mg}$ Pt.cm ${ }^{-2}$ no anodo e $0,6 \mathrm{mg}$ Pt. $\mathrm{cm}^{-2}$ no catodo. A temperatura da célula foi fixada em $70{ }^{\circ} \mathrm{C}$ e do umidificador em $85{ }^{\circ} \mathrm{C}$. 


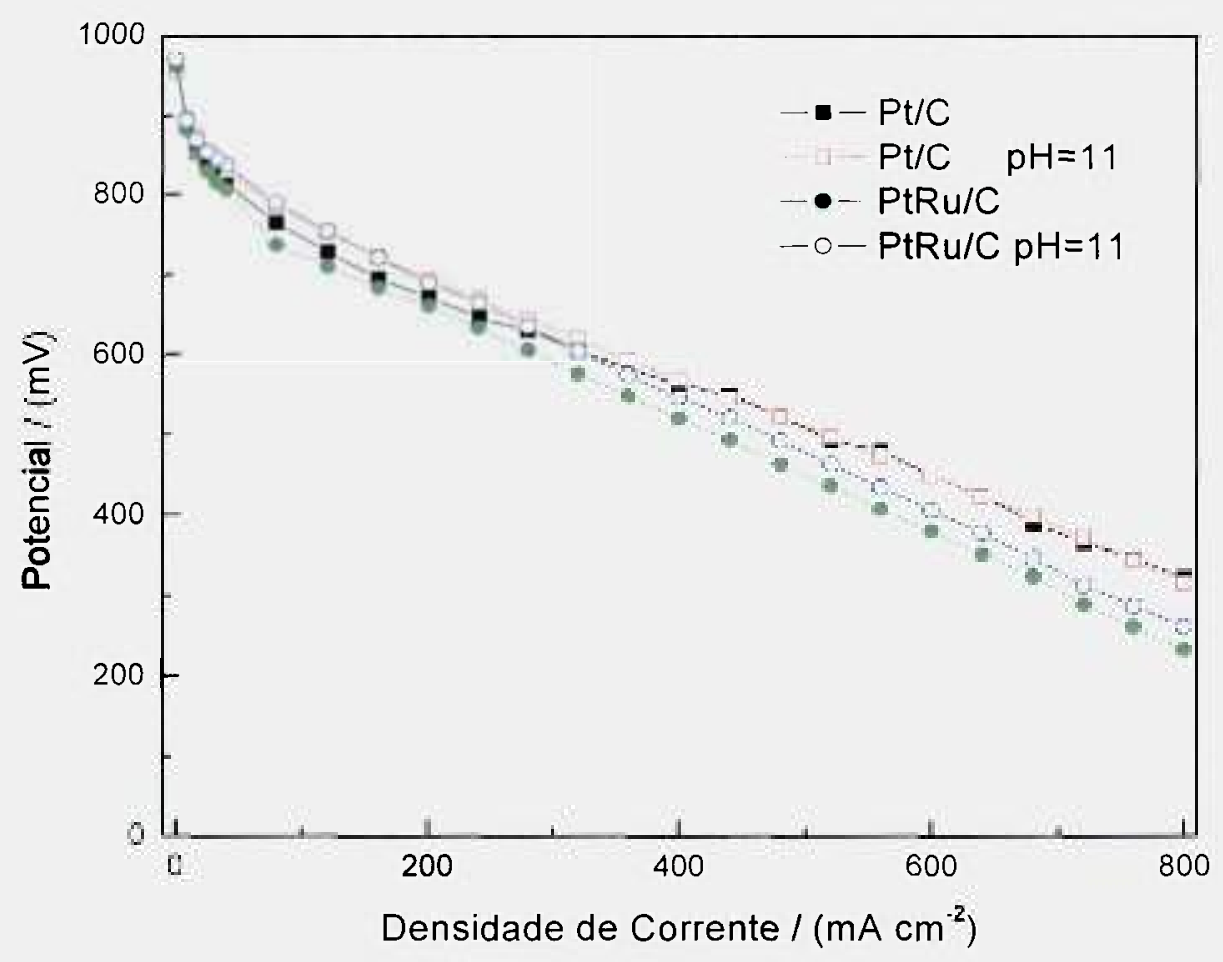

FIGURA 29 - Curvas de polarização de MEAs com $25 \mathrm{~cm}^{2}$ de área eletródica operando com $\mathrm{H}_{2} / \mathrm{O}_{2}$, sendo os eletrocatalisadores confeccionados pelo método de redução por álcool, fixando ou não o pH da solução, aplicados diretamente no tecido de carbono

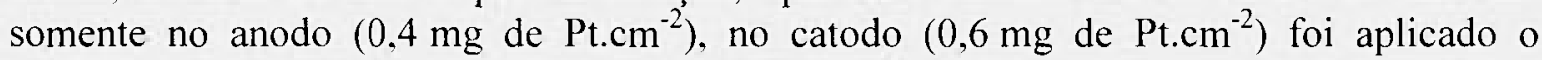
eletrocatalisador $\mathrm{P} t / \mathrm{C}$ comercial da E-TEK diretamente no tecido de carbono. Temperaturas: célula a $70^{\circ} \mathrm{C}$ e umidificador a $85^{\circ} \mathrm{C}$.

Observa-se na FIGURA 29 que os MEAs preparados pelos eletrocatalisadores $\mathrm{Pt} / \mathrm{C}$ obtiveram um comportamento muito aproximado em suas curvas de polarização, entretanto o MEA preparado pelo eletrocatalisador $\mathrm{PtRu} / \mathrm{C}$ com a fixação do $\mathrm{pH}$ durante a preparação do eletrocatalisador apresentou um aumento na densidade de corrente (285 para $330 \mathrm{~mA} \cdot \mathrm{cm}^{-2}$ a $600 \mathrm{mV}$ ) comparado ao eletrocatalisador sem a fixação do pH. Este aumento no potencial é muito provavelmente devido a uma redução no tamanho das partículas (como pode ser observado na TABELA 4) e ainda a uma maior homogeneidade das partículas do eletrocatalisador ancorado no carbono (como observado na FIGURA 31).

Os difratogramas de raios $\mathrm{X}$ destes eletrocatalisadores são mostrados na FIGURA 30. Analisando os difratogramas de raios $X$ dos eletrocatalisadores observa-se que os eletrocatalisadores apresentaram picos de difração em $2 \theta=40,47,67$ e $82^{\circ}$, característica da fase fcc da platina e ligas de platina ${ }^{(108-110]}$, exceto o eletrocatalisador $\mathrm{PtRu} / \mathrm{C} \mathrm{pH}=11$, devido ao tamanho de partícula inferior à $2 \mathrm{~nm}$. O pico sobre $2 \theta=25^{\circ}$ é 
associado ao material de suporte Vulcan XC 72R. Nenhum outro pico de rutênio, fase hcp ou óxido de rutênio foi observado para os eletrocatalisadores PtRu/C.

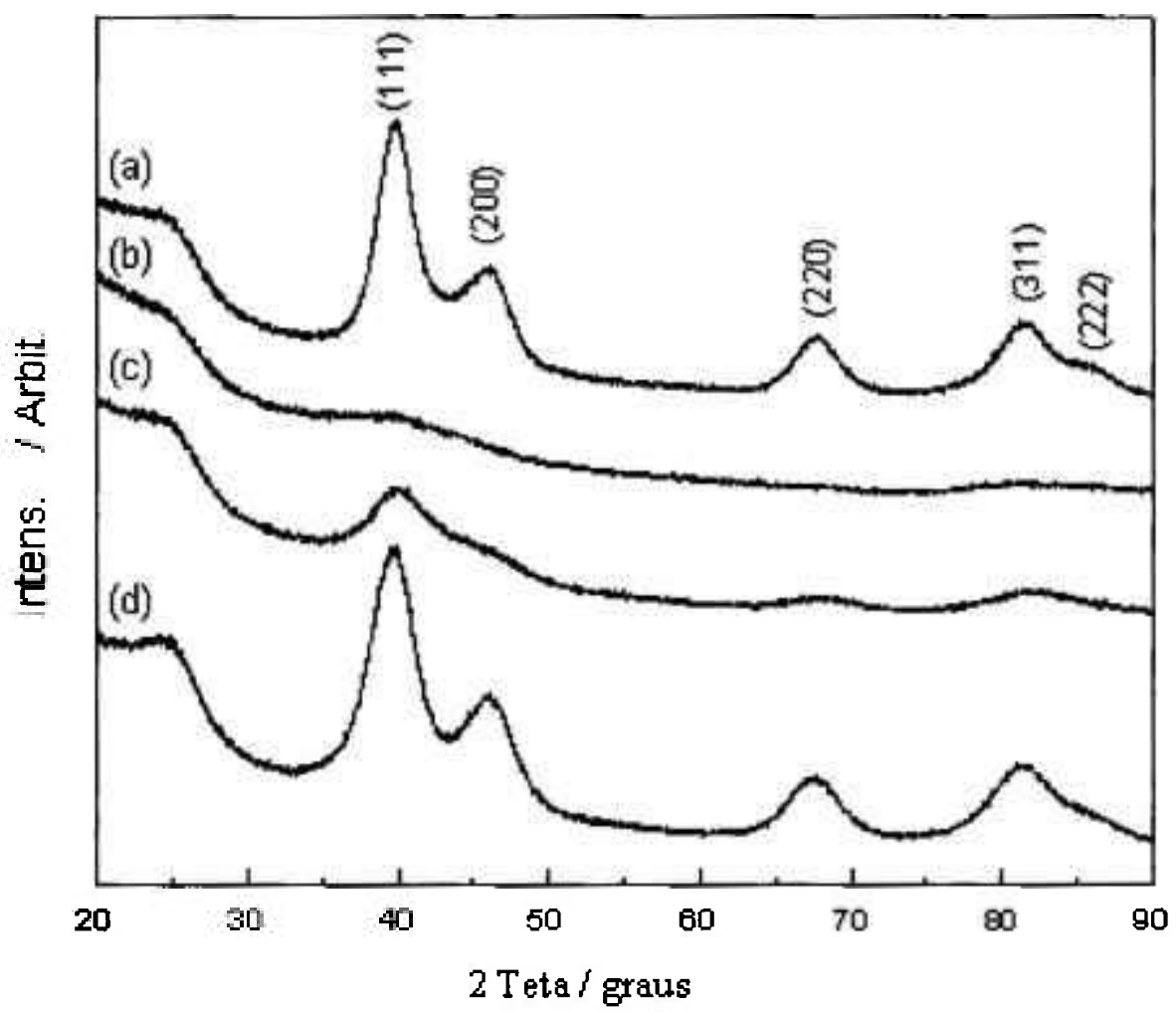

FIGURA 30 - Difratogramas de raios $\mathrm{X}$ de diferentes eletrocatalisadores: (a) PtRu/C método de redução por álcool sem controle do $\mathrm{pH}$; (b) $\mathrm{PtRu} / \mathrm{C}$ método de redução por álcool com controle do $\mathrm{pH}$; (c) $\mathrm{PtRu} / \mathrm{C}$ comercial da E-TEK e (d) $\mathrm{Pt} / \mathrm{C}$ comercial da E-TEK.

Na FIGURA 31 são mostradas as micrografias de MET dos eletrocatalisadores $\mathrm{Pt} / \mathrm{C}$ e $\mathrm{PtRu} / \mathrm{C}$ pelo método de redução por álcool, com e sem controle do $\mathrm{pH}$. A micrografia de MET dos eletrocatalisadores $\mathrm{Pt} / \mathrm{C}$ preparados pelo método de redução por álcool com pH=11 (FIGURA 31a) mostra uma distribuição homogênea das nanopartículas, com tamanho médio observado em 2,9 nm. Para o eletrocatalisador $\mathrm{Pt} / \mathrm{C}$, sem controle de $\mathrm{pH}$ (FIGURA 31b), a distribuição das nanopartículas não se apresentou tão homogênea quando comparado ao eletrocatalisador $\mathrm{Pt} / \mathrm{C}$ com controle do $\mathrm{pH}$, mas o tamanho médio das nanopartículas diminuiu para $2,5 \mathrm{~nm}$ (como observado na TABELA 4). Os eletrocatalisadores $\mathrm{PtRu} / \mathrm{C}$ preparados pelo método de redução por álcool com $\mathrm{pH}=11$ (FIGURA 31c) apresentaram nanopartículas com tamanho médio de 2,0 nm. Entretanto, a distribuição das nanopartículas não se apresentou tão homogênea comparada com $\mathrm{PtRu} / \mathrm{C}$ 
sem o controle do pH (FIGURA 31d), o qual tem nanopartículas um pouco maior, com tamanho médio de $2,8 \mathrm{~nm}$.

Uma possível explicação para este fenômeno seria que, para o eletrocatalisador $\mathrm{Pt} / \mathrm{C}$, obtém-se uma melhor homogeneidade com o controle do $\mathrm{pH}$, mas este $\mathrm{pH}$ não acarreta numa redução do tamanho médio de partícula, fundamental para uma boa atividade catalítica. Contrariamente, para o catalisador $\mathrm{PtRu} / \mathrm{C}$, o controle do $\mathrm{pH}$ diminui sensivelmente o tamanho médio de partícula, mas este controle não garante uma ótima distribuição das nanopartículas do eletrocatalisador.

Assim, observa-se que os MEAs $\mathrm{Pt} / \mathrm{C}$ apresentaram um comportamento muito aproximado em suas curvas de polarização, entretanto os MEAs $\mathrm{PtRu} / \mathrm{C}$ confeccionado com o eletrocatalisador com o controle do $\mathrm{pH}$ apresentou uma maior densidade de corrente (45 mA.cm ${ }^{-2}$ de diferença a $600 \mathrm{mV}$ ).

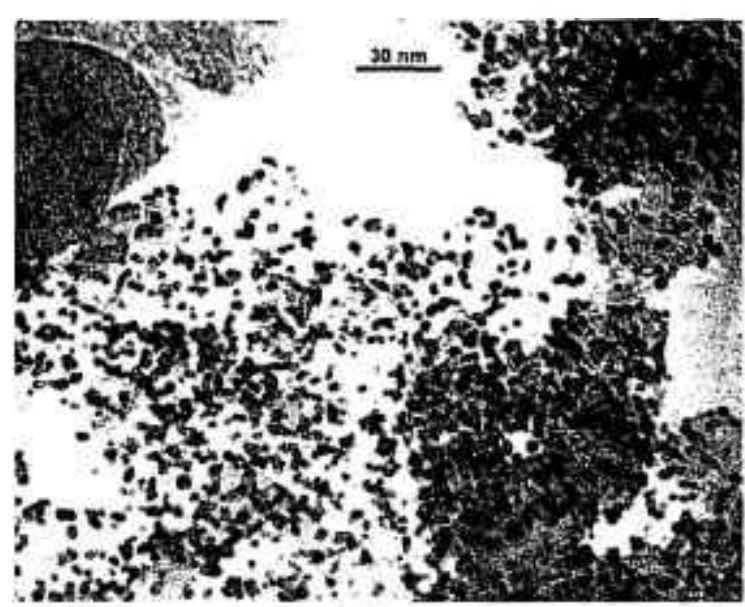

(a)

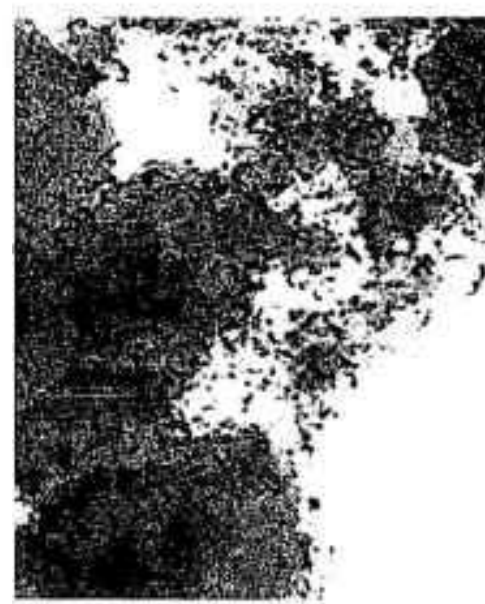

(c)

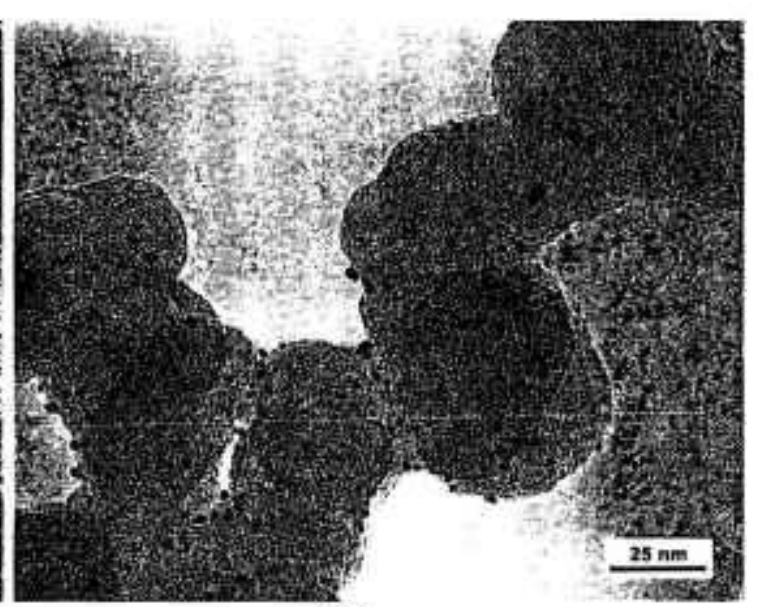

(b)

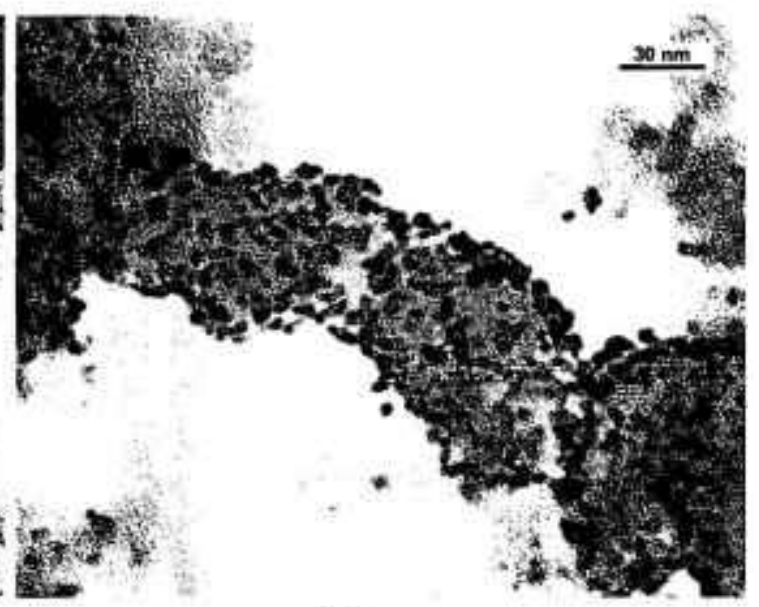

(d)

FIGURA 31 - Micrografias de MET de eletrocatalisadores Pt/C e PtRu/C obtidos pelo método de redução por álcool: (a) $\mathrm{Pt} / \mathrm{C}$ com controle do $\mathrm{pH}$, (b) $\mathrm{Pt} / \mathrm{C}$ sem controle do $\mathrm{pH}$, (c) $\mathrm{PtRu} / \mathrm{C}$ com controle do $\mathrm{pH}$ e (d) $\mathrm{PtRu} / \mathrm{C}$ sem controle do $\mathrm{pH}$. 
$\mathrm{Na}$ FIGURA 32 estão representadas as micrografias de MET do eletrocatalisador Pt/C comercial da E-TEK. Pode-se observar nesta figura uma distribuição homogênea das nanopartículas de Pt/C comercial da E-TEK com tamanho médio calculado em 2,0 nm.

$\mathrm{Na}$ FIGURA 33 estão representadas as micrografias de MET do eletrocatalisador $\mathrm{PtRu} / \mathrm{C}$ comercial da E-TEK. Observa-se nesta figura uma distribuição homogênea das nanopartículas de PtRu/C comercial da E-TEK, com tamanho médio de partícula calculado em $1,8 \mathrm{~nm}$, ou seja, menor que para os eletrocatalisadores $\mathrm{PtRu} / \mathrm{C}$ pelo método de redução por álcool (2,8 nm sem controle de $\mathrm{pH}$ e $2,0 \mathrm{~nm}$ com controle de $\mathrm{pH})$. Entretanto, quando se compara a homogeneidade, os eletrocatalisadores $\mathrm{PtRu} / \mathrm{C}$ obtidos pelo método de redução por álcool apresentaram uma melhor distribuição das nanopartículas do que o eletrocatalisador comercial. Com esta análise, pode-se esperar que, se se conseguir uma melhor homogeneidade do eletrocatalisador $\mathrm{PtRu} / \mathrm{C}$ pelo método de redução por álcool com controle do $\mathrm{pH}$, pode-se obter um ótimo eletrocatalisador para a utilização em células a combustível do tipo DMFC, pois este eletrocatalisador teria um pequeno tamanho de partícula $(2,0 \mathrm{~nm})$ e uma boa homogeneidade destas nanopartículas no substrato de carbono, fundamental para uma boa performance eletrocatalítica.

$\mathrm{Na}$ FIGURA 34 estão os histogramas do tamanho de partícula dos eletrocatalisadores preparados pelo método de redução por álcool, confeccionados a partir das micrografias de MET (mínimo de 300 partículas): (a) $\mathrm{Pt} / \mathrm{C}$ com controle do $\mathrm{pH}$, (b) $\mathrm{Pt} / \mathrm{C}$ sem controle do $\mathrm{pH}$, (c) $\mathrm{PtRu} / \mathrm{C}$ com controle do $\mathrm{pH}$ e (d) $\mathrm{PtRu} / \mathrm{C}$ sem controle do $\mathrm{pH}$.

$\mathrm{Na}$ FIGURA 35 estão os histogramas do tamanho de partícula dos eletrocatalisadores comerciais da E-TEK, também obtidos a partir das micrografias de MET (mínimo de 300 partículas): (a) Pt/C e (b) $\mathrm{PtRu} / \mathrm{C}$.

Os histogramas da FIGURA 34 vêm reforçar as análises feitas anteriormente sobre a distribuição e o tamanho de partículas dos eletrocatalisadores preparados pelo método de redução por álcool e dos eletrocatalisadores comerciais. Observa-se no histograma (a) da FIGURA 34 que o eletrocatalisador Pt/C com controle do $\mathrm{pH}$, apresenta uma distribuição de partículas bem uniforme, com um tamanho médio de 2,9 nm, já o eletrocatalisador $\mathrm{Pt} / \mathrm{C}$ sem controle do $\mathrm{pH}$, histograma (b), apresenta um tamanho médio de partículas de 2,5 nm e uma distribuição uniforme. Ainda na FIGURA 34, no histograma (c) o eletrocatalisador $\mathrm{PtRu} / \mathrm{C}$ com controle do $\mathrm{pH}$, apresenta duas faixas características de distribuição das partículas (bimodal) de $1,8 \mathrm{~nm}$ e de $2,2 \mathrm{~nm}$, acarretando um tamanho médio de partícula de $2,0 \mathrm{~nm}$. Já o eletrocatalisador $\mathrm{PtRu} / \mathrm{C}$ sem o controle do $\mathrm{pH}$ 
de Células a Combustível a Membrana Polimérica (PEMFC)

(histograma (d)), nota-se somente uma faixa de distribuição das partículas, mas com tamanho maior sendo a média de $2,8 \mathrm{~nm}$, além disto o eletrocatalisador apresenta uma distribuição mais uniforme de partículas.

No histograma da FIGURA 35 pode observar que para o eletrocatalisador $\mathrm{PtRu} / \mathrm{C}$ comercial da E-TEK, histograma (a), assim como o eletrocatalisador $\mathrm{Pt} / \mathrm{C}$ comercial da E-TEK, histograma (b) apresentam somente uma faixa característica de distribuição de nanopartículas, com tamanho médio de $1,8 \mathrm{~nm}$ e $2,0 \mathrm{~nm}$ respectivamente.

As análises de EDX e do tamanho médio de partícula dos eletrocatalisadores (calculado tanto por XRD como a partir das micrografias de MET) são mostrados na TABELA 4.

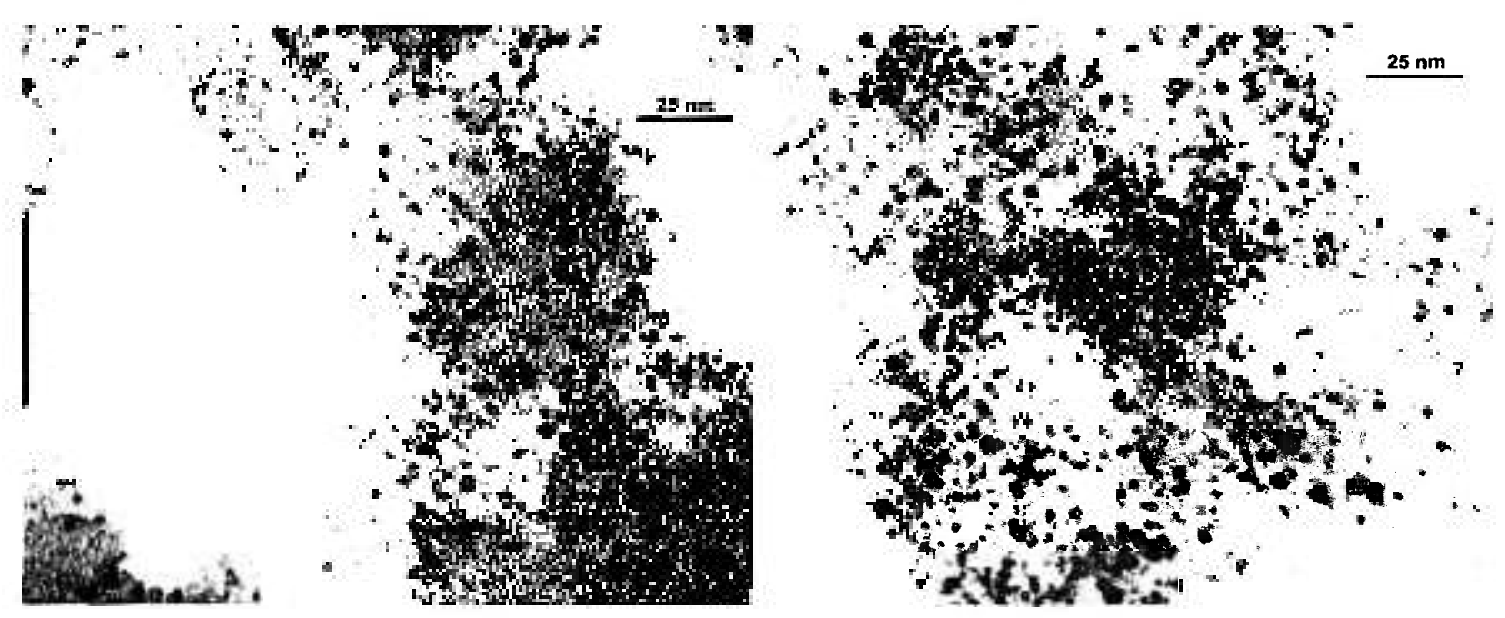

FIGURA 32 - Micrografias de MET do eletrocatalisador Pt/C comercial da E-TEK.

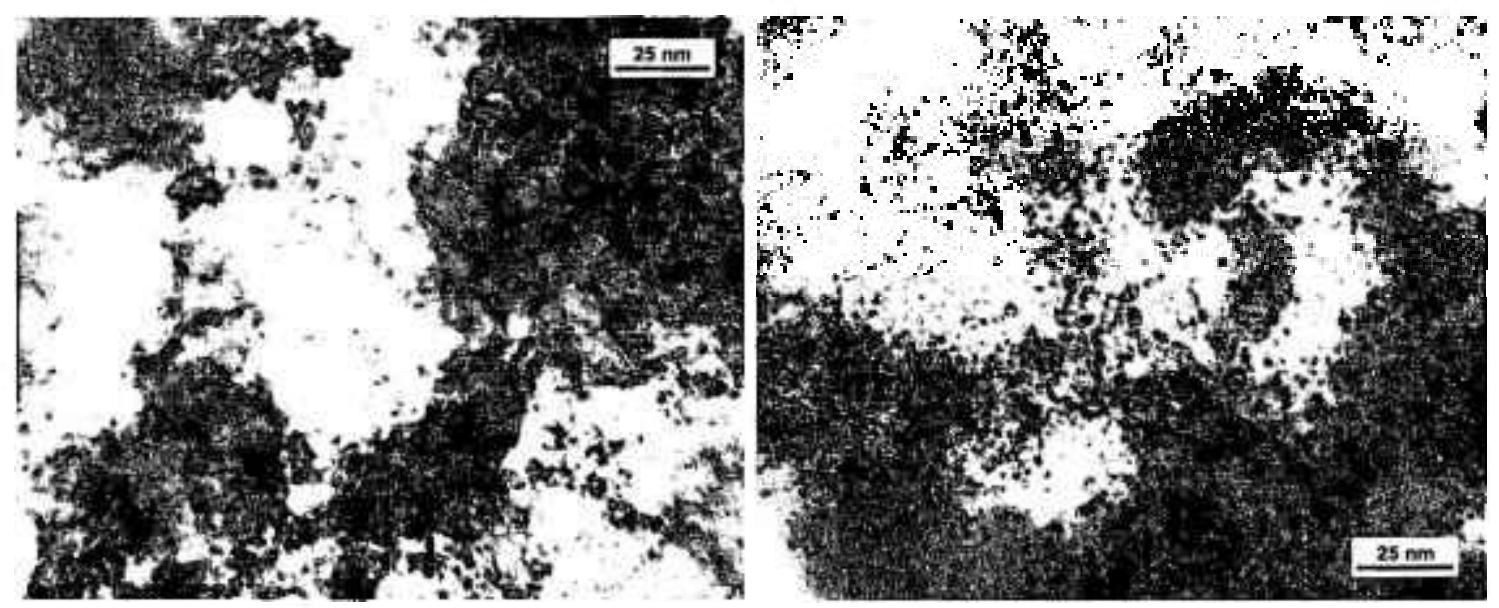

FIGURA 33 - Micrografias de MET do eletrocatalisador PtRu/C comercial da E-TEK. 


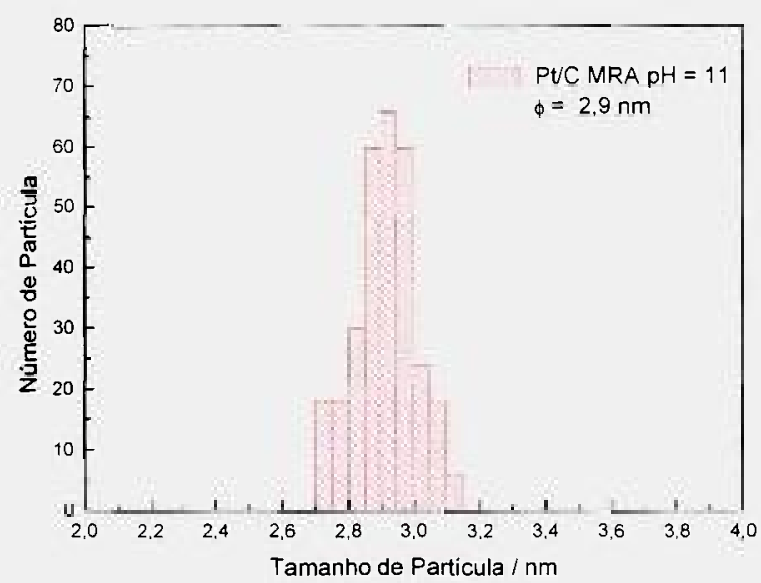

(a)

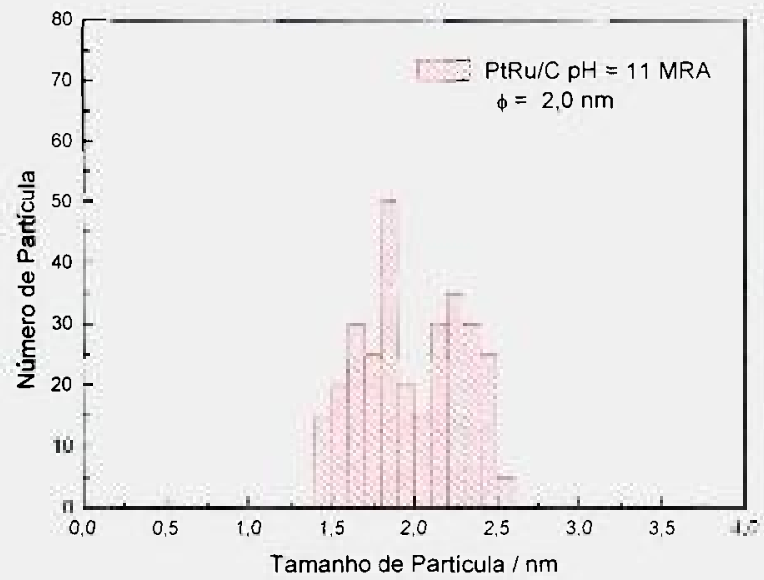

(c)

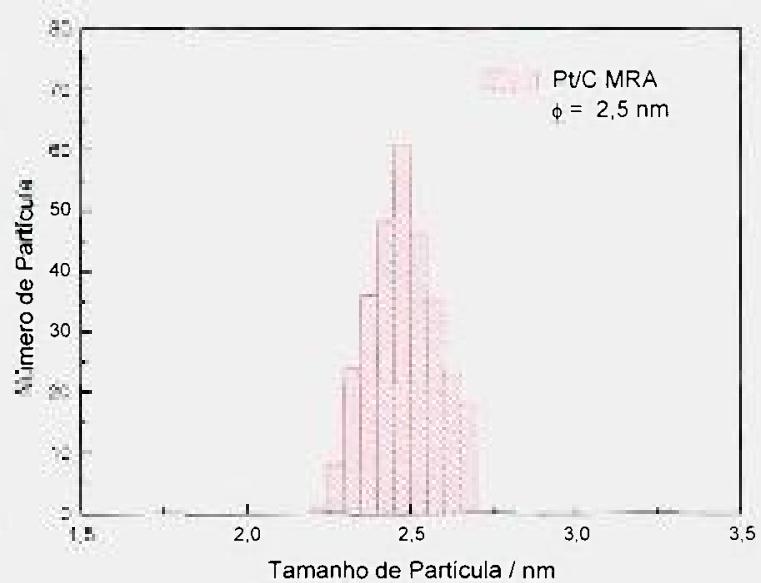

(b)

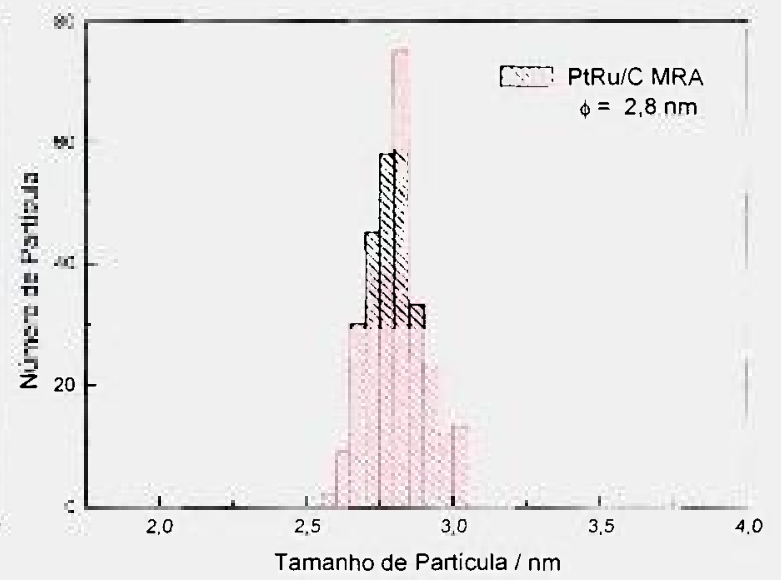

(d)

FIGURA 34 - Histogramas do tamanho de partícula dos eletrocatalisadores preparados pelo método de redução por álcool, confeccionados a partir das micrografias de MET: (a) $\mathrm{Pt} / \mathrm{C}$ com controle do $\mathrm{pH}$, (b) $\mathrm{Pt} / \mathrm{C}$ sem controle do $\mathrm{pH}$, (c) $\mathrm{PtRu} / \mathrm{C}$ com controle do $\mathrm{pH}$ e (d) $\mathrm{PtRu} / \mathrm{C}$ sem controle do $\mathrm{pH}$.

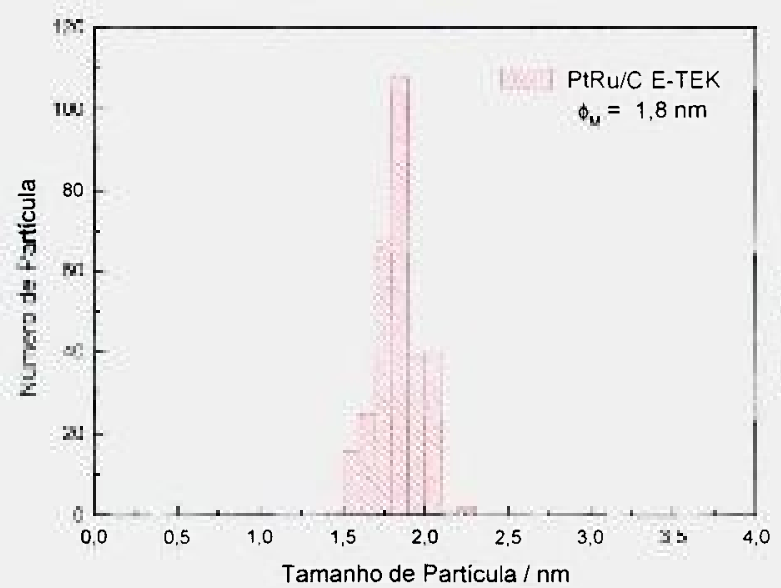

(a)

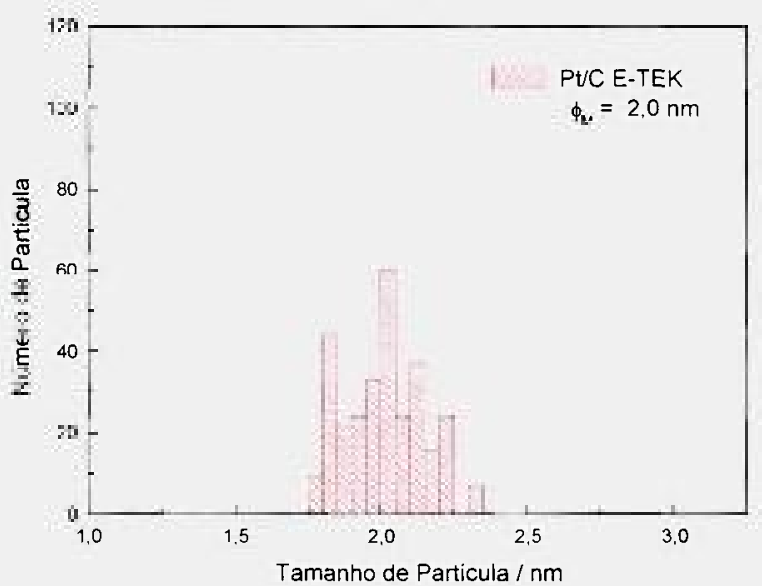

(b)

FIGURA 35 - Histogramas do tamanho de partícula dos eletrocatalisadores comerciais da E-TEK, ambos confeccionados a partir das micrografias de MET: (a) PtRu/C e (b) Pt/C. 
Observa-se na TABELA 4 que a proporção atômica dos eletrocatalisadores Pt:Ru preparados pelo método de redução por álcool são similares às proporções atômicas iniciais. $\mathrm{O}$ tamanho médio de partícula, $L$, foi estimado para os parâmetros listados na TABELA 4, utilizando a equação de Scherrer ${ }^{[11]]}$,

$$
L=\frac{0.9 \lambda_{k_{\alpha 1}}}{B_{(2 \theta)} \cos \theta_{\max }}
$$

onde $\lambda_{k_{p 1}}$ é igual a $1,54056 \AA$, e $B_{(2 \theta)}$ é dado em radianos.

O tamanho médio de partícula foi determinado em $2,5 \mathrm{~nm}$ para o eletrocatalisador PtRu/C com uma diminuição no tamanho médio de partícula para $>2 \mathrm{~nm}$ para o eletrocatalisador $\mathrm{PtRu} / \mathrm{C}$ com $\mathrm{pH}=11$, o que pode ser atribuído ao incremento do controle do $\mathrm{pH}$ da solução obtendo um melhor controle sobre a redução das nanopartículas.

TABELA 4 - Proporção atômica dos eletrocatalisadores a base de PtRu e comparação do tamanho médio de partícula dos eletrocatalisadores por XRD e a partir dos dados de MET.

\begin{tabular}{|c|c|c|c|c|c|c|c|}
\hline \multicolumn{2}{|c|}{ Eletrocatalisadores } & \multicolumn{2}{|c|}{$\begin{array}{c}\text { Composição } \\
\text { Estequiométrica Inicial } \\
(\%)\end{array}$} & $\begin{array}{c}\text { Composição Atômica } \\
\text { (EDX) } \\
\text { (\%) }\end{array}$ & $\begin{array}{c}\text { Tamanho } \\
\text { Médio de } \\
\text { Partícula }\end{array}$ & $\begin{array}{c}\text { Tamanho } \\
\text { Médio de } \\
\text { Partícula }\end{array}$ \\
\cline { 2 - 8 } & $\mathrm{Pt}$ & $\mathrm{Ru}$ & $\mathrm{Pt}$ & $\mathrm{Ru}$ & (nm) $^{*}$ & $(\mathrm{~nm})^{* *}$ \\
\hline \multirow{2}{*}{$\begin{array}{c}\text { Método de } \\
\text { Redução } \\
\text { por Álcool }\end{array}$} & $\mathrm{PtRu} / \mathrm{C}$ & 50 & 50 & 52 & 48 & 2,5 & 2,8 \\
\cline { 2 - 8 } & $\mathrm{PtRu} / \mathrm{C} \mathrm{pH}=11$ & 50 & 50 & 50 & 50 & $>2,0$ & 2,0 \\
\hline \multirow{2}{*}{\begin{tabular}{c} 
Comercial \\
\cline { 2 - 8 }
\end{tabular}} & PtRu/C E-TEK & 50 & 50 & 47 & 53 & 2,1 & 1,8 \\
\cline { 2 - 8 } & $\mathrm{Pt} / \mathrm{C}$ E-TEK & 100 & -- & 100 & -- & 2,4 & 2,0 \\
\hline
\end{tabular}

* Tamanho médio de cristalito calculado a partir de difratograma de raios X utilizando a equação de Scherrer.

** Tamanho médio de partícula calculado a partir de micrografias de MET.

\subsubsection{Operação com Metanol/ $\mathrm{O}_{2}$}

Todos os MEAs alimentados com álcoois apresentam a mesma carga de metal $\left(\right.$ Pt.cm $\left.{ }^{-2}\right)$ que os MEAs alimentados com hidrogênio $(0,4 / 0,6)$, para uma melhor compreensão do efeito da carga de metal pela resistência do combustível utilizado.

$\mathrm{Na}$ FIGURA 36 estão representadas as curvas de polarização dos mesmos MEAs descritos na FIGURA 29, desta vez sob operação com uma solução de metanol 2,0 mol. $\mathrm{L}^{-1}$, como combustivel. A temperatura da célula foi de $85^{\circ} \mathrm{C}$ e a temperatura dos 
frascos de umidificação usados para vaporizar o metanol foi de $95{ }^{\circ} \mathrm{C}$ e a temperatura do umidificador no catodo foi de $85^{\circ} \mathrm{C}$.

Observa-se na FIGURA 36 que os MEAs alimentados com metanol têm um desempenho muito inferior que os alimentados com hidrogênio como combustível (de 43 para $608 \mathrm{~mA} . \mathrm{cm}^{-2}$ a $400 \mathrm{mV}$ ). Outro fato que se observa é que para os potenciais alcançados pelos MEAs contendo eletrocatalisadores preparados com rutênio, o melhor resultado foi para o MEA confeccionado com o $\mathrm{pH}$ da solução fixado. Uma das explicações para este fato é o menor tamanho de partícula do eletrocatalisador $(2,0$ contra $2,8 \mathrm{~nm})$ que favorece a eletrooxidação do metanol ${ }^{[112-114]}$.

Os eletrocatalisadores de $\mathrm{Pt} / \mathrm{C}$ não apresentaram problemas de distribuição das nanopartículas muito acentuados, como se pode observar na FIGURA 31a e na FIGURA 31 b. Um dos problemas quando se preparam os catalisadores de $\mathrm{Pt} / \mathrm{C}$ é o controle do tamanho de partícula, que apresenta muita variação de tamanho e pode ser maior do que o tamanho ideal para que as reações sejam mais eficientes. Assim pode-se dizer que, com a fixação do pH não se conseguiu manter o controle do tamanho de partícula.

Pode-se salientar ainda que o método de alimentação do combustível não foi muito eficiente, visto que o arraste por nitrogênio é bom para baixas densidades de corrente. Quando se aumenta a densidade de corrente de operação, o fluxo de combustível dentro da célula não é contínuo, fazendo com que o combustível dentro da célula não seja adequado, acarretando um decaimento drástico do potencial.

Assim, optou-se pela alimentação por gravidade, ou seja, o combustível é acondicionado a uma altura superior à célula, de onde é injetado diretamente dentro da célula que opera a uma temperatura de $100{ }^{\circ} \mathrm{C}$ para melhor evaporar o combustível. Entretanto, estes MEAs já haviam sido destruídos para as análises de MEV, e por isto não foi possível repetir os testes com o novo sistema de alimentação de metanol e etanol. 


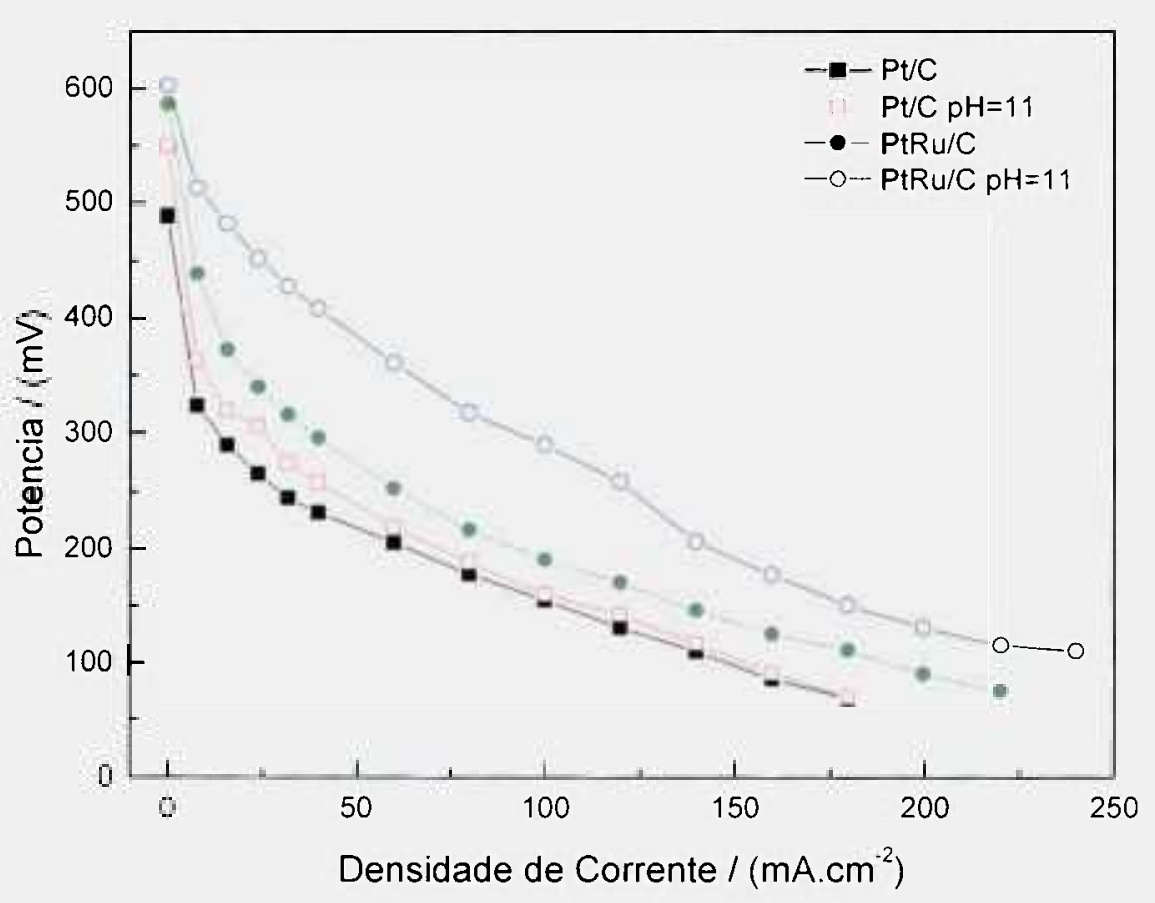

FIGURA 36 - Curvas de polarização de MEAs com $25 \mathrm{~cm}^{2}$ de área eletródica operando com metanol 2,0 mol.L $\mathrm{L}^{-1}$, sendo os eletrocatalisadores confeccionados pelo método de redução por álcool, fixando ou não o $\mathrm{pH}$ da solução, tinta aplicada diretamente no tecido

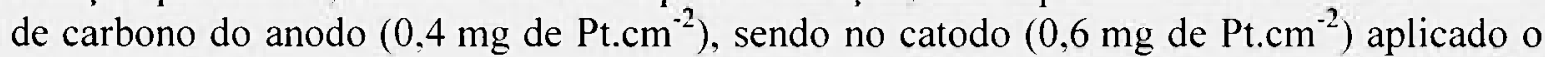
eletrocatalisador $\mathrm{Pt} / \mathrm{C}$ comercial da E-TEK diretamente no tecido de carbono. Temperaturas: célula a $85^{\circ} \mathrm{C}$ e umidificador a $95^{\circ} \mathrm{C}$.

\subsubsection{Eletrocatalisadores $\mathrm{PtSn} / \mathrm{C}$ e $\mathrm{Pt}_{50} \mathrm{Sn}_{40} \mathrm{Ni}_{10} / \mathrm{C}$}

Considerando um dos objetivos deste trabalho que é a oxidação direta de etanol como combustível na célula, investigaram-se sistemas de eletrocatalisadores que pudessem melhorar o desempenho da célula nestas condições. Como $\mathrm{PtRu} / \mathrm{C}$ não se mostra tão eficiente para o oxidação direta de etanol ${ }^{[53,115]}$, direcionou-se as pesquisas para $\mathrm{PtSn} / \mathrm{C}$ (estado da arte) ${ }^{[54.60]}$, e outras combinações de eletrocatalisadores. Estes MEAs também foram utilizados para avaliações frente a oxidação de hidrogênio e metanol.

\subsubsection{Operação com $\mathrm{H}_{2} / \mathrm{O}_{2}$}

Na FIGURA 37 estão representadas as curvas de polarização para os MEAs com $25 \mathrm{~cm}^{2}$ de área eletródica, confeccionados com $\mathrm{PtSn} / \mathrm{C}$ e $\mathrm{Pt}_{50} \mathrm{Sn}_{40} \mathrm{Ni}_{10} / \mathrm{C}$ pelo método de redução por álcool (MRA) e PtRu/C comercial da E-TEK. Todos os MEAs foram confeccionados com 0,4 mg de Pt.cm ${ }^{-2}$ no anodo e $0,6 \mathrm{mg}$ de $\mathrm{Pt} . \mathrm{cm}^{-2}$ no catodo utilizando membrana de Nafion ${ }^{\mathbb{B}} 105$, operando com $\mathrm{H}_{2} / \mathrm{O}_{2}$. A temperatura da célula foi de $70{ }^{\circ} \mathrm{C}$ e do umidificador de $85^{\circ} \mathrm{C}$. 
Observa-se nas curvas de polarização da FIGURA 37 que o eletrocatalisador $\mathrm{PtSn} / \mathrm{C}$ preparado pelo método de redução por álcool apresenta um desempenho similar ao do eletrocatalisador PtRu/C comercial da E-TEK, ambos com uma alta densidade de corrente de $380 \mathrm{~mA} . \mathrm{cm}^{-2}$ a um potencial de $600 \mathrm{mV}$, que é o potencial de funcionamento geralmente utilizado para uma célula a combustível. Este comportamento provavelmente se deve a uma boa homogeneidade das nanopartículas de PtSn (MRA) e de PtRu (comercial) ancoradas na superfície do carbono e também ao reduzido tamanho de partícula (TABELA 5) destes eletrocatalisadores $(1,7$ e $1,8 \mathrm{~nm}$, respectivamente). Já o eletrocatalisador $\mathrm{Pt}_{50} \mathrm{Sn}_{40} \mathrm{Ni}_{10} / \mathrm{C}$ MRA não apresentou uma alta densidade de corrente, isto pode estar relacionado ao tamanho de partícula deste eletrocatalisador, que teve um tamanho médio de partícula de 2,4 nm (TABELA 5), uma migração de estanho e níquel para o exterior da partícula ou ainda uma lixiviação do óxido de estanho. Testes complementares deverão ser feitos para avaliar estas possíveis causas, como XAS e testes de estabilidade dos eletrocatalisadores com mais de $200 \mathrm{~h}$ de funcionamento em célula.

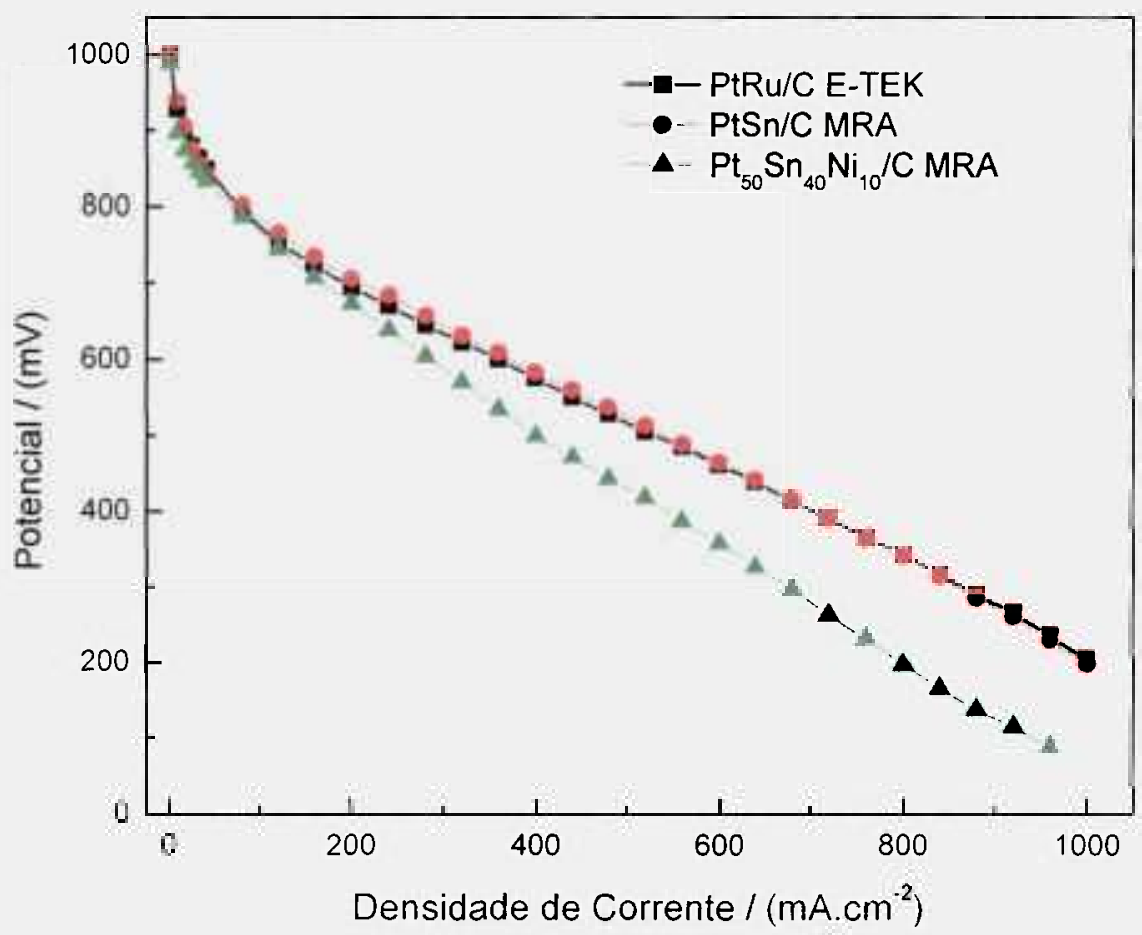

FIGURA 37 - Curvas de polarização de MEAs com $25 \mathrm{~cm}^{2}$ de área eletródica, preparados com PtSn/C e $\mathrm{Pt}_{50} \mathrm{Sn}_{40} \mathrm{Ni}_{10} / \mathrm{C}$ MRA e PtRu/C comercial da E-TEK. Todos os MEAs com $0,4 \mathrm{mg}$ de Pt.cm ${ }^{-2}$ no anodo e $0,6 \mathrm{mg}$ de $\mathrm{Pt} . \mathrm{cm}^{-2}$ no catodo (Pt/C comercial da E-TEK), utilizando membrana de Nafion ${ }^{\mathbb{R}} 105$, operando com $\mathrm{H}_{2} / \mathrm{O}_{2}$. Temperaturas: célula a $70{ }^{\circ} \mathrm{C}$ e umidificador a $85^{\circ} \mathrm{C}$. 
Análise por Impedância Eletroquímica "on-line" de Conjuntos Eletrodo/Membrana (MEA) de Células a Combustível a Membrana Polimérica (PEMFC)

\subsubsection{Operação com Metanol/ $\mathrm{O}_{2}$}

Na FIGURA 38 estão representadas as curvas de polarização para os MEAs com $25 \mathrm{~cm}^{2}$ de área eletródica, confeccionados com $\mathrm{PtSn} / \mathrm{C}$ e $\mathrm{Pt}_{50} \mathrm{Sn}_{40} \mathrm{Ni}_{10} / \mathrm{C} \mathrm{MRA}$ e $\mathrm{PtRu} / \mathrm{C}$ comercial da E-TEK. Todos os MEAs com $0,4 \mathrm{mg}$ de Pt.cm ${ }^{-2}$ no anodo e $0,6 \mathrm{mg}$ de Pt. $\mathrm{cm}^{-2}$ no catodo utilizando membrana de Nafion ${ }^{\circledR} 105$, operando com Metanol/O $\mathrm{O}_{2}$. A temperatura da célula foi de $100{ }^{\circ} \mathrm{C}$ e do umidificador de $90{ }^{\circ} \mathrm{C}$.

Para as curvas de polarização mostradas na FIGURA $38 \mathrm{com}$ Metanol $/ \mathrm{O}_{2}$, verificou-se que o eletrocatalisador $\mathrm{PtSn} / \mathrm{C}$ MRA apresentou uma boa densidade de corrente, $62,4 \mathrm{~mA} . \mathrm{cm}^{-2}$ a $300 \mathrm{mV}$, seguido pelo eletrocatalisador $\mathrm{Pt}_{50} \mathrm{Sn}_{40} \mathrm{Ni}_{10} / \mathrm{C} \mathrm{MRA}$, $36,7 \mathrm{~mA} \cdot \mathrm{cm}^{-2}$ a $300 \mathrm{mV}$, e o eletrocatalisador PtRu/C E-TEK, 26,4 mA.cm ${ }^{-2}$ a $300 \mathrm{mV}$. Esta análise vem a corroborar com dados da literatura ${ }^{[116-121]}$. Este comportamento pode ser explicado provavelmente pelo menor tamanho de partícula, junto com uma melhor homogeneidade das nanopartículas obtidas pelo MRA e também por uma ótima adsorção/dehidrogenação do metanol pelo eletrocatalisador $\mathrm{PtSn} / \mathrm{C}$, que aqui é a responsável pela etapa limitante da Reação de Oxidação de Metanol (ROM) em baixas densidades de corrente na célula, requerendo um fluxo menor de metanol.

Em densidades de correntes intermediárias, $30-70 \mathrm{~mA} . \mathrm{cm}^{-2}$, a adsorção/dehidrogenação de metanol é um processo mais rápido, e a etapa limitante da ROM passa a ser a oxidação de $\mathrm{CO}_{\text {ads }}$. Em altas densidades de correntes, onde um incremento do consumo de metanol é requerido, o processo difusional é o responsável pela etapa limitante da ROM. 


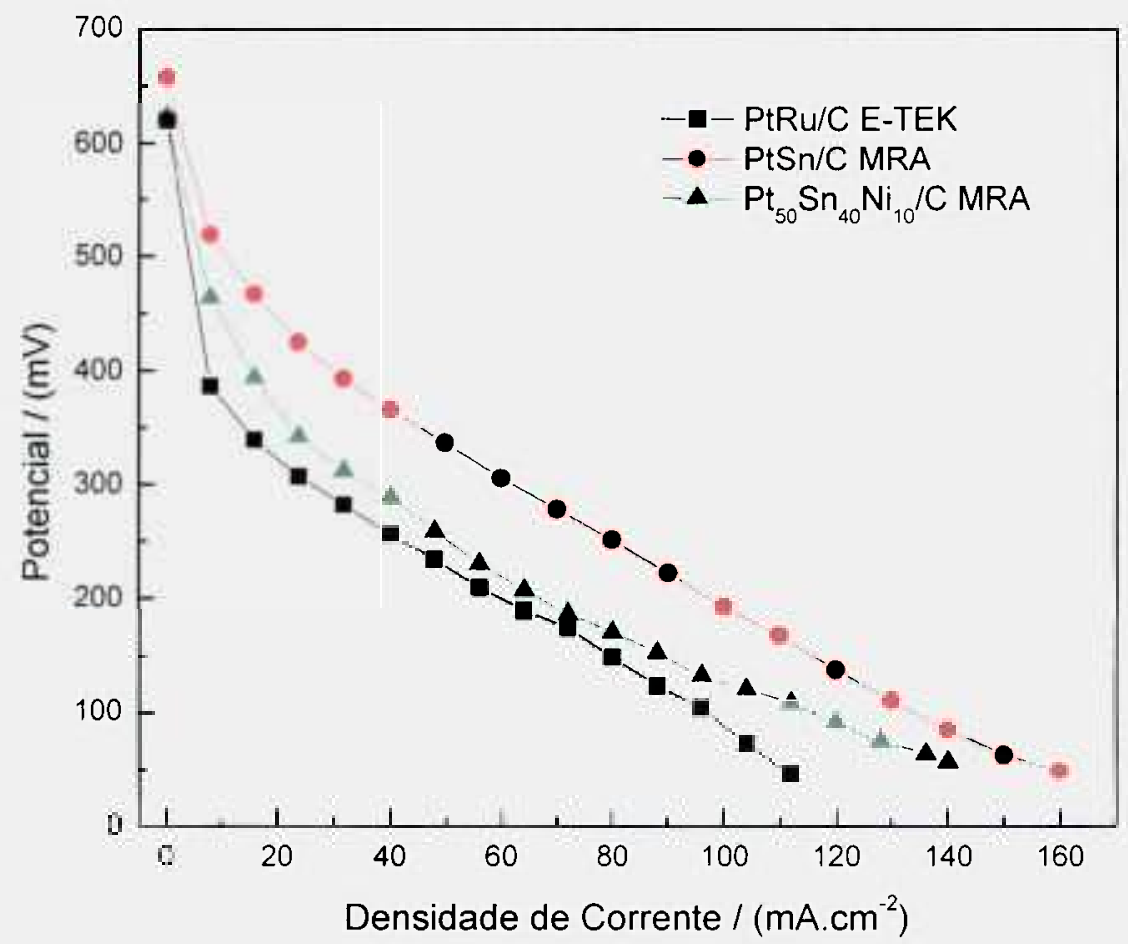

FIGURA 38 - Curvas de polarização de MEAs com $25 \mathrm{~cm}^{2}$ de área eletródica, preparados com PtSn/C e $\mathrm{Pt}_{50} \mathrm{Sn}_{40} \mathrm{Ni}_{10} / \mathrm{C}$ MRA e PtRu/C comercial da E-TEK. Todos os MEAs com $0,4 \mathrm{mg}$ de Pt.cm ${ }^{-2}$ no anodo e $0,6 \mathrm{mg}$ de $\mathrm{Pt} . \mathrm{cm}^{-2}$ no catodo (Pt/C comercial da E-TEK), utilizando membrana de $\mathrm{Nafion}^{\circledR} 105$, operando com Metanol/ $\mathrm{O}_{2}$. Temperaturas: célula a $100{ }^{\circ} \mathrm{C}$ e umidificador a $90^{\circ} \mathrm{C}$.

\subsubsection{Operação com Etanol/OO}

Na FIGURA 39 estão representadas curvas de polarização para MEAs com $25 \mathrm{~cm}^{2}$ de área eletródica, preparados com $\mathrm{PtSn} / \mathrm{C}$ e $\mathrm{Pt}_{50} \mathrm{Sn}_{40} \mathrm{Ni}_{10} / \mathrm{C}$ pelo método de redução por álcool e PtRu/C E-TEK. Todos os MEAs com $0,4 \mathrm{mg}$ de $\mathrm{Pt}_{\mathrm{cm}} \mathrm{cm}^{-2}$ no anodo e $0,6 \mathrm{mg}$ de $\mathrm{Pt} . \mathrm{cm}^{-2}$ no catodo utilizando membrana de Nafion ${ }^{(\mathbb{R}} 105$, operando com Etanol/ $/ \mathrm{O}_{2}$. A temperatura da célula foi mantida constante a $100^{\circ} \mathrm{C}$ e do umidificador a $90{ }^{\circ} \mathrm{C}$.

Para as curvas de polarização da FIGURA $39 \mathrm{com} \mathrm{Etanol} / \mathrm{O}_{2}$, verifica-se que o eletrocatalisador PtSn/C MRA apresenta uma maior densidade de corrente, $33.8 \mathrm{~mA} . \mathrm{cm}^{-2}$ a $200 \mathrm{mV}$, seguido pelo eletrocatalisador $\mathrm{Pt}_{50} \mathrm{Sn}_{40} \mathrm{Ni}_{10} / \mathrm{C}$ MRA, $28,2 \mathrm{~mA} \cdot \mathrm{cm}^{-2}$ a $200 \mathrm{mV}$, e o eletrocatalisador PtRu/C E-TEK, 23,5 mA.cm ${ }^{-2}$ a $300 \mathrm{mV}$. Esta análise vem a corroborar com dados da literatura ${ }^{[122-128]}$, onde há relatos que o eletrocatalisador $\mathrm{PtSn} / \mathrm{C}$ pelo método de redução por álcool é o melhor eletrocatalisador estudado atualmente para a utilização em células a combustível operando com etanol como combustível. 


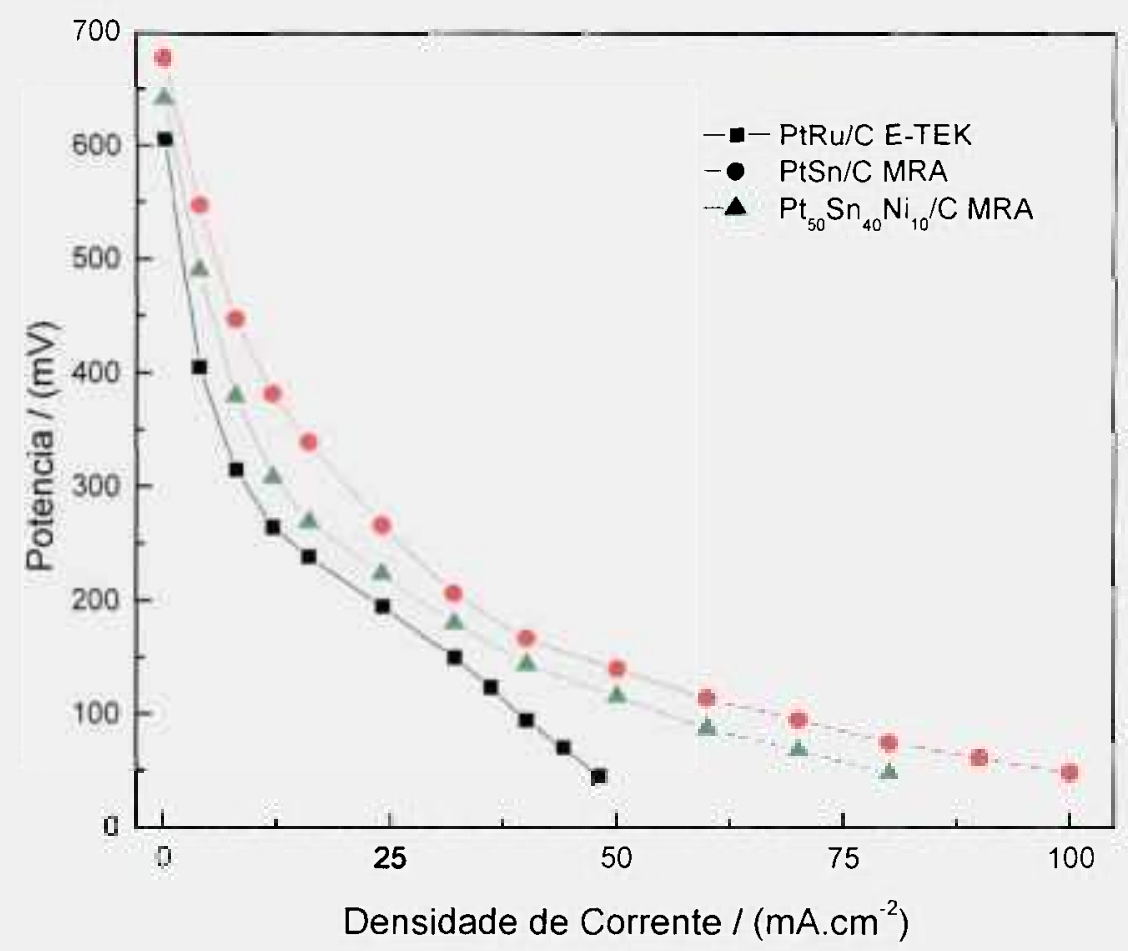

FIGURA 39 - Curvas de polarização de MEAs com $25 \mathrm{~cm}^{2}$ de área eletródica, preparados com $\mathrm{PtSn} / \mathrm{C}$ e $\mathrm{Pt}_{50} \mathrm{Sn}_{40} \mathrm{Ni}_{10} / \mathrm{C}$ MRA e PtRu/C comercial da E-TEK. Todos os MEAs com $0,4 \mathrm{mg}$ de Pt.cm ${ }^{-2}$ no anodo e $0,6 \mathrm{mg}$ de $\mathrm{Pt} . \mathrm{cm}^{-2}$ no catodo (Pt/C comercial da E-TEK), utilizando membrana de Nafion ${ }^{R} 105$, operando com Etanol/ $\mathrm{O}_{2}$. Temperaturas: célula a $100{ }^{\circ} \mathrm{C}$ e umidificador a $90^{\circ} \mathrm{C}$.

A caracterização destes novos sistemas pode dar mais informações sobre a homogeneidade e o tamanho de particula, para podermos traçar um paralelo destes dados físicos ao comportamento eletrocatalítico apresentado.

Na FIGURA 40 estão os difratogramas de raios X para os eletrocatalisadores $\mathrm{PtSn} / \mathrm{C}$ e $\mathrm{Pt}_{50} \mathrm{Sn}_{40} \mathrm{Ni}_{10} / \mathrm{C}$ MRA e PtRu/C comercial da E-TEK.

Observa-se na FIGURA 40 que os eletrocatalisadores $\mathrm{PtSn} / \mathrm{C}$ e $\mathrm{Pt}_{50} \mathrm{Sn}_{40} \mathrm{Ni}_{10} / \mathrm{C}$ MRA, além dos já citados picos característicos da fase fcc da platina, apresentam picos em $2 \theta=34$ e $52^{\circ}$ que são associados aos planos (101) e (211), respectivamente, que são característicos da fase cassiterita $\mathrm{SnO}_{2}$. Observa-se ainda, que o eletrocatalisador $\mathrm{PtSn} / \mathrm{C}$ apresenta um menor tamanho de partícula, comparado com o eletrocatalisador $\mathrm{Pt}_{50} \mathrm{Sn}_{40} \mathrm{Ni}_{10} / \mathrm{C}$.

Na FIGURA 41 são mostradas as micrografias de TEM dos eletrocatalisadores $\mathrm{PtSn} / \mathrm{C}$ (a) e $\mathrm{Pt}_{50} \mathrm{Sn}_{40} \mathrm{Ni}_{10} / \mathrm{C}$ (b) pelo método de redução por álcool. 


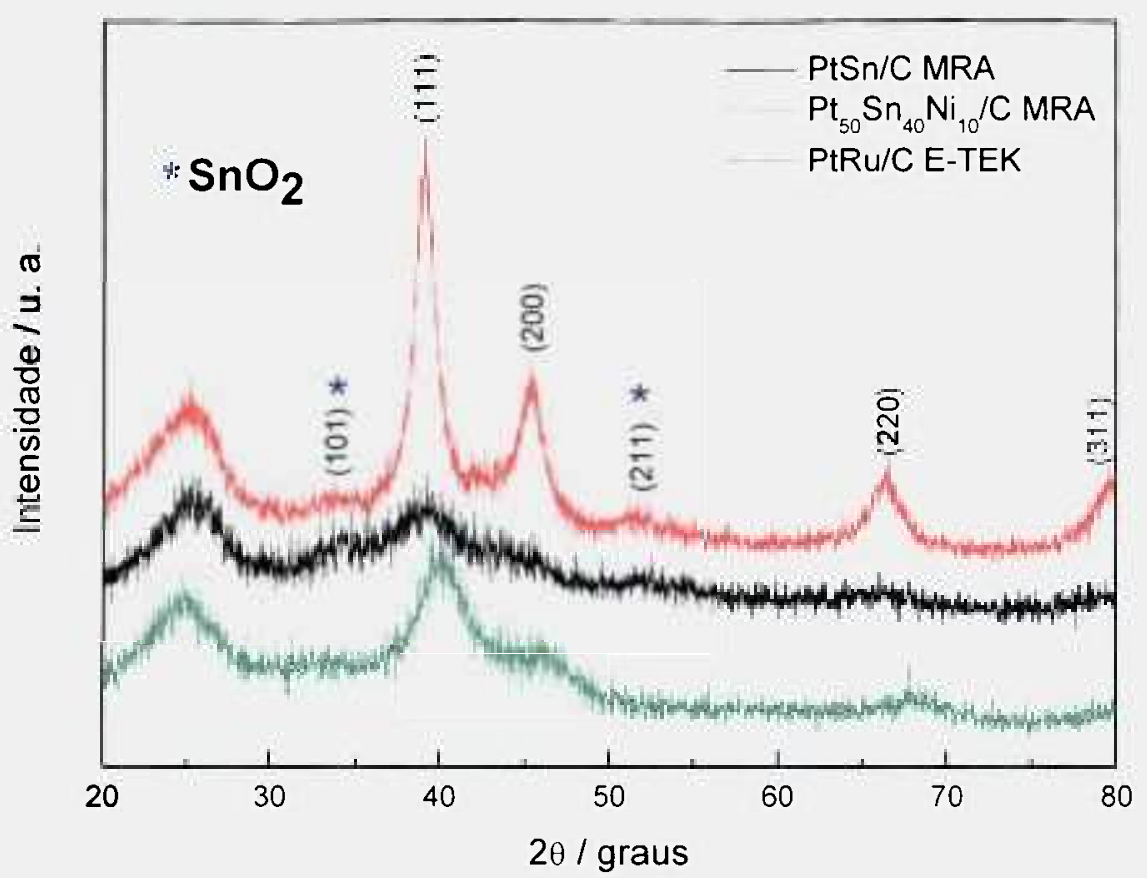

FIGURA 40 - Difratogramas de raios $\mathrm{X}$ dos eletrocatalisadores: (a) PtSn/C MRA, (b) $\mathrm{Pt}_{50} \mathrm{Sn}_{40} \mathrm{Ni}_{10} / \mathrm{C}$ MRA e (c) PtRu/C comercial da E-TEK.

A micrografia de MET do eletrocatalisador PtSn/C. FIGURA 41 a mostra uma distribuição homogênea das nanopartículas, com tamanho médio observado de $1,7 \mathrm{~nm}$. Para o eletrocatalisador $\mathrm{Pt}_{50} \mathrm{Sn}_{40} \mathrm{Ni}_{10} / \mathrm{C}$, FIGURA $4 \mathrm{lb}$, a distribuição das nanopartículas não é tão homogênea quando comparado ao eletrocatalisador PtSn/C, e o tamanho médio das nanopartículas observado é maior $(2,4 \mathrm{~nm})$. Em comparação, o eletrocatalisador PtRu/C comercial da E-TEK, FIGURA 33, apresenta nanopartículas com tamanho médio de $1.8 \mathrm{~nm}$, ou seja, relativamente igual ao eletrocatalisador PtSn/C MRA $(1,7 \mathrm{~nm})$ e ligeiramente menor que o eletrocatalisador $\mathrm{Pt}_{50} \mathrm{Sn}_{40} \mathrm{Ni}_{10} / \mathrm{C}$ MRA $(2,4 \mathrm{~nm})$.

Entretanto, quando se compara a homogeneidade, os eletrocatalisadores, a base de estanho, obtidos pelo método de redução por álcool apresentaram uma distribuição das nanopartículas e uma homogeneidade semelhante ao eletrocatalisador comercial da E-TEK. Com esta análise, pode-se esperar que, se conseguir uma redução no tamanho das nanopartículas dos eletrocatalisadores a base de Sn obtidos pelo MRA, pode-se obter ótimos eletrocatalisadores para a utilização em células a combustível tipo DMFC e DEFC. 


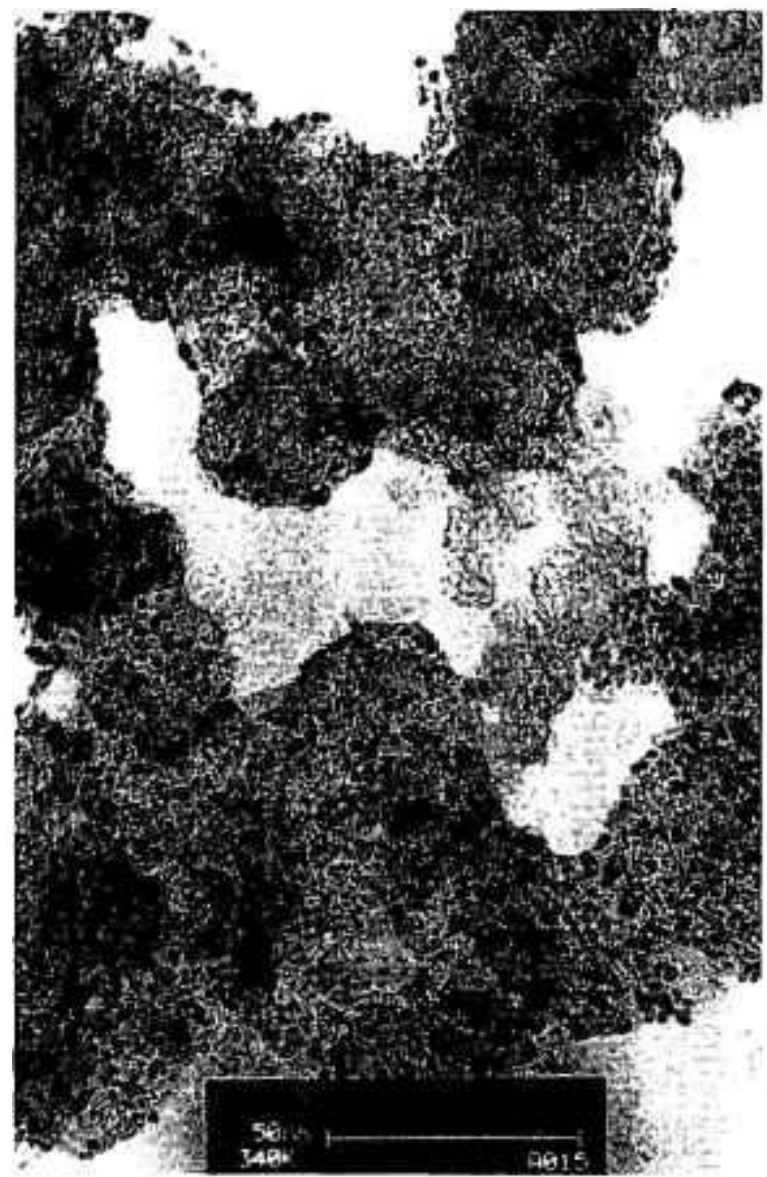

(a)

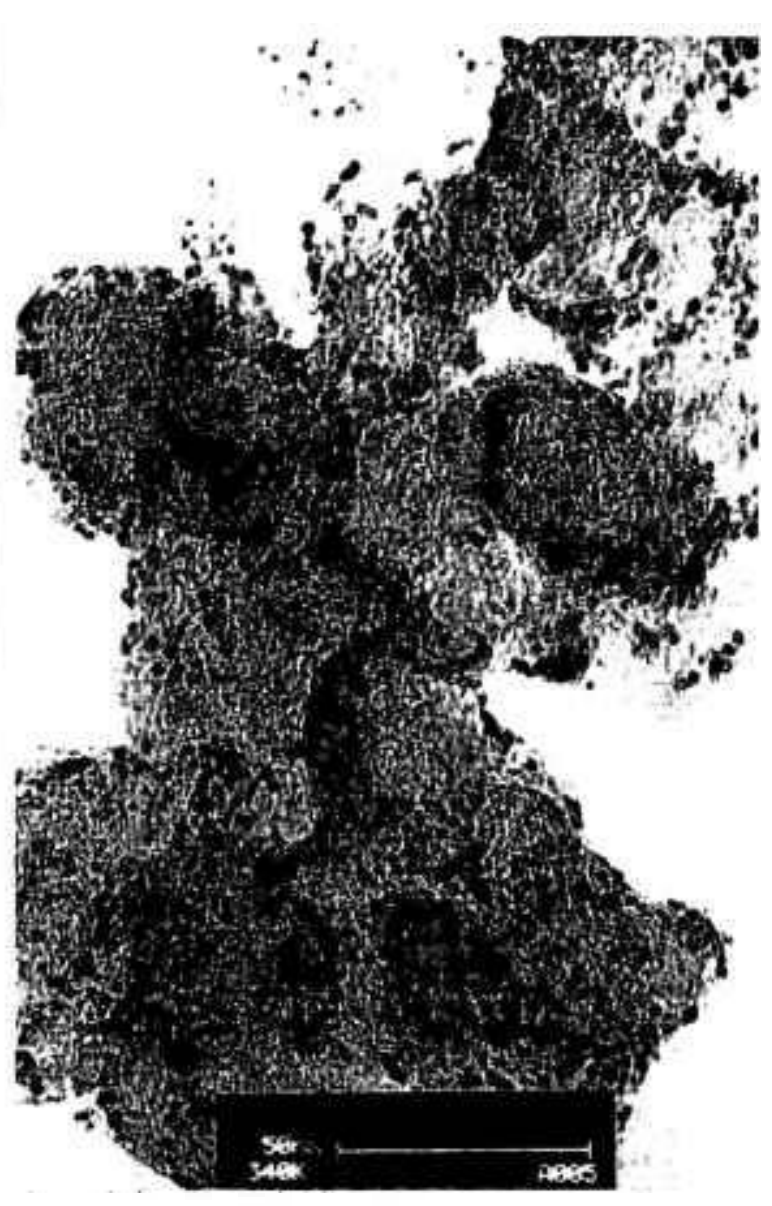

(b)

FIGURA 41 - Micrografias de MET de eletrocatalisadores obtidos pelo método de redução por álcool: (a) $\mathrm{PtSn} / \mathrm{C}$ e (b) $\mathrm{Pt}_{50} \mathrm{Sn}_{40} \mathrm{Ni}_{10} / \mathrm{C}$.

Na FIGURA 42 estão os histogramas do tamanho médio de partícula obtidos através de micrografias de MET (no mínimo 300 partículas) do eletrocatalisador $\mathrm{PtSn} / \mathrm{C}$ (a) e $\mathrm{Pt}_{50} \mathrm{Sn}_{40} \mathrm{Ni}_{10} / \mathrm{C}$ (b), ambos preparados pelo método de redução por álcool.

Os histogramas da FIGURA 42 vêm reforçar as análises feitas anteriormente sobre a distribuição e o tamanho das nanopartículas dos eletrocatalisadores, a base de estanho, preparados pelo método de redução por álcool. Observa-se no histograma (a) que para o eletrocatalisador $\mathrm{PtSn} / \mathrm{C}$, há uma grande distribuição de partículas entre $1.3 \mathrm{~nm}$ e $2,0 \mathrm{~nm}$, acarretando em um tamanho médio de 1,7 nm. Entretanto para o eletrocatalisador $\mathrm{Pt}_{50} \mathrm{Sn}_{40} \mathrm{Ni}_{10} / \mathrm{C}$ apresentado no histograma(b), nota-se uma grande distribuição das partículas entre $2,0 \mathrm{~nm}$ e $2,8 \mathrm{~nm}$, acarretando em um tamanho médio de 2,4 nm. 


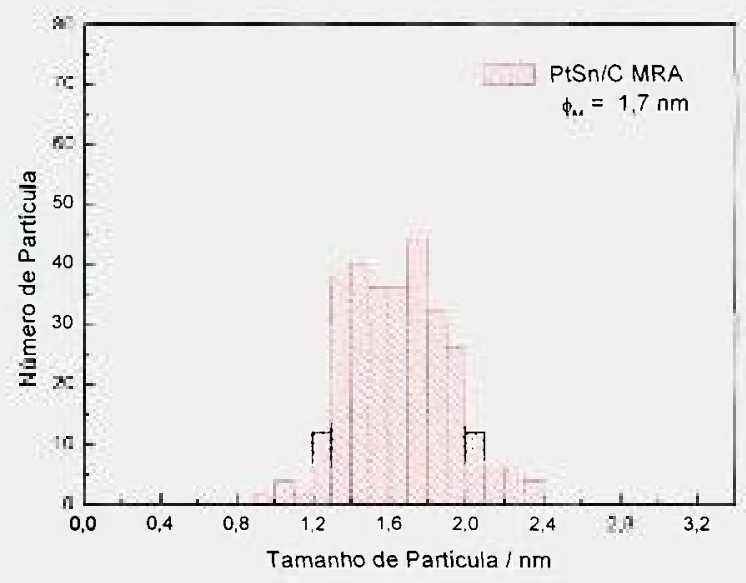

(a)

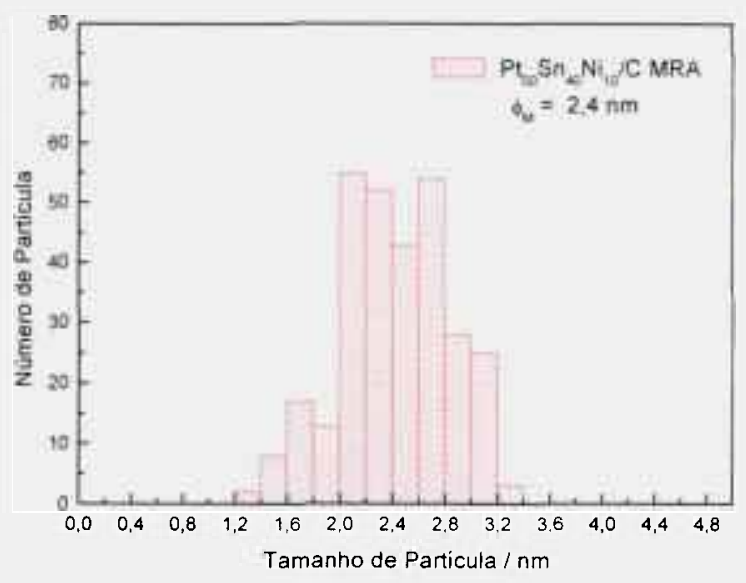

(b)

FIGURA 42 - Histogramas do tamanho de partícula dos eletrocatalisadores preparados pelo método de redução por álcool, obtidos a partir de dados das micrografias de MET: (a) $\mathrm{PtSn} / \mathrm{C}$ e (b) $\mathrm{Pt}_{50} \mathrm{Sn}_{40} \mathrm{Ni}_{10} / \mathrm{C}$.

As análises de EDX e do tamanho médio de partícula dos eletrocatalisadores são mostrados na TABELA 5. Na TABELA 5 pode-se observar que as composições atômicas dos eletrocatalisadores estão muito próximas às composições estequiométricas iniciais. Pode-se observar ainda, um fato em relação ao eletrocatalisador $\mathrm{Pt}_{50} \mathrm{Sn}_{40} \mathrm{Ni}_{10} / \mathrm{C}$; este eletrocatalisador apresenta em sua composição atômica, analisada por EDX, uma quantidade menor (40\%) de níquel em sua composição estequiométrica desejada. Para se verificar o motivo (está na superfície ou no interior da partícula) da pequena quantidade de Ni presente no eletrocatalisador $\mathrm{Pt}_{50} \mathrm{Sn}_{40} \mathrm{Ni}_{10} / \mathrm{C}$ MRA e também em que estado de oxidação este se encontra, utilizou-se a técnica de XPS.

TABELA 5 - Proporção atômica dos eletrocatalisadores a base de PtSn e comparação do tamanho médio de partícula dos eletrocatalisadores por XRD e a partir dos dados de MET.

\begin{tabular}{|c|c|c|c|c|c|c|c|c|c|c|c|}
\hline \multirow{2}{*}{\multicolumn{2}{|c|}{ Eletrocatalisadores }} & \multicolumn{4}{|c|}{$\begin{array}{c}\text { Composição } \\
\text { Estequiométrica Inicial } \\
(\%)\end{array}$} & \multicolumn{4}{|c|}{$\begin{array}{c}\text { Composição Atômica } \\
(\mathrm{EDX}) \\
(\%)\end{array}$} & \multirow{2}{*}{$\begin{array}{c}\text { Tamanho } \\
\text { Médio de } \\
\text { Particula } \\
(\mathrm{nm})^{*}\end{array}$} & \multirow{2}{*}{$\begin{array}{l}\text { Tamanho } \\
\text { Médio de } \\
\text { Partícula } \\
(\mathrm{nm})^{* *}\end{array}$} \\
\hline & & $\mathrm{Pt}$ & Sn & $\mathrm{Ni}$ & $\mathrm{Ru}$ & $\mathrm{Pt}$ & Sn & $\mathrm{Ni}$ & $\mathrm{Ru}$ & & \\
\hline \multirow{2}{*}{$\begin{array}{l}\text { Método } \\
\text { Redução } \\
\text { por } \\
\text { Álcool }\end{array}$} & $\mathrm{PtSn} / \mathrm{C}$ & 50 & 50 & -- & -- & 52 & 48 & -- & -- & 2,6 & 1,7 \\
\hline & $\mathrm{Pt}_{50} \mathrm{Sn}_{40} \mathrm{Ni}_{10} / \mathrm{C}$ & 50 & 40 & 10 & -- & 52 & 42 & 06 & -- & 3,1 & 2,4 \\
\hline $\begin{array}{c}\text { Comer- } \\
\text { cial }\end{array}$ & PtRu/C E-TEK & 50 & -- & -- & 50 & 47 & -- & $=$ & 53 & 2,1 & 1,8 \\
\hline
\end{tabular}

* Tamanho médio de cristalito calculado a partir de difratograma de raio X utilizando a equação de Scherrer.

** Tamanho médio de partícula calculado a partir de micrografias de MET. 
$\mathrm{Na}$ FIGURA 43 está representado o espectro amplo de XPS para o eletrocatalisador PtSn/C MRA. Na FIGURA 44 e 45 estão representados os espectros de XPS com o ajuste do fotopico do $\mathrm{Sn} 3 \mathrm{~d}_{5 / 2}$ e $\mathrm{Pt} 4 \mathrm{f}_{7 / 2}$, respectivamente.

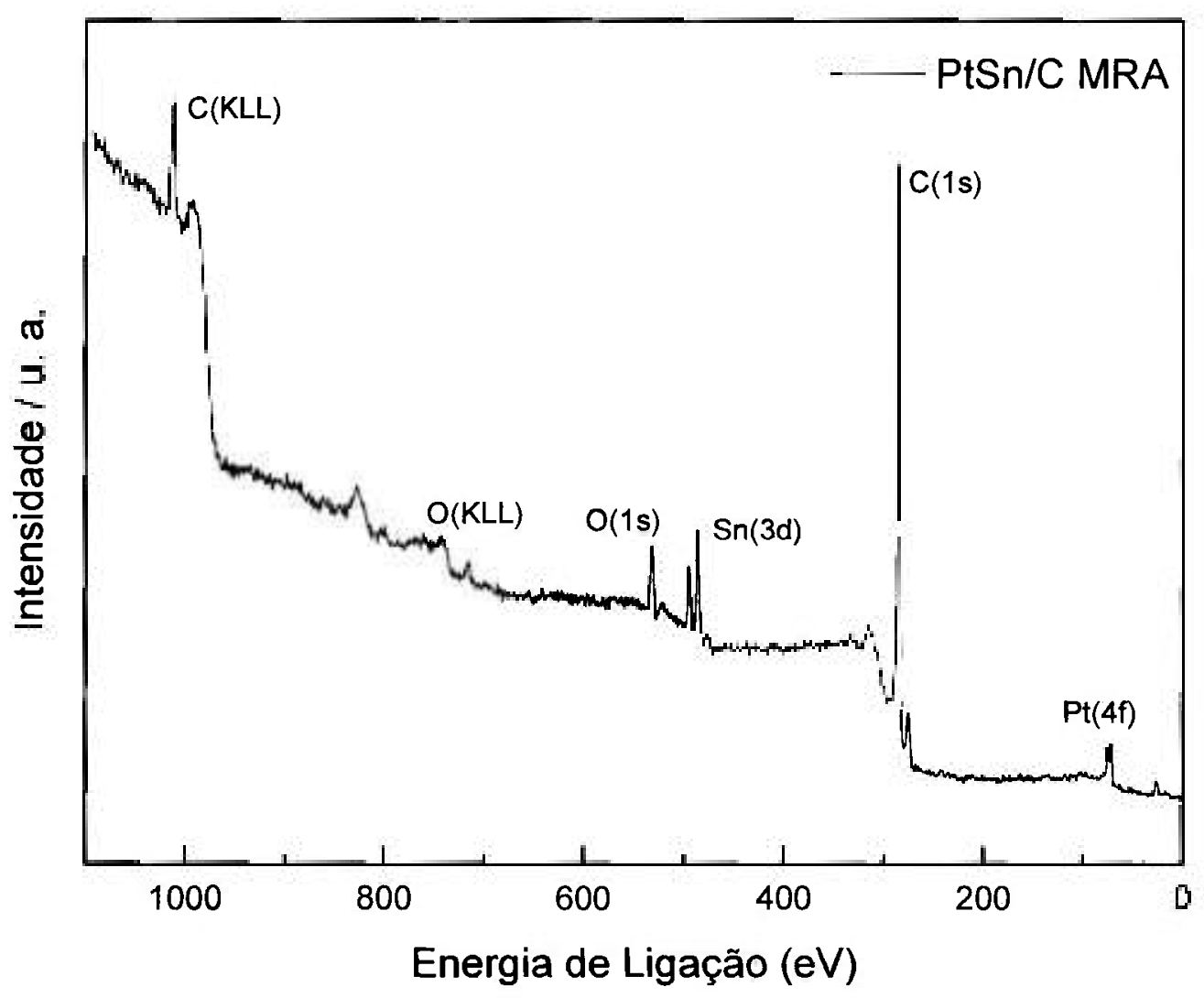

FIGURA 43 - Espectro de XPS para o eletrocatalisador PtSn/C MRA.

Observa-se na FIGURA 43 que a composição química elementar do eletrocatalisador PtSn/C MRA apresenta picos de O, Sn, C e Pt. Os espectros detalhados dos picos $\mathrm{Sn}(5 \mathrm{~d})$ e Pt (4f) indicam fases oxidadas e metálicas. No ajuste do pico do Sn $3 \mathrm{~d}_{5 / 2}$ na FIGURA 44, pode-se observar duas componentes, uma a 485,5 eV correspondente ao $\mathrm{Sn}^{0}$ e outra, mais intensa, em $486,9 \mathrm{eV}$ a qual não é possível distinguir se é devido ao $\mathrm{Sn}^{2+}$ ou $\mathrm{Sn}^{4+}$. A análise do pico $\mathrm{Pt} 4 \mathrm{f}_{7 / 2}$ na FIGURA 45, indica a presença de $\mathrm{Pt}^{0}$, componente situada a $71,87 \mathrm{eV}$ e de $\mathrm{Pt}^{2+}$ a $73,21 \mathrm{eV}$. 


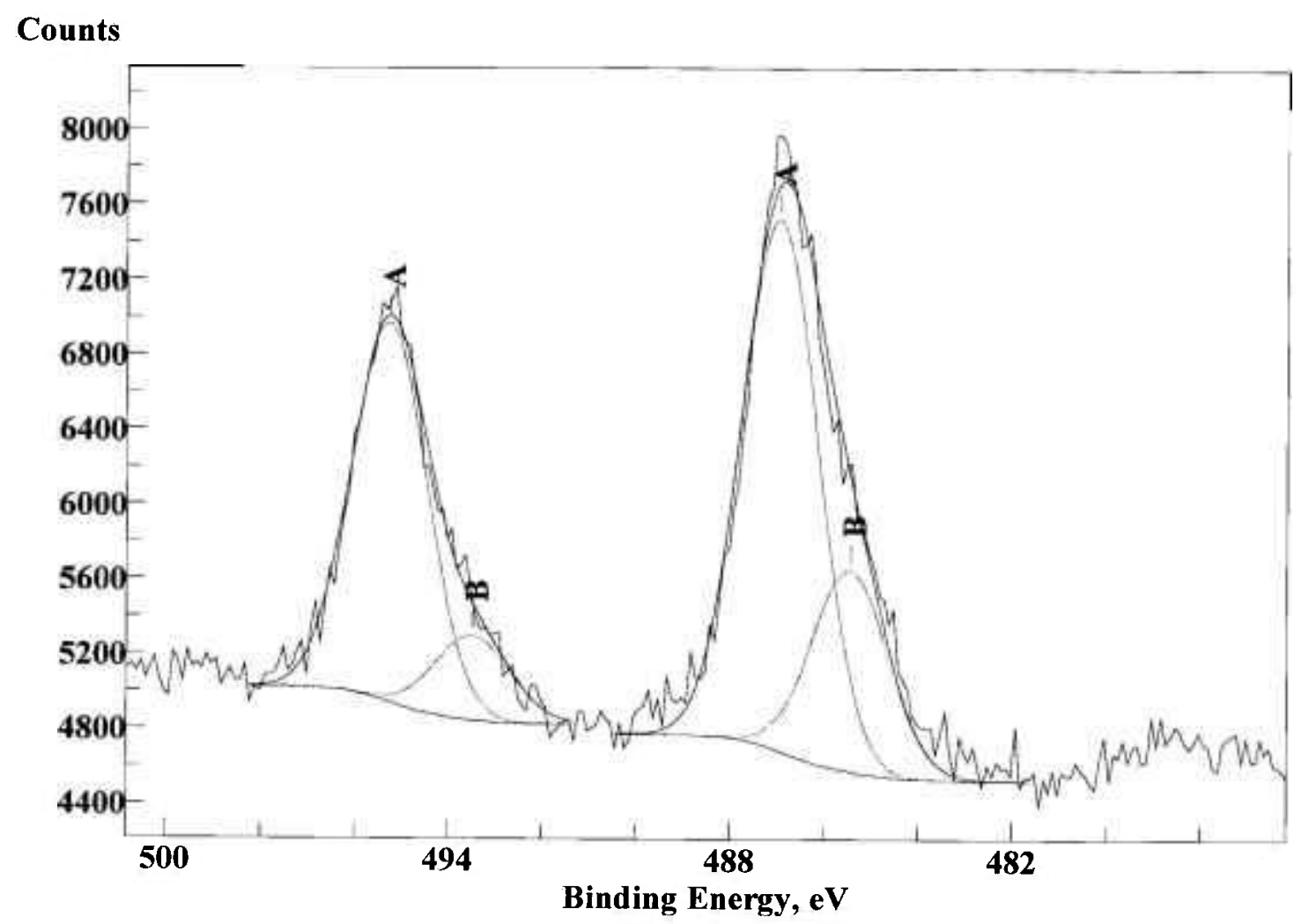

FIGURA 44 - Espectro detalhado do fotopico Sn 3d para o eletrocatalisador PtSn/C MRA.

\section{Counts}

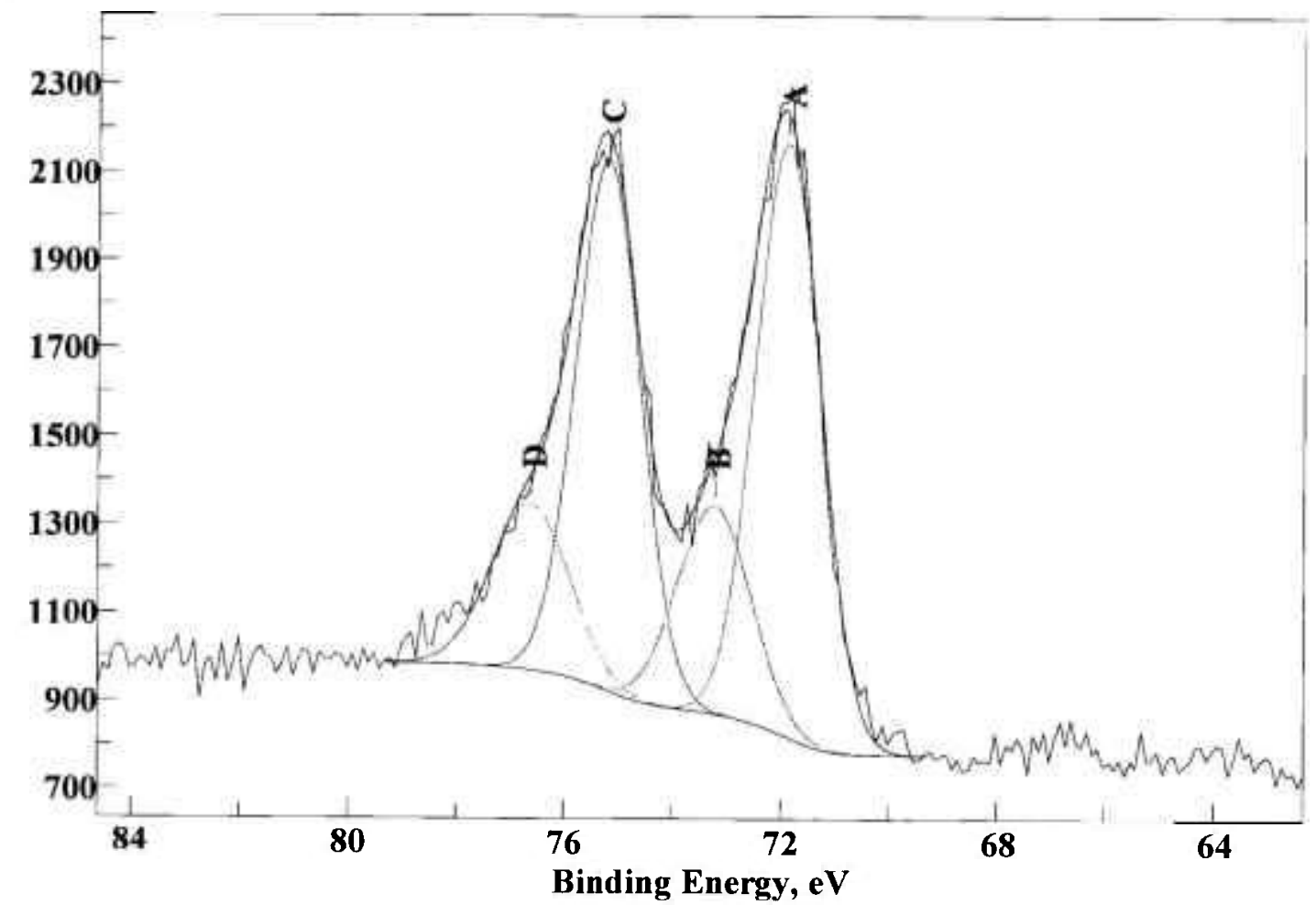

FIGURA 45 - Espectro detalhado do fotopico Pt 4f para o eletrocatalisador PtSn/C MRA. 
Na FIGURA 46 está representada o espectro amplo de XPS para o eletrocatalisador $\mathrm{Pt}_{50} \mathrm{Sn}_{40} \mathrm{Ni}_{10} / \mathrm{C}$ MRA. Na FIGURA 47 e 48 estão representadas as espectros de XPS com o ajuste do fotopico do $\mathrm{Sn} 3 \mathrm{~d}_{5 / 2}$ e $\mathrm{Pt} 4 \mathrm{f}_{7 / 2}$, respectivamente. Observa-se na FIGURA 46 que a composição química elementar do eletrocatalisador $\mathrm{Pt}_{50} \mathrm{Sn}_{40} \mathrm{Ni}_{10} / \mathrm{C}$ MRA apresenta picos de $\mathrm{Sn}, \mathrm{C}, \mathrm{Pt}, \mathrm{O}$ e Cu. A presença de cobre se justifica, pois o porta-amostra onde o eletrocatalisador foi colado para a análise é deste material. Os espectros detalhados dos picos $\mathrm{Sn}(5 \mathrm{~d})$ e Pt (4f) indicam fases oxidadas e metálicas. Os picos são semelhantes aos do eletrocatalisador $\mathrm{PtSn} / \mathrm{C}$, no ajuste do pico do $\mathrm{Sn} 3 \mathrm{~d}_{5 / 2}$ na FIGURA 47, pode-se observar duas componentes, uma a 485,5 eV correspondente ao $\mathrm{Sn}^{0} \mathrm{e}$ outra, mais intensa, em $486,9 \mathrm{eV}$ a qual não é possível distinguir se é devido ao $\mathrm{Sn}^{2+}$ ou $\mathrm{Sn}^{4+}$. A análise do pico $\mathrm{Pt} 4 \mathrm{f}_{7 / 2}$ na FIGURA 48, indica a presença de $\mathrm{Pt}^{0}$, componente situada a $71,88 \mathrm{eV}$ e de $\mathrm{Pt}^{2+}$ a $73,22 \mathrm{eV}$.

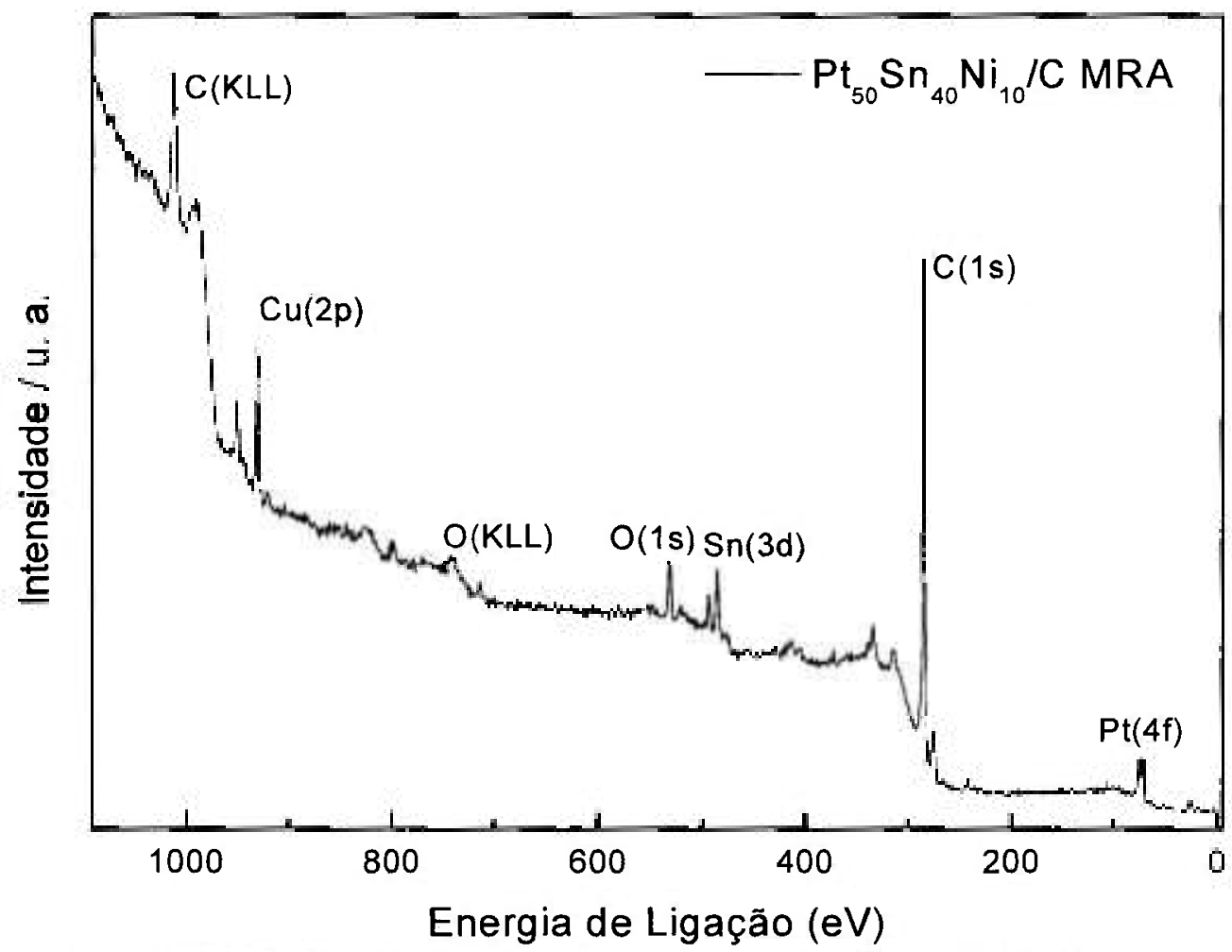

FIGURA 46 - Espectro de XPS para o eletrocatalisador $\mathrm{Pt}_{50} \mathrm{Sn}_{40} \mathrm{Ni}_{10} / \mathrm{C}$ MRA. 


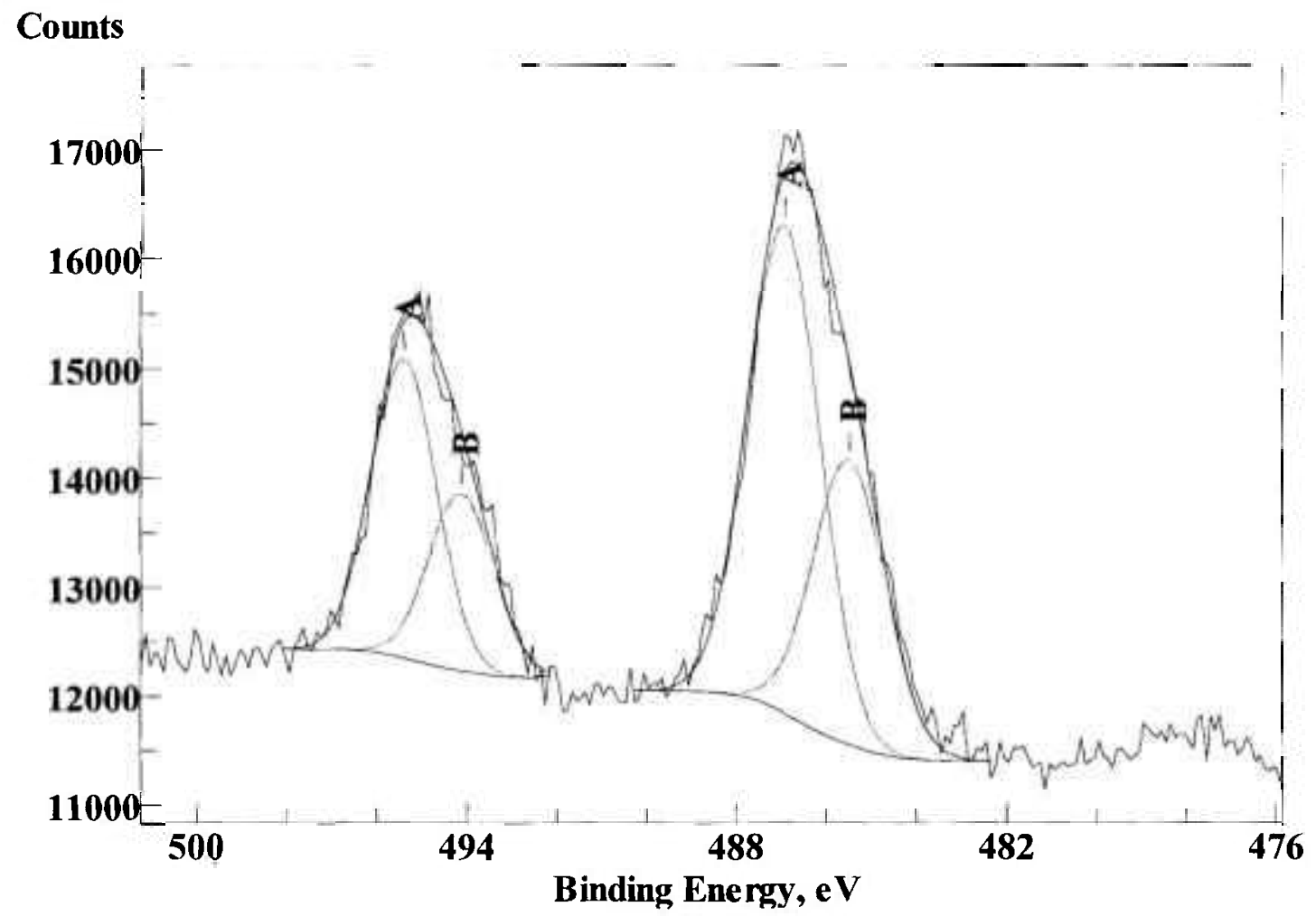

FIGURA 47 - Espectro detalhado do fotopico Sn 3d para o eletrocatalisador $\mathrm{Pt}_{50} \mathrm{Sn}_{40} \mathrm{Ni}_{10} / \mathrm{C}$ MRA.

\section{Counts}

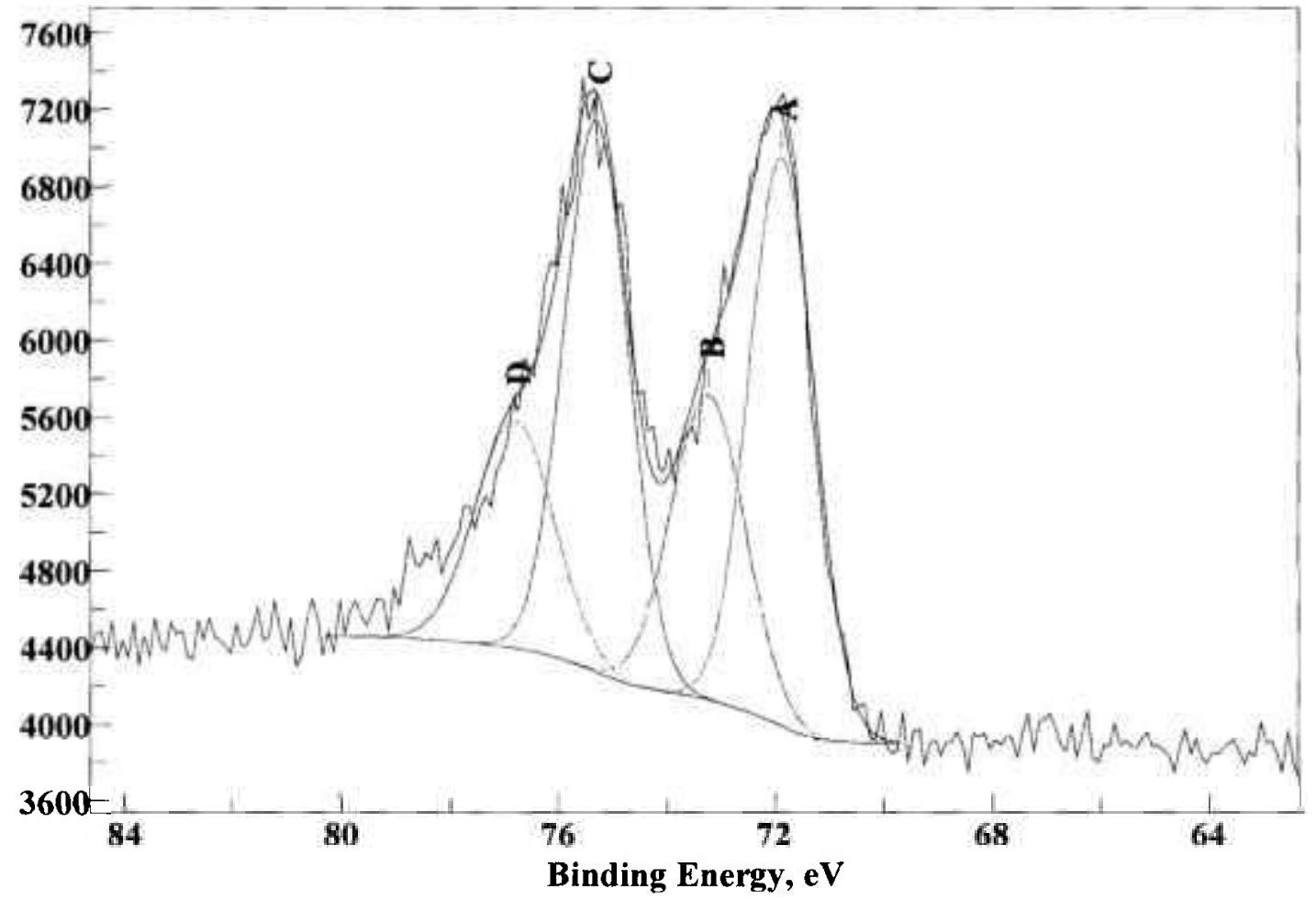

FIGURA 48 - Espectro detalhado do fotopico Pt 4f para o eletrocatalisador $\mathrm{Pt}_{50} \mathrm{Sn}_{40} \mathrm{Ni}_{10} / \mathrm{C}$ MRA. 
Na FIGURA 49 está representado os resultados de Espectroscopia Mössbauer (descrita no capítulo 5.4) para os eletrocatalisadores $\mathrm{PtSn} / \mathrm{C}$ e $\mathrm{Pt}_{50} \mathrm{Sn}_{40} \mathrm{Ni}_{10} / \mathrm{C}$ ambos preparados pelo método de redução por álcool.

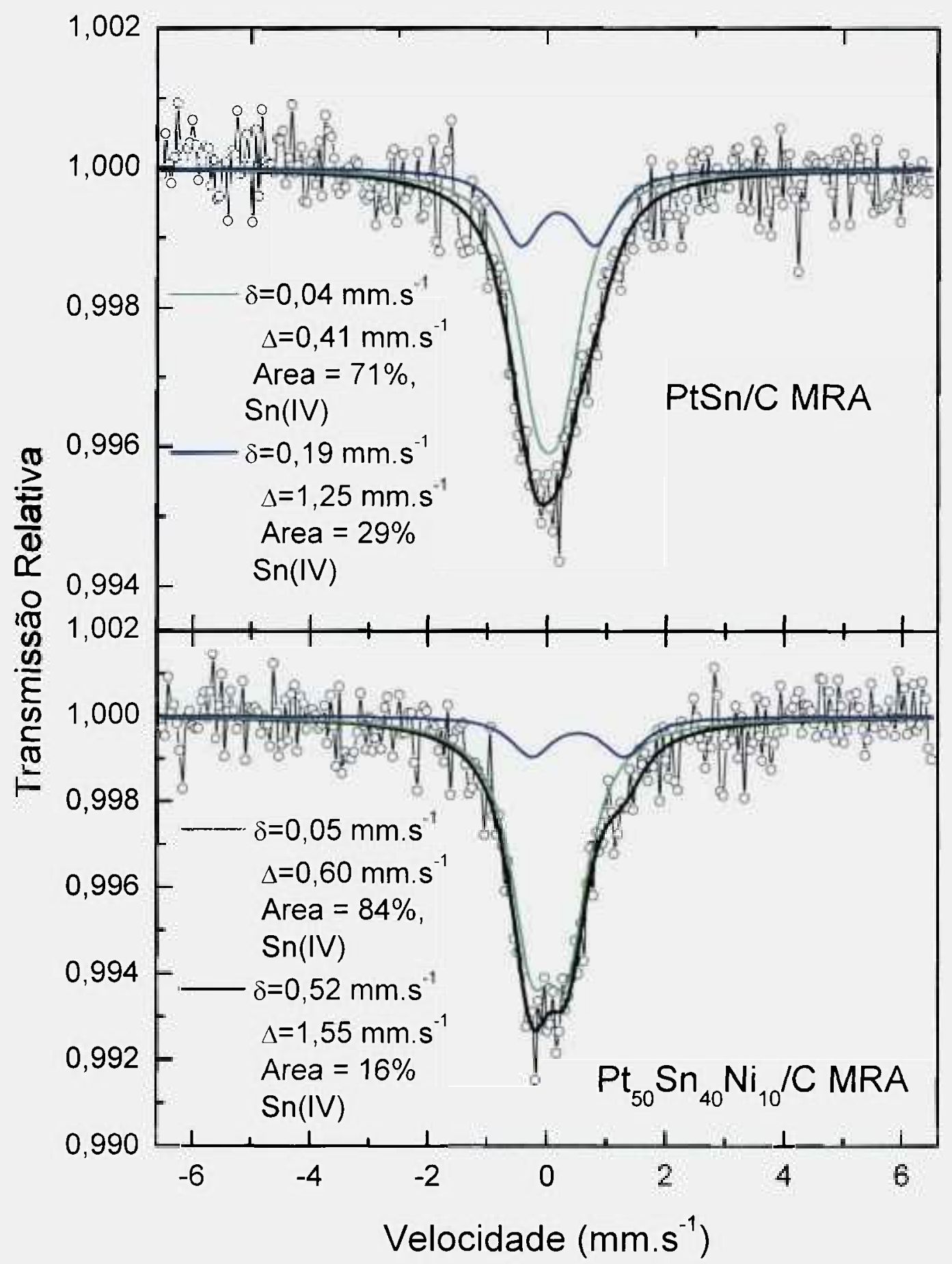

FIGURA 49 - Análise de Mössbauer para os eletrocatalisadores $\mathrm{PtSn} / \mathrm{C}$ e $\mathrm{Pt}_{50} \mathrm{Sn}_{40} \mathrm{Ni}_{10} / \mathrm{C}$ MRA. 
Observa-se nos resultados de Mössbauer da FIGURA 49 que o eletrocatalisador $\mathrm{PtSn} / \mathrm{C}$ MRA mostra apenas fase oxidada (predominância de fase $\mathrm{Sn}^{4+}$ ), contrariando o resultado obtido na FIGURA 44 que mostram fase oxidada e metálica. Possivelmente o aparecimento desta fase metálica é efeito do processo de preparação das amostras para o experimento de XPS por sputtering. Sabe-se da literatura ${ }^{[129]}$ que existe a possibilidade do sputtering com íons de argônio causar este efeito em ferritas de níquel.

Observa-se na FIGURA 49 e também na FIGURA 46 que não há presença de nenhuma representação referente a níquel na análise do eletrocatalisador $\mathrm{Pt}_{50} \mathrm{Sn}_{40} \mathrm{Ni}_{10} / \mathrm{C}$ MRA. Este fato não descarta a possibilidade da presença de níquel no eletrocatalisador, sendo que o níquel pode estar presente no interior da partícula, e recoberto por platina e estanho impedindo que os raios $\mathrm{X}(\mathrm{E}=1253,6 \mathrm{eV})$ penetrassem até a camada da presença de níquel (a vários Á de espessura).

Outros fatores importantes que podem ter contribuído para o melhor resultado dos MEAs fabricados com os eletrocatalisadores provenientes do MRA é referente ao grau de recobrimento superficial de metais na superfície catalítica dos MEAs, aumentando assim a área ativa para a reação, e também ao menor tamanho de partícula dos eletrocatalisadores em comparação ao eletrocatalisador PtRu/C comercial da E-TEK.

\subsection{EIE}

\subsubsection{Operação com $\mathrm{H}_{2} / \mathrm{O}_{2}$}

Os espectros de EIE foram analisados on-line, ou seja, com a célula a combustível em operação com densidades de correntes de 0 até $640 \mathrm{~mA} \cdot \mathrm{cm}^{-2}$.

Na FIGURA 50, estão representados os diagramas de Nyquist da operação online de um MEA com $25 \mathrm{~cm}^{2}$ de área eletródica, confeccionado pelo método spray/prensagem a quente ${ }^{[104]} \mathrm{com} \mathrm{Pt} / \mathrm{C}$ comercial da E-TEK, contendo 0,4 mg de Pt.cm ${ }^{-2}$ no anodo e $0,6 \mathrm{mg}$ de $\mathrm{Pt} . \mathrm{cm}^{-2}$ no catodo, ambos sob operação com $\mathrm{H}_{2} / \mathrm{O}_{2}$. A temperatura da célula foi de $70^{\circ} \mathrm{C}$ e do umidificador de $85^{\circ} \mathrm{C}$.

Na FIGURA 51, 52 e 53 estão representados os diagramas de Nyquist de um MEA com $25 \mathrm{~cm}^{2}$ de área eletródica, confeccionado pelo método spray/prensagem a quente com $\mathrm{PtRu} / \mathrm{C}$ comercial da E-TEK, PtSn/C MRA e $\mathrm{Pt}_{50} \mathrm{Sn}_{40} \mathrm{Ni}_{10} / \mathrm{C} \mathrm{MRA}$, respectivamente, contendo $0,4 \mathrm{mg}$ de $P t . \mathrm{cm}^{-2}$ no anodo e $0,6 \mathrm{mg}$ de $\mathrm{Pt}_{\mathrm{cm}} \mathrm{cm}^{-2}$ no càtodo, tọdos sob operação com $\mathrm{H}_{2} / \mathrm{O}_{2}$. A temperatura da célula foi de $70{ }^{\circ} \mathrm{C}$ e do umidificador de $85{ }^{\circ} \mathrm{C}$. 


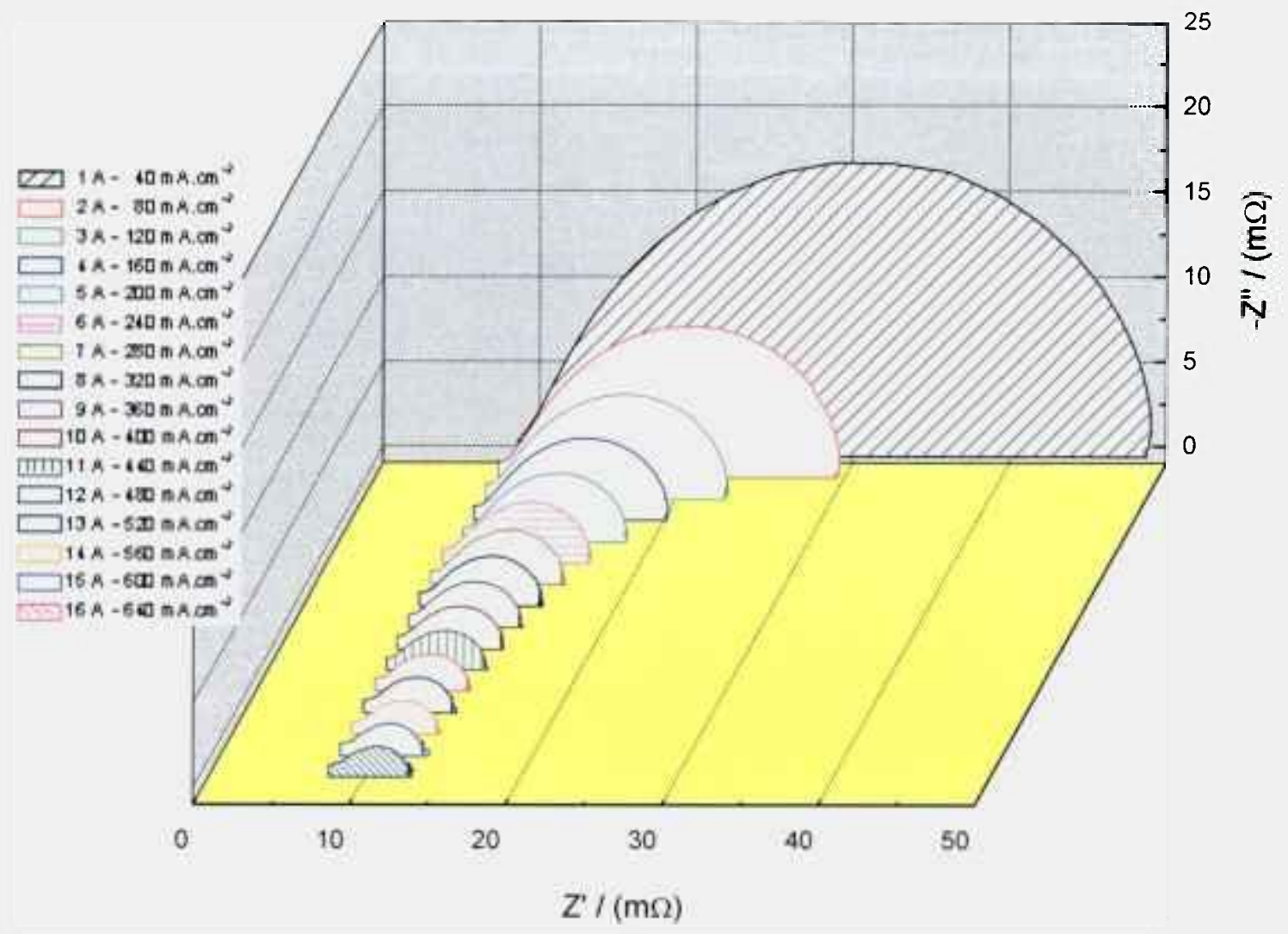

FIGURA 50 - Diagramas de Nyquist, para MEA Pt/C comercial da E-TEK com $25 \mathrm{~cm}^{2}$ de área eletródica, com tinta catalítica aplicada sobre o tecido de carbono com $0.4 \mathrm{mgPt} . \mathrm{cm}^{-2}$ no anodo e $0,6 \mathrm{mgPt} . \mathrm{cm}^{-2}$ no catodo (Pt/C comercial da E-TEK), utilizando membrana de Nafion $^{\text {B }} 105$, em várias correntes de operação com $\mathrm{H}_{2} / \mathrm{O}_{2}$. Temperaturas: célula a $70{ }^{\circ} \mathrm{C}$ e umidificador a $85^{\circ} \mathrm{C}$. 


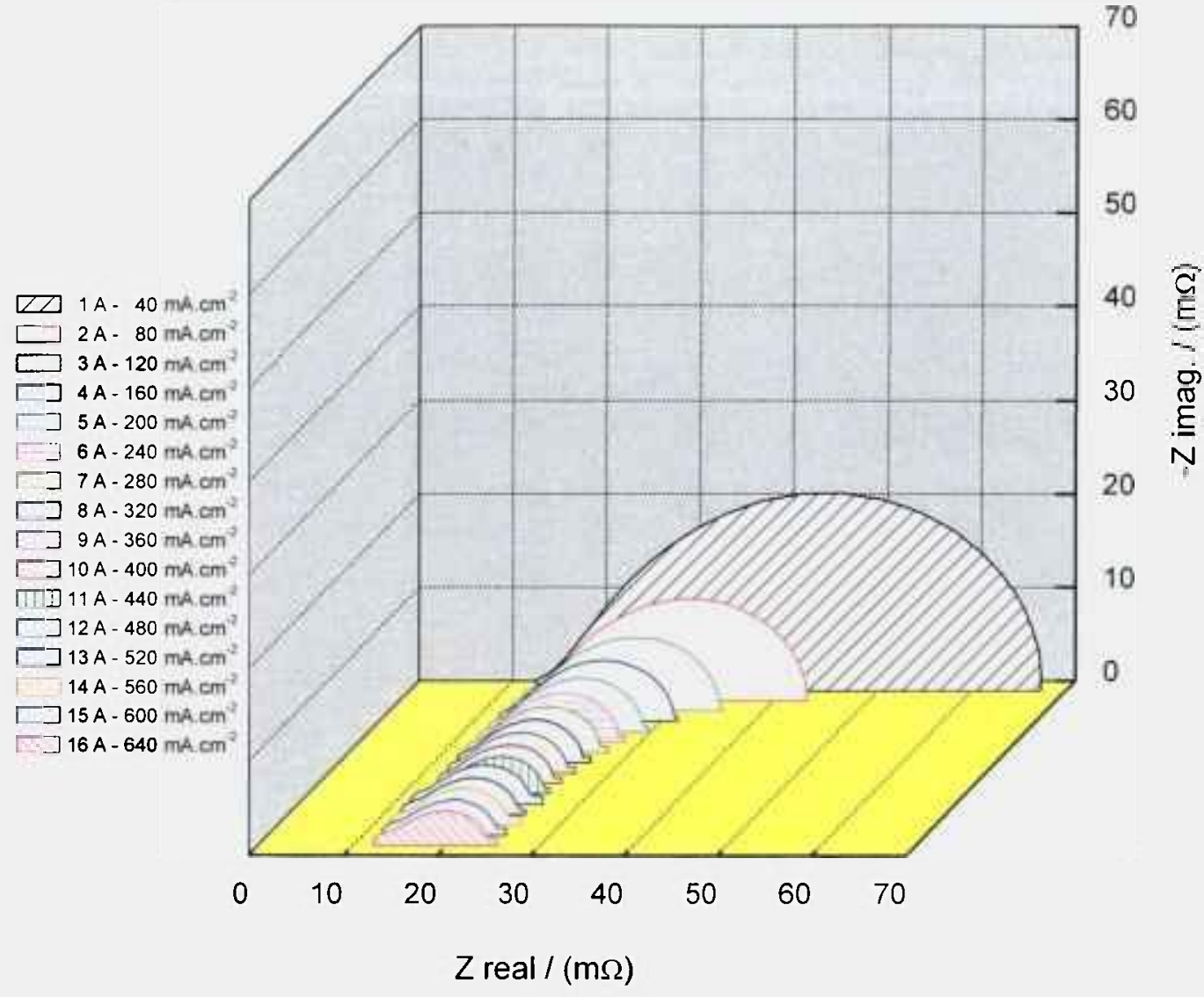

FIGURA 51 - Diagramas de Nyquist, para MEA PtRu/C comercial da E-TEK com $25 \mathrm{~cm}^{2}$ de área eletródica, com tinta catalítica aplicada sobre o tecido de carbono com $0.4 \mathrm{mgPt} . \mathrm{cm}^{-2}$ no anodo e $0.6 \mathrm{mgPt} . \mathrm{cm}^{-2}$ no catodo (Pt/C comercial da E-TEK), utilizando membrana de $\mathrm{Nafion}^{\mathbb{B}} 105$, em várias correntes de operação com $\mathrm{H}_{2} / \mathrm{O}_{2}$. Temperaturas: célula a $70{ }^{\circ} \mathrm{C}$ e umidificador a $85^{\circ} \mathrm{C}$. 
Análise por Impedância Eletroquímica "on-line" de Conjuntos Eletrodo/Membrana (MEA)

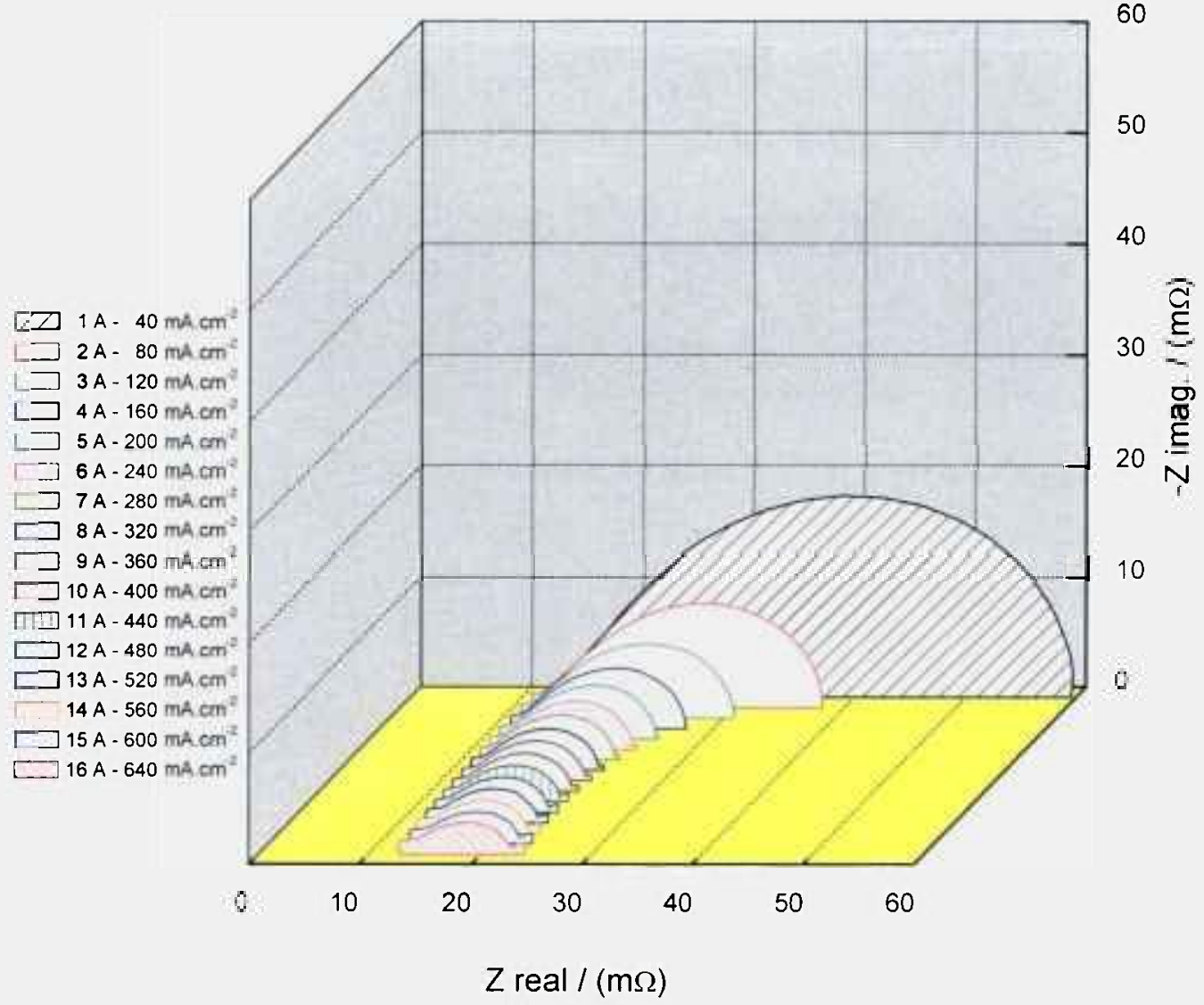

FIGURA 52 - Diagramas de Nyquist, para MEA PtSn/C MRA com $25 \mathrm{~cm}^{2}$ de área eletródica, com tinta catalítica aplicada sobre o tecido de carbono com $0,4 \mathrm{mgPt} . \mathrm{cm}^{-2}$ no anodo (MRA) e $0,6 \mathrm{mgPt} . \mathrm{cm}^{-2}$ no catodo (Pt/C comercial da E-TEK), utilizando membrana de Nafion ${ }^{\overline{\mathrm{P}}} 105$, em várias correntes de operação com $\mathrm{H}_{2} / \mathrm{O}_{2}$. Temperaturas: célula a $70{ }^{\circ} \mathrm{C}$ e umidificador a $85{ }^{\circ} \mathrm{C}$. 


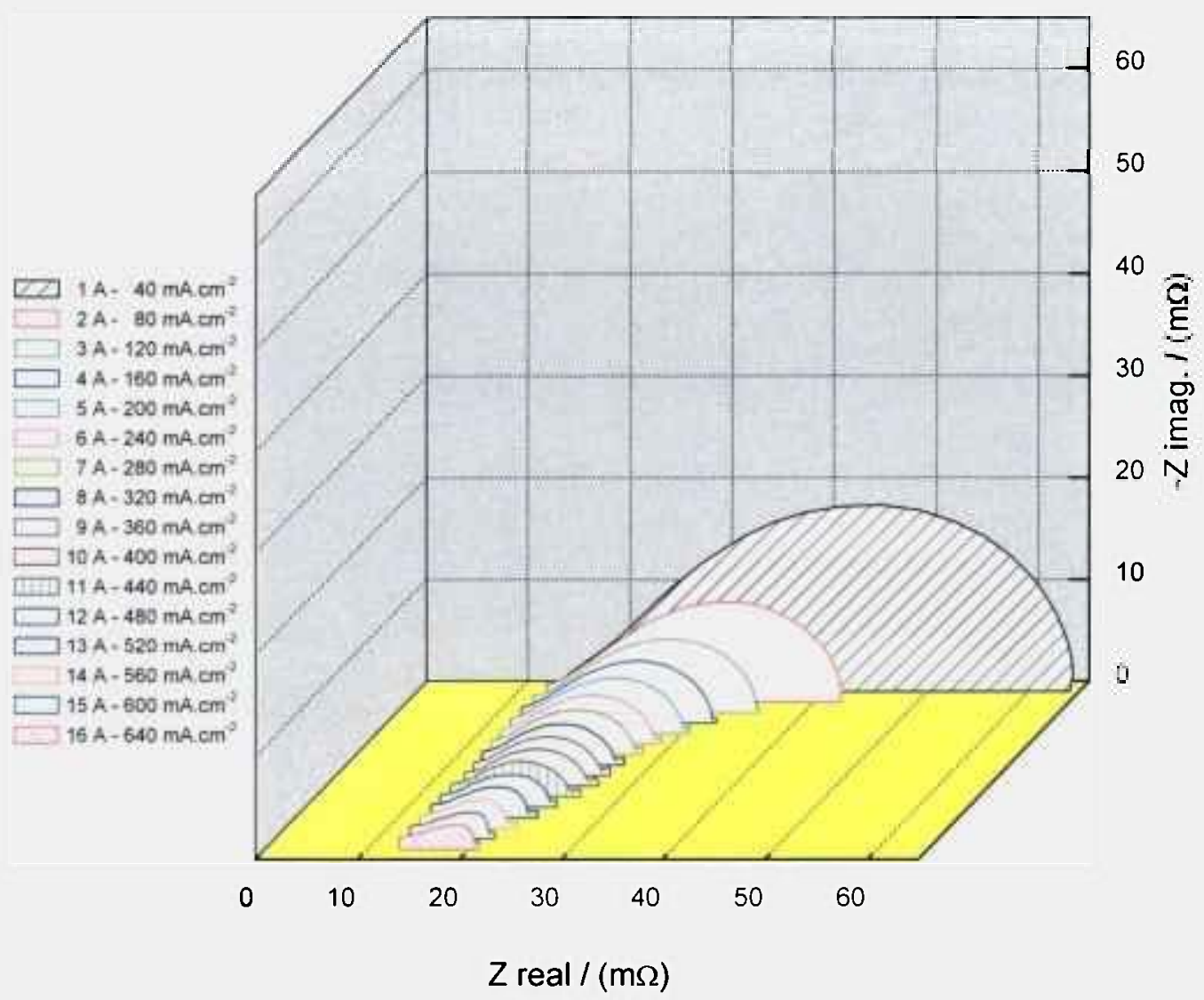

FIGURA 53 - Diagramas de Nyquist, para MEA $\mathrm{Pt}_{50} \mathrm{Sn}_{40} \mathrm{Ni}_{10} / \mathrm{C}$ MRA com $25 \mathrm{~cm}^{2}$ de área eletródica, com tinta catalítica aplicada sobre o tecido de carbono com $0,4 \mathrm{mgPt} . \mathrm{cm}^{-2}$ no anodo (MRA) e $0,6 \mathrm{mgPt}_{\mathrm{cm}}{ }^{-2}$ no catodo (Pt/C comercial da E-TEK), utilizando membrana de Nafion ${ }^{\text {k }} 105$, em várias correntes de operação com $\mathrm{H}_{2} / \mathrm{O}_{2}$. Temperaturas: célula a $70{ }^{\circ} \mathrm{C}$ e umidificador a $85^{\circ} \mathrm{C}$. 
Observa-se nos diagramas de Nyquist da FIGURA 50 até a FIGURA 53 que as resistências dos MEAs obtidos nos diagramas de Nyquist, estão diretamente correlacionadas com as correntes de operação da célula, e quanto maior a corrente de operação, menor a resistência total dos MEAs. Observa-se também um comportamento linear da resistência total dos diagramas para as correntes acima de $6,0 \mathrm{~A}$ ou $240 \mathrm{~mA} . \mathrm{cm}^{-2}$. Entretanto, para correntes abaixo de 6,0 A ou $240 \mathrm{~mA} \cdot \mathrm{cm}^{-2}$ o comportamento da resistência total varia exponencialmente.

Além disso, os diagramas fornecem valores da resistência ôhmica dos MEAs onde o valor de impedância total ( $Z$ real),que corresponde ao menor valor de freqüência $(0,1 \mathrm{mHz})$, representa a resistência total do conjunto eletrodo/eletrólito ${ }^{\text {[106̆ }}$ e o valor de impedância correspondente ao maior valor de freqüência $(10 \mathrm{kHz})$ representa a resistência da membrana de Nafion ${ }^{\circledR}$ 105. Observa-se ainda somente um semicírculo bem definido nos diagramas de Nyquist, indicando uma polarização por transferência de carga (a baixas densidades de corrente), onde a etapa determinante de velocidade é a transferência de carga na interface onde ocorre à reação de redução de oxigênio (catodo), cuja dependência com o potencial é governada pela equação de Tafel ${ }^{[105]}$, como representada na Equação 61 .

Outra observação importante nos diagramas da FIGURA 50 à FIGURA 53 diz respeito ao tempo de relaxação, que não apresenta interferência nos MEAs estudados. O tempo de relaxação é relacionado à velocidade de recuperação quando uma perturbação é aplicada ao sistema em seu estado estacionário. Este fato pode ser observado a baixas freqüências, onde o tempo de relaxação deveria ser tão pequeno quanto possível, para corresponder a uma maior liberdade de transporte dentro da célula.

Em freqüências menores que $0,5 \mathrm{~Hz}$ os diagramas de impedância não têm uma forma específica e, portanto, não se pode dar um significado físico a este fenômeno [310]. Por esta razão, não se utilizou neste estudo, freqüências abaixo de $0,1 \mathrm{~Hz}$ (exceto em circuito aberto).

Um possível modelo proposto neste trabalho, que representa os elementos presentes na célula $\mathrm{e}$ as reações envolvidas no anodo e no catodo é mostrado na FIGURA 54. Utilizou-se este modelo de circuito elétrico para comparar os valores analisados diretamente na célula. Nas FIGURA 55, FIGURA 56, FIGURA 57 e a FIGURA 58, estão apresentados os ajustes $(F I T)$ das simulações, geradas a partir do modelo apresentado na FIGURA 54, para os eletrocatalisadores Pt/C comercial da E-TEK, $\mathrm{PtRu} / \mathrm{C}$ comercial da E-TEK, $\mathrm{PtSn} / \mathrm{C}$ MRA e $\mathrm{Pt}_{50} \mathrm{Sn}_{40} \mathrm{Ni}_{10} / \mathrm{C}$ MRA, respectivamente. 


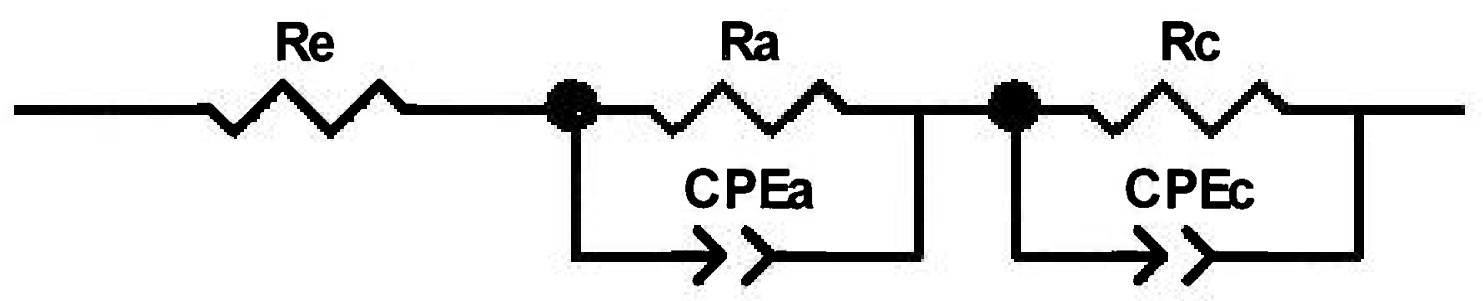

FIGURA 54 - Modelo escolhido de circuito elétrico para EIE "on-line" em operação com $\mathrm{H}_{2} / \mathrm{O}_{2}$.

O modelo sugerido apresenta 3 partes distintas, a saber:

1) Re: Resistência em série que representa a resistência ôhmica do eletrólito, ou seja, a membrana de Nafion $^{\circledR} 105$.

2) Rc e CPEc: Colocados em paralelo, representando as resistências do processo de transferência de carga envolvida no catodo (resistência ao fluxo de oxigênio ao atravessar o GDL e permear na tinta eletrocatalítica) e da dupla camada elétrica da reação de redução de oxigênio, respectivamente.

3) Ra e CPEa: Colocados em paralelo, representam as resistências do processo de transferência de carga envolvida no anodo (resistência ao fluxo de hidrogênio ao atravessar o GDL e permear na tinta eletrocatalítica) e da dupla camada elétrica na interface da reação de oxidação de hidrogênio, respectivamente. 


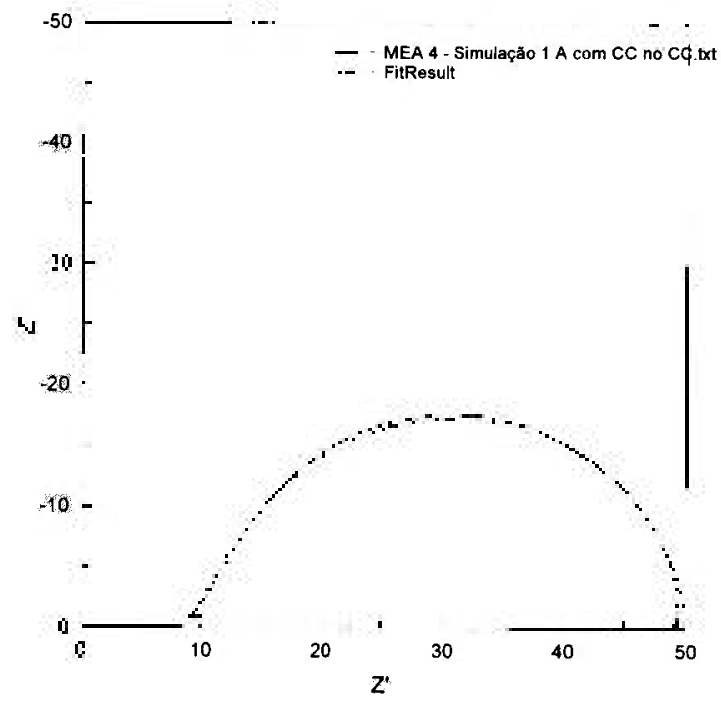

a)

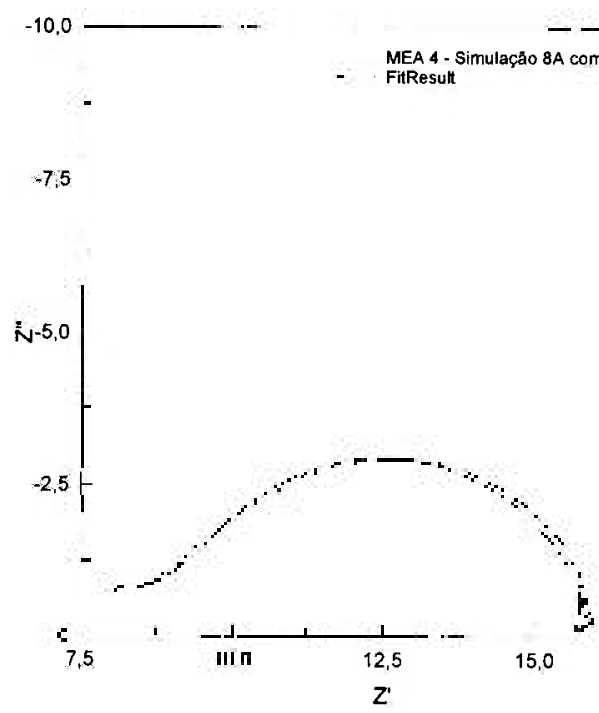

c)

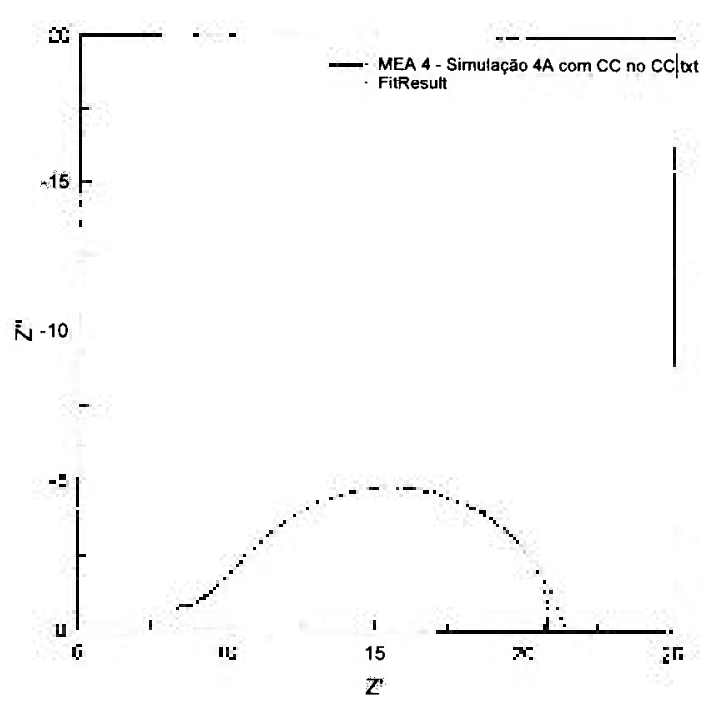

b)

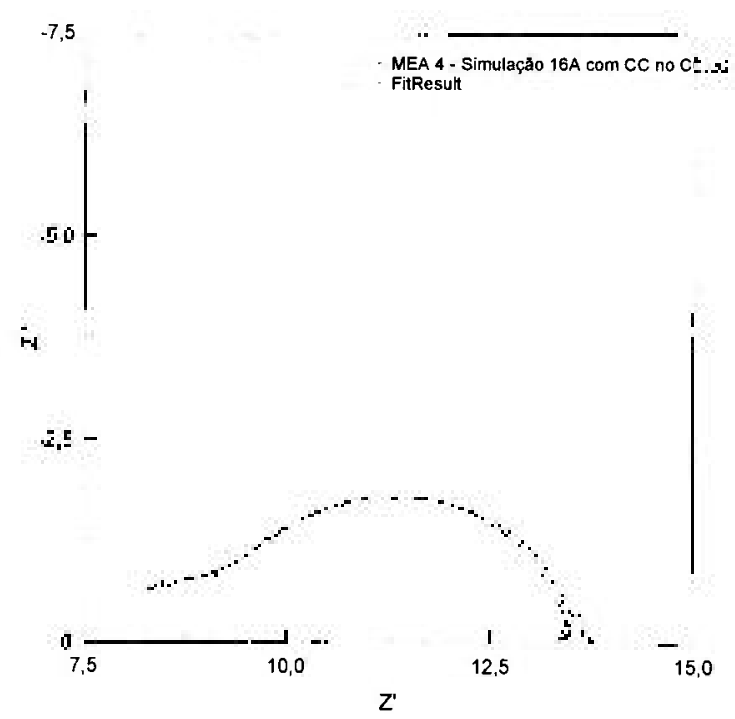

d)

FIGURA 55 - Diagrama de Nyquist para Pt/C comercial da E-TEK, operando com $\mathrm{H}_{2} / \mathrm{O}_{2}$. a) $1 \mathrm{~A}-40 \mathrm{~mA} \cdot \mathrm{cm}^{-2}$, b) $4 \mathrm{~A}-160 \mathrm{~mA} \cdot \mathrm{cm}^{-2}$, c) $8 \mathrm{~A}-320 \mathrm{~mA} \cdot \mathrm{cm}^{-2}$, d) $16 \mathrm{~A}-320 \mathrm{~mA} \cdot \mathrm{cm}^{-2}$. 


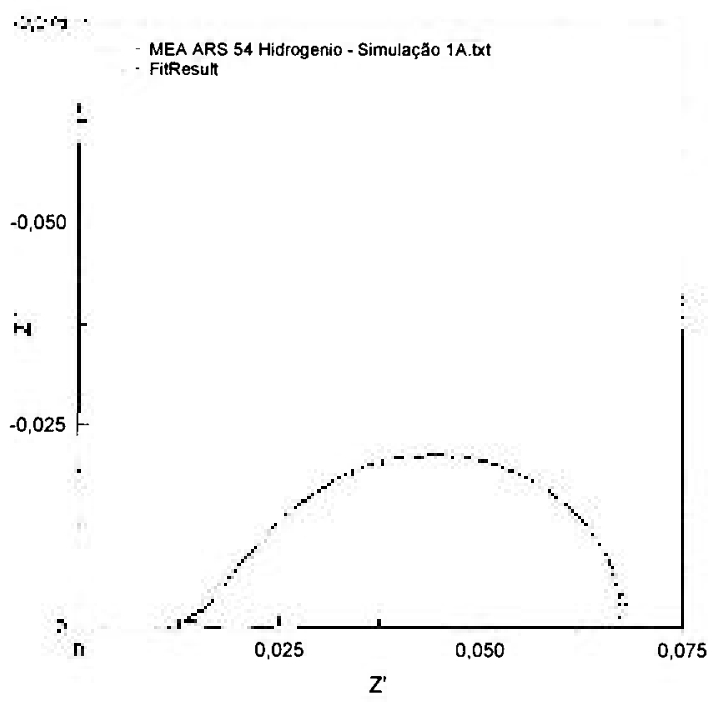

a)

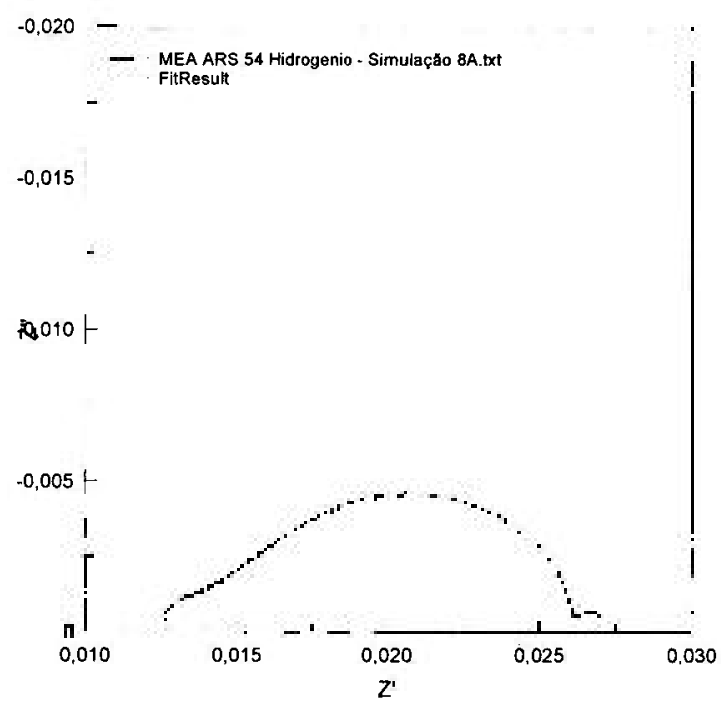

c)

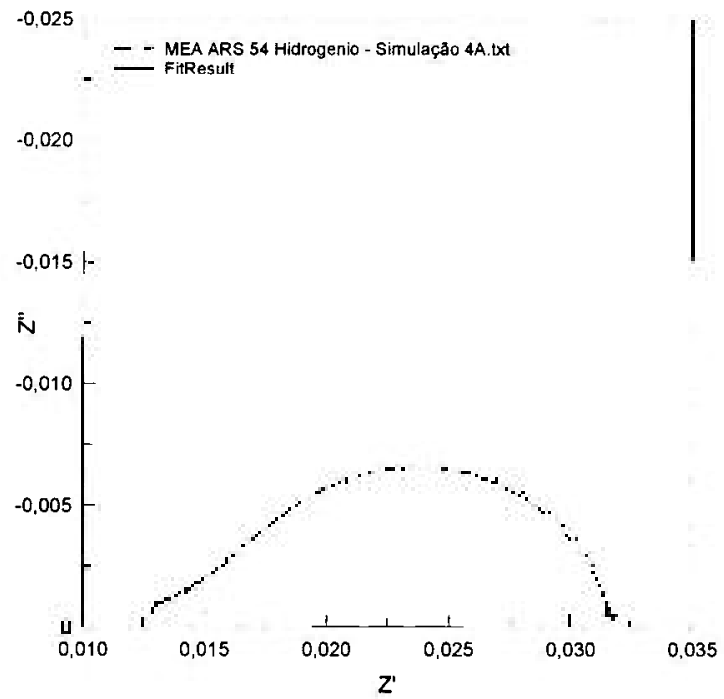

b)

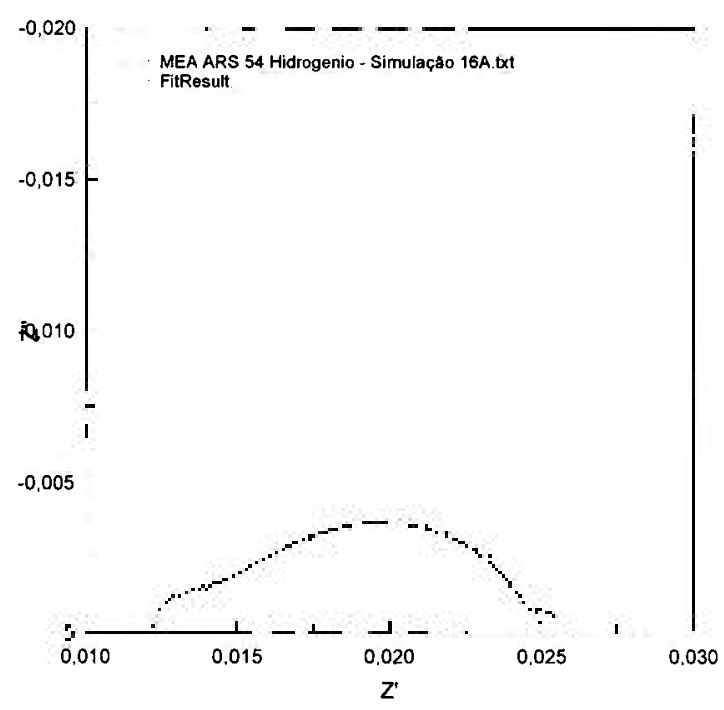

d)

FIGURA 56 - Diagrama de Nyquist para PtRu/C comercial da E-TEK, operando com $\mathrm{H}_{2} / \mathrm{O}_{2}$. $\begin{array}{lll}\text { a) } 1 \mathrm{~A}-40 \mathrm{~mA} \cdot \mathrm{cm}^{-2}, & \text { b) } 4 \mathrm{~A}-160 \mathrm{~mA} \cdot \mathrm{cm}^{-2}, & \text { c) } 8 \mathrm{~A}-320 \mathrm{~mA} \cdot \mathrm{cm}^{-2} \text { e }\end{array}$ d) $16 \mathrm{~A}-320 \mathrm{~mA} \cdot \mathrm{cm}^{-2}$. 


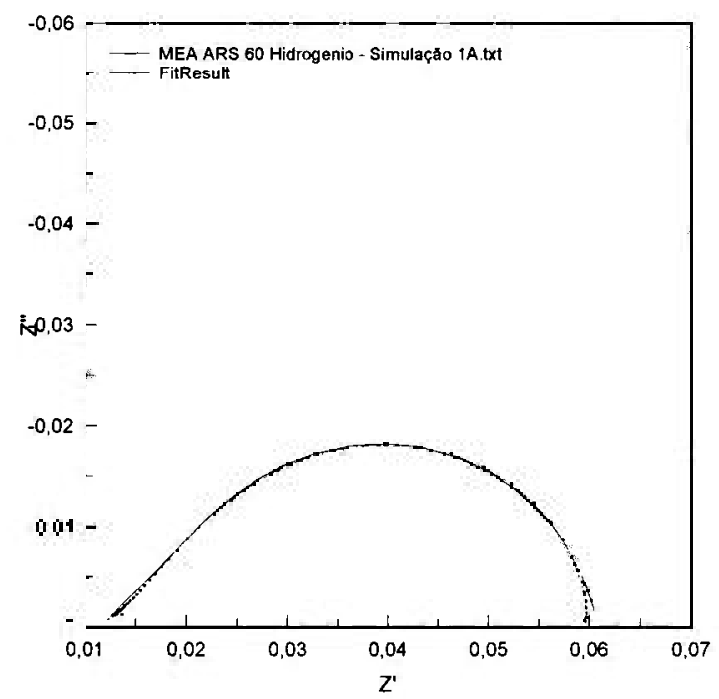

a)
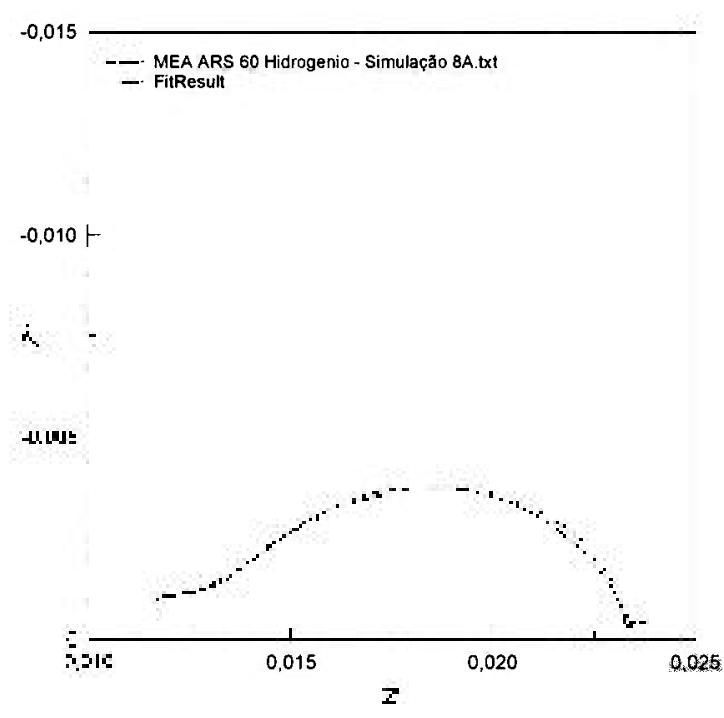

c)

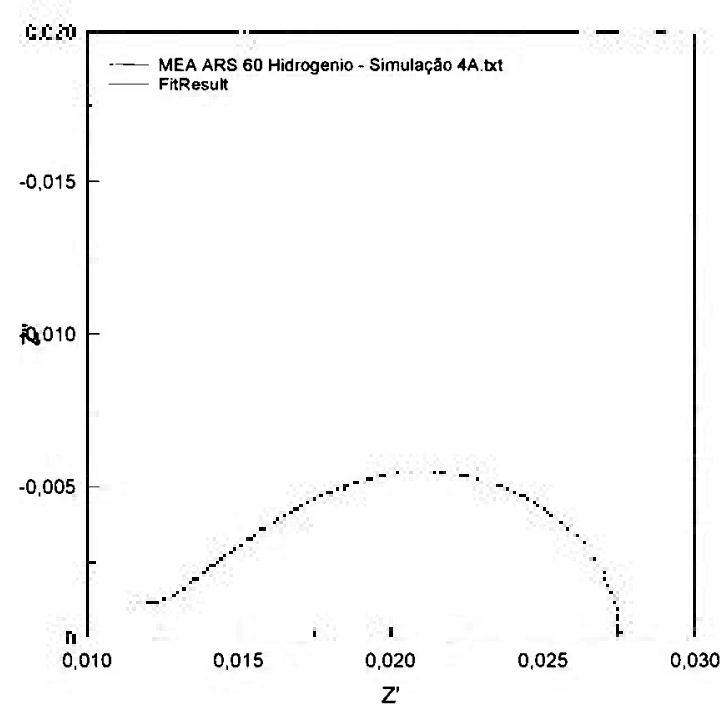

b)

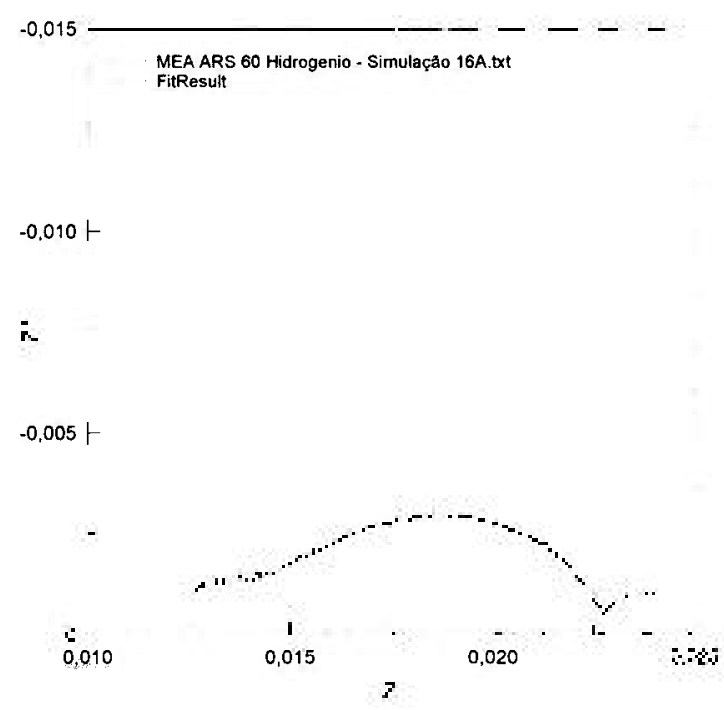

d)

FIGURA 57 - Diagrama de Nyquist para PtSn/C MRA, operando com $\mathrm{H}_{2} / \mathrm{O}_{2}$. a) $1 \mathrm{~A}-40 \mathrm{~mA} \cdot \mathrm{cm}^{-2}$, b) $4 \mathrm{~A}-160 \mathrm{~mA} \cdot \mathrm{cm}^{2-2}$, c) $8 \mathrm{~A}-320 \mathrm{~mA} \cdot \mathrm{cm}^{-2}$, d) $16 \mathrm{~A}-320 \mathrm{~mA} \cdot \mathrm{cm}^{-2}$. 


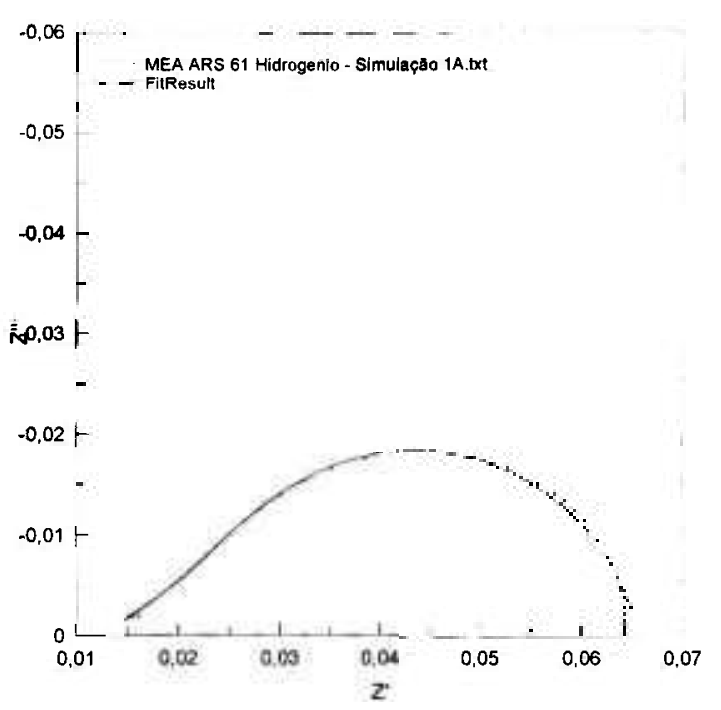

a)

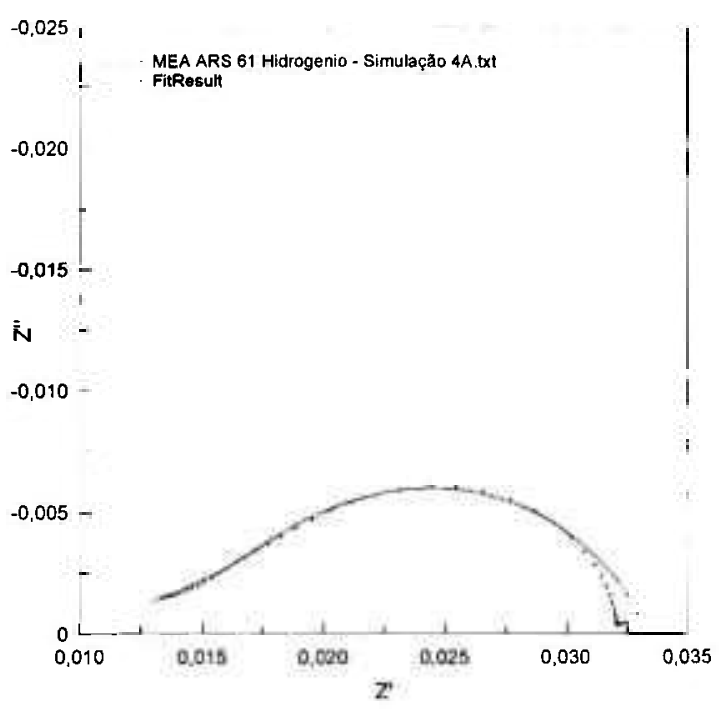

b)

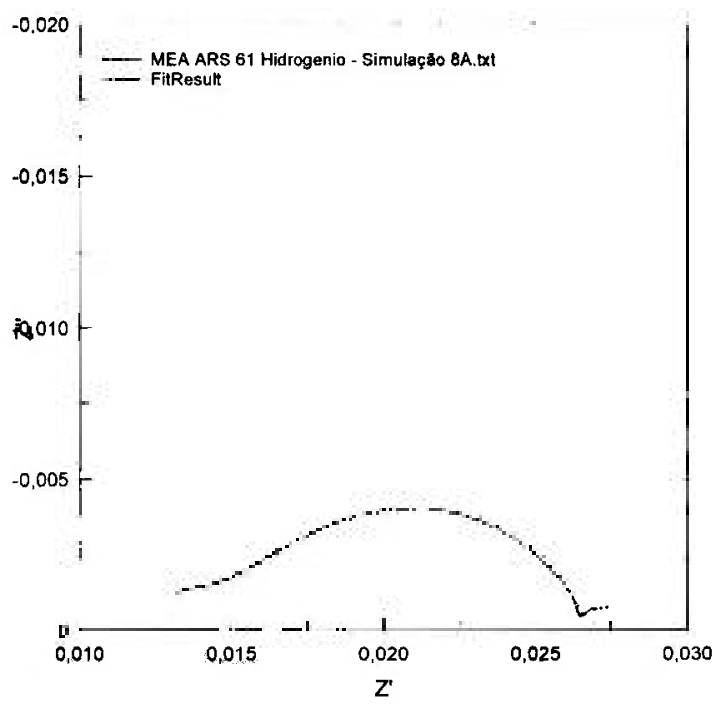

c)

FIGURA 58 - Diagrama de Nyquist para $\mathrm{Pt}_{50} \mathrm{Sn}_{40} \mathrm{Ni}_{10} / \mathrm{C}$ MRA, operando com $\mathrm{H}_{2} / \mathrm{O}_{2}$. a) $1 \mathrm{~A}-40 \mathrm{~mA} \cdot \mathrm{cm}^{-2}$, b) $4 \mathrm{~A}-160 \mathrm{~mA} \cdot \mathrm{cm}^{-2}$ e c) $8 \mathrm{~A}-320 \mathrm{~mA} \cdot \mathrm{cm}^{-2}$.

Na TABELA 6 estão os valores da simulação do circuito elétrico para os diagramas de Nyquist dos MEAs testados com $\mathrm{H}_{2} / \mathrm{O}_{2}$. 
TABELA 6 - Valores dos elementos componentes do circuito elétrico para os MEAs da FIGURA 55, 56, 57 e 58.

\begin{tabular}{|c|c|c|c|c|c|}
\hline & & $\begin{array}{c}\mathbf{I}=\mathbf{1} \mathbf{A} \\
\mathbf{i}=40 \mathrm{~mA} \cdot \mathrm{cm}^{-2}\end{array}$ & $\begin{array}{c}I=4 \mathbf{A} \\
\mathrm{i}=160 \mathrm{~mA} \cdot \mathrm{cm}^{-2}\end{array}$ & $\begin{array}{c}\mathbf{I}=\mathbf{8} \mathbf{A} \\
\mathrm{i}=320 \mathrm{~mA} \cdot \mathrm{cm}^{-2}\end{array}$ & $\begin{array}{c}I=16 \mathrm{~A} \\
\mathrm{i}=640 \mathrm{~mA} \cdot \mathrm{cm}^{-2}\end{array}$ \\
\hline \multirow{7}{*}{ 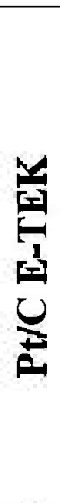 } & $\operatorname{Re}[\mathrm{m} \Omega]$ & 8,54 & 6,95 & 6,16 & 7,26 \\
\hline & $\mathrm{Ra}[\mathrm{m} \Omega]$ & 5,28 & 3,96 & 3,64 & 2,54 \\
\hline & $\mathrm{CPEa}[\mathrm{F}]$ & 0,55 & 0,50 & $0, \overline{20}$ & 0,11 \\
\hline & CPEa Exp. & 0,57 & $0, \overline{41}$ & $\overline{0,45}$ & 0,57 \\
\hline & $\mathrm{Rc}[\mathrm{m} \Omega]$ & 36,39 & 10,58 & 6,27 & 3,73 \\
\hline & $\mathrm{CPEc}[\mathrm{F}]$ & 0,72 & 0,78 & 0,63 & 0,67 \\
\hline & CPEc Exp. & 0,95 & 0,90 & 0,91 & 0,91 \\
\hline \multirow{7}{*}{ 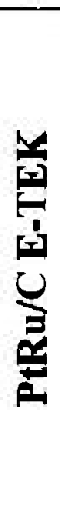 } & $\operatorname{Re}[\mathrm{m} \Omega]$ & 13,07 & 11,99 & 12,03 & 11,80 \\
\hline & $\mathrm{Ra}[\mathrm{m} \Omega]$ & 10,92 & 6,13 & 4,33 & 3,18 \\
\hline & $\mathrm{CPEa}[\mathrm{F}]$ & 3,15 & 3,64 & 1,69 & 0,52 \\
\hline & CPEa Exp. & 0,65 & 0,90 & 0,59 & 0,72 \\
\hline & $\mathrm{Rc}[\mathrm{m} \Omega]$ & 44,65 & 13,81 & 10,06 & 7,08 \\
\hline & CPEc [F] & 1,99 & 1,08 & 1,04 & 1,99 \\
\hline & CPEc Exp. & 0,93 & 0,90 & 0,88 & 0,78 \\
\hline \multirow{7}{*}{ 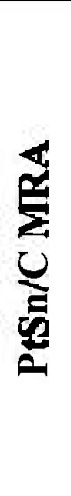 } & $\operatorname{Re}[\mathrm{m} \Omega]$ & 11,75 & 11,62 & 9,17 & 9,85 \\
\hline & $\overrightarrow{\mathrm{Ra}}[\mathrm{m} \Omega]$ & 11,23 & 5,52 & 5,40 & 5,00 \\
\hline & CPEa [F] & 3,60 & 2,21 & 2,31 & 2,08 \\
\hline & CPEa Exp. & 0,58 & 0,91 & 0,41 & 0,42 \\
\hline & $\mathrm{Rc}[\mathrm{m} \Omega]$ & 37,98 & 10,65 & 9,06 & 6,26 \\
\hline & $\mathrm{CPEc}[\mathrm{F}]$ & 1,41 & 1,17 & 1,12 & 1,12 \\
\hline & CPEc Exp. & 0,91 & 0,91 & 0,83 & 0,83 \\
\hline \multirow{7}{*}{ 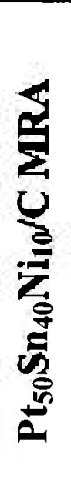 } & $\operatorname{Re}[\mathrm{m} \Omega]$ & 13,27 & 10,62 & 10,02 & 9,76 \\
\hline & $\mathrm{Ra}[\mathrm{m} \Omega]$ & 15,05 & 8,22 & 6,89 & 5,68 \\
\hline & CPEa [F] & 2,88 & 2,61 & 2,03 & 5,13 \\
\hline & CPEa Exp. & 0,51 & 0,43 & 0,40 & $0, \overline{32}$ \\
\hline & $\mathrm{Rc}[\mathrm{m} \Omega]$ & 37,61 & 14,68 & 9,98 & 2,90 \\
\hline & CPEc [F] & 1,01 & 0,89 & 1,10 & 0,84 \\
\hline & CPEc Exp. & 0,91 & $0, \overline{78}$ & 0,79 & 0,97 \\
\hline
\end{tabular}


Observando os diagramas experimentais de Nyquist e os diagramas de Nyquist gerados pela simulação, observou-se uma coerência na escolha do modelo do circuito elétrico para os MEAs utilizando $\mathrm{H}_{2} / \mathrm{O}_{2}$, visto que o comportamento do diagrama gerado pela simulação está, para quase toda a totalidade do diagrama, sobre o diagrama experimental. Esta coerência indica que outras resistências não consideradas no modelo, como por exemplo, o tempo de relaxação, resistências de contato, a resistência da porosidade dos eletrodos e a impedância de difusão, não são relevantes na resistência total dos MEAs em operação com hidrogênio.

Com os valores da resistência de transferência de carga no anodo e no catodo da célula presentes na TABELA 6, construiu-se um gráfico comparativo da contribuição destas resistências na operação da célula, mostrado na FIGURA 59.

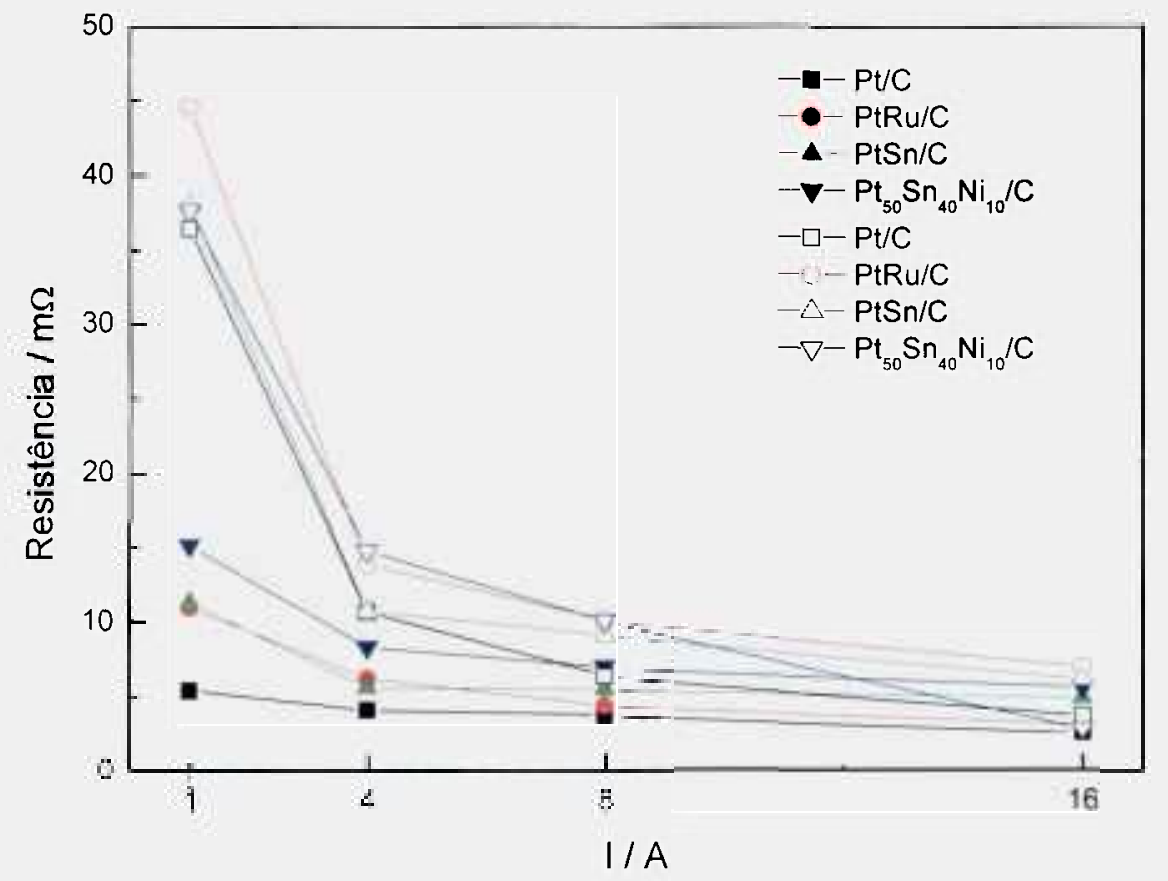

FIGURA 59 - Variação da resistência de transferência de carga no anodo (símbolo cheio) e no catodo (símbolo vazado) dos MEAs utilizados sob operação com $\mathrm{H}_{2} / \mathrm{O}_{2}$.

Observa-se na FIGURA 59 que a contribuição da resistência de transferência de carga para a reação de oxidação do hidrogênio no anodo é menor que a da redução do oxigênio no catodo para o funcionamento em todas as correntes de operação da célula. Observa-se também que para baixas correntes (menores que $4 \mathrm{~A}$ ou $160 \mathrm{~mA} . \mathrm{cm}^{-2}$ ) a resistência de transferência de carga do oxigênio torna-se bem maior. 


\subsubsection{Operação com Metanol/ $\mathrm{O}_{2}$}

Nas FIGURA 60, 61 e 62 estão representados os diagramas de Nyquist on-line de um MEA com $25 \mathrm{~cm}^{2}$ de área eletródica, confeccionado pelo método spray/prensagem a quente com PtRu/C comercial da E-TEK, PtSn/C MRA e $\mathrm{Pt}_{50} \mathrm{Sn}_{40} \mathrm{Ni}_{10} / \mathrm{C}$ MRA respectivamente, contendo $0,4 \mathrm{mg}$ de $\mathrm{Pt}_{\mathrm{cm}} \mathrm{cm}^{-2}$ no anodo e $0,6 \mathrm{mg}$ de $\mathrm{Pt} . \mathrm{cm}^{-2}$ no catodo, ambos sob operação com Metanol $/ \mathrm{O}_{2}$ a várias densidades de corrente. A temperatura da célula foi de $100{ }^{\circ} \mathrm{C}$ e do umidificador de $90{ }^{\circ} \mathrm{C}$.
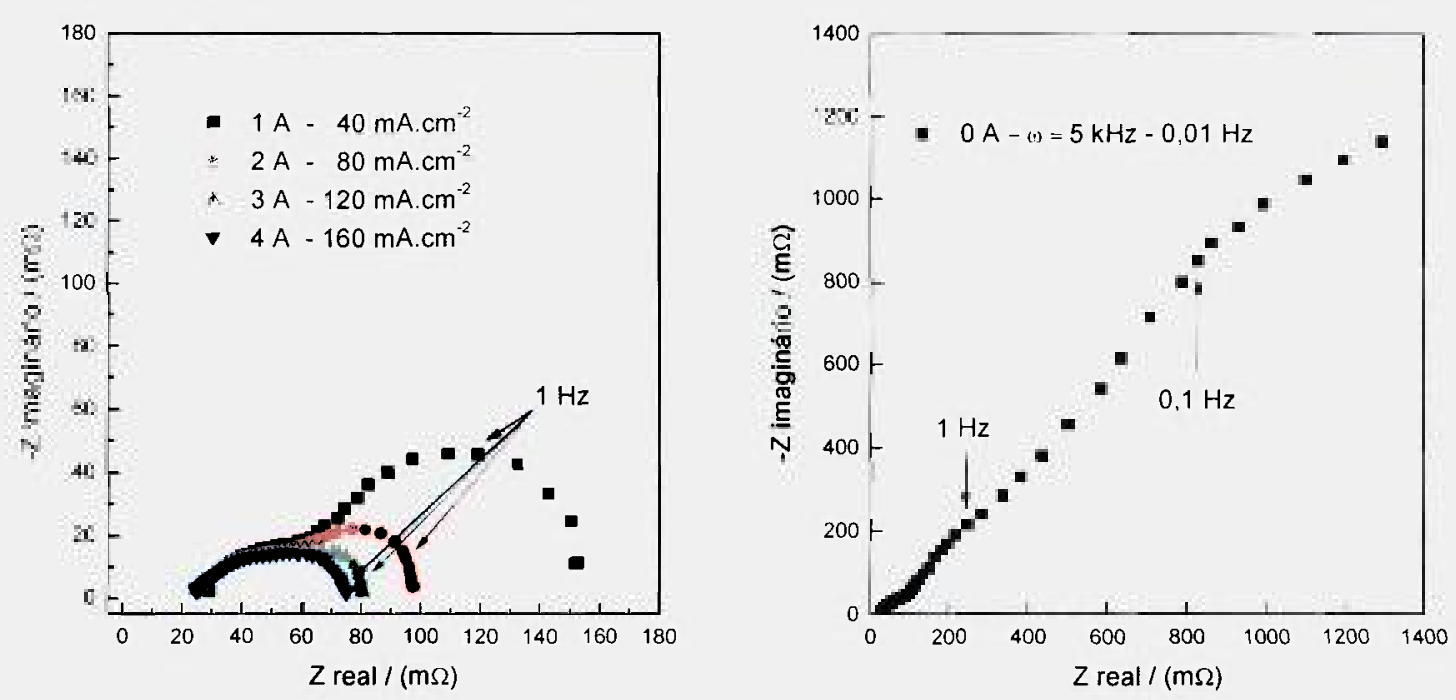

FIGURA 60 - Diagramas de Nyquist, para MEA PtRu/C comercial da E-TEK com $25 \mathrm{~cm}^{2}$ de área eletródica, com tinta catalítica aplicada sobre o tecido de carbono com $0,4 \mathrm{mgPt} . \mathrm{cm}^{-2}$ no anodo e $0,6 \mathrm{mgPt} . \mathrm{cm}^{-2}$ no catodo (Pt/C comercial da E-TEK), utilizando membrana de Nafion ${ }^{\circledR} 105$, em várias correntes de operação com Metanol $/ \mathrm{O}_{2}$. Temperaturas: célula a $100{ }^{\circ} \mathrm{C}$ e umidificador a $90{ }^{\circ} \mathrm{C}$.

Observa-se nos diagramas de Nyquist da FIGURA 60, FIGURA 61 e FIGURA 62, que as resistências dos MEAs obtidos nos diagramas de Nyquist, estão diretamente correlacionadas com as correntes de operação da célula, e quanto maior a corrente de operação, menor a resistência total dos MEAs. Os diagramas de Nyquist a altas freqüências, não apresentaram características indutivas de conexões elétricas. Observou-se também um comportamento exponencial da resistência total do MEA nos diagramas para as correntes abaixo de $3,0 \mathrm{~A}$ ou $120 \mathrm{~mA} \cdot \mathrm{cm}^{-2}$. Este comportamento pode ser explicado pelo grande arco capacitivo proveniente do metanol adsorvido no MEA a baixas densidades de corrente. 

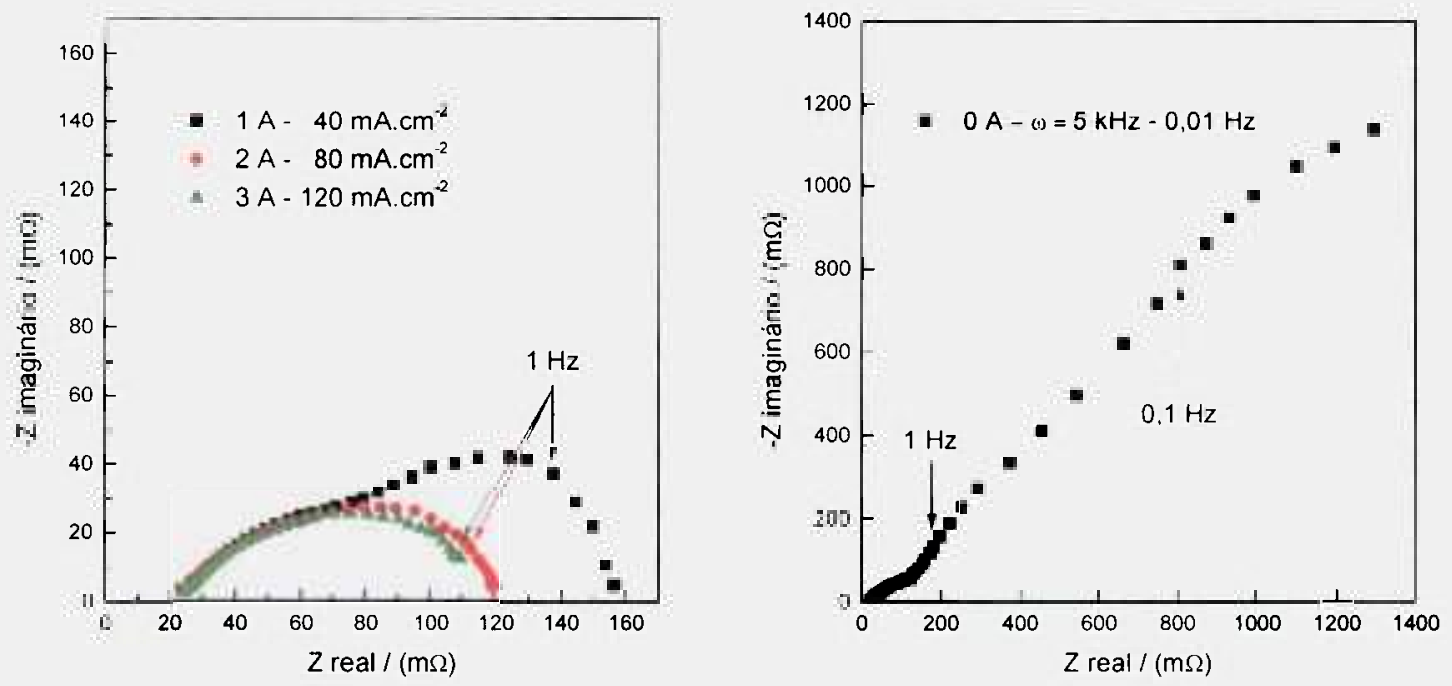

FIGURA 61 - Diagramas de Nyquist, para MEA PtSn/C MRA com $25 \mathrm{~cm}^{2}$ de área

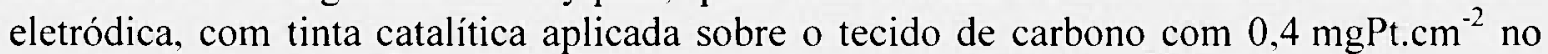
anodo e $0,6 \mathrm{mgPt} . \mathrm{cm}^{-2}$ no catodo (Pt/C comercial da E-TEK), utilizando membrana de Nafion $^{\sqrt{B}} 105$, em várias correntes de operação com Metanol/ $/ \mathrm{O}_{2}$. Temperaturas: célula a $100{ }^{\circ} \mathrm{C}$ e umidificador a $90^{\circ} \mathrm{C}$.
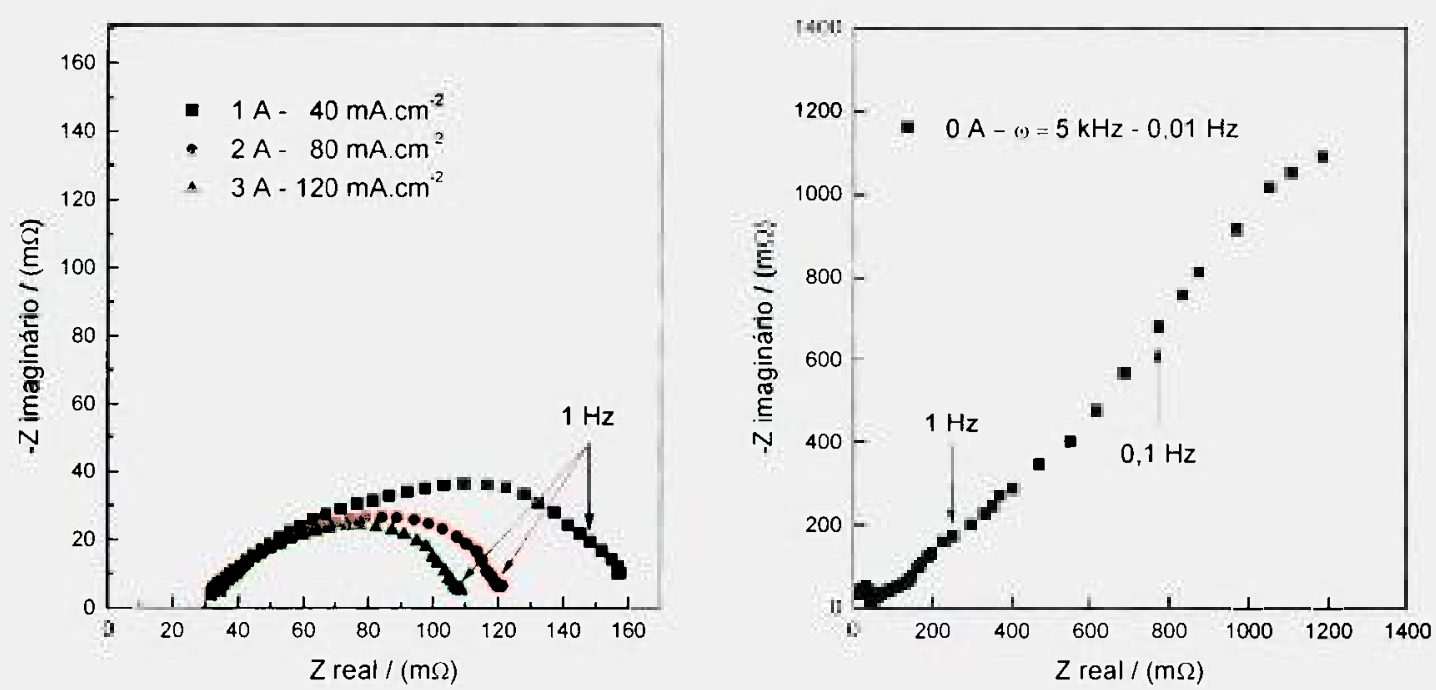

FIGURA 62 - Diagramas de Nyquist, para MEA $\mathrm{Pt}_{50} \mathrm{Sn}_{40} \mathrm{Ni}_{10} / \mathrm{C}$ MRA $20 \%$ com $25 \mathrm{~cm}^{2}$ de área eletródica, com tinta catalítica aplicada sobre o tecido de carbono com $0,4 \mathrm{mgPt} . \mathrm{cm}^{-2}$ no anodo e $0,6 \mathrm{mgPt} . \mathrm{cm}^{-2}$ no catodo (Pt/C comercial da E-TEK), utilizando membrana de Nafion $^{\mathbb{B}} 105$, em várias correntes de operação com $\mathrm{Metanol} / \mathrm{O}_{2}$. Temperaturas: célula a $100^{\circ} \mathrm{C}$ e umidificador a $90^{\circ} \mathrm{C}$. 
Os diagramas de Nyquist do eletrocatalisador PtRu/C comercial da E-TEK apresentaram diferentes características. Para 120 e $160 \mathrm{~mA} . \mathrm{cm}^{-2}$ nota-se somente um semicírculo, relacionado a cinética de eletrooxidação do metanol, já para 40 e $80 \mathrm{~mA} \cdot \mathrm{cm}^{-2}$ notam-se dois semicírculos, um a altas freqüências, que está relacionado a cinética de eletrooxidação do metanol e um a baixas freqüências, que está relacionado a transferência de massa de oxigênio. Esta transferência de massa está relacionada ao crossover do metanol pela membrana que, entre outros fenômenos, bloqueia (por adsorção específica) os sítios de platina, gerando bolhas de $\mathrm{CO}_{2}$ por oxidação, que dificultam a chegada de oxigênio aos sítios ativos de platina no catodo ${ }^{[7,90,96]}$ (ver detalhes no capítulo 6.4). Já para o eletrocatalisador PtSn/C MRA notam-se dois semicírculos somente para $40 \mathrm{~mA} . \mathrm{cm}^{-2}$. Para o eletrocatalisador $\mathrm{Pt}_{50} \mathrm{Sn}_{40} \mathrm{Ni}_{10} / \mathrm{C}$ MRA nota-se somente um semicírculo em todos os diagramas de Nyquist. Decorre-se desta observação que os eletrocatalisadores provenientes do MRA obtiveram os melhores resultados na oxidação de metanol.

Um possível modelo proposto neste trabalho que representa os elementos presentes na célula e as reações envolvidas no anodo e no catodo é mostrado na FIGURA 63. Utilizou-se este modelo de circuito elétrico para comparar os valores analisados diretamente na célula. Na FIGURA 64, FIGURA 65 e a FIGURA 66, estão apresentados os ajustes $(F I T)$ gerados a partir do modelo apresentado na FIGURA 63 para os eletrocatalisadores PtRu/C comercial da E-TEK, PtSn/C MRA e Pt ${ }_{50} \mathrm{Sn}_{40} \mathrm{Ni}_{10} / \mathrm{C}$ MRA, respectivamente.

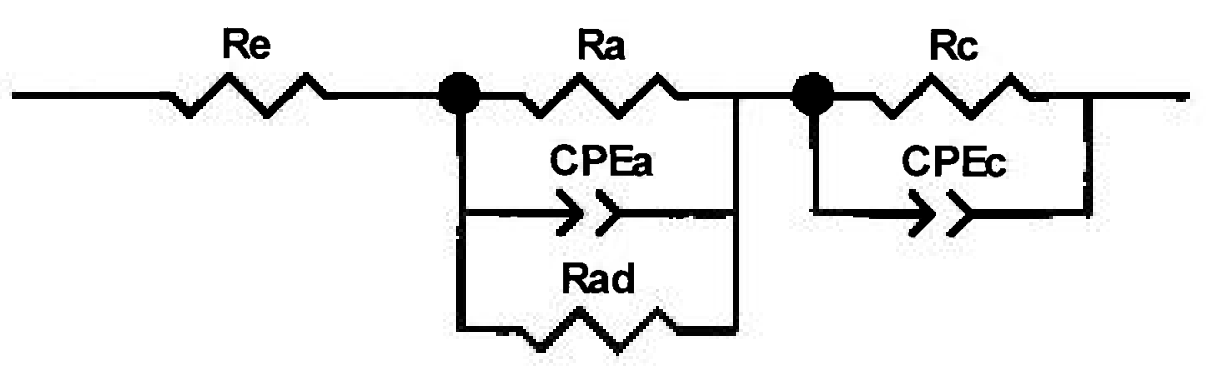

FIGURA 63 - Modelo proposto de circuito elétrico para EIE "on-line" em operação com Metanol/O $/$.

O modelo escolhido apresenta 3 partes distintas, a saber:

1) Re: Resistência em série que representa a resistência ôhmica do eletrólito, ou seja, a membrana de Nafion ${ }^{(B)} 105$. 
2) $\mathrm{Ra}, \mathrm{CPEa}$ e Rad: Colocados em paralelo, representando as resistências do processo de transferência de carga envolvida no anodo (resistênçia ao fluxo de metanol ao atravessar o GDL e permear na tinta eletrocatalítica), da dupla camada elétrica da reação de oxidação de metanol, e do processo de adsorção e dehidrogenação de metanol nas nanopartículas do eletrocatalisador, respectivamente.

3) Rc e CPEc: Colocados em paralelo, representando as resistências do processo de transferência de carga envolvida no catodo (resistência ao fluxo de oxigênio ao atravessar o GDL e permear na tinta eletrocatalítica) e da dupla camada elétrica na interface da reação de redução de oxigênio, respectivamente.

Os processos de adsorção e dehidrogenação de metanol nas nanopartículas do eletrocatalisador podem ser descritos pelas equações abaixo:

$$
\begin{aligned}
\left(\mathrm{CH}_{3} \mathrm{OH}\right)_{s o l} & \rightarrow\left(\mathrm{CH}_{3} \mathrm{OH}\right)_{a d s} \\
\left(\mathrm{CH}_{3} \mathrm{OH}\right)_{a d s} & \rightarrow \mathrm{CO}_{a d s}+4 \mathrm{H}^{+}+4 e^{-} \\
\mathrm{H}_{2} \mathrm{O} & \rightarrow(\mathrm{OH})_{a d s}+\mathrm{H}^{+}+e^{-} \\
(\mathrm{CO})_{a d s}+(\mathrm{OH})_{a d s} & \rightarrow \mathrm{CO}_{2}+\mathrm{H}^{+}+e^{-} \\
\hline \mathrm{CH}_{3} \mathrm{OH}+\mathrm{H}_{2} \mathrm{O} & \rightarrow \mathrm{CO}_{2}+6 \mathrm{H}^{+}+6 e^{-}
\end{aligned}
$$

Este processo representa um mecanismo geralmente aceito para a reação de eletrooxidação de metanol em $\mathrm{PtRu} / \mathrm{C}^{[42,131,132]}$. A reação de dehidrogenação do metanol, equação 75, é realizada em um processo multi-etapas, com uma ou mais espécies geradas. Entretanto, somente as espécies $(\mathrm{CO})_{\text {ads }}$ são detectadas pela espectroscopia de impedância eletroquímica, implicando provavelmente que os outros intermediários presentes na superfície do eletrocatalisador têm um tempo de vida muito curto para ser detectado pela técnica. 


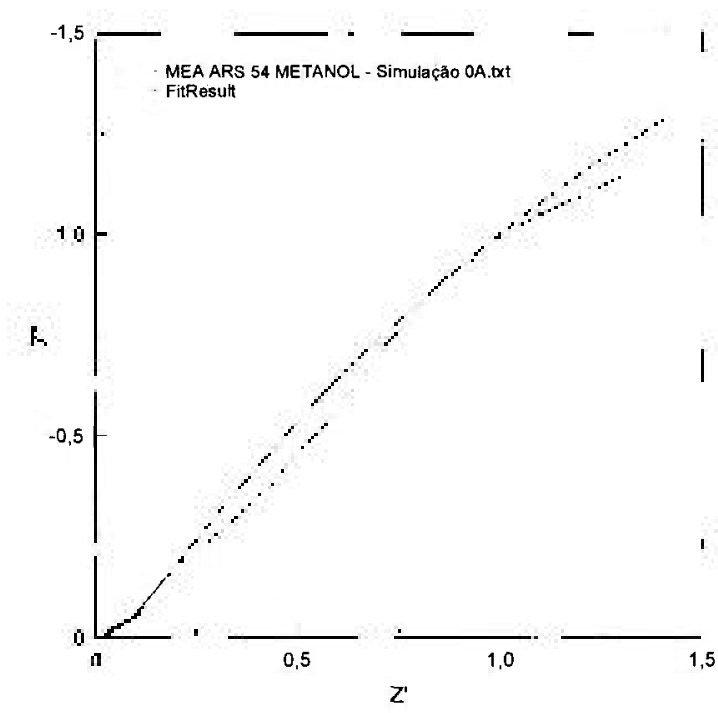

a)
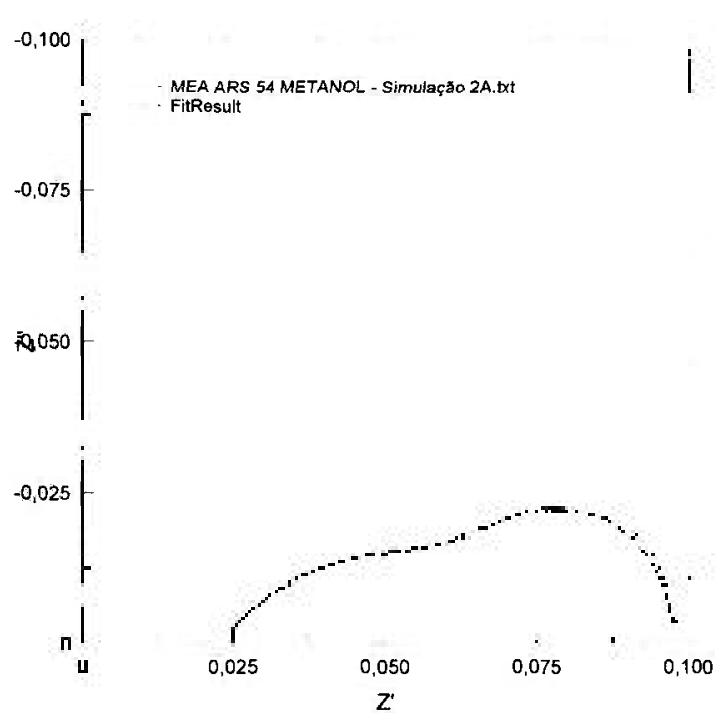

c)

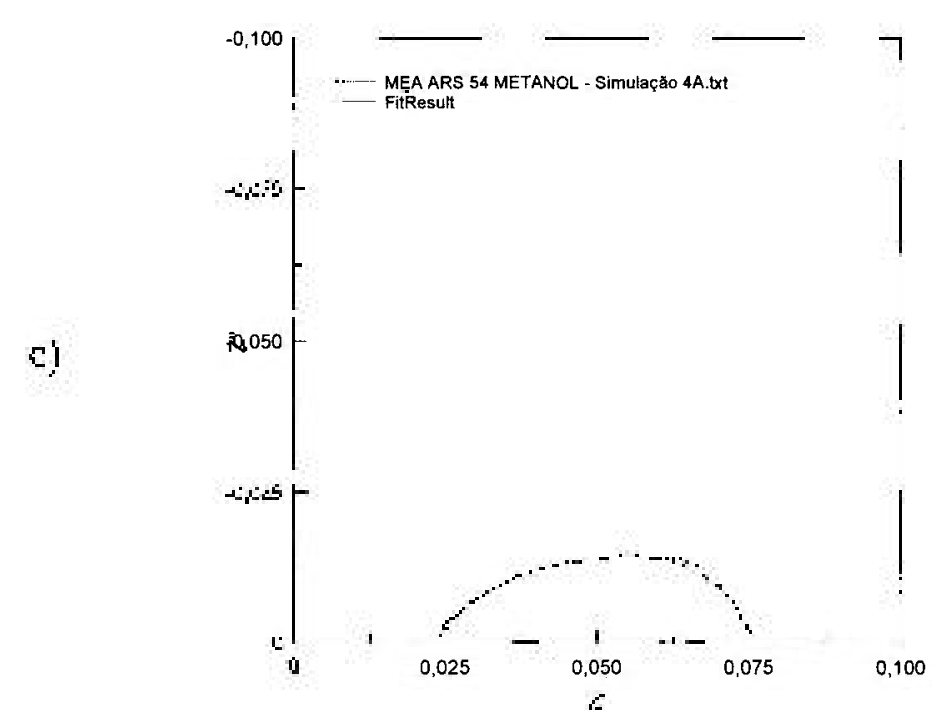

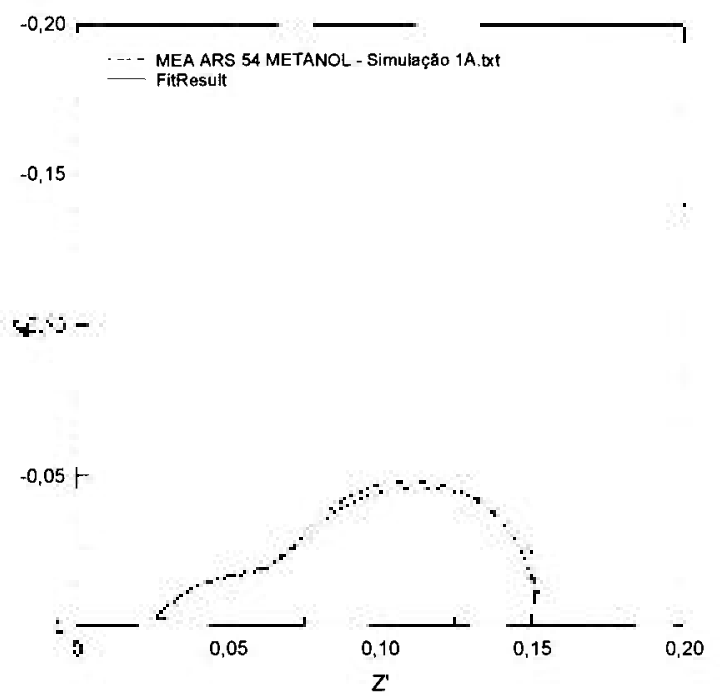

b)

$+4$ - MEA ARS 54 METANOL - Simulaçăo 3A.txt
FitResult $-0,075 \vdash$ 和050 个 $-0,025 \vdash$

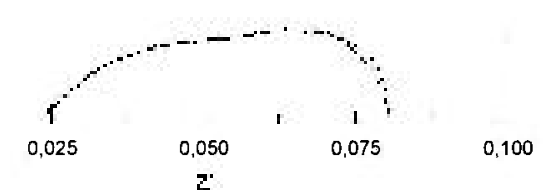

d) 


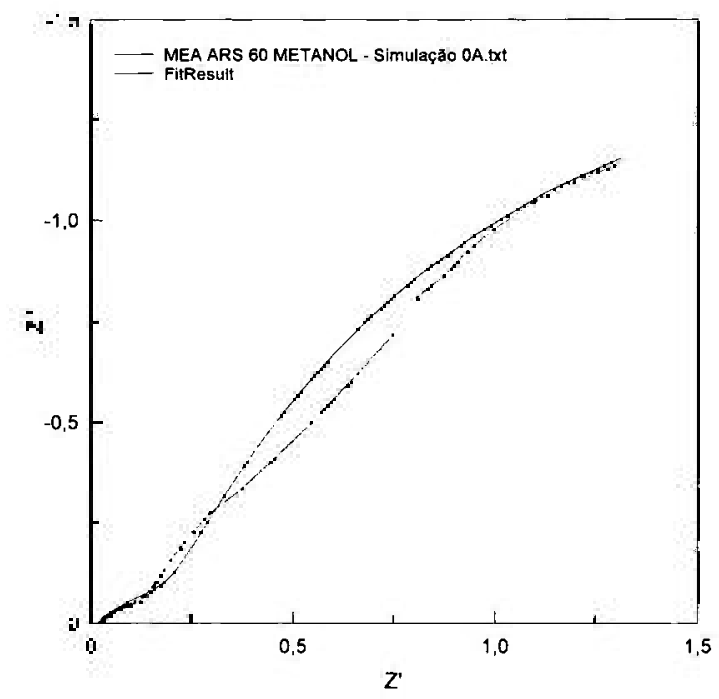

a)

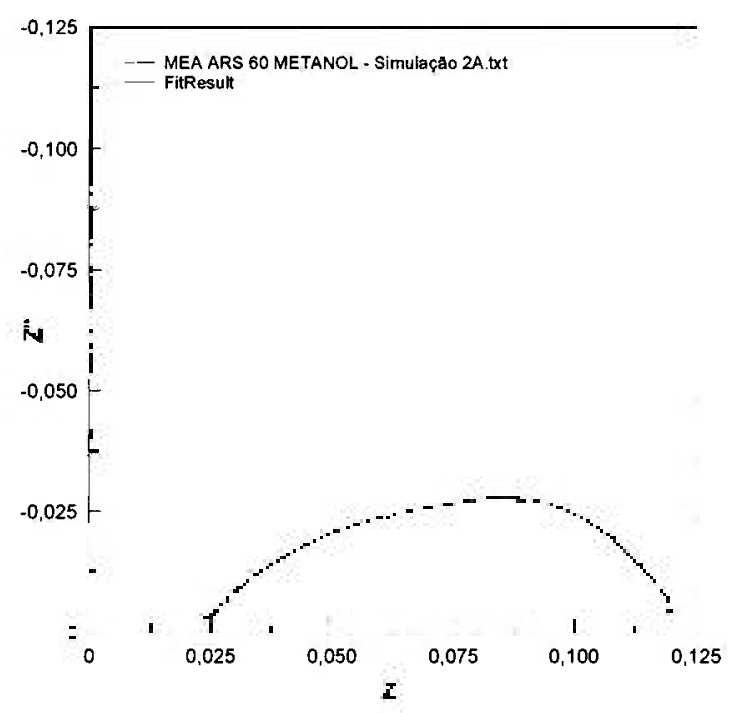

c)

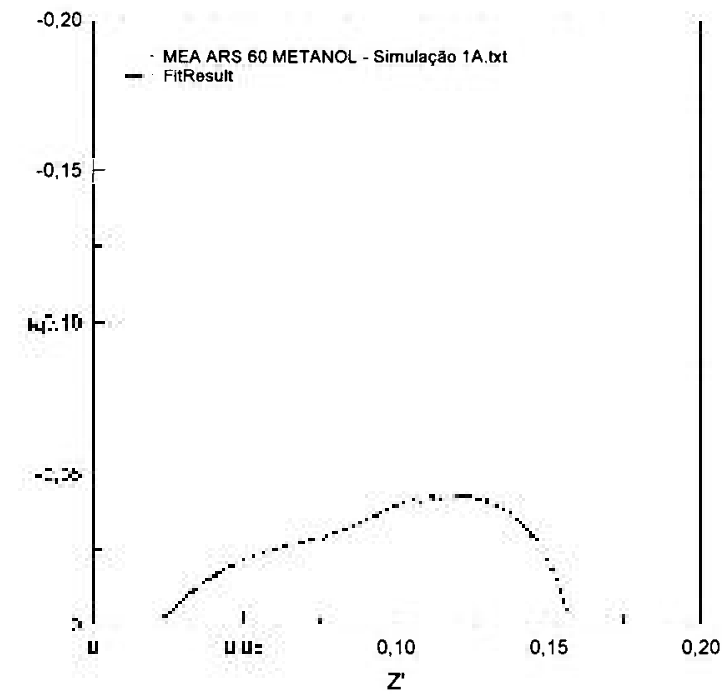

b)

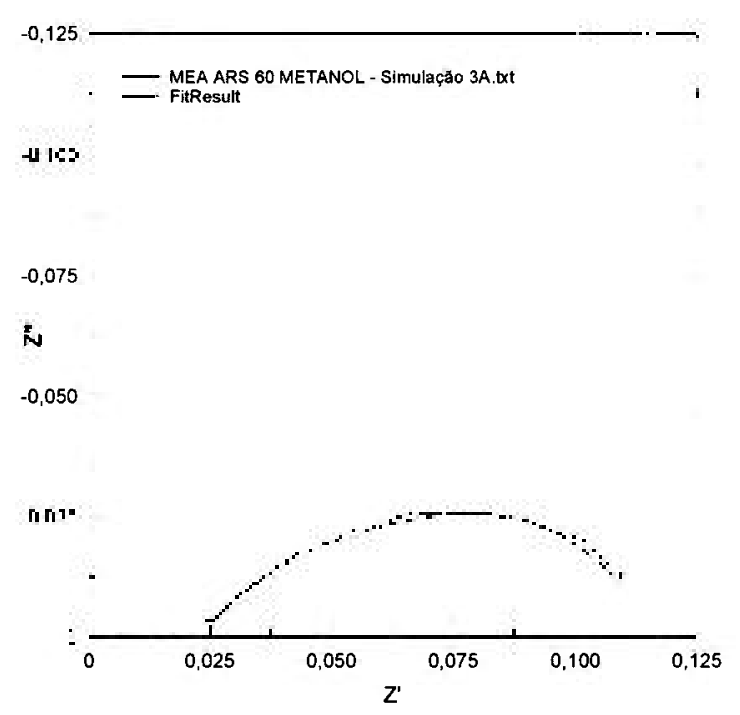

d)

FIGURA 65 - Diagrama de Nyquist para PtSn/C MRA, operando com Metanol/O 2 . a) $0 \mathrm{~A}-0 \mathrm{~mA} \cdot \mathrm{cm}^{-2}$, b) $1 \mathrm{~A}-40 \mathrm{~mA} \cdot \mathrm{cm}^{-2}$, c) $2 \mathrm{~A}-80 \mathrm{~mA} \cdot \mathrm{cm}^{-2}$, d) $3 \mathrm{~A}-120 \mathrm{~mA} \cdot \mathrm{cm}^{-2}$. 


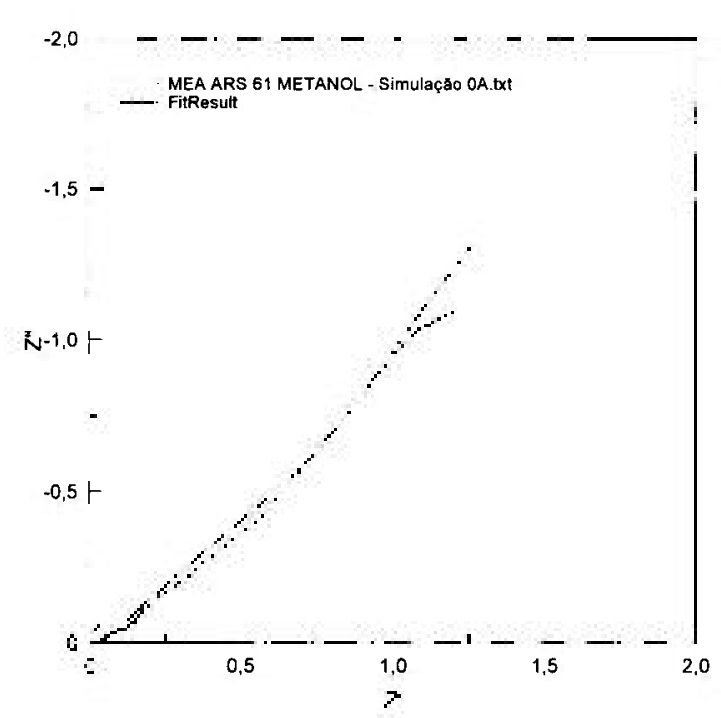

a)

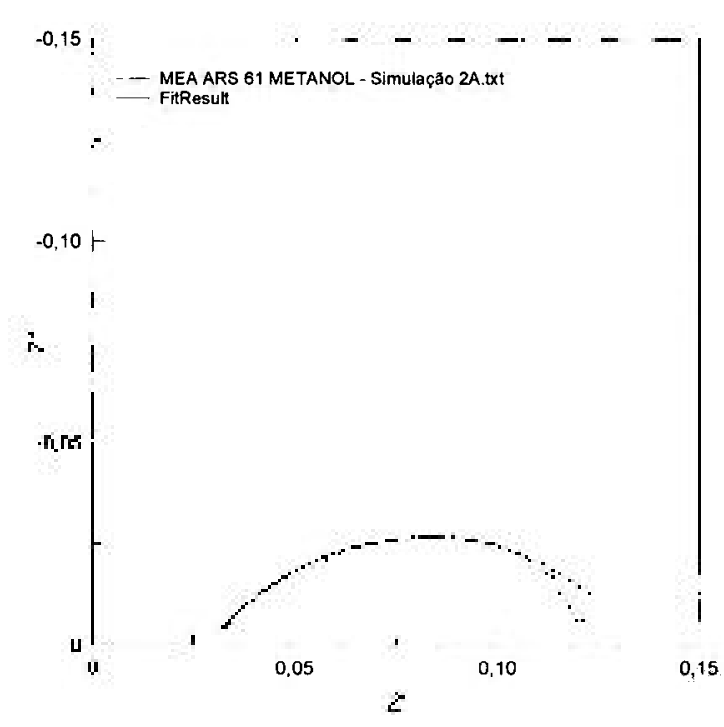

c)

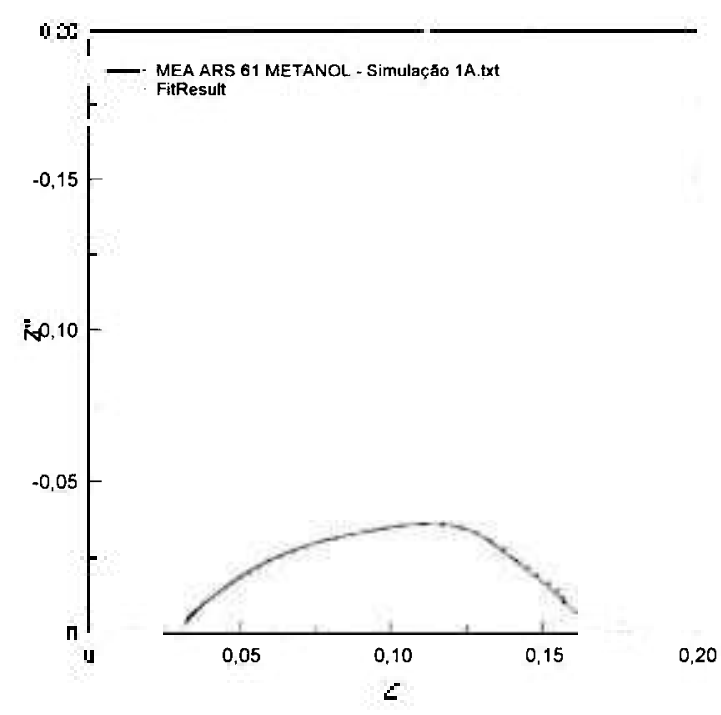

b)

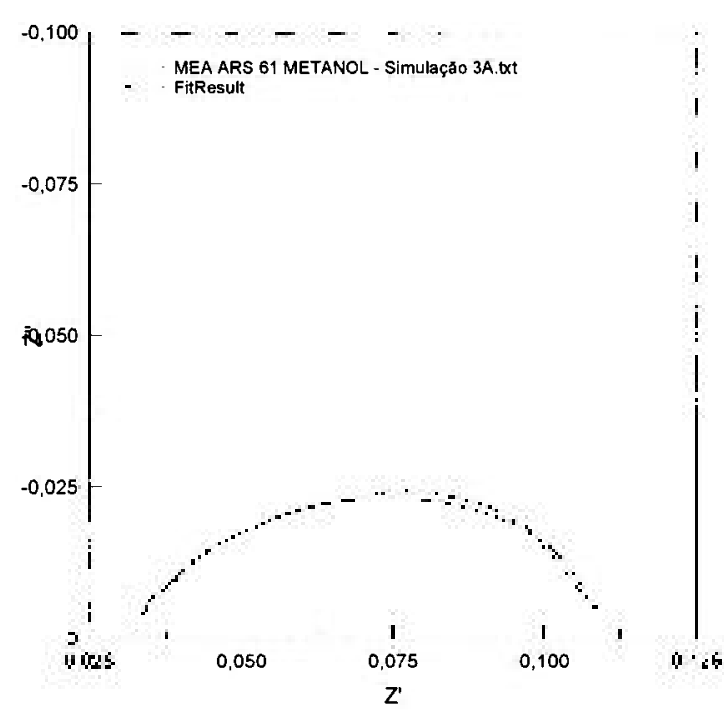

d)

FIGURA 66 - Diagrama de Nyquist para $\mathrm{Pt}_{50} \mathrm{Sn}_{40} \mathrm{Ni}_{10} / \mathrm{C}$ MRA, operando com Metanol/O $\mathrm{O}_{2}$. a) $0 \mathrm{~A}-0 \mathrm{~mA} \cdot \mathrm{cm}^{-2}$, b) $1 \mathrm{~A}-40 \mathrm{~mA} \cdot \mathrm{cm}^{-2}$, c) $2 \mathrm{~A}-80 \mathrm{~mA} \cdot \mathrm{cm}^{-2}$, d) $3 \mathrm{~A}-120 \mathrm{~mA} \cdot \mathrm{cm}^{-2}$.

Observando os diagramas experimentais de Nyquist e os diagramas de Nyquist gerados pela simulação, observou-se uma coerência na escolha do modelo do circuito elétrico para os MEAs utilizando $\mathrm{Metanol} / \mathrm{O}_{2}$, visto que o comportamento do diagrama gerado pela simulação está, para quase toda a totalidade do diagrama, sobre o diagrama experimental. Esta coerência indica que outras resistências não consideradas no modelo, como por exemplo, resistências de contato, a resistência da porosidade dos eletrodos e a 
impedância de difusão, não são relevantes na resistência total dos MEAs em operação com metanol.

Na TABELA 7 estão os valores da simulação do circuito elétrico para os diagramas de Nyquist dos MEAs testados com Metanol/ $\mathrm{O}_{2}$.

TABELA 7 - Valores dos elementos componentes do circuito elétrico para os MEAs da FIGURA 64, 65 e 66.

\begin{tabular}{|c|c|c|c|c|c|}
\hline & & $\begin{array}{c}\mathbf{I}=\mathbf{0} \mathbf{A} \\
\mathbf{i}=0 \mathrm{~mA} \cdot \mathrm{cm}^{-2}\end{array}$ & $\begin{array}{c}\mathbf{I}=\mathbf{1} \mathbf{A} \\
\mathbf{i}=40 \mathrm{~mA} \cdot \mathrm{cm}^{-2}\end{array}$ & $\begin{array}{c}I=2 A \\
i=80 \mathrm{~mA} \cdot \mathrm{cm}^{-2}\end{array}$ & $\begin{array}{c}\mathbf{I}=\mathbf{3} \mathbf{A} \\
\mathbf{i}=120 \mathrm{~mA} \cdot \mathrm{cm}^{-2}\end{array}$ \\
\hline \multirow{8}{*}{ 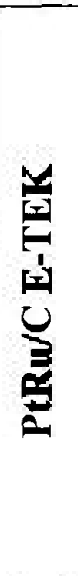 } & $\operatorname{Re}[\mathrm{m} \Omega]$ & 32,11 & 35,08 & 23,14 & 22,91 \\
\hline & $\mathrm{Ra}[\mathrm{m} \Omega]$ & 12,10 & 11,06 & 10,79 & 9,84 \\
\hline & $\mathrm{CPEa}[\mathrm{F}]$ & 1,33 & 0,67 & 0,89 & 0,77 \\
\hline & CPEa Exp. & 0,52 & 0,64 & 0,58 & 0,61 \\
\hline & $\operatorname{Rad}[\mathrm{m} \Omega]$ & 107,07 & 55,71 & 45,43 & 39,77 \\
\hline & $\mathrm{Rc}[\mathrm{m} \Omega]$ & 71,80 & 49,76 & 18,90 & 9,98 \\
\hline & $\mathrm{CPEc}[\mathrm{F}]$ & 1,68 & 1,46 & 1,69 & 1,75 \\
\hline & CPEc Exp. & 0,63 & 1,00 & 1,00 & 1,00 \\
\hline \multirow{8}{*}{ 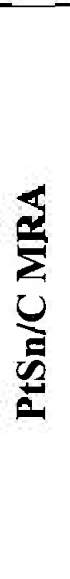 } & $\operatorname{Re}[\mathrm{m} \Omega]$ & 26,31 & 22,43 & 22,51 & 23,15 \\
\hline & $\mathrm{Ra}[\mathrm{m} \Omega]$ & 14,24 & 15,35 & 13,97 & 13,06 \\
\hline & $\mathrm{CPEa}[\mathrm{F}]$ & 0,87 & 0,69 & 0,91 & $0, \overline{92}$ \\
\hline & CPEa Exp. & 0,59 & 0,60 & 0,59 & 0,58 \\
\hline & $\operatorname{Rad}[\mathrm{m} \Omega]$ & 131,80 & 74,01 & 66,41 & 56,63 \\
\hline & $\mathrm{Rc}[\mathrm{m} \Omega]$ & 76,88 & 42,21 & 21,24 & 19,16 \\
\hline & CPEc $[\mathrm{F}]$ & 3,47 & 1,45 & 2,41 & 2,43 \\
\hline & CPEc Exp. & 0,78 & 1,00 & 1,00 & 1,00 \\
\hline \multirow{8}{*}{ 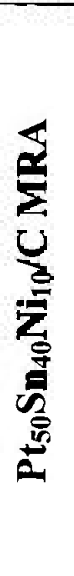 } & $\operatorname{Re}[\mathrm{m} \Omega]$ & 31,68 & 29,09 & 28,60 & 30,09 \\
\hline & $\mathrm{Ra}[\mathrm{m} \Omega]$ & 13,76 & 15,97 & 13,79 & 11,51 \\
\hline & $\mathrm{CPEa}[\mathrm{F}]$ & $0, \overline{53}$ & 1,00 & 1,00 & 0,53 \\
\hline & CPEa Exp. & 1,32 & 1,42 & 1,51 & 0,61 \\
\hline & $\operatorname{Rad}[\mathrm{m} \Omega]$ & 137,00 & 70,15 & 63,94 & 51,33 \\
\hline & $\operatorname{Rc}[\mathrm{m} \Omega]$ & 73,91 & 43,08 & 20,65 & 17,60 \\
\hline & CPEc [F] & 1,73 & 0,65 & 0,33 & 0,48 \\
\hline & CPEc Exp. & 0,50 & 0,58 & 0,59 & 0,89 \\
\hline
\end{tabular}


Com os valores da resistência de adsorção e transferência de carga no anodo e no catodo da célula presentes na TABELA 7, construiu-se um gráfico comparativo da contribuição destas resistências na operação da célula, mostrado na FIGURA 67.

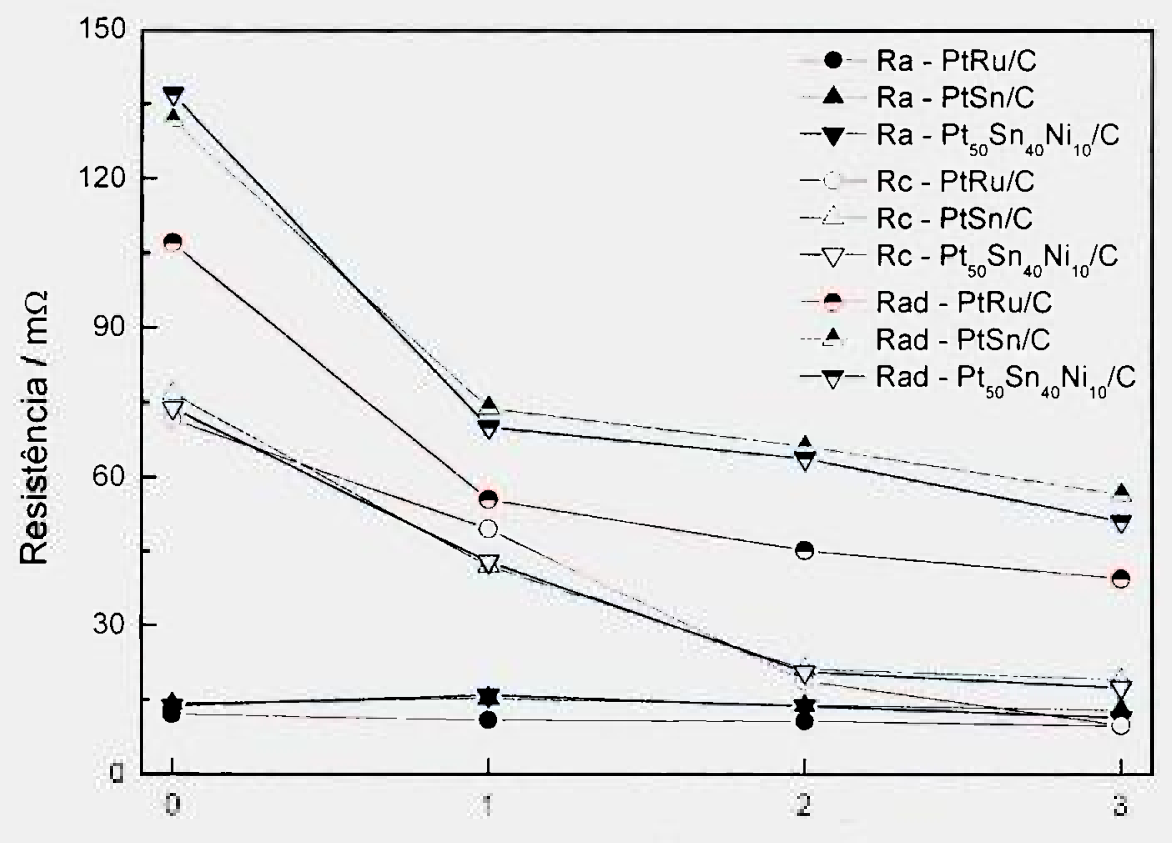

I/A

FIGURA 67 - Variação da resistência de transferência de carga no anodo (símbolo cheio) e no catodo (símbolo vazado), e da resistência de adsorção (símbolos semi vazados) dos MEAs utilizados, sob operação com Metanol/ $\mathrm{O}_{2}$.

Observa-se na FIGURA 67 que a contribuição da resistência de transferência de carga para a reação de oxidação do metanol no anodo é menor que a da redução do oxigênio no catodo para todas as correntes de funcionamento da célula. Entretanto, a contribuição da resistência de adsorção é muito maior que as outras resistências presente na célula, conforme se observa nas equações 17 a 23 no capítulo 3.7.3. Observa-se ainda, que quando a célula está em circuito aberto $(I=0)$ a resistência de adsorção do metanol assume valores muito grandes, em torno de $130 \mathrm{~m} \Omega$. Outra informação importante que se extrai da FIGURA 67 também foi observada por Diard e colaboradores ${ }^{[98]}$. A soma das resistências presentes no anodo (impedância do anodo) é muito maior que a soma das resistências do catodo (impedância do catodo), onde $Z_{A} \gg Z_{C}$ para altas densidades de correntes de operação da célula. Sendo a impedância total de uma DMFC a soma da impedância do anodo e do catodo $\left(Z_{G}=Z_{A}+Z_{C}\right)$, pode-se dizer que a é a impedância da DMFC é dada por $Z_{\mathrm{G}} \approx Z_{\mathrm{A}}$ para altas densidades de correntes. 


\subsubsection{Operação com Etanol/ $\mathrm{O}_{2}$}

Os espectros de EIE foram analisados on-line, ou seja, com a célula a combustível em operação com densidades de correntes de 0 até $48 \mathrm{~mA} . \mathrm{cm}^{-2}$.

$\mathrm{Na}$ FIGURA 68, 69 e 70 estão representados os diagramas de Nyquist da operação on-line de um MEA com $25 \mathrm{~cm}^{2}$ de área eletródica, confeccionado pelo método spray/prensagem ${ }^{[104]}$ a quente com $\mathrm{PtRu} / \mathrm{C}$ comercial da E-TEK, PtSn/C MRA e $\mathrm{Pt}_{50} \mathrm{Sn}_{40} \mathrm{Ni}_{10} / \mathrm{C}$ MRA respectivamente, contendo $0,4 \mathrm{mg} \mathrm{de} \mathrm{Pt.cm}{ }^{-2}$ no anodo e $0,6 \mathrm{mg}$ de Pt.cm ${ }^{-2}$ no catodo, ambos sob operação com Etanol $/ \mathrm{O}_{2}$. A temperatura da célula foi de $100{ }^{\circ} \mathrm{C}$ e do umidificador de $90{ }^{\circ} \mathrm{C}$.

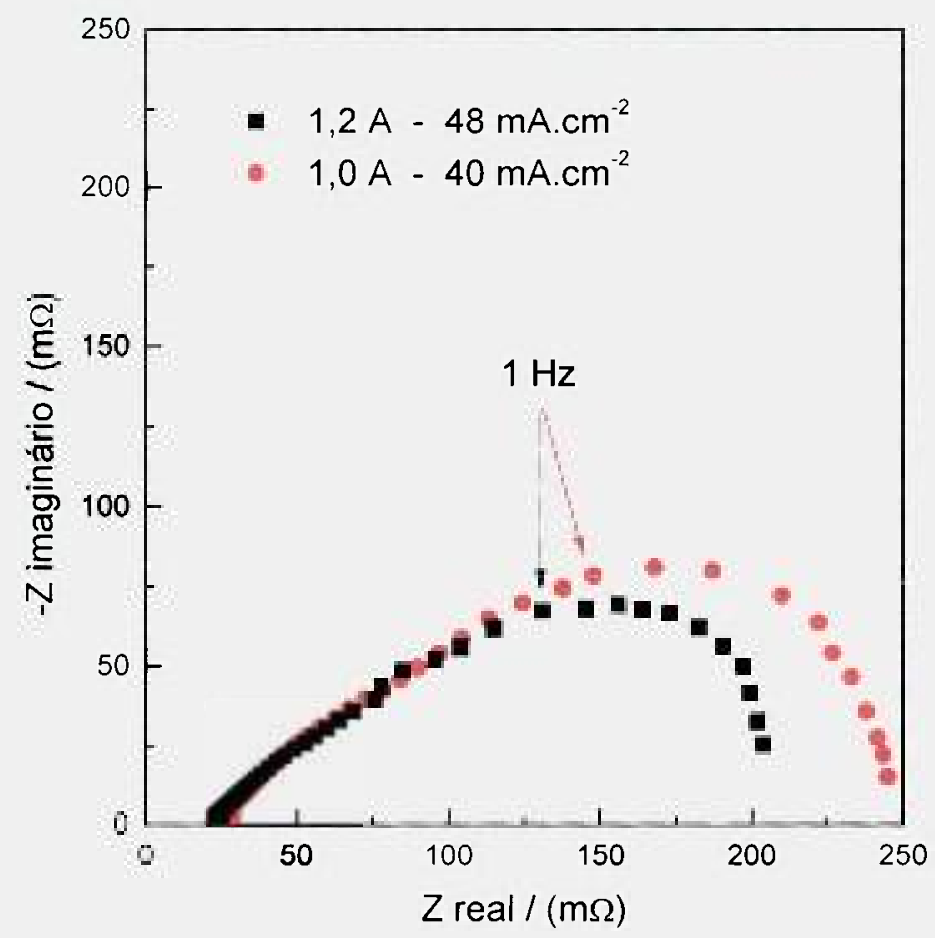

FIGURA 68 - Diagramas de Nyquist, para MEA PtRu/C comercial da E-TEK com $25 \mathrm{~cm}^{2}$ de área eletródica, com tinta catalítica aplicada sobre o tecido de carbono com $0,4 \mathrm{mgPt} . \mathrm{cm}^{-2}$ no anodo e $0,6 \mathrm{mgPt} . \mathrm{cm}^{-2}$ no catodo (Pt/C comercial da E-TEK), utilizando membrana de Nafion ${ }^{\mathbb{B}} 105$, em várias correntes de operação com Etanol $/ \mathrm{O}_{2}$. Temperaturas: célula a $100{ }^{\circ} \mathrm{C}$ e umidificador a $90{ }^{\circ} \mathrm{C}$. 

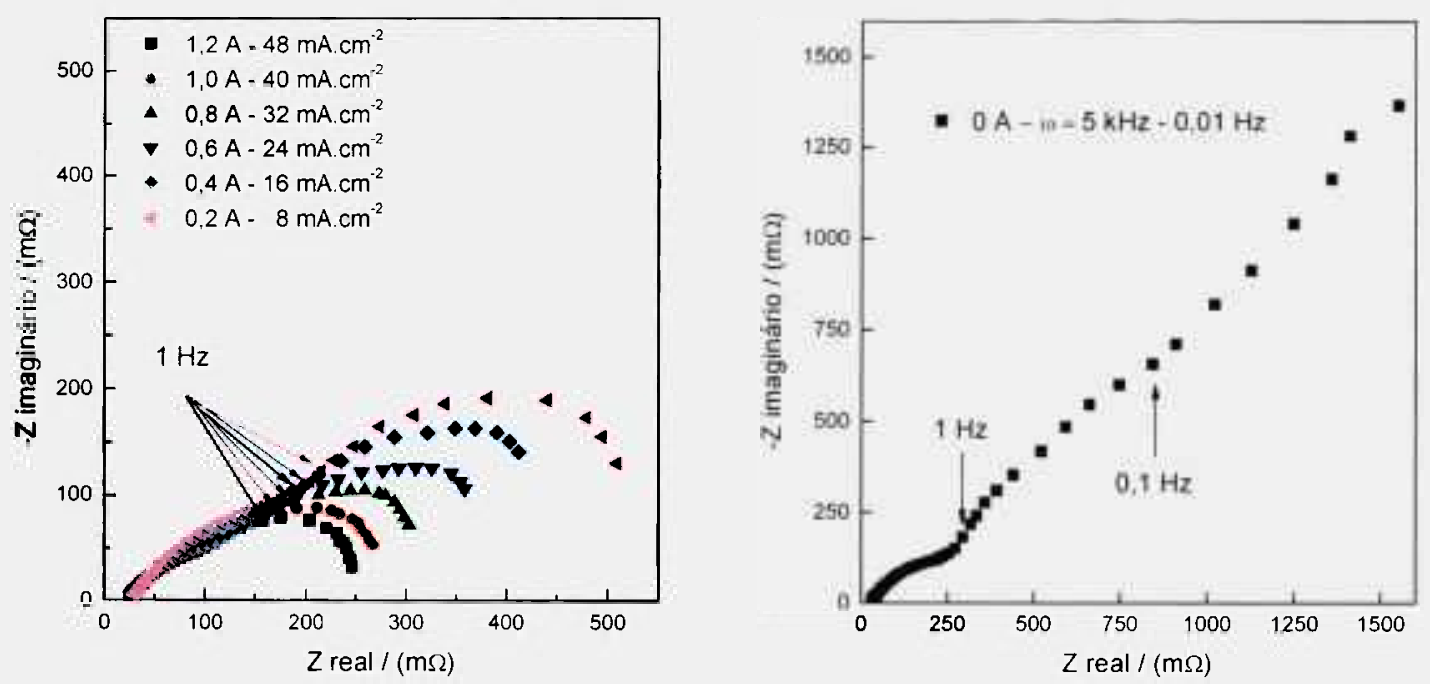

FIGURA 69 - Diagramas de Nyquist, para MEA PtSn/C MRA com $25 \mathrm{~cm}^{2}$ de área eletródica, com tinta catalítica aplicada sobre o tecido de carbono com $0,4 \mathrm{mgPt} . \mathrm{cm}^{-2}$ no anodo e $0,6 \mathrm{mgPt}_{\mathrm{cm}} \mathrm{cm}^{-2}$ no catodo (Pt/C comercial da E-TEK), utilizando membrana de Nafion $^{\circledR} 105$, em várias correntes de operação com Etanol $/ \mathrm{O}_{2}$. Temperaturas: célula a $100{ }^{\circ} \mathrm{C}$ e umidificador a $90{ }^{\circ} \mathrm{C}$.
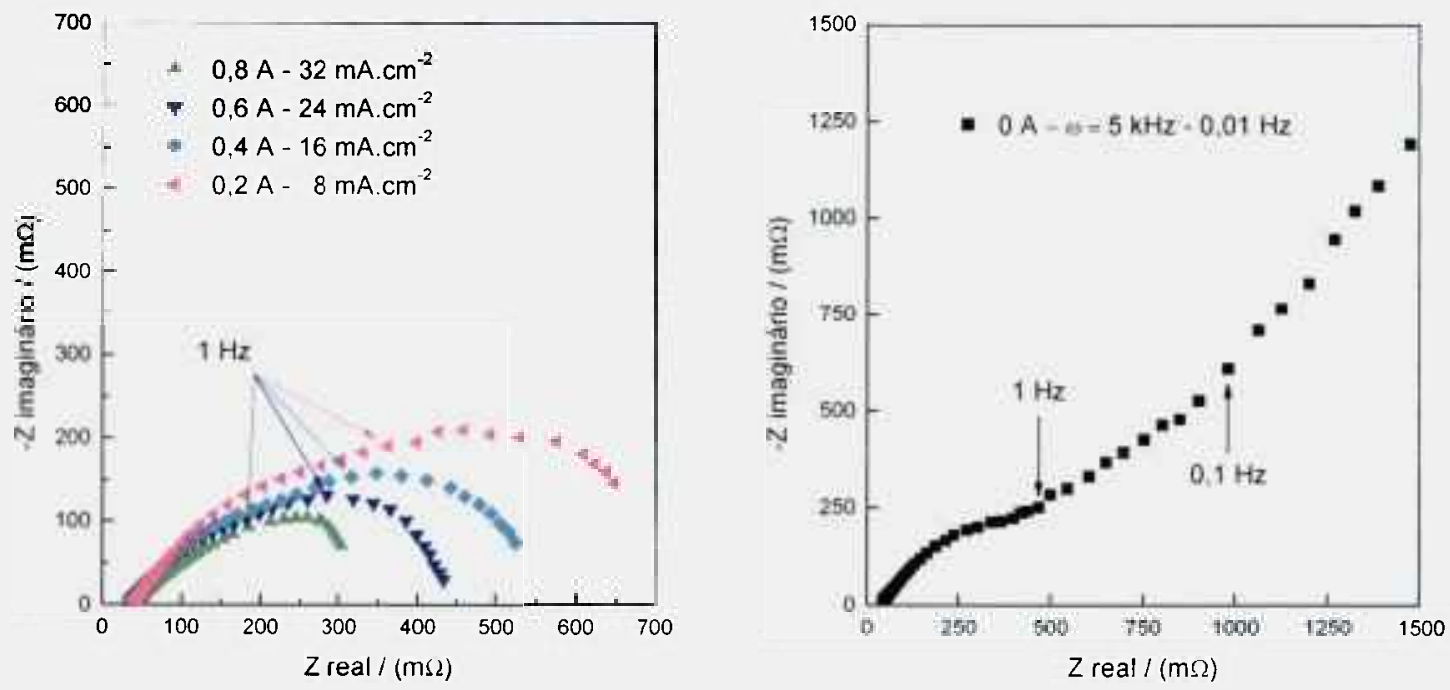

FIGURA 70 - Diagramas de Nyquist, para MEA $\mathrm{Pt}_{50} \mathrm{Sn}_{40} \mathrm{Ni}_{10} / \mathrm{C}$ MRA com $25 \mathrm{~cm}^{2}$ de área eletródica, com tinta catalítica aplicada sobre o tecido de carbono com $0,4 \mathrm{mgPt} . \mathrm{cm}^{-2}$ no anodo e $0,6 \mathrm{mgPt} . \mathrm{cm}^{-2}$ no catodo (Pt/C comercial da E-TEK), utilizando membrana de Nafion $^{\mathbb{R}} 105$, em várias correntes de operação com Etanol/ $\mathrm{O}_{2}$. Temperaturas: célula a $100{ }^{\circ} \mathrm{C}$ e umidificador a $90^{\circ} \mathrm{C}$. 
Observa-se nos diagramas de Nyquist da FIGURA 68, FIGURA 69 e FIGURA 70, que as resistências dos MEAs obtidos nos diagramas de Nyquist, estão diretamente correlacionadas com as correntes de operação da célula, e quanto maior a corrente de operação, menor a resistência total dos MEAs. Observa-se também um comportamento exponencial dos arcos do diagrama para as correntes abaixo de $0,4 \mathrm{~A}$ ou $16 \mathrm{~mA} \cdot \mathrm{cm}^{-2}$. Este comportamento é devido a uma grande resistência capacitiva proveniente do etanol adsorvido no MEA a baixas densidades de corrente. Os diagramas de Nyquist a altas freqüências, não apresentam características indutivas de conexões elétricas.

Os diagramas de Nyquist do eletrocatalisador PtSn/C MRA apresentaram diferentes características. Para 1,2 e $1,0 \mathrm{~A} . \mathrm{cm}^{-2}$ nota-se somente um semicírculo relacionado à cinética de eletrooxidação do etanol. Entretanto, para 0,$8 ; 0,6 ; 0,4$ e $0,2 \mathrm{~mA} \cdot \mathrm{cm}^{-2}$ notam-se dois semicírculos, um a altas freqüências, que está relacionado à cinética de eletrooxidação do etanol e um a baixas freqüências, que está relacionado à transferência de massa de oxigênio. Mais uma vez, esta transferência de massa é afetada pelo crossover do etanol pela membrana, que bloqueia (por adsorção específica) os sítios de platina, gerando bolhas de $\mathrm{CO}_{2}$, que dificultam a chegada de oxigênio aos sítios ativos de platina no catodo, analogamente a operação com metanol. Já para $\mathrm{Pt}_{50} \mathrm{Sn}_{40} \mathrm{Ni}_{10} / \mathrm{C} \mathrm{MRA}$ nota-se somente um semicírculo nos diagramas de Nyquist. Assim, conclui-se que os eletrocatalisadores provenientes do MRA geraram os melhores resultados para a oxidação de etanol.

Um possível modelo, proposto neste trabalho, que representa os elementos presentes na célula e as reações envolvidas no anodo e no catodo é mostrado na FIGURA 71. Utilizou-se este modelo de circuito elétrico para comparar os valores analisados diretamente na célula. Na FIGURA 72, FIGURA 73 e a FIGURA 74, estão apresentados os ajustes (FIT) gerados a partir do modelo apresentado na FIGURA 71 para os eletrocatalisadores PtRu/C comercial da E-TEK, PtSn/C MRA e $\mathrm{Pt}_{50} \mathrm{Sn}_{40} \mathrm{Ni}_{10} / \mathrm{C} \mathrm{MRA}$, respectivamente. 


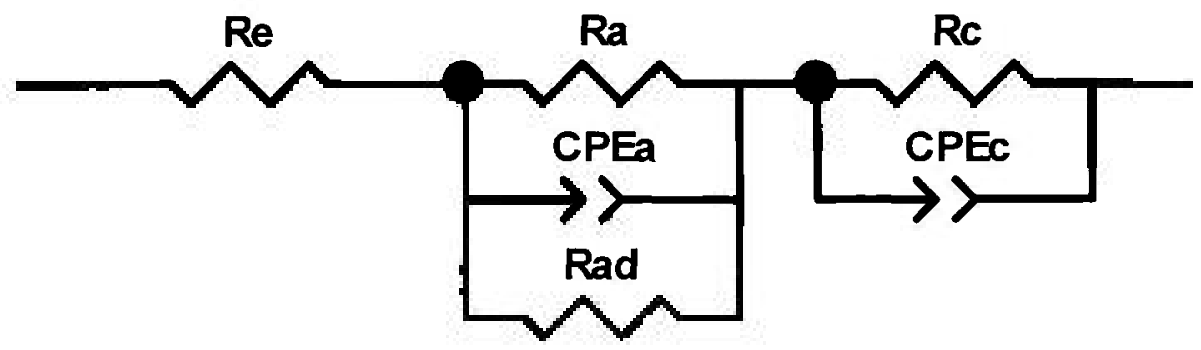

FIGURA 71 - Modelo proposto de circuito elétrico para EIE "on-line" em operação com Etanol $/ \mathrm{O}_{2}$.

Este modelo apresenta 3 partes distintas, a saber:

1) Re: Resistência em série que representa a resistência ôhmica do eletrólito, ou seja, a membrana de Nafion $\left.^{(}\right) 105$.

2) $\mathrm{Ra}, \mathrm{CPEa}$ e Rad: Colocados em paralelo, representando as resistências do processo de transferência de carga envolvida no anodo (resistência ao fluxo de etanol ao atravessar o GDL e permear na tinta eletrocatalítica), da dupla camada elétrica da reação de oxidação de etanol, e do processo de adsorção e dehidrogenação de etanol (como mostra o esquema 2, página 22) nas nanopartículas do eletrocatalisador, respectivamente.

3) Rc e CPEc: Colocados em paralelo, representando as resistências do processo de transferência de carga envolvida no catodo (resistência ao fluxo de oxigênio ao atravessar o GDL e permear na tinta eletrocatalítica) e da dupla camada elétrica na interface da reação de redução de oxigênio, respectivamente.

Observando os diagramas experimentais de Nyquist e os diagramas de Nyquist gerados pela simulação, observou-se uma coerência na escolha do modelo do circuito elétrico para os MEAs utilizando Etanol/O $/ \mathrm{O}_{2}$, visto que o comportamento do diagrama gerado pela simulação está, para quase toda a totalidade do diagrama, sobre o diagrama experimental. Esta coerência indica que outras resistências não consideradas no modelo, como por exemplo, a resistência de contato, a resistência da porosidade dos eletrodos e a impedância de difusão, não são relevantes na resistência total dos MEAs em operação com etanol.

Na TABELA 8 estão os valores da simulação do circuito elétrico para os diagramas de Nyquist dos MEAs testados com Etanol/ $\mathrm{O}_{2}$. 


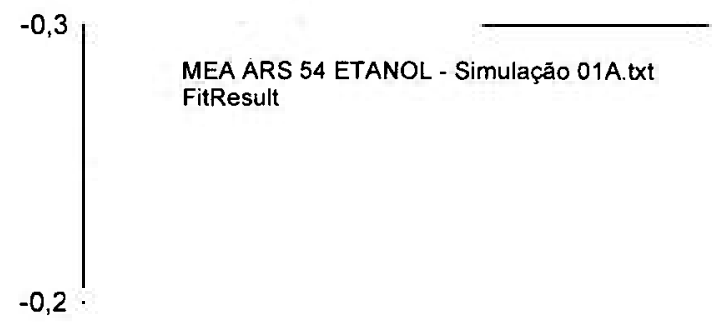

iv

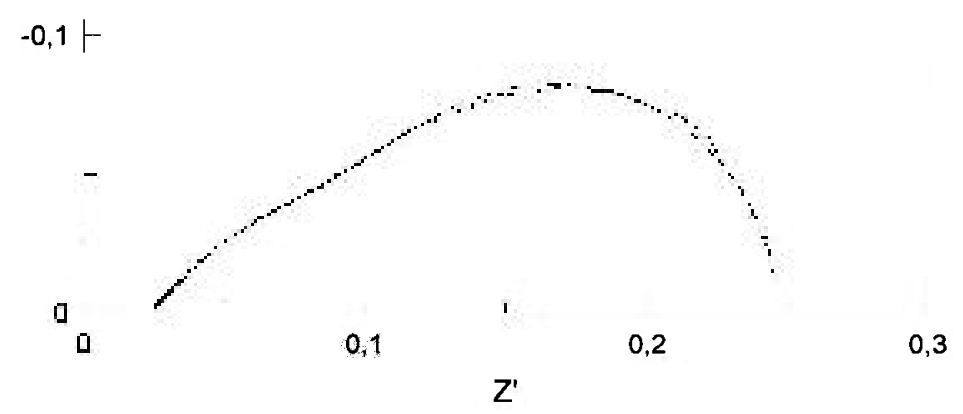

FIGURA 72 - Diagrama de Nyquist para PtRu/C comercial da E-TEK, operando com Etanol $/ \mathrm{O}_{2}$ a 1,0 A - 40 mA.cm ${ }^{-2}$. 

de Células a Combustível a Membrana Polimérica (PEMFC)

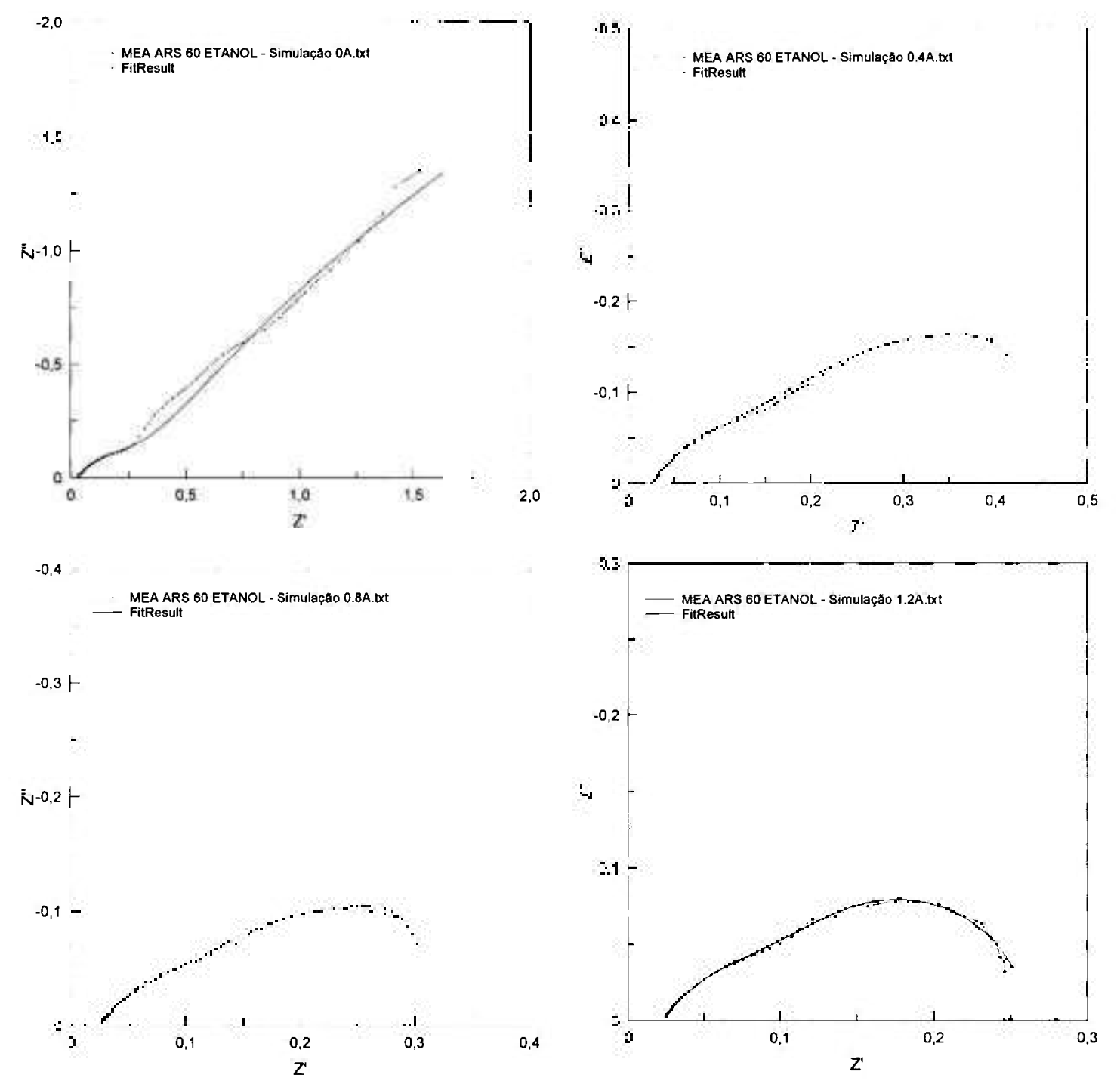

FIGURA 73 - Diagrama de Nyquist para PtSn/C MRA, operando com Etanol/O 2 , sob várias correntes de operação.

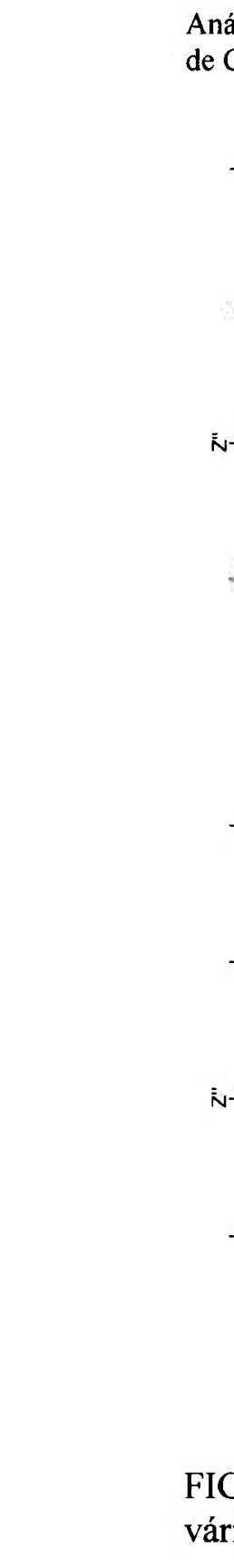


TABELA 8 - Valores dos elementos componentes do circuito elétrico para os MEAs da FIGURA 72, 73 e 74.

\begin{tabular}{|c|c|c|c|c|c|}
\hline & & $\begin{array}{c}\mathbf{I}=\mathbf{0} \mathbf{A} \\
\mathbf{i}=0 \mathrm{~mA} \cdot \mathrm{cm}^{-2}\end{array}$ & $\begin{array}{c}I=\mathbf{0 , 4 A} \\
\mathrm{i}=16 \mathrm{~mA} \cdot \mathrm{cm}^{-2}\end{array}$ & $\begin{array}{c}I=\mathbf{0 , 8} \mathbf{A} \\
\mathbf{i}=32 \mathrm{~mA} \cdot \mathrm{cm}^{-2}\end{array}$ & $\begin{array}{c}I=1,2 \mathrm{~A} \\
\text { hei } \mathbf{i}= \\
48 \mathrm{~mA} . \mathrm{cm}^{-2} \\
\end{array}$ \\
\hline \multirow{8}{*}{ 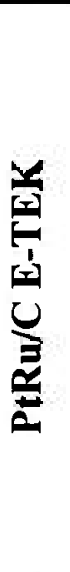 } & $\operatorname{Re}[\mathrm{m} \Omega]$ & & 24,16 & 20,68 & \\
\hline & $\operatorname{Ra}[\mathrm{m} \Omega]$ & & 21,02 & 26,13 & \\
\hline & $\mathrm{CPEa}[\mathrm{F}]$ & & 1,21 & 2,22 & \\
\hline & CPEa Exp. & & 0,59 & 0,51 & \\
\hline & $\operatorname{Rad}[\mathrm{m} \Omega]$ & & 160,69 & 156,02 & \\
\hline & $\overline{R c}[\mathrm{~m} \Omega]$ & & 177,69 & 151,17 & \\
\hline & $\mathrm{CPEc}[\mathrm{F}]$ & & 2,14 & 3,79 & \\
\hline & CPEc Exp. & & 1,00 & 1,00 & \\
\hline \multirow{8}{*}{ 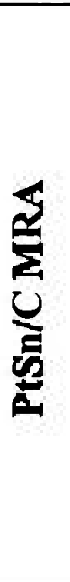 } & $\operatorname{Re}[\mathrm{m} \Omega]$ & 28,19 & 22,43 & $22, \overline{51}$ & 23,15 \\
\hline & $\operatorname{Ra}[\mathrm{m} \Omega]$ & 15,28 & 15,35 & 13,97 & 13,06 \\
\hline & $\mathrm{CPEa}[\mathrm{F}]$ & 0,54 & 0,69 & 0,91 & 0,92 \\
\hline & CPEa Exp. & 0,59 & 0,60 & 0,59 & 0,58 \\
\hline & $\operatorname{Rad}[\mathrm{m} \Omega]$ & 263,79 & 194,01 & 166,41 & 126,63 \\
\hline & $\operatorname{Rc}[\mathrm{m} \Omega]$ & 199,97 & 142,21 & 110,24 & 90,16 \\
\hline & $\mathrm{CPEc}[\mathrm{F}]$ & 2,40 & 1,45 & 2,41 & 2,43 \\
\hline & CPEc Exp. & 0,60 & 1,00 & 1,00 & 1,00 \\
\hline \multirow{8}{*}{ 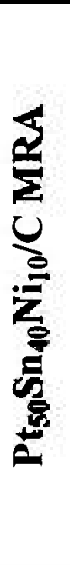 } & $\operatorname{Re}[\mathrm{m} \Omega]$ & 35,58 & 29,09 & 28,60 & \\
\hline & $\mathrm{Ra}[\mathrm{m} \Omega]$ & 19,59 & 19,71 & 17,90 & \\
\hline & $\mathrm{CPEa}[\mathrm{F}]$ & 0,36 & 1,24 & 1,77 & \\
\hline & CPEa Exp. & 0,99 & 1,00 & 1,00 & \\
\hline & $\operatorname{Rad}[\mathrm{m} \Omega]$ & 262,59 & 207,15 & 163,94 & \\
\hline & $\operatorname{Rc}[\mathrm{m} \Omega]$ & 199,93 & 130,80 & 106,50 & \\
\hline & $\mathrm{CPEc}[\mathrm{F}]$ & 1,55 & 0,65 & 0,33 & \\
\hline & CPEc Exp. & 0,46 & 0,58 & 0,59 & \\
\hline
\end{tabular}

Com os valores da resistência de adsorção e da transferência de carga no anodo e no catodo da célula presentes na TABELA 8, construiu-se um gráfico comparativo da contribuição destas resistências na operação da célula, mostrado na FIGURA 75. 


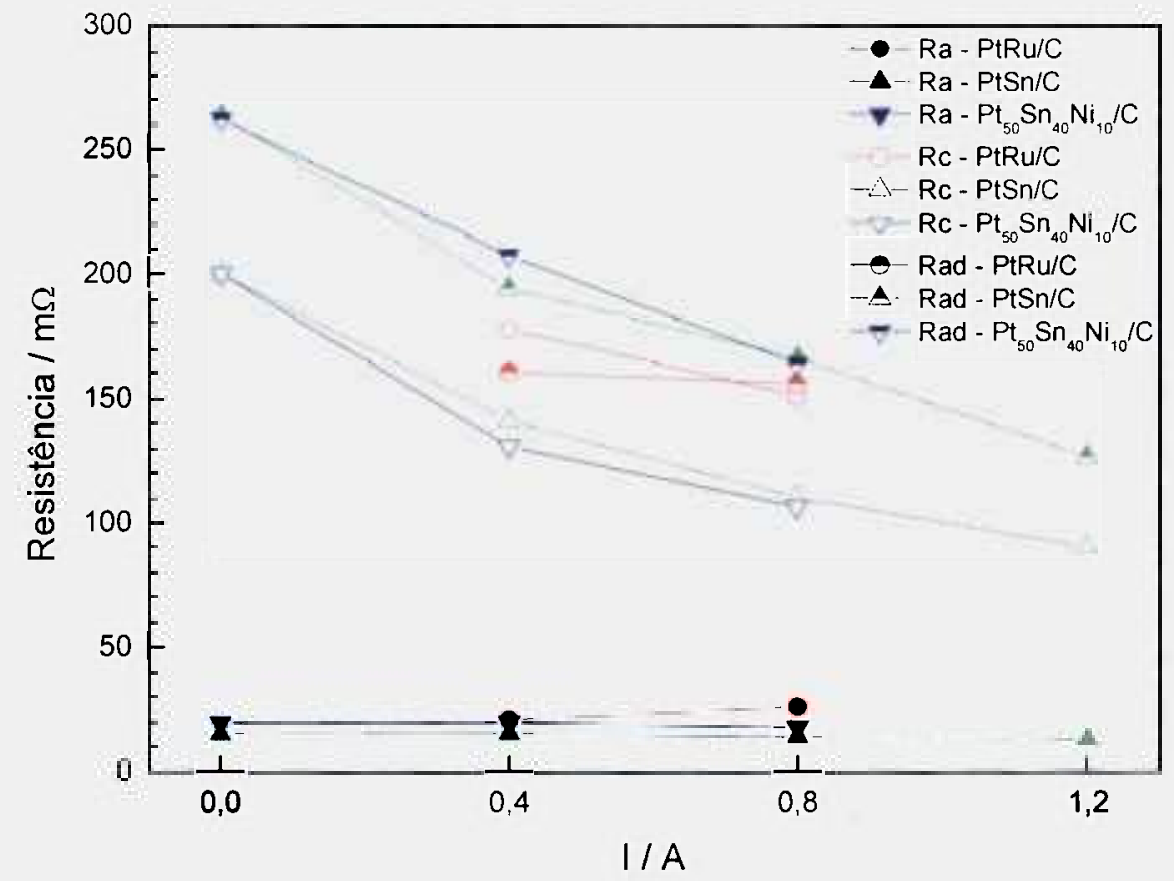

FIGURA 75 - Variação da resistência de transferência de carga no anodo (símbolo cheio) e no catodo (símbolo vazado), e da resistência de adsorção (símbolo semi vazado) dos MEAs utilizados sob operação com Etanol/ $\mathrm{O}_{2}$.

Observa-se na FIGURA 75 que a contribuição da resistência de transferência de carga para a reação de oxidação do etanol no anodo (praticamente igual a de metanol) é muito menor que a da redução do oxigênio no catodo (que é 2,7 vezes a de metanol) para todas as correntes de funcionamento. Este fato pode ser explicado por uma maior taxa de crossover de etanol comparado à taxa de crossover de metanol na célula. Song e colaboradores $^{[133]}$ encontraram para a membrana de Nafion ${ }^{[\mathbb{R}} 115$ uma porosidade no valor de 0,4162 para uma solução de etanol a $2,0 \mathrm{~mol} . \mathrm{L}^{-1}$. Entretanto, observa-se que a contribuição da resistência de adsorção é muito maior que as outras resistências presentes na célula. Observa-se ainda, que quando a célula está em circuito aberto $(I=0)$ a resistência de adsorção do etanol assume um grande valor, na ordem de $260 \mathrm{~m} \Omega$, o dobro do valor para a resistência de adsorção para metanol. Este fato pode ser explicado pelo potencial de adsorção de etanol em eletrodos de $\mathrm{PtRu} / \mathrm{C}, \pm 100 \mathrm{mV}$, o dobro que para metanol, $\pm 50 \mathrm{mV}$.

Ainda na FIGURA 75 pode ser observado que a resistência do catodo é bem maior que a resistência do anodo. 


\subsection{Comparação da Pressão de $\mathrm{O}_{2}$}

Na FIGURA 76 e 77 estão representados os diagramas de Nyquist de um MEA $\operatorname{com} 25 \mathrm{~cm}^{2}$ de área eletródica, confeccionado pelo método spray/prensagem a quente com $\mathrm{PtRu} / \mathrm{C}$ comercial da E-TEK contendo $0,4 \mathrm{mg}$ de $\mathrm{Pt} . \mathrm{cm}^{-2}$ no anodo e $0,6 \mathrm{mg}$ de Pt.cm ${ }^{-2}$ no catodo, sob operação com Metanol $/ \mathrm{O}_{2}$ e Etanol $/ \mathrm{O}_{2}$, respectivamente, onde variou-se a pressão de entrada de oxigênio na célula. A temperatura da célula foi de $100^{\circ} \mathrm{C}$ e do umidificador de $90{ }^{\circ} \mathrm{C}$. Esta comparação na pressão dos gases foi feita para comprovar a influência da porosidade da membrana no processo de crossover com a relação a perda de desempenho da célula. A porosidade da membrana de $\mathrm{Nafion}^{\overline{\mathrm{B}}}$ aumenta quando a membrana incha com o aumento da concentração do álcool. Este fenômeno pode ser explicado levando-se em conta as interações eletrostáticas no polímero. De acordo com Hsu e Gierke ${ }^{[134]}$, a membrana é descrita como umas séries de agrupamentos interconectados através de estreitos poros. Em cada agrupamento, as cargas fixas na membrana têm que criar um campo eletrostático que se estende dentro do centro de cada esfera do agrupamento do polímero.

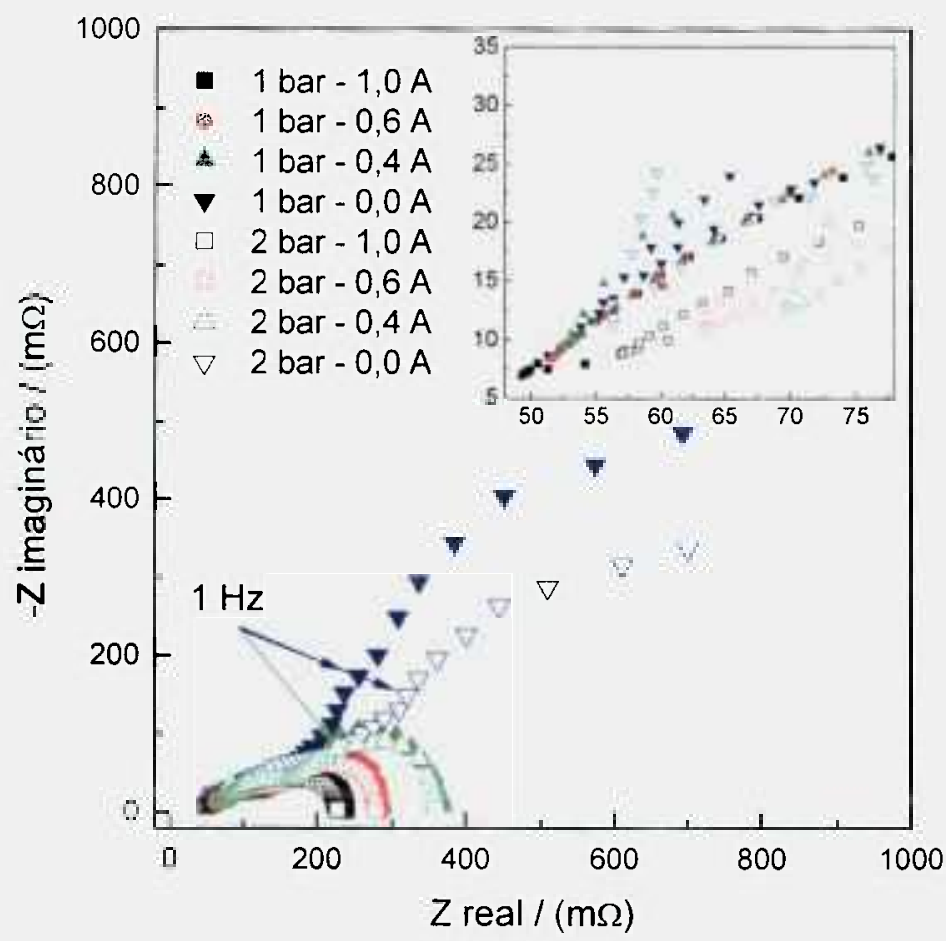

FIGURA 76 - Diagramas de Nyquist, para MEA PtRu/C comercial da E-TEK com $25 \mathrm{~cm}^{2}$ de área eletródica, com tinta catalítica aplicada sobre o tecido de carbono com $0,4 \mathrm{mgPt} . \mathrm{cm}^{-2}$ no anodo e $0,6 \mathrm{mgPt} . \mathrm{cm}^{-2}$ no catodo (Pt/C comercial da E-TEK), utilizando membrana de Nafion ${ }^{(B)} 105$, em várias correntes de operação com Metanol/ $\mathrm{O}_{2}$ a 1 e 2 bar de pressão de oxigênio. Temperaturas: célula a $100^{\circ} \mathrm{C}$ e umidificador a $90{ }^{\circ} \mathrm{C}$. 


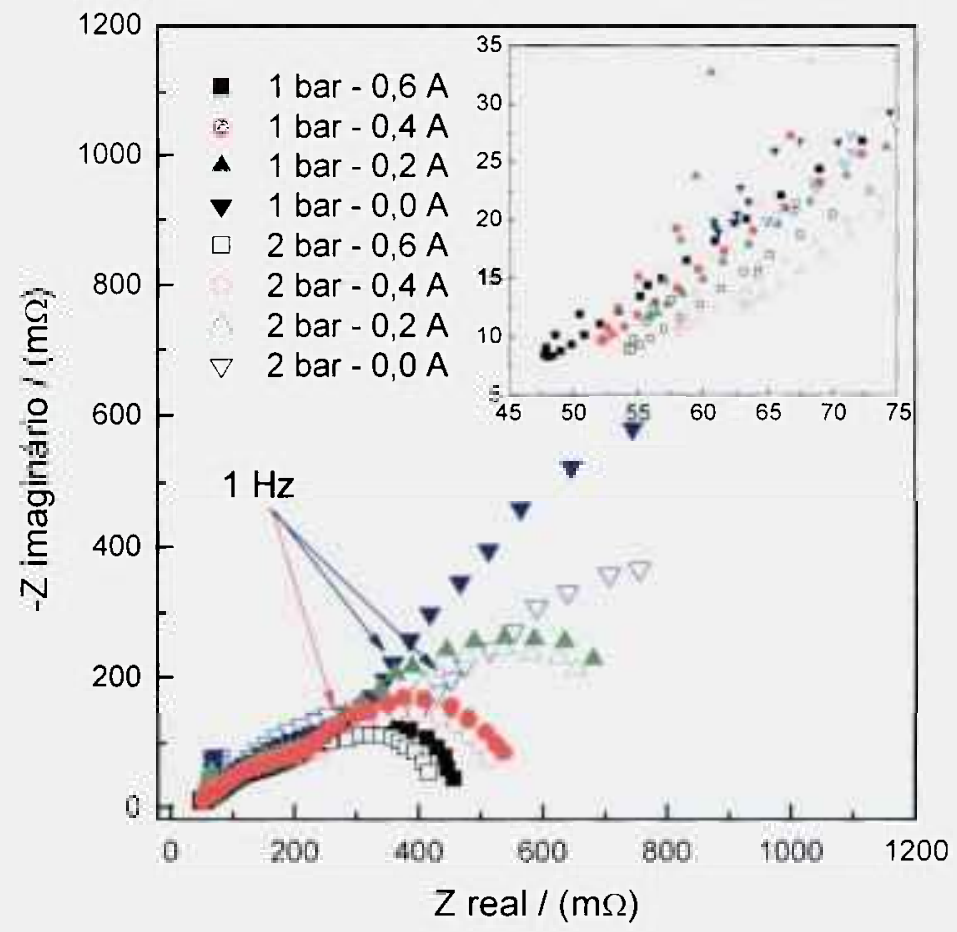

FIGURA 77 - Diagramas de Nyquist, para MEA PtRu/C comercial da E-TEK com $25 \mathrm{~cm}^{2}$ de área eletródica, com tinta catalítica aplicada sobre o tecido de carbono com $0,4 \mathrm{mgPt} . \mathrm{cm}^{-2}$ no anodo e $0,6 \mathrm{mgPt} . \mathrm{cm}^{-2}$ no catodo (Pt/C comercial da E-TEK), utilizando membrana de Nafion ${ }^{(\mathbb{3})} 105$, em várias correntes de operação com Etanol/ $\mathrm{O}_{2}$ a 1 e 2 bar de pressão de oxigênio. Temperaturas: célula a $100{ }^{\circ} \mathrm{C}$ e umidificador a $90{ }^{\circ} \mathrm{C}$.

Observa-se na FIGURA 76 que os diagramas de Nyquist apresentaram, para todas as correntes de operação analisadas, uma menor resistência total quando a célula operou a uma pressão de oxigênio de 2 bar em relação a 1 bar de pressão. Observou-se também a 2 bar de pressão e em altas freqüências, houve um deslocamento da resistência para maiores valores, indicando um aumento na resistência da membrana, ou seja, houve um acúmulo de metanol na membrana; metanol este que a pressão de 1 bar sofreria, preferencialmente um maior crossover e se difundiria para o catodo da célula não permanecendo na membrana. Este crossover de metanol é mais evidenciado em circuito aberto, visto que a $1,0 \mathrm{~A}$ ou $40 \mathrm{~mA} \cdot \mathrm{cm}^{-2}$, o eletrocatalisador consegue oxidar grande parte do metanol no anodo e restando assim, pouco metanol para permear a membrana.

Observa-se que aumentando a pressão no catodo obtêm-se uma melhora significativa quanto à resistência da célula devido ao menor envenenamento, por crossover, da platina presente no catodo.

Na FIGURA 77 pode-se observar que os diagramas de Nyquist apresentam um comportamento similar à operação com metanol (FIGURA 76), onde a resistência total da 
célula em todas as correntes de operação analisadas foi menor quando a célula opera a uma pressão de 2 bar de oxigênio. Observa-se também, em altas freqüências, um deslocamento da resistência para maiores valores, indicando um aumento na resistência da membrana, analogamente ao metanol, devido ao acúmulo de etanol na membrana, etanol que a uma pressão menor sofreria crossover e iria para o catodo da célula, não permanecendo na membrana. 


\section{7 - CONCLUSÕES}

As principais conclusões obtidas neste trabalho de pesquisa são descritas a seguir.

Aplicando-se a tinta catalítica diretamente no TC, se obtém uma menor resistência global do MEA, e uma melhor homogeneidade dos eletrocatalisadores. O TC da EletroChem apresentou uma menor resistência ôhmica e consequentemente elevou o desempenho da célula, otimizando o processo de fabricação de MEAs.

O Método de Redução por Álcool para a preparação dos eletrocatalisadores (Patente IPEN) é um processo viável e reprodutivo, resultando em nanopartículas de tamanho médio entre $2-5 \mathrm{~nm}$, com uma boa homogeneidade no substrato.

Os sistemas de eletrocatalisadores $\mathrm{PtRu} / \mathrm{C}$ com $\mathrm{pH}=11$ e $\mathrm{PtSn} / \mathrm{C}$ obtidos pelo MRA, surgem como promissores para aplicação em célula a combustível direta a metanol (DMFC).

O eletrocatalisador $\mathrm{PtSn} / \mathrm{C}$ obtido pelo MRA proporciona uma significativa melhora no desempenho da célula comparado com PtRu/C comercial da E-TEK, utilizando álcoois como combustíveis.

Os circuitos elétricos sugeridos para a avaliação dos MEAs comerciais e obtidos pelo MRA apresentaram uma resposta coerente com os dados experimentais, tanto para operações com hidrogênio ou com álcoois como combustíveis.

Observou-se nos diagramas de Nyquist que as resistências dos MEAs em operação com os combustíveis estudados estão diretamente correlacionadas com as correntes de operação da célula, e quanto maior a corrente de operação, menor a resistência total dos MEÃS.

Observou-se também um comportamento exponencial da resistência total do diagrama para as correntes abaixo de $2,0 \mathrm{~A}$ ou $80 \mathrm{~mA} \cdot \mathrm{cm}^{-2}$. Supõe-se que este comportamento é devido ao grande arco capacitivo proveniente do metanol adsorvido no MEA a baixas densidades de corrente. 
O aumento da pressão na alimentação catódica resulta num melhor desempenho da célula, devido a uma menor resistência total em todas as correntes de operação, comparado com a operação a 1 bar, demonstrado pelo diagramas de Nyquist.

Observou-se também que a 2 bar, em altas freqüências, há uma significativa diminuição do crossover de álcoois para o catodo da célula, fato comprovado pela técnica de EIE.

A técnica de EIE mostrou-se excelente como diagnóstico de processos de confecção de eletrocatalisadores e MEAs de células PEMFC em condições reais de operação, objetivo principal deste trabalho.

Os objetivos propostos para este projeto foram alcançados e os resultados contribuirão significativamente para os futuros projetos de pesquisas no laboratório de células a combustível do IPEN. 


\section{8 - REFERÊNCIAS BIBLIOGRÁFICAS}

${ }^{1}$ P. Waszczuk, G.-Q. Lu, A. Wieckowsk, C. Lu, C. Rice, R. I. Masel, Electrochim. Acta, 47, 3637 (2002).

${ }^{2}$ M. Watanabe, M. Uchida, S. Motoo, J. Electroanal. Chem., 239, 395 (1987).

${ }^{3}$ D. R. Sena, E. A. Ticianelli, V. A. Paganin, E. R. Gonzalez, J. Electroanal. Chem., 447, 164 (1999).

${ }^{4}$ T. E. Springer, T. Rockward, T. A. Zawodzinski, S. Gottesfeld, J. Electrochem. Soc., 148, A11 (2001).

${ }^{5}$ V. M. Schmidt, H. -F. Oetjen, J. Divisek, J. Electrochem. Soc., 144, L237 (1997).

${ }^{6}$ L. M. Perry, T. F. Fuller, J. Electrochem. Soc., 149, S59 (2002).

${ }^{7}$ T. Page, R. Johnson, J. Hormes, S. Noding, B. Rambabu, J. Electroanal. Chem., 485, 34 (2000).

${ }^{8}$ T. J. Schmidt, M. Noeske, H. A. Gasteiger, R. J. Behm, J. Electrochem. Soc., 145, 925 (1998).

${ }^{9}$ T. J. Schimdt, H. A. Gasteiger, R. J. Behm, J. Electrochem. Soc., 146, 1296 (1999).

${ }^{10}$ J. Shim, D.-Y. Yoo, J.-S. Lee, Electrochim. Acta, 45, 1943 (2000).

${ }^{11}$ K. Kordesch, G. Simader, Fuel Cells and Their Application, VCH, 1996.

${ }^{12}$ I. D. Raistrick, "Electrode assembly for use in a solid polymer electrolyte fuel cell." US Patent 4.876.115, USA, 24 October 1989.

${ }^{13}$ H. Wendt, M. Götz, M. Linardi, Química Nova, 23 (4), 538 (2000).

${ }^{14}$ S. Mukerjee, J. Appl. Electrochem., 20, 537 (1990).

${ }^{15}$ C. A. Bessel, K. Laubernds, N. M. Rodrigues, R. T. K. Baker, J. Phys. Chem., 105, 6 (2001).

${ }^{16}$ E. S. Steigerwalt, G. A. Deluga, D. E. Cliffel, C. M. Lukerhat, J. Phys. Chem. B, 105, 8097 (2001).

${ }^{17}$ E. S. Steigerwalt, G. A. Deluga, C. M. Lukerhat, J. Phys. Chem. B, 106, 760 (2002). 
${ }^{18}$ S. Ball, A. Hodgkinson, G. Hoogers, S. Maniguet, D. Thompsett, B. Wong, Electrochem and Solid-state Letters, 5, A31 (2002).

${ }^{19}$ W. F. Lin, T. Iwasita, W. Vielstich, J. Phys. Chem. B, 103, 3250 (1999).

${ }^{20}$ B. C. H. Steele, A. Heinzel, Nature, 414, 345 (2001).

${ }^{21}$ Y. Ishikawa, M.-S. Liao, C. R. Cabrera, Surface Science, ARTICLE IN PRESS.

${ }^{22}$ M.-S. Liao, C. R. Cabrera, Y. Ishikawa, Surface Science, 445, 267 (2000).

${ }^{23}$ H. Uchida, H. Ozuka, M. Watanabe, Electrochim. Acta, 47, 3629 (2002).

${ }^{24}$ H. A. Gasteiger, N. Markovic, P. N. Ross Jr., E. J. Cairns, J. Phys. Chem., 98, 617 (1994).

${ }^{25}$ H. A. Gasteiger, N. M. Markovic, P. N. Ross Jr., J. Phys. Chem., 99, 8290 (1995).

${ }^{26}$ H. A. Gasteiger, N. M. Markovic, P. N. Ross Jr., J. Phys. Chem., 99, 16757 (1995).

${ }^{27}$ K. Wang, H. A. Gasteiger, N. M. Markovic, P. N. Ross Jr., Electrochim. Acta, 41, 2587 (1996).

${ }^{28}$ K. L. Ley, R. Liu, C. Pu, Q. Fan, N. Leyarovska, C. Segree, E. S. Smotkin, J. Electrochem. Soc., 144, 1543 (1997).

${ }^{29}$ B. N. Gregur, G. Zhuang, N. M. Markovic, P. N. Ross Jr., J. Phys. Chem., 101, 3910 (1997).

${ }^{30}$ W. T. Napporn, J.-M. Leger, C. Lamy, J. Electroanal. Chem., 408, 141 (1996).

${ }^{31}$ K. Y. Chen, P. K. Shen, A. C. C. Tseung, J. Electrochem. Soc., 142, L185 (1995).

${ }^{32}$ K. Y. Chen, A. C. C. Tseung, J. Electrochem. Soc., 143, 2703 (1996).

${ }^{33}$ C. Rice, Y. Tong, E. Oldfield, A. Wieckowski, F. Hahn, F. Gloaguen, J. -M. Léger, C. Lamy, J. Phys. Chem. B, 104, 5803 (2000).

${ }^{34}$ H. N. Dinh, X. Ren, F. H. Garzon, P. Zelenay, S. Gottesfeld, J. Electroanal. Chem. 491, $222(2000)$.

${ }^{35}$ S. J. Lee, S. Mukerjee, E. A. Ticianelli, J. McBreen, Electrochim. Acta, 44, 3283 (1999).

${ }^{36}$ T. J. Schmidt, M. Noeske, H. A. Gasteiger, R. J. Behm, P. Britz, W. Brijoux, H. Bönnemman, Langmuir, 13, 2592 (1997).

${ }^{37}$ E. Grantscharova, A. B. Anderson, Electrochim. Acta, 44, 4543 (1999).

${ }^{38}$ B. E. Hayden, Catal. Today, 38, 473 (1997).

${ }^{39}$ H. Wendt, E. V. Spinacé, A. O. Neto, M. Linardi, Química Nova, 28 (6), 1066 (2005).

${ }^{40}$ R. Parsons, T. Vandernoot, J. Electroanal. Chem., 257, 9 (1988).

${ }^{41}$ A. Hamnett. Catal. Today, 38, 445 (1997). 
${ }^{42}$ H. A. Gasteiger, N. M. Markovic, P. N. Ross, E. J. Cairns, J. Phys. Chem., 97, 12020 (1993).

${ }^{43}$ T. Iwasita, H. Hoster, A. John-Anacker, W. F. Lin, W. Vielstich. Langmuir, 16, 522 (2000).

${ }^{44}$ J. P. I. Souza, F. J. B. Rabelo, I. R. de Moraes, F. C. Nart, J. Electroanal. Chem., 420, 17 (1997).

${ }^{45}$ R. Ianniello, V. M. Schmidt, J. L. Rodrigues, E. Pastor, J. Electroanal. Chem., 471, 167 (1999).

${ }^{46}$ N. Fujiwara, K. A. Friedrich, U. Stimming, J. Electroanal. Chem., 472, 120 (1999).

${ }^{47}$ T. Iwasita, E. Pastor, Electrochim. Acta, 39, 531 (1994).

${ }^{48}$ J.W. Shin, J. Tornquist, C. Korzeniewski, C. S. Hoaglund, Surf. Sci., 364, 122 (1996).

${ }^{49}$ B. Bittins-Cattaneo, S. Wilhelm, E. Cattaneo, H. W. Buschmann, Berlim Bun. Fur Phys. Chem., 92, 1210 (1988).

${ }^{50}$ U. Schmiemann, U. Muller, H. Baltruschat, Electrochim. Acta, 40, 99 (1995).

${ }^{51}$ J. F. E. Gootzen, W. Visscher, J. A. R. Vanveen, Langmuir, 12, 5076 (1996).

52 J. Wang, S. Wasmus, R. F. Savinelli, J. of Electrochem. Soc., 142, 4218 (1995).

${ }^{53}$ A. O. Neto, M. J. Giz, J. Perez, E. A. Ticianelli, E. R. Gonzalez, J. Electrochem. Soc., 149 (3), A272 (2002).

${ }^{54}$ E. V. Spinacé, M. Linardi, A. O. Neto, Eletrochem Comm., 7, 365 (2005).

${ }^{55}$ X. Wang, I-M. Hsing, Electrochim. Acta, 47, 2981 (2002).

${ }^{56}$ W. Chen, J. Y. Lee, Z. Lui, Chem. Commun., 2, 2588 (2002).

${ }^{57}$ W. Zhou, Z. Zhou, S. Song, W. Li, G. Sun, P. Tsiakaras, Q. Xin, App. Catalysis B: Envirommental, 46, 273 (2003).

${ }^{58}$ J. M. Léger, Electrochim. Acta, 50, 3123 (2005).

${ }^{59}$ L. Jiang, G. Sun, Z. Zhou, W. Zhou, Q.Xin, Catalysis Today, 93, 665 (2004).

${ }^{60}$ A. O. Neto, R. R. Dias, V. A. Ribeiro, E. V. Spinacé, M. Linardi, Eclética Química, 31 (1), 81 (2006).

${ }^{6]}$ E. Barsoukov, J. R. Macdonald. Impedance Spectroscopy: Theory, Experiment, and Applications - Second Edition, New York, John Wiley, 2005.

${ }^{62}$ Disponível em: http://www.solartronanalytical.com/technicalsupport. Acesso em: 28 de setembro de 2005.

${ }^{63}$ M. Sluyters-Rehbach, Pure \& Applied Chem., 66 (9), 1831 (1994) 
${ }^{64}$ A. Primer. Electrochemical Impedance Spectroscopy Primer, Gamry Instruments, Warminster, 2005.

${ }^{65}$ A. Lasia. Electrochemical Impedance Spectroscopy and its Application, Modern Asp. Electrochem, New York, 1999.

${ }^{66}$ E. A. Ticianelli, E. R. Gonzales. Eletroquímica - Segunda Edição, São Paulo, Edusp, 2005.

${ }^{67}$ E.A. Ticianelli, C.R. Derouin, A. Redondo, S. Srinivasan, J. Electrochem. Soc., 135(9), 2209(1988).

${ }^{68}$ H. Gerischer, Z. Phys. Chem., NF 1, 278 (1954).

${ }^{69}$ P. Kurzweil, H. J. Fischle, J. Power Sources, 127, 331 (2004).

${ }^{70}$ G.L. Brug, A.L.G. Van Den Eeden, M. Sluyters-Rehbach, J.H. Sluyters, J. Electroanal. Chem., 176, 275 (1984).

${ }^{71}$ P. Zoltowski, J. Electroanal. Chem., 443, 149 (1998).

${ }^{72}$ F.H. Van Heuveln, J. Electrochem. Soc., 141 (12), 3423 (1994).

${ }^{73}$ A. Sadkowski, Electrochim. Acta, 38 (14), 2051 (1993).

${ }^{74}$ G. Lang, K.E. Heusler, J. Electroanal. Chem., 457, 257 (1998).

${ }^{75}$ J. Bisquert, G. Garcia-Belmonte, F. Fabergat-Santiago, and Paulo Roberto Bueno, J. Electroanal. Chem., 475, 152 (1999).

${ }^{76}$ J.C. Wang, Electrochim. Acta, 33 (5), 707 (1988).

${ }^{77}$ W.H. Mulder, J.H. Sluyters, J. Electroanal. Chem., 285, 103 (1990).

${ }^{78}$ T.C. Halsey, M. Leibig, Electrochim. Acta, 36 (11/12), 1699 (1991).

${ }^{79}$ B. Andreaus, A. J. McEvoy, G. G. Sherer, Electrochim. Acta, 47, 2223 (2002).

${ }^{80}$ T. J. P. Freire, E. R. Gonzalez, J. Electroanal. Chem., 503, 57 (2001).

81 J. -P. Diard, B. L. Gorrec, C. Montella, C. Poinsignon, G. Vitter, J. of Power Sources, 74, 244 (1998).

${ }^{82}$ M. Ciureanu, S. D. Mikhailenko, S. Kaliaguine, Catalysis Today, 206, 195 (2003).

${ }^{83}$ G. Bender, M. S. Wilson, T. A. Zawodzinski, J. of Power Sources, 123, 163 (2003).

${ }^{84}$ M. C. Wintersgill, J. J. Fontanella, Electrochim. Acta, 43, 1533 (1998).

${ }^{85}$ A. Küver, W. Vielstich, J. of Power Sources, 74, 211 (1998).

${ }^{86}$ T. S. Sorensen, S. Kjeldtrup, J. of Colloid and Interface Science, 248, 355 (2002).

${ }^{87}$ J. M. Song, S. Y. Cha, W. M. Lee, J. of Power Sources, 94, 78 (2001).

${ }^{\text {ss }}$ R. Mohr, V. Kudela, J. Schauer, K. Richau, Desalination, 147, 191 (2002). 
${ }^{89}$ V. A. Paganin, C. L. F. Oliveira, E. A. Ticianelli, T. E. Springer, E. R. Gonzalez, Electrochim. Acta, 43, 3761 (1998).

90 J. T. Mueller, P. M. Urban, J. of Power Sources, 75, 139 (1998).

${ }^{91}$ J.-N. Han. G.-G. Park, Y.-G. Yoon, T.-H. Yang, W.-Y. Lee, C.-S. Kim, International J. of Hydrogen Energy, 28, 609 (2003).

92 T. R. Castañón, L. G. Arriaga, U. C. Castilho, J. of Power Sources, 118, 179 (2003).

93 J. D. Kim, Y. I. Park, K. Kobayashi, M. Nagai, M. kunimatsu, Solid State Ionics, 140, 313 (2001).

${ }^{94}$ M. Eikerling, A. A. Kornyshev, J. Electroanal. Chem. 475, 107 (1999).

95 Y. J. Leng, X. Wang, I. M. Hsing, J. Electroanal. Chem. 528, 145 (2002).

96 J. T. Müller, P. M. Urban, W. F. Hölderich, J. of Power Sources, 84, 157 (1999).

${ }^{97}$ X. Wang, I. M. Hsing, Y. J. Leng, P. L. Yue, Electrochim. Acta, 46, 4397 (2001).

${ }^{98}$ J. -P. Diard, N. Glandut, P. Landaud, B. L. Gorrec, C. Montella, Electrochim. Acta, 48, 555 (2003).

${ }^{99}$ L. Wang. A. Husar, T. Zhou, H. Liu, International J. of Hydrogen Energy, 28, 1263 (2003).

${ }^{100}$ W. Jenseit, 0. Böhme, F. U. Leidich, H. Wendt, Eletrochimica Acta, 38, 2115 (1993).

${ }^{101}$ N. Toshima, T. Yonezawa, New. J. Chem. 1, 1179 (1998).

102 A. O. Neto, T. R. R. Vasconcelos, R. W. R. V. da Silva, M. Linardi, E. V. Spinacé, J. of A. Eletrochem., 35, 193 (2005).

${ }^{103}$ M. Linardi, E. V. Spinace, A. O. Neto, T. R. R. Vasconcelos, "Processo de Preparação de Catalisadores Via Redução por Álcool”, INPI-RJ, PI0304121-2, Brasil.

${ }^{104}$ M. Linardi, W. R. Baldo, S. A. A. Bueno, A. M. Saliba-Silva. "Método Híbrido de Spray e Prensagem a Quente", com patente sob pedido de depósito no INPI, Brasil, em julho de 2003.

${ }^{105}$ The University of Texas Health Science Center at San Antonio (UTHSCSA) ImageTool. Disponível em: http://ddsdx.uthscsa.edu/dig/itdesc.html. Acesso em: $10 \mathrm{de}$ agosto de 2006.

${ }^{106}$ V. A. Paganin, Desenvolvimento e Caracterização de Eletrodos de Difusão de Gás para Células a Combustível Contendo Nafion como Eletrólito. Tese de Doutorado, IQSC/USP, São Carlos (1997).

${ }^{107}$ H. G. de Melo, Impedância - Apostila de Curso, IQ/USP, São Paulo (2003).

${ }^{108}$ C. Roth, N. Martz, H. Fuess, Physical Chemistry Chemical Physics, 3, 315 (2001). 
${ }^{109}$ C. Roth, M. Goetz, H. Fuess, Journal of Applied Electrochemistry, 31, 793 (2001).

${ }^{110}$ C. Roth, N. Martz, H. Fuess, Journal of Applied Electrochemistry, 34, 345 (2004).

111 P. Scherrer, Nach. Ges. Wiss., 26, 98 (1918).

${ }^{112}$ R. O'Hayre, S.-J. Lee, S.-W. Cha, F. B. Prinz, J. of Power Sources, 109, 483 (2002).

${ }^{113}$ T. Frelink, W. Vischer, J. A. R. van Veen, J. Electroanal. Chem., 382, 65 (1995).

${ }^{114}$ S. Mukerjee, J. McBreen, J. Electroanal. Chem., 448, 163 (1998).

${ }^{115}$ F. Colmati, E. Antolini, E. R. Gonzalez, Electrochim. Acta, 50, 5496 (2005).

${ }^{116}$ M. M. P. Janssen, J. Moolhuysen, Electrochim. Acta, 21, 861 (1976).

${ }^{117}$ M. Watanabe, Y. Furuuchi, S. Motoo, J. Electroanal. Chem., 191, 367 (1985).

${ }^{118}$ B. D. McNicol, R. T. Short, A. G. Chapman, J. Chem. Soc. Faraday I, 72, 2735 (1976).

${ }^{119}$ M. A. Abdel Rahim, M. W. Khalil, H. B. Hassan, J. Appl. Electrochem., 30, 151 (2000).

${ }^{120}$ I. Honma, T. Toda, J. Electrochem. Soc., 150 A, 1689 (2003).

${ }^{121}$ K. J. Cathro, J. Electrochem. Soc., 116, 1608 (1969).

${ }^{122}$ T. Iwasita, Electrochim. Acta, 47, 3663 (2002).

${ }^{123}$ F. Vigier, C. Coutanceau, A. Perrard, E. M. Belgsir, C. Lamy, J. Appl. Electrochem., 34, 439 (2004).

${ }^{124}$ C. Lamy, S. Rousseau, E. M. Belgsir, C. Counteceau, J. M. Léger, Electrochim. Acta, 49, 3901,(2004).

${ }^{125}$ W. Zhou, Z. Zhou, S. Song, W. Li, G. Sun, P. Tsiakaras, Q. Xin, Appl. Catal. B Environ., 46, 273 (2003).

${ }^{126}$ W. J. Zhou, B. Zhou, W. Z. Li, Z. H. Zhou, S. Q. Song, G. Q. Sun, Q. Xin, S. Douvartzides, M. Goula, P. Tsiakaras, J. Power Sources, 126, 16 (2004).

${ }^{127}$ W. J. Zhou, W. Z. Li, S. Q. Song, Z. H. Zhou, L. H. Jiang, G. Q. Sun, Q. Xin, K. Poulianitis, S. Kontou, P. Tsiakaras, J. Power Sources, 131, 217 (2004).

${ }^{128}$ W. J. Zhou, S. Q. Song, W. Z. Li, G. Q. Sun, Q. Xin, S. Kontou, K. Poulianitis, P. Tsiakaras, Solid State Ionics, 175, 797 (2004).

${ }^{129}$ P. J. Tatsch, Deposição de Filmes Finos - Apostila de Curso da $V$ Oficina de Microeletrônica, CCS/UNICAMP, Campinas (2003).

${ }^{130}$ M. U. Iftikhar, D. Riu, F. Druart, S. Rosini, Y. Bultel, N. Retière, J. Power Sources, 160, 1170 (2006).

${ }^{13 ̋ !}$ N. M. Markovic, H. A. Gasteiger, P. N. Ross Jr., X. Jiang, I. Villegas, J. Weaver, Electrochim. Acta, 40, 91 (1995). 

de Células a Combustível a Membrana Polimérica (PEMFC)

${ }^{132}$ T. Yajima, H. Uchida, M. Watanabe, J. Phys. Chem. B, 108, 2654 (2004).

${ }^{133}$ S. Song, G. Wang, W. Zhou, X. Zhao, G. Sun, Q. Xin, S. Kontou, P. Tsiakaras, J. Power Sources, 140, 103 (2005).

${ }^{134}$ W. Y. Hsu, T. D. Gierke, J. Membr. Sci., 13 (3), 307 (1983). 